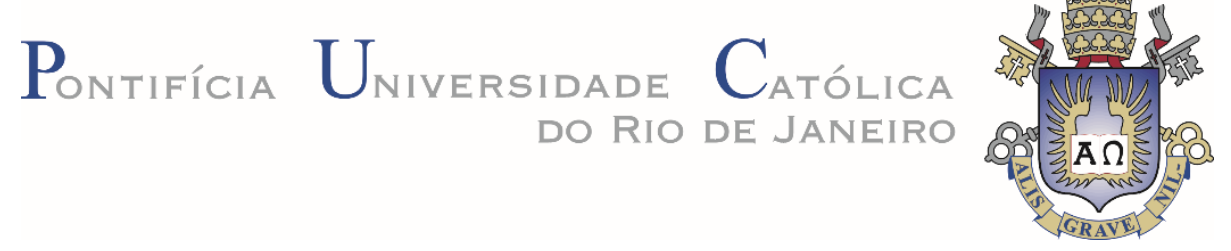

lamberg Souza da Silva

\title{
Planejamento da Expansão da Transmissão com Critérios de Segurança via Algoritmo Genético Especializado
}

Dissertação de Mestrado

Dissertação apresentada ao Programa de PósGraduação em Engenharia Elétrica do Departamento de Engenharia Elétrica da PUC-Rio como requisito parcial para obtenção do grau de Mestre em Engenharia Elétrica.

Orientador: Armando Martins Leite da Silva Coorientador: Fernando Aparecido de Assis

Rio de Janeiro Setembro de 2020 


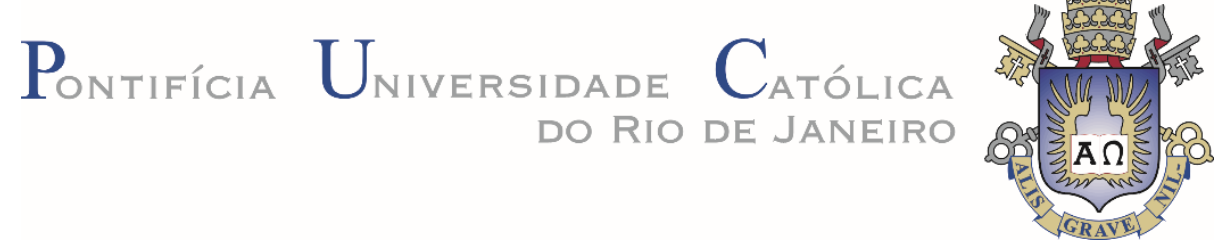

lamberg Souza da Silva

\section{Planejamento da Expansão da Transmissão com Critérios de Segurança via Algoritmo Genético Especializado}

Dissertação apresentada como requisito parcial para obtenção do grau de Mestre pelo Programa de Pós-Graduação em Engenharia Elétrica da PUC-Rio. Aprovada pela Comissão Examinadora abaixo:

Prof. Armando Martins Leite da Silva

Orientador

Departamento de Engenharia Elétrica - PUC-Rio

Prof. Fernando Aparecido de Assis

Coorientador

UFSJ

Prof. Muriell de Rodrigues e Freire IFSP - Campus São João da Boa Vista

Prof. Warlley de Sousa Sales

UFSJ

Rio de Janeiro, 11 de Setembro de 2020 
Todos os direitos reservados. É proibida a reprodução total ou parcial do trabalho sem autorização da universidade, do autor e do orientador.

\section{lamberg Souza da Silva}

Graduou-se em Engenharia Elétrica, com ênfase em Sistemas Elétricos de Potência pelo Centro Federal de Educação Tecnológica Celso Suckow da Fonseca (CEFET-RJ) em 2017 com período sanduíche na Cork Institute of Technology - Irlanda, de setembro de 2015 a maio de 2016.

Ficha Catalográfica

Silva, lamberg Souza da

Planejamento da expansão da transmissão com critérios de segurança via algoritmo genético especializado / lamberg Souza da Silva ; orientador: Armando Martins Leite da Silva ; coorientador: Fernando Aparecido de Assis. - 2020.

142 f. : il. color. ; $30 \mathrm{~cm}$

Dissertação (mestrado)-Pontifícia Universidade Católica do Rio de Janeiro, Departamento de Engenharia Elétrica, 2020. Inclui bibliografia

1. Engenharia Elétrica - Teses. 2. Algoritmo genético. 3. Otimização metaheurística. 4. Critérios de segurança. 5. Planejamento da expansão da transmissão. 6. Planejamento de sistemas de potência. I. Silva, Armando M. Leite da (Armando Martins Leite). II. Assis, Fernando Aparecido de. III. Pontifícia Universidade Católica do Rio de Janeiro. Departamento de Engenharia Elétrica. IV. Título. 


\section{Agradecimentos}

Agradeço primeiramente à minha mãe Ione dos Santos Souza da Silva e ao meu pai Rosemberg Correia da Silva, que sempre me apoiaram e me deram toda estrutura para seguir em frente, obrigado pelo carinho, compreensão e incentivo, obrigado por me ajudarem sempre a me tornar a pessoa que sou hoje, à vocês eu devo tudo.

Aos meus orientadores, Armando M. Leite da Silva e Fernando Aparecido de Assis, por todos os ensinamentos, pelo estímulo, confiança e paciência. Vocês são uma inspiração e um modelo de excelência profissional a se seguir.

À minha namorada Danielle Andrade Hatherly, por toda amizade, carinho e companheirismo, mesmo nos momentos mais difíceis, por me acolher durante essa pandemia, me apoiando e me incentivando a continuar sempre. Sua presença me dá forças e renova minhas energias.

Aos meus amigos da PUC-Rio, em especial à Laís Fonseca Araújo e Mariana Simões N. da Silva, por estarem comigo em mais esta importante etapa da minha vida, tornando-a mais fácil e prazerosa.

Por fim, agradeço à PUC-Rio e à Capes pela oportunidade e auxílios concedidos, sem os quais não poderia realizar este trabalho.

O presente trabalho foi realizado com apoio da Coordenação de Aperfeiçoamento de Pessoal de Nível Superior - Brasil (CAPES) - Código de Financiamento 001. 


\section{Resumo}

Silva, Iamberg Souza da; Leite da Silva, Armando Martins; Assis, Fernando Aparecido de; Planejamento da Expansão da Transmissão com Critérios de Segurança via Algoritmo Genético Especializado. Rio de Janeiro, 2020. 142p. Dissertação de Mestrado - Departamento de Engenharia Elétrica, Pontifícia Universidade Católica do Rio de Janeiro.

A solução do problema de planejamento da expansão da transmissão (PET) tem por objetivo geral identificar reforços a serem construídos na rede de forma a garantir a adequada interligação entre carga e geração, previstos para um determinado horizonte de estudo. No processo de solução desse problema, busca-se manter o equilíbrio ótimo entre os custos envolvidos (investimento e operação) e os níveis de qualidade e desempenho na operação do sistema reforçado. Nesse sentido, é proposta nesta dissertação de mestrado uma ferramenta de otimização especializada para solução do problema PET, a qual é baseada na técnica metaheurística Algoritmo Genético. A ferramenta proposta, denominada Algoritmo Genético Especializado (AGE-PET), faz uso de informações heurísticas fundamentadas em análises atualizadas de fluxo de potência da rede realizadas durante o processo evolutivo de solução do problema. Essas informações heurísticas são traduzidas por meio de índices de sensibilidade, os quais são integrados aos operadores genéticos inerentes à ferramenta, conduzindo a solução do problema na direção de planos de expansão de boa qualidade. Para análise e validação da metodologia proposta, é solucionado o problema PET estático de longo prazo, considerando o modelo linearizado DC com perdas ôhmicas e atendimento do critério de segurança "N-1" para a rede de transmissão. Sistemas elétricos de transmissão com diferentes características e dimensões, incluindo um subsistema atual da rede interligada brasileira, são empregados nos estudos realizados.

\section{Palavras-Chave}

Algoritmo Genético; Otimização metaheurística; Critérios de segurança; Planejamento da expansão da transmissão; Planejamento de sistemas de potência. 


\section{Abstract}

Silva, Iamberg Souza da; Leite da Silva, Armando Martins; Assis, Fernando Aparecido de; Transmission Expansion Planning with Security Criteria via Specialized Genetic Algorithm. Rio de Janeiro, 2020. 142p. Dissertação de Mestrado - Departamento de Engenharia Elétrica, Pontifícia Universidade Católica do Rio de Janeiro.

The main goal in the solution of the transmission expansion planning (TEP) is to identify reinforcements to be built in the network in order to guarantee the adequate interconnection between load and electric power generation, both foreseen for a given future planning horizon. In the process of solving this problem, the aim is to maintain the optimal balance between the costs involved (investment and operation) and the levels of quality and performance in the operation of the reinforced system. Thus, it is proposed in this dissertation a specialized optimization tool for solving the TEP problem, which is based on the metaheuristic Genetic Algorithm technique. The proposed tool, called Specialized Genetic Algorithm (SGA-TEP), makes use of heuristic information based on updated network power flow analyses carried out during the evolutionary process of solving the problem. This heuristic information is translated by means of sensitivity indices, which are integrated with the genetic operators inherent to the tool, leading to the solution of the problem in the direction of good quality expansion plans. For analysis and validation of the proposed methodology, the long-term static TEP problem is solved, considering the linearized DC model with ohmic losses and the compliance of the "N-1" security criterion for the transmission network. Electric transmission systems with different characteristics and dimensions, including a recent subsystem of the Brazilian interconnected grid, are used in the case studies.

\section{Keywords}

Genetic Algorithm; Metaheuristic optimization; Security criteria; Transmission expansion planning; Electrical power system planning. 


\section{Sumário}

1 . Introdução 15

1.1. Considerações Gerais $\quad 15$

1.2. Estado da Arte 16

1.3. Estrutura da Dissertação 24

2. Planejamento da Expansão da Transmissão 26

2.1. Introdução 26

2.2. Modelagem do Problema PET 26

2.3. Técnicas de Solução 30

2.3.1. Otimização Clássica 30

2.3.2. Otimização Heurística 33

2.3.3. Otimização Metaheurística 34

2.4. Conclusões 46

3. Algoritmo Genético Especializado para Solução do Problema PET 48

3.1. Introdução 48

3.2. Formulação do Problema 48

3.2.1. Subproblema de investimento 51

3.2.2. Subproblema de Operação 52

3.3. Representação das Soluções

3.4. Dinâmica Evolutiva do AGE-PET 55

3.4.1. Mecanismo de Cruzamento 58

3.4.2. Mecanismo de Mutação 59

3.4.3. Mecanismo de Seleção 65

3.4.4. Mecanismo de Refinamento 66

3.4.5. Mecanismo de Lista Tabu 67

3.5. Considerações Finais do AGE-PET 68

3.6. Conclusões 70

4. Resultados e Discussões 71 
4.1. Introdução 71

4.2. Parametrização do AGE-PET 71

4.3. Índices de Desempenho 73

4.4. Resultados - IEEE-RTS 74

4.5. Resultados - SSB 82

4.6. Resultados - SGSB 90

4.6.1. Cenário Norte Úmido 91

4.6.2. Cenário Norte Seco 96

4.7. AGE-PET versus Algoritmo Genético Básico 103

4.8. Conclusões 107

5. Conclusões e Trabalhos Futuros 109

5.1. Conclusões 109

5.2. Propostas de Trabalhos Futuros 110

6. Referências Bibliográficas 112

Anexo A. Dados do Sistema IEEE-RTS 121

A.1. Dados de Barra 121

A.2. Dados de Ramos 122

Anexo B. Dados do Sistema Sul Brasileiro (SSB) 123

B.1. Dados de Barra 123

B.2. Dados de Ramos 124

Anexo C. Dados do Sistema Geoelétrico Sul do Brasil (SGSB) $\quad 126$

C.1. Dados de Barra 126

C.2. Dados de Ramos Existentes 130

C.3. Dados de Ramos Candidatos 140 


\section{Lista de Figuras}

Figura 3.1 - Representação de uma população de indivíduos. 55

Figura 3.2 - Fluxograma da ferramenta AGE-PET. 57

Figura 3.3 - Mecanismo de Mutação da ferramenta AGE-PET. 64

Figura 4.1 - Diagrama Unifilar do Sistema IEEE-RTS. Adaptado de [94]. 75

Figura 4.2 - Desvio percentual entre os melhores indivíduos de cada EE e o melhor investimento conhecido para o sistema IEEE-RTS - Seleção por torneio.

Figura 4.3 - Desvio percentual entre os melhores indivíduos de cada EE e o melhor investimento conhecido para o sistema IEEE-RTS - Seleção por clusterização.

Figura 4.4 - Diagrama Unifilar Sistema Sul Brasileiro (SSB). Adaptado de [67].

Figura 4.5 - Desvio percentual entre os melhores indivíduos de cada EE e o melhor investimento conhecido para o sistema SSB - Seleção por torneio.

Figura 4.6 - Histogramas de probabilidade dos desvios percentuais verificados para o sistema SSB - Seleção por clusterização.

89

Figura 4.7 - Desvio percentual entre os melhores indivíduos de cada EE e o melhor investimento conhecido para o cenário Norte Úmido do sistema SGSB - Seleção por torneio. 


\section{Lista de Tabelas}

Tabela 4.1 - Parâmetros utilizados na implementação do AGE-PET 72 Tabela 4.2 - Conjunto das 10 melhores soluções conhecidas - Top10IEEE-RTS.

Tabela 4.3 - Índices de desempenho para IEEE-RTS - Seleção por torneio.

Tabela 4.4 - Índices de desempenho para IEEE-RTS - Seleção por clusterização.

Tabela 4.5 - Conjunto das 10 melhores soluções conhecidas - Top10-SSB

Tabela 4.6 - Índices de desempenho para o SSB - Seleção por torneio. 85

Tabela 4.7 - Índices de desempenho para o SSB - Seleção por clusterização.

Tabela 4.8 - Índices de desempenho para o SSB e NMAX-EE = 10 - Seleção por clusterização.

Tabela 4.9 - Top10 para o cenário Norte Úmido do sistema SGSB 92

Tabela 4.10 - Índices de desempenho com cenário Norte Úmido do sistema SGSB - Seleção por torneio.

Tabela 4.11 - Índices de desempenho com cenário Norte Úmido do sistema SGSB - Seleção por clusterização. 95

Tabela 4.12 - Top10 [2] para o cenário Norte Seco do sistema SGSB 97 Tabela 4.13 - Índices de desempenho com cenário Norte Seco do sistema SGSB - Seleção por torneio.

Tabela 4.14 - Índices de desempenho com cenário Norte Seco do sistema SGSB - Seleção por clusterização.

Tabela 4.15 - Melhores soluções identificadas no Teste D.3 para o cenário Norte Seco do sistema SGSB - Seleção por clusterização 101

Tabela 4.16 - Melhores soluções identificadas no Teste D.4 para o cenário Norte Seco do sistema SGSB - Seleção por clusterização 101

Tabela 4.17 - Novo Top10 para o Cenário Norte Seco do SGSB. 102

Tabela 4.18 - Índices de desempenho para IEEE-RTS com algoritmo GAB.

104

Tabela 4.19 - Índices de desempenho para o SSB com algoritmo GAB.105

Tabela 4.20 - Índices de desempenho para o cenário Norte Úmido do SGSB com algoritmo GAB. 106

Tabela 4.21 - Índices de desempenho para o cenário Norte Seco do SGSB com algoritmo GAB 
Tabela A.1 - Dados de barra - Sistema IEEE-RTS 121

Tabela A.2 - Dados de ramos - Sistema IEEE-RTS. 122

Tabela B.1 - Dados de barra - Sistema Sul Brasileiro (SSB) 123

Tabela B.2 - Dados de ramos - Sistema Sul Brasileiro (SSB) 124

Tabela C.1 - Dados de Barra - Sistema SGSB 126

Tabela C.2 - Dados de ramos existentes - Sistema SGSB 130

Tabela C.3 - Dados de ramos candidatos - Sistema SGSB 140 


\section{Lista de Siglas}

ACO - $\quad$ Otimização por Colônia de Formigas (Ant Colony Optimization)

ACS - $\quad$ Sistemas de Colônia de Formigas (Ant Colony Systems)

AGE-PET - Algoritmo genético especializado proposto para solução do problema PET

$\mathrm{AHC}-\quad$ Algoritmo Heurístico Construtivo

AIS - $\quad$ Sistemas Imunológicos Artificiais (Artificial Immune System)

DE - $\quad$ Evolução Diferencial (Differential Evolution)

EC - $\quad$ Computação Evolucionária (Evolutionary Compution)

EE - $\quad$ Execução Evolutiva

EENS - $\quad$ Valor esperado de energia não suprida (Expected Energy Not-Supplied)

ES - $\quad$ Estratégia Evolutiva (Evolutionary Strategy)

EspMut - Operador de mutação especialista

FACTS - $\quad$ Sistemas flexíveis de transmissão em corrente alternada (Flexible AC Transmission Systems)

GA - $\quad$ Algoritmo Genético (Genetic Algorithm)

GAB - $\quad$ Algoritmo Genético Básico

GRASP - $\quad$ Procedimento de Busca Adaptativa Aleatória Gulosa (Greedy Randomized Adaptive Search Procedure)

LOLC - $\quad$ Custo de corte de carga (Loss of Load Cost)

LOLE - $\quad$ Expectativa de perda de carga (Loss of Load Expectation)

"N-k" - $\quad$ Critério de segurança com contingência de k equipamentos

PerMut Operador de mutação por permuta

PET - $\quad$ Planejamento da expansão da transmissão

PSO - $\quad$ Otimização por Enxame de Partículas (Particle Swarm Optimization)

SA - $\quad$ Recozimento Simulado (Simulated Annealing)

SGSB - $\quad$ Sistema Geoelétrico Sul do Brasil

SSB - $\quad$ Sistema Sul Brasileiro

TS - $\quad$ Busca Tabu (Tabu Search) 


\section{Lista de Símbolos}

$I n d_{c h-i j}-\quad$ Índice de sensibilidade para verificação do carregamento hipotético do ramo $i-j$ na condição de rede intacta

Ind sctros $_{\text {out }}$ - Índice de sensibilidade para verificação da sobrecarga e do corte de carga causados pelo ramo $i-j$ na condição "N-1"

Ind scóprij $_{\text {prio }}$ Índice de atratividade para verificação da sobrecarga sofrida pelo ramo $i-j$ na condição " $\mathrm{N}-1$ "

"N-1" - Condição de contingência simples da rede do sistema

"N-2" - Condição de contingência dupla da rede do sistema

$N_{\mathrm{EL}}-\quad \quad \quad \quad \quad$ úmero de indivíduos selecionados através da estratégia de seleção por elitismo

$N_{\text {GER-EST }}-\quad$ Critério de convergência de uma EE do AGE-PET

$N_{G E R-L T}^{M A ́ X}$ - Número de gerações consideradas para a atualização do conjunto $\Omega_{\mathrm{LT}}$, de ramos considerados "tabu"

$N_{\mathrm{IV}}-\quad$ Tamanho do conjunto $\Omega_{\mathrm{IV}}$, de indivíduos viáveis

$N_{\text {MAX-EE }}-\quad$ Número máximo de EEs realizadas no AGE-PET

$N_{\text {MAX-GER }}$ - Número máximo de gerações de uma EE

$N_{\mathrm{POP}}-\quad$ Tamanho do conjunto $\Omega_{\mathrm{POP}}$

$\alpha_{a d i}-\quad$ Taxa de adição de reforços para EspMut

$\alpha_{\mathrm{CR}}-\quad$ Taxa de cruzamento do AGE-PET

$\alpha_{\mathrm{MT}}-\quad$ Taxa de mutação do AGE-PET

$\alpha_{\text {sub }}-\quad$ Taxa de subtração de reforços para EspMut

$\Omega_{\mathrm{B} 15}-\quad$ Conjunto dos 15 melhores indivíduos identificados

$\Omega_{\mathrm{IV}}-\quad$ Conjunto de indivíduos viáveis

$\Omega_{\mathrm{LT}}-\quad$ Conjunto de reforços definidos como tabu a cada geração de cada EE

$\Omega_{\mathrm{MZ}}-\quad$ Conjunto de reforços não visitados durante determinado número de gerações

$\Omega_{\text {NOVo }}-\quad$ Conjunto dos novos indivíduos gerados a partir da aplicação dos mecanismos evolutivos, a cada geração de cada EE

$\Omega_{\mathrm{POP}}-\quad$ Conjunto dos indivíduos da população corrente em uma EE 


\section{1. Introdução}

\section{1. Considerações Gerais}

A solução do problema de Planejamento da Expansão da Transmissão (PET) tem por objetivo geral identificar reforços a serem construídos na rede visando à garantia do adequado escoamento da energia elétrica produzida para o atendimento da demanda do sistema, considerando seu crescimento para um determinado horizonte de planejamento. Os custos de investimento, assim como os custos relacionados a um possível déficit de energia causado pela falta de estrutura necessária do sistema de transmissão, são relativamente elevados [1]. Portanto, um bom plano de expansão deve ser capaz de manter o equilíbrio entre os custos envolvidos (investimento e operação) e os níveis de qualidade/desempenho do sistema. Neste sentido, devem ser atendidos critérios adequados de confiabilidade da operação do sistema, a fim de garantir o atendimento da carga mesmo em situações de contingência.

As atuais dimensões dos sistemas de transmissão e as incertezas intrínsecas ao processo, como aquelas relacionadas ao crescimento de carga e à disponibilidade de fontes energéticas, fazem com que a solução do problema PET venha se tornando uma tarefa cada vez mais difícil. Além disso, novos desafios, como a alta penetração de fontes de energia renovável nos sistemas, as novas políticas regulatórias, os avanços relacionados à Geração Distribuída, os novos mecanismos do mercado de energia e o constante crescimento do movimento de proteção ambiental, aumentam ainda mais a complexidade de solução desse problema [2], [3] e [4]. Com o objetivo de contornar essas dificuldades, diversos trabalhos vêm sendo propostos na literatura, apresentando diferentes métodos de solução. Dentre esses trabalhos, aqueles baseados em técnicas heurísticas e metaheurísticas de otimização vêm apresentando crescente aplicação e aceitação [5]. Isso se dá, principalmente, devido à capacidade dessas técnicas de lidar com as não linearidades 
do problema, além de apresentarem um menor nível de dificuldade de implementação e de tratamento de incertezas [4]- [6].

Tendo em vista as dificuldades inerentes à solução do problema PET e as experiências dos trabalhos relacionados, é proposta nessa Dissertação de Mestrado uma ferramenta especializada de otimização baseada na técnica metaheurística Algoritmo Genético (Genetic Algorithm - GA), denominada Algoritmo Genético Especializado (AGE-PET). Com a utilização de informações heurísticas fundamentadas em análises de fluxo de potência da rede, a ferramenta proposta é capaz de auxiliar na solução do problema de forma eficiente. Essas informações são baseadas no carregamento de circuitos e em eventuais sobrecargas e cortes de carga ocorridos durante a análise de contingência da rede, sendo integradas aos mecanismos evolutivos durante o processo de solução do problema PET. Esse método busca aprimorar os planos de expansão, selecionando os reforços mais atrativos baseado nos índices de sensibilidade de cada solução e conduzindo-as em direção a planos de expansão de ótima qualidade.

A abordagem adotada neste trabalho, para a solução do problema PET estático com horizonte de longo prazo, considera a implementação de um modelo DC da rede com a inclusão das perdas ôhmicas, em que o critério determinístico de segurança "N-1" deve ser atendido. De forma geral, visa-se à construção de uma ferramenta robusta e capaz de equilibrar de forma eficiente a solução do problema, isso do ponto de vista dos custos envolvidos (investimento e operação), do desempenho operativo do sistema e do esforço computacional requerido.

\section{2.}

\section{Estado da Arte}

De forma geral, o PET é considerado um problema de otimização de difícil solução, que pode ser definido como um problema de programação não linear inteira mista [3] e [6]. Conforme literatura relacionada, o PET pode ser analisado a partir de diferentes aspectos, que incluem, principalmente, o horizonte de planejamento, o tratamento de incertezas, a modelagem da rede, os métodos de solução e os critérios de segurança [3], [4], [6] e [7].

O horizonte de planejamento tem grande influência na tratativa dada ao PET, que pode ser classificada em abordagem estática ou multiestágio. Em uma abordagem estática, o objetivo é determinar a configuração final do sistema sem 
se preocupar com o momento dentro do horizonte de planejamento em que cada reforço deve ser construído. Assim, objetiva-se na abordagem estática otimizar "onde" e "quantos" reforços devem ser instalados na rede a fim de garantir o atendimento à demanda ao final do horizonte de planejamento, não importando com "quando" esses reforços serão instalados. Alguns exemplos de trabalhos que utilizam a abordagem estática na solução do problema PET são [2], [8], [9], [10], entre outros.

Por outro lado, em uma abordagem multiestágio, também conhecida como abordagem dinâmica ${ }^{1}$, o horizonte de planejamento é dividido em estágios menores nos quais são realizados os investimentos. Nesse tipo de abordagem, deve-se determinar não somente a posição e a quantidade de cada reforço, mas também em qual dos estágios dentro do horizonte de planejamento cada reforço deverá ser construído [3]- [7]. Quando comparado à abordagem estática, a modelagem matemática de um PET multiestágio apresenta um número maior de variáveis e restrições a serem consideradas, aumentando o tamanho e a complexidade do problema e, por consequência, o custo computacional necessário para a sua solução. Essa característica pode fazer com que esse tipo de abordagem se torne inviável em algumas situações, como nas fases preliminares do planejamento, quando o nível de incerteza é ainda muito elevado [3] e [7]. Apesar disso, a abordagem multiestágio é a mais indicada quando se deseja aproximar os resultados da realidade, permitindo antecipar ou postergar reforços, gerando soluções mais baratas e garantindo um investimento mais "inteligente" [3] e [11]. Alguns exemplos de trabalhos que utilizam esse tipo de abordagem são: [5], [12], [13], [14] e [15].

Uma alternativa que pode ser utilizada para contornar o problema de inviabilidade de uma abordagem multiestágio é a utilização de uma abordagem estática sequencial, na qual, assim como realizado na abordagem multiestágio, o horizonte de planejamento é também dividido em vários estágios. Essa abordagem pode ser realizada de forma forward, que consiste em realizar uma sequência de planos estáticos, partindo da suposição de que todos os investimentos realizados no estágio anterior estarão disponíveis até o fim do horizonte de planejamento ou, de forma backward, que consiste em resolver o problema estático para o final do

\footnotetext{
${ }^{1}$ Dinâmica, neste caso, se refere à subdivisão do horizonte de planejamento, sendo que a operação do sistema pode continuar sendo analisada em regime permanente assim como na abordagem estática do problema PET.
} 
horizonte e ir retrocedendo de forma a tentar antecipar determinados reforços a fim de solucionar possíveis "gargalos" em cada um dos estágios [4] e [7].

Em geral o horizonte de planejamento da expansão da transmissão pode variar de alguns anos a décadas, podendo ser classificado como de curto, médio ou longo prazo. Quanto maior for o horizonte de planejamento, maiores são as incertezas envolvidas no processo (e.g., incertezas da carga e da disponibilidade de geração, dos custos e da disponibilidade das fontes energéticas e equipamentos, das políticas regulatórias e de mercado [2]). De acordo com a tratativa dada a essas incertezas, os modelos podem ser classificados como determinísticos ou nãodeterminísticos. Em um modelo determinístico as incertezas são definidas para um único cenário e consideradas imutáveis durante todo o processo [3]. Essa abordagem leva em consideração algumas simplificações, que diminuem a complexidade do processo, porém podem levar a uma solução sub-ótima do problema. Este modelo pode representar uma boa alternativa para análises iniciais do planejamento da expansão da transmissão.

Em contrapartida, um modelo não-determinístico pode ser caracterizado, por exemplo, pela consideração de diferentes cenários de operação do sistema, de forma a tornar o planejamento mais condizente com a realidade, gerando planos de expansão mais robustos e capazes de lidar com as incertezas inerentes ao problema. Porém, devido à grande complexidade e esforço computacional requerido para solução do problema a partir desse tipo de modelo, poucos trabalhos o utilizam para casos reais e/ou horizontes de análise muito distantes. Algumas técnicas utilizadas na consideração dessas incertezas incluem [16] e [17]: modelagem probabilística e estocástica (e.g., [18] e [19]), simulação Monte Carlo (e.g., [20]), conjuntos Fuzzy (e.g., [21] e [22]), técnicas de cenário (e.g., [23]) e otimização robusta (e.g., [24] e [25]). Uma comparação entre um modelo determinístico e não-determinístico para a solução do problema PET é apresentada em [26].

Em relação à representação da rede elétrica, os principais modelos utilizados são: o modelo AC, relacionado à solução das equações não lineares do fluxo de potência da rede, e o modelo DC, relacionado à linearização dessas equações. Este último, o modelo DC, é o mais utilizado para problemas de médio/longo prazo [27] devido, principalmente, aos elevados níveis de incerteza envolvidos no processo. Dado o horizonte de planejamento sob estudo, o modelo DC é o modelo empregado no presente trabalho. 
Apesar de sua origem nas equações linearizadas de fluxo de potência (fluxo DC) o modelo DC é considerado um problema de programação não-linear, porém de nível de complexidade reduzido quando comparado ao modelo AC, uma vez que considera os módulos de tensão nas barras constante e iguais a 1 p.u, além de desprezar o fluxo de potência reativa na rede, o que permite sua aplicação em sistemas de grande porte com um custo computacional reduzido. Porém, pelo fato da análise feita a partir desse modelo só considerar a capacidade do sistema em relação ao fluxo de potência ativa, estudos de planejamento e alocação de potência reativa na rede devem ser realizados de forma separada ao planejamento da expansão da transmissão, em fases posteriores do estudo de planejamento.

Além disso, devido às simplificações feitas, o modelo DC acaba por introduzir incertezas ao problema, como por exemplo, as considerações referentes às perdas ôhmicas nas linhas de transmissão, o que faz com que as soluções encontradas por esse modelo acabem necessitando de reforços adicionais quando realizados estudos mais detalhados utilizando o modelo AC [28]. De forma a diminuir essa diferença nas soluções encontras em ambos os modelos, alguns trabalhos vêm incorporando um cálculo aproximado, realizado de forma iterativa, das perdas ôhmicas no sistema de transmissão junto ao modelo DC, como por exemplo: [5], [29], [30] e [31]. A inclusão das perdas ôhmicas ao modelo DC para solução do problema PET é também considerada no presente trabalho.

Além dos modelos citados, outros modelos linearizados, baseados em simplificações ou variações do modelo DC, são também comumente utilizados na literatura para representar a rede elétrica (e.g., modelo de transporte [32], modelo híbrido [33] e modelo disjuntivo [34]). De forma geral, esses modelos buscam diminuir ou remover a não linearidade ainda presente no modelo DC, apresentando cada um, vantagens e desvantagens específicas, conforme discutido em [35].

Outra ótica de abordagem referente ao problema PET remete ao nível de interação do planejador com a solução do problema, o qual define as abordagens interativa e automática [11]. Em uma abordagem interativa, o planejador deve interagir com o algoritmo, tomando decisões baseadas em estudos complementares e em sua própria experiência, sendo o resultado obtido totalmente dependente das escolhas feitas durante o processo. Em contrapartida, em uma abordagem automática, o processo é inteiramente conduzido pelo algoritmo, sem qualquer inter- 
ferência do planejador, a não ser na definição dos valores iniciais dos parâmetros considerados no problema.

Quanto aos métodos de solução utilizados na obtenção dos planos de expansão, os principais podem ser classificados em: métodos clássicos, técnicas heurísticas ou técnicas metaheurísticas [2]. A escolha do método adequado está fortemente ligada à modelagem adotada para o problema.

Em uma metodologia clássica, tem-se por objetivo encontrar valores para um conjunto de variáveis de decisão que otimizem uma função objetivo (normalmente relacionadas à minimização dos custos de investimento e operação do sistema), sujeita a um conjunto de restrições que visam modelar, no caso do problema PET, alguns critérios de cunho técnico (e.g., leis de Kirchhoff, balanço de energia, capacidades máximas de transmissão, etc.), econômico, social e de confiabilidade, baseando-se em formulações matemáticas de otimização [3] e [36].

Uma das vantagens de se utilizar métodos clássicos de otimização é que, de maneira geral, a solução encontrada será a solução ótima global do problema modelado. Por outro lado, deve-se reforçar que, devido à incapacidade de se modelar todos os aspectos do sistema, principalmente em sistemas reais e/ou horizontes de longo prazo, a solução encontrada só pode ser considerada ótima do ponto de vista das restrições e critérios utilizados, o que significa que os planos de expansão encontrados devem ainda ser avaliados no que diz respeito aos critérios não incluídos no modelo. Ademais, a utilização de métodos clássicos de otimização enfrenta alguns obstáculos em algumas aplicações do problema PET. Devido à natureza não-linear do problema e a não convexidade do seu espaço de busca, o algoritmo pode apresentar problemas de convergência, além de apresentar um tempo computacional elevado quando utilizadas variáveis discretas [7].

Por outro lado, em um modelo que utiliza técnicas heurísticas e metaheurísticas, o algoritmo vai aos poucos construindo, modificando e aprimorando possíveis planos de expansão até atingir uma convergência [7]. Com o emprego destes tipos de ferramentas, não é possível garantir que a solução encontrada será a solução ótima global, porém, em algoritmos bem construídos e adaptados, é possível encontrar soluções de ótima qualidade em um tempo computacional razoável. Essa característica torna viável a utilização dessas técnicas para solução de problemas de natureza combinatória como o planejamento da expansão da transmissão [36], principalmente em sistemas reais e de grande porte, onde o problema da 
explosão combinatória se torna mais evidente. Além disso, essas metodologias apresentam relativa facilidade de implementação, capacidade de lidar com as não linearidades e incertezas do problema e fornecem, ainda, não apenas uma única solução, mas um conjunto de soluções de boa qualidade obtidas a partir de um mesmo critério de modelagem do problema [4]- [6]. De posse de um conjunto de boas soluções, o planejador pode escolher aquela que melhor atende às necessidades e aos critérios impostos ao problema em fases posteriores de estudo.

A fim de assegurar o pleno atendimento a carga futura, não somente em situações normais de operação, mas também em situações de contingência, outro fator importante a ser considerado na solução do problema PET são os critérios de segurança/confiabilidade do sistema. Devido ao grande aumento na complexidade do problema quando levados em consideração, esses fatores são negligenciados em grande parte dos estudos disponíveis na literatura, sendo realizados estudos considerando apenas o desempenho de operação da rede intacta do sistema [30].

Em relação ao critério de segurança utilizado, o estudo do PET pode ser basicamente classificado como de abordagem determinística ou abordagem probabilística [2]. Em uma abordagem determinística do problema PET, ou como é normalmente chamado, critério "N-k", o sistema deve garantir o pleno atendimento à demanda do sistema mesmo frente à perda simultânea (ou contingência) de pelo menos um número k de equipamentos da rede de transmissão. Neste caso, os critérios mais comumente utilizados são os critérios de segurança "N-1" e "N-2", onde o sistema deve garantir o total atendimento da carga mesmo com a perda de um ou simultaneamente de dois equipamentos, respectivamente, sem que haja sobrecarga em quaisquer dos outros componentes do sistema. Alguns exemplos de trabalhos que utilizam esse critério podem ser vistos em [37], [38] [39] e [40].

Algumas estratégias podem ser utilizadas para a consideração do critério de segurança determinístico "N-k" em um estudo de planejamento da expansão da transmissão. Uma delas consiste na avaliação do atendimento ao critério de segurança somente para o melhor plano ou conjunto de planos encontrados durante o processo de busca, realizado considerando somente a condição de rede intacta. Essa estratégia permite contornar o aumento da complexidade do problema e o grande esforço computacional requerido na avaliação dos planos candidatos, porém, não há garantias de que o plano, após atualização para atender ao critério de segurança utilizado, seja ótimo. De forma geral, planos obtidos a partir desta es- 
tratégia podem apresentar investimentos maiores do que os observados quando o critério de segurança é considerado durante o processo [30]. Essa estratégia é utilizada em [41], em que a cada iteração do algoritmo, somente o melhor plano corrente, definido através de uma análise da condição de rede intacta, é analisado quanto à conformidade ao critério de segurança. Caso ele não atenda ao critério, o algoritmo então seleciona um novo melhor plano e realiza a validação do critério. Esse processo continua até que o plano avaliado atenda totalmente ao critério de segurança, permitindo, então, que o algoritmo siga para a próxima iteração.

Outra estratégia de consideração do critério determinístico de segurança consiste em considerar o critério de segurança durante o processo de solução, como uma restrição do problema ou como parte da função objetivo. Ou seja, todos os planos candidatos deverão, durante todo o processo de solução, ser avaliados não somente para a condição de rede intacta, mas também para a contingência de um determinado número de equipamentos, a depender do critério adotado. Neste caso, o melhor plano encontrado é aquele que atende completamente a esses critérios ao menor custo de investimento possível. Esta estratégia é considerada no presente trabalho, onde os planos de expansão devem atender completamente o critério determinístico de segurança "N-1" da rede de transmissão.

Exemplos de consideração do critério determinístico de segurança durante o processo de solução podem ser encontrados em [11] e em [37]. Nestes trabalhos, é adotado o critério de segurança " $\mathrm{N}-1$ " como uma restrição do problema durante todo o processo de otimização, além de incluir ainda uma análise de uma versão relaxada dessas restrições, que permite uma pequena sobrecarga dos equipamentos em caso de contingência. Essa estratégia permite reduzir os custos de investimento dos planos de expansão quando comparada ao critério não relaxado.

Em sistemas reais, de maior porte, a consideração de critérios de segurança durante a solução do problema PET requer um alto custo computacional podendo tornar inviável a análise de contingência de todos os equipamentos do sistema. Por este motivo, a fim de simplificar a solução do problema, em [30] é proposta a utilização de listas de contingências contendo os circuitos e áreas mais críticas para o sistema, onde o critério de segurança "N-k" deve ser respeitado completamente. Neste caso, despreza-se a perda de equipamentos de menor relevância, cuja saída da rede causaria pouca influência ao atendimento da carga. Porém, dada a dinâmica do sistema e a já mencionada complexidade do problema PET, a construção de 
uma lista deste tipo não é uma tarefa trivial, visto que para diferentes planos um mesmo equipamento pode ter diferentes níveis de prioridade. Em [39], as contingências são classificadas através da primeira derivada do índice denominado Performance Index (PI) em relação à admitância da linha. Nesta aplicação, quanto maior for a derivada de PI, maiores as chances de sobrecarga causadas por essa linha. Caso o plano não apresente sobrecargas após um determinado número de contingências realizadas uma a uma em ordem decrescente de prioridade, ele então é considerado como em concordância com o critério de segurança "N-1" considerado. Já em [40], são consideradas apenas contingências com probabilidade de ocorrência maior do que um determinado valor limite, sendo a probabilidade de ocorrência de uma contingência calculada a partir da taxa de falha dos equipamentos (geradores e linhas) do sistema.

Como alternativa à abordagem determinística, na abordagem probabilística o nível de confiabilidade/segurança de operação do sistema é medido por meio de índices de confiabilidade relativos ao atendimento à demanda, como LOLE (Loss of Load Expectation), EENS (Expected Energy Not-Supplied) e LOLC (Loss of Load Cost). Essa abordagem tem como principal contraponto o alto custo computacional necessário na avaliação dos planos candidatos, principalmente em se tratando de sistemas de grande porte. Outro fator que dificulta a utilização da abordagem probabilística é a dificuldade de um consenso sobre o quão confiável um sistema deve ser baseado nesses índices, dado que estes índices são dependentes do modelo de carga utilizado [30]. Apesar disso, somente uma abordagem probabilística é capaz de considerar mais fielmente as aleatoriedades ocasionadas no sistema devido à disponibilidade de fontes de geração e de equipamentos, assim como da flutuação de carga [29]. Um estudo mais aprofundado sobre planejamento da transmissão utilizando uma abordagem probabilística pode ser encontrado em [42].

Uma das estratégias utilizadas na consideração da abordagem probabilística na solução do problema PET consiste na incorporação do custo relativo à interrupção do atendimento à demanda na função objetivo do problema por meios de índices, como o LOLC. Um exemplo dessa estratégia ocorre em [43] onde o custo total de uma alternativa de expansão é dado pela soma dos custos de investimento, produção e dos custos de interrupção (LOLC). Além disso, é proposto ainda neste trabalho um método de seleção de alternativas por etapa, onde cada etapa funciona 
de forma semelhante a um filtro em que são utilizados métodos de enumeração de estados e simulação Monte Carlo. As alternativas de expansão são selecionadas com base no índice EENS.

A estratégia de incorporação do custo de interrupção (LOLC) à função objetivo do problema PET é também utilizada em [29] e [44], porém, dado o alto custo computacional requerido na avaliação do índice, em ambos os trabalhos o índice LOLC é calculado em um "loop” externo, após a identificação das melhores alternativas de expansão. Devido a isso, as soluções encontradas podem sofrer ainda uma reordenação após a consideração desse fator, fazendo-se notar a importância da avaliação da confiabilidade do sistema na solução do problema PET.

Outra estratégia também utilizada para consideração da abordagem probabilística na solução do problema PET é a consideração de valores máximos para os índices de confiabilidade apresentados através de restrições do problema. Essa estratégia é utilizada em [45] e [46], onde além das restrições de balanço de carga é considerada também uma restrição referente ao critério de confiabilidade probabilístico que define um limite máximo em horas por ano do índice LOLE.

Em resumo, o problema PET é uma tarefa complexa que envolve diferentes aspectos a serem considerados (e.g., horizonte de planejamento, tratamento de incertezas, modelagem da rede, métodos de solução e critérios de segurança). Dessa forma, se faz necessário o uso de ferramentas de otimização eficientes, ou seja, capazes de garantir um equilíbrio entre a qualidade das soluções identificadas e o custo computacional exigido. Neste sentido, de acordo com os objetivos determinados pelo planejador, deve-se selecionar de forma adequada dentre as diferentes abordagens propostas para lidar com cada uma das variáveis do problema, aquelas que, pelas características mencionadas nesta seção, sejam capazes de garantir tal equilíbrio.

\section{3.}

\section{Estrutura da Dissertação}

O presente trabalho se constitui de cinco capítulos. O presente capítulo contextualiza de forma geral o problema PET, destacando dificuldades inerentes à sua solução, que motivaram o desenvolvimento desse trabalho. Além disso, neste capítulo é também apresentado um resumo do estado da arte sobre as principais 
formas de abordagem do problema e os principais aspectos analisados durante os estudos realizados.

No Capítulo 2, são descritos, de forma mais aprofundada a partir de uma revisão da literatura atual, os modelos de rede adotados no problema PET, assim como os principais métodos de otimização utilizados em sua solução.

No Capítulo 3 é detalhada a formulação do problema PET estático considerada neste trabalho, que é baseada em um modelo DC com a consideração das perdas ôhmicas e do critério determinístico de segurança "N-1". É ainda apresentada neste capítulo uma descrição da ferramenta proposta para a solução do problema, incluindo uma descrição detalhada dos mecanismos evolutivos e dos índices de sensibilidade que caracterizam a ferramenta AGE-PET proposta.

Já no Capítulo 4, o algoritmo proposto (AGE-PET) é empregado na solução do problema PET para três sistemas elétricos distintos, de forma a avaliar o desempenho da ferramenta e dos ajustes dos parâmetros utilizados pela metodologia. Os sistemas em questão possuem tamanhos e níveis de complexidade diferentes entre si, sendo eles: o Sistema IEEE-RTS de 24 barras; o Sistema Sul Brasileiro (SSB) de 46 barras, planejado para a década de 90; e uma versão atual e de grande porte deste último sistema, aqui denominado Sistema Geoelétrico Sul do Brasil (SGBS). Para o SGBS são consideradas duas diferentes condições de carga e geração (ou seja, dois diferentes cenários de geração e carga). Os resultados de cada teste são apresentados e analisados de forma detalhada neste capítulo.

Por fim, no Capítulo 5, são apresentadas e debatidas as conclusões e considerações observadas nesse trabalho, assim como propostas para a confecção de trabalhos futuros. 


\section{2. \\ Planejamento da Expansão da Transmissão}

\section{1. Introdução}

Neste capítulo, são detalhados por meio de uma revisão bibliográfica conceitos referentes à modelagem e à solução do problema PET, tema principal dessa dissertação.

\section{2. \\ Modelagem do Problema PET}

Com o desenvolvimento da tecnologia e a evolução das ferramentas computacionais, houve um movimento em direção à criação e utilização de modelos computacionais para a solução do problema do planejamento da expansão da transmissão (PET), visando, principalmente, sobrepor as crescentes dificuldades relacionadas ao aumento das dimensões do sistema de potência [2]. Neste sentido, Garver [32] desenvolveu um dos primeiros trabalhos publicados sobre o assunto, trazendo a formulação do primeiro modelo simplificado para o tratamento do problema PET.

A partir de então, novos trabalhos foram surgindo na literatura, trazendo diferentes formas de modelar e representar a rede elétrica para solução do problema. Esses modelos podem ser classificados, basicamente, em lineares e não-lineares. Os modelos classificados como lineares são aqueles que consideram somente o fluxo de potência ativa da rede, além de definir o módulo de tensão nas barras constante e iguais ao seu valor nominal de 1 pu [3]. Em termos de classificação, esses modelos podem ser ainda ser divididos em: modelo disjuntivo, modelo de transporte, modelo híbrido e modelo DC. Já a classe de modelos não-lineares contempla o chamado modelo AC, cuja solução está relacionada às equações matemáticas exatas de fluxo de potência AC, que contemplam em sua formulação também o fluxo de potência reativa da rede. 
Em problemas PET com horizonte de planejamento de longo prazo, os modelos ditos lineares são os mais comumente utilizados na representação da rede elétrica [35], dado o elevado nível de incertezas associadas a essa fase de estudo (e.g., incertezas no crescimento da carga e na disponibilidade de fontes energéticas). O mais comum e mais completo entre esses modelos é o modelo DC, que é considerado por grande parte dos pesquisadores como aquele que possui a melhor relação entre qualidade e complexidade de solução. Ele permite que o algoritmo de otimização obtenha bons resultados em um tempo computacional hábil. Apesar de ser classificado como um modelo linear de planejamento, devido à sua origem nas equações linearizadas de fluxo de potência (fluxo DC), este modelo representa ainda um problema de programação não-linear. Isto se deve ao produto entre as variáveis de decisão de investimento e de fase de tensão nodal presente na restrição do problema de otimização referente à lei de Kirchhoff das tensões. A não linearidade desse modelo é melhor evidenciada no Capítulo 3 do presente trabalho, onde as equações do problema de otimização são apresentadas.

O modelo DC, principalmente quando consideradas as perdas ôhmicas na transmissão, permite uma boa representação da rede do sistema. Contudo, suas soluções, quando comparadas às soluções obtidas via modelo $\mathrm{AC}$, necessitam ainda da adição de reforços extras, isso devido ao fluxo de reativo não contemplado. A consideração das perdas ôhmicas nesse modelo pode ser realizada de forma iterativa, onde são calculadas a cada iteração, e de forma aproximada, as perdas na rede a partir da solução do fluxo de potência (e.g., [5], [29], [30] e [31]). Essas perdas são então divididas igualmente entre as barras conectadas por cada circuito na forma de cargas fictícias, para que então o cálculo do fluxo de potência seja novamente calculado.

Dentre os modelos classificados como lineares, o modelo de transportes, utilizado primeiramente em [32], é o mais simples. Esse modelo pode ser considerado como uma simplificação do modelo DC completo, que tem por intuito remover a não-linearidade gerada pela lei de Kirchhoff das tensões. Dessa forma, no modelo de transportes é considerado apenas a lei de Kirchhoff das correntes, apresentando somente equações lineares em suas restrições e reduzindo a complexidade na solução do problema PET. Por ser essencialmente um problema linear de otimização, na solução do problema PET com modelo de transportes podem ser utilizadas técnicas de programação linear inteira mista. 
Por outro lado, devido às simplificações consideradas no modelo de transportes, as soluções encontradas apresentam qualidade reduzida quando comparados aos modelos mais completos, como o modelo DC ou o AC. Além disso, as soluções encontradas utilizando o modelo de transportes podem apresentar cortes de carga para a rede intacta quando consideradas as restrições referentes à lei de Kirchhoff das tensões, necessitando assim de reforços adicionais a fim de garantir o correto atendimento à demanda, podendo levar a custos de investimentos maiores. Alguns exemplos de trabalhos que utilizam modelos de transporte são: [32], [47] e [48].

Outro modelo linear de planejamento da transmissão muito utilizado na literatura é o modelo disjuntivo, primeiramente proposto em [34]. Nesse modelo, o problema PET é convertido de um problema de programação não-linear inteira mista em um equivalente linear com variáveis binárias por meio da utilização de um coeficiente disjuntivo de valor suficientemente elevado. Esse modelo tem como vantagem a facilidade da solução de um problema de programação linear inteira binária. Em contrapartida, uma complicação gerada pelo o uso desse modelo é a determinação do valor do coeficiente disjuntivo, além do considerável aumento do número de variáveis do problema. Alguns exemplos da utilização do modelo disjuntivo na solução do problema PET podem ser encontrados em [49], [50] e [51].

Já o modelo híbrido incorpora características do modelo de transportes e do modelo DC, de forma a reduzir a complexidade do problema relacionado ao modelo DC, isso, ao mesmo tempo em que aprimora a qualidade das soluções apresentadas a partir do modelo de transportes. No modelo híbrido, os fluxos de potência referente aos ramos presentes no caso base do problema e os fluxos de potência relacionados aos novos ramos adicionados são tratados de forma distinta. Dessa forma, as restrições relacionadas à lei de Kirchhoff das tensões são avaliadas somente para os ramos presentes na topologia base do sistema, enquanto que para os novos ramos adicionados são mantidas as considerações originais referentes ao modelo de transportes.

Uma vantagem referente ao modelo híbrido é a redução da complexidade do problema PET, tornando-o de mais fácil solução quando comparado a modelos mais completos como o próprio modelo DC. Contudo, as diferentes tratativas dadas aos fluxos de potência dos novos ramos, muitas vezes pode levar à inviabili- 
dade das soluções quando considerado um estudo com modelos mais completos. Um exemplo da aplicação do modelo híbrido pode ser visto em [33].

Já o modelo AC é o modelo mais completo dentre os modelos mencionados. Nele, são consideradas todas as não linearidades referentes às equações de fluxo de potência, além de não considerar as simplificações feitas pelos modelos lineares referentes ao nível de tensão das barras. Neste sentindo o modelo AC permite a consideração dos cálculos não somente do fluxo de potência ativo, como também planejamento e alocação de potência reativa de forma conjunta ao PET, levando a um conjunto de soluções finais mais próximas da realidade do sistema, e com uma menor necessidade de adaptações posteriores. Outras vantagens referentes ao modelo AC podem ainda ser citadas, como: representação mais precisa das perdas de potência da rede e a possibilidade de realização de outros estudos em conjunto ao problema PET (e.g., estudos de estabilidade de tensão e transitória). Além disso, o modelo AC permite a consideração de outros elementos nãolineares na solução do problema, como os Sistemas Flexíveis de Transmissão em Corrente Alternada (FACTS) [6].

Apesar das vantagens apresentadas, algumas características de sistema reais podem dificultar a utilização do modelo AC, como, por exemplo, a presença de sistemas isolados, situação comum no início do planejamento. Além disso, o considerável aumento na complexidade de solução aliado ao alto nível de incertezas associadas ao PET e ao problema da explosão combinatória, podem tornar inviável o uso desse modelo para sistemas de grande porte e/ou problemas com horizonte de planejamento de longo prazo. Exemplos da aplicação do modelo AC podem ser vistas em [28], [52] e [53].

Neste sentido, dada a complexidade de se usar um modelo AC, pouquíssimos trabalhos o utilizam em uma primeira análise do problema, podendo, portanto, a utilização de modelos lineares (principalmente o modelo DC com perdas) ser considerada uma ótima estratégia para análises iniciais do problema [28]. As soluções encontradas através desses modelos são então futuramente reavaliadas utilizando-se modelos mais completos, como realizado em [54], onde primeiramente é realizada uma busca utilizando-se um modelo DC e, em seguida, as soluções encontradas são então avaliadas em relação às restrições do modelo AC. Caso essas soluções não sejam viáveis, é realizada uma busca utilizando-se um modelo $\mathrm{AC}$ a fim de se determinar os ramos adicionais e os compensadores reativos a serem 
instalados na rede visando ao pleno atendimento da carga ativa e reativa do sistema.

\section{3.}

\section{Técnicas de Solução}

De forma geral, problemas de otimização no ambiente de planejamento visam à alocação de recursos no sistema de forma ótima, a fim de se maximizar ou minimizar função(ões) de uma ou mais variáveis, a(s) qual(is) pode(m) estar ou não limitada(s) por um conjunto de restrições. As restrições, por sua vez, são representadas por uma série de equações e/ou inequações. O problema PET, além de essencialmente ser considerado um problema de programação não-linear inteira mista, apresenta natureza combinatória e pode ser considerado um problema do tipo NP-completo [15] e [55], ou seja, não há nenhum método que possa resolvêlo em tempo polinomial.

Dessa forma, a fim de se atender a necessidade de se obter uma boa razão entre qualidade da solução encontrada e custo computacional requerido para encontrar essa solução, da mesma forma que foram propostos diferentes modelos de representação da rede elétrica, também têm sido apresentados na literatura diferentes métodos de solução para o problema PET.

Tais métodos de solução podem ser classificados, basicamente, em métodos de otimização clássica, técnicas heurísticas e técnicas metaheurísticas. A seguir são apresentadas e discutidas as principais características relacionadas a esses métodos.

\subsection{1.}

\section{Otimização Clássica}

As técnicas de otimização clássica configuram os primeiros modelos de otimização propostos na literatura para a solução do problema PET, sendo apresentados sob perspectiva de modelos de programação linear [56]. Essas técnicas visam encontrar valores exatos/ótimos para o conjunto de variáveis de decisão que levem a minimização ou maximização do problema que se deseja otimizar. Dentre os principais modelos de otimização clássica propostos para a solução do problema PET, podem ser citadas as técnicas de programação linear (e.g., [32], [57], [58] e [59]), programação não-linear (e.g., [60] e [61]), programação inteira mista 
(e.g., [62], [63], [64] e [50]), decomposição matemática (e.g., [56], [48], [65], [49] e [66]) e algoritmo branch-and-bound (e.g., [33] e [67]).

Uma vantagem das técnicas de otimização clássica é que, de forma geral, são capazes de encontrar a solução ótima global para o problema PET, apresentando grande eficiência para problemas menores e de baixa complexidade. Porém, dada a natureza combinatória, a não-linearidade e a não convexidade do problema PET, principalmente em sistemas de médio e grande porte, o emprego dessas técnicas pode apresentar problemas de convergência, além de um custo computacional elevado, tornando difícil a construção de algoritmos que possam ser executados em tempo razoável [3].

Um exemplo da utilização de técnicas de programação linear na solução do problema PET pode ser encontrado em [32]. Neste trabalho, é utilizado na solução do fluxo de potência o modelo de transportes, sendo adicionado a cada fase do algoritmo um circuito ao ramo que apresente maior sobrecarga. Já em [57], as técnicas de programação linear são utilizadas na solução de duas redes, uma composta pelos elementos já existentes na rede, representada por um modelo DC, e uma composta por elementos fictícios, representada por um modelo de transportes, sendo essa última utilizada para a identificação da necessidade de reforços no sistema. Além dos modelos citados, pode-se mencionar ainda alguns outros trabalhos que utilizam técnicas de programação linear para a solução de modelos lineares então propostos: [58] e [59].

Os modelos baseados em técnicas de programação linear ignoram a natureza discreta das decisões de investimento (variáveis de decisão com valores inteiros). Neste caso, se faz necessária a utilização de técnicas de programação linear inteira mista, que por sua vez são utilizadas em diversos trabalhos na literatura (e.g., [62], [63], [64] e [50]), sendo, dentre as técnicas de otimização clássica, a mais utilizada para lidar com a solução do problema PET baseado em um modelo DC [4].

Tanto as técnicas de programação linear quanto as de programação inteira mista citadas não são capazes de lidar de forma direta com não-linearidades como as presentes em um modelo AC (ou mesmo no modelo DC completo). Neste caso, podem ser utilizadas técnicas de programação não-linear como é o caso em [61], onde uma ferramenta de otimização comercial de programação não-linear, chamada MINOS/Augmented, é utilizada para acomodar as não-linearidades de um 
modelo AC. Essa ferramenta implementa um algoritmo do tipo Lagrangiano Aumentado na solução de problemas de não-lineares de larga escala.

Em [60], é evidenciado uma importante dificuldade relacionada aos métodos de programação não-linear: determinar o ponto de partida do processo. Isso, pois dependendo do valor escolhido, o algoritmo pode recair, durante o processo iterativo inerente, em um ótimo local e, portanto, não sendo a técnica capaz de encontrar a solução ótima global para o problema. Isso se deve principalmente ao fato de que as técnicas de programação não-linear consistem, em geral, em métodos iterativos que envolvem o cálculo de derivadas, como é o caso dos métodos de Newton-Raphson, método do maior declive, entre outros.

Outras ferramentas de otimização clássica amplamente difundidas para a solução do problema PET, principalmente quando considerada a natureza estocástica das incertezas do problema, são aquelas baseadas em técnicas de decomposição, como a de decomposição de Benders (e.g., [48], [49], [56] e [65]). Nesta decomposição, o problema original é dividido em dois subproblemas, chamados de mestre e escravo (no caso do problema PET, subproblemas de investimento e operação, por exemplo). Estes subproblemas são resolvidos de forma iterativa e alternada, onde os valores encontrados a partir da solução do subproblema mestre serão fixados e utilizados pelo subproblema escravo, que por sua vez retorna informações relevantes ao problema mestre na forma de novas restrições chamadas de corte de Benders. Outro exemplo é a decomposição hierárquica, proposta por Romero e Monticelli em [66]. Nela, são utilizados três níveis diferentes de modelos de rede: modelo de transportes, modelo híbrido e modelo DC. Estes modelos são empregados na decomposição hierárquica de maneira alternada, do modelo mais simples ao modelo mais completo, conforme o algoritmo se aproxima da solução final. A cada fase, o problema é ainda decomposto segundo o método de Benders.

Em [33], é utilizada outra técnica de otimização clássica para a solução de um problema PET estático, quando representado por um modelo híbrido de rede, o chamado algoritmo branch-and-bound (B\&B). Normalmente utilizado em problemas de otimização combinatória, esta técnica tem como ideia principal relaxar e dividir o problema em vários subproblemas de forma a facilitar a busca da solução ótima por meio de comparação. Durante o processo de solução é criada uma árvore de enumeração sistêmica e inteligente, onde a cada iteração do algoritmo os limites superiores e inferiores são atualizados, de forma a se realizar uma "po- 
da" na árvore, descartando soluções consideradas ineficazes. Outro exemplo da aplicação do algoritmo B\&B na solução do problema PET a partir de um modelo de transportes pode ser vista em [67].

\subsection{2. \\ Otimização Heurística}

Dadas as dificuldades e limitações apresentadas na utilização de métodos de otimização clássica, os métodos heurísticos surgem como uma alternativa para a solução do problema PET. Apesar de não garantirem a solução ótima, os métodos heurísticos apresentam taxas de convergência maiores e um custo computacional bastante reduzido quando comparados às técnicas clássicas. Apesar disso, principalmente quando aplicados a sistemas de grande porte, podem apresentar soluções de baixa qualidade [3] e [68].

Em resumo, os métodos heurísticos são técnicas iterativas de otimização (algoritmos heurísticos construtivos - AHC) que, a cada passo, selecionam, constroem e avaliam possíveis planos de expansão. O processo de construção desses métodos é baseado em regras lógicas ou empíricas, normalmente traduzidas em índices de sensibilidade. Esses índices são então utilizados para selecionar os ramos a serem adicionados no sistema [27], sendo que, de forma geral, os algoritmos heurísticos adicionam somente um novo circuito por vez. A convergência do algoritmo se dá quando um plano de expansão viável é encontrado.

Ademais, alguns reforços adicionados durante o processo construtivo podem se tornar obsoletos após a inserção de outro de maior importância para o problema. Neste sentido, em [69], após a convergência do algoritmo, os reforços são ordenados e removidos, um a um, sendo verificada a viabilidade do plano após cada remoção. Caso a remoção do ramo não afete a viabilidade (factibilidade) da solução, o mesmo é então removido permanentemente, reduzindo assim o investimento necessário na solução final. Tal estratégia é também considerada na proposição da ferramenta de otimização realizada no presente trabalho.

Existem basicamente dois diferentes tipos de AHC, que se diferem somente pela definição dada aos índices de sensibilidade: algoritmos heurísticos que utilizam fatores elétricos do sistema, como em [70], e algoritmos que utilizam versões relaxadas do próprio modelo para identificar o melhor ramo a ser reforçado, como 
é o caso de trabalhos [71], [28] e [32], sendo este último tipo, o primeiro AHC proposto na literatura.

Em [70], um AHC é utilizado na solução do problema PET com modelagem DC. As informações sobre a folga de capacidade de transmissão em cada ramo candidato, obtidas por meio da solução do problema de operação utilizando a configuração corrente, são utilizadas para selecionar as linhas saturadas, ou seja, com folgas menores que um determinado valor definido pelo planejador. Diferente do que é normalmente encontrado na literatura, neste trabalho mais de um reforço pode ser adicionado simultaneamente.

Em [32], os índices de sensibilidade que representam informações heurísticas do problema são calculados da solução do então utilizado modelo de transportes, considerando o relaxamento da natureza discreta das decisões de investimento. A mesma estratégia de relaxamento é observada em [71] e [28], onde são utilizados modelos de programação não-linear inteira mista, sendo respectivamente, um modelo DC e um modelo AC. Em ambos os casos, o cálculo dos índices de sensibilidade é realizado, portanto, via solução de problema de programação nãolinear.

Em [72] é realizado uma análise de algoritmos heurísticos para a solução do problema PET estático utilizando um modelo de transportes. Além disso, é proposta neste trabalho uma extensão do algoritmo apresentado em [32], para a solução do problema multiestágio do PET.

\subsection{3.}

\section{Otimização Metaheurística}

Métodos de otimização metaheurística são, de certa forma, uma classe especial de técnicas heurísticas e, assim como tais, não permitem a garantia de identificação da solução ótima global para o problema. Essas técnicas possuem procedimentos aprimorados de busca, normalmente baseadas em fenômenos da natureza, capazes de evitar ótimos locais e exercer uma busca eficiente no espaço de soluções. De forma geral, a qualidade das soluções encontradas por técnicas metaheurísticas é superior à qualidade das soluções obtidas através de técnicas heurísticas tradicionais, possibilitando bons desempenhos até mesmo em sistemas de grande porte, com a identificação de soluções de alta qualidade [3], [11] e [16]. 
Uma das principais vantagens da utilização de técnicas metaheurísticas, em geral, é a baixa dependência do problema. Diferente do que é visto no emprego de técnicas heurísticas e em técnicas de otimização clássica, no uso de técnicas metaheurísticas são necessárias poucas ou nenhuma informação do problema para guiar o processo de busca, podendo o mesmo algoritmo ser aplicado a uma ampla gama de problemas de forma mais simplificada, ou seja, necessitando de poucos ajustes em seus parâmetros [3] e [6]. Apesar disso, entre os trabalhos publicados, pode-se encontrar algoritmos metaheurísticos dedicados à solução do problema PET, ficando sua aplicação limitada a este tipo de problema [11].

Nos últimos anos, diversos trabalhos vêm sendo publicados apresentando diferentes técnicas de otimização metaheurísticas, dentre às quais vale a pena citar: Recozimento Simulado (Simulated Annealing - SA) (e.g., [73], [74] e [75]), Busca Tabu (Tabu Search - TS) (e.g., [9] [29], [76] e [77]), Otimização por Enxame de Partículas (Particle Swarm Optimization - PSO) (e.g., [8] e [41]), Sistemas Imunológicos Artificiais (Artificial Immune System - AIS) (e.g., [31]), Estratégia Evolutiva (Evolutionary Strategy - ES) (e.g., [30] e [78]), Algoritmo Genético (Genetic Algorithm - GA) (e.g., [10], [12], [13], [15], [38], [39], [54], [55] e [79]), Evolução Diferencial (Differential Evolution - DE) (e.g., [80], [81] e [82]), Otimização por Colônia de Formigas (Ant Colony Optimization - ACO) (e.g., [44] e [83]) e Busca Adaptativa Aleatória Gulosa (Greedy Randomized Adaptive Search Procedures - GRASP) (e.g., [84] e [85]).

As técnicas metaheurísticas citadas se diferenciam principalmente no tipo de estratégia utilizada no processo de busca e, embora cada um dos algoritmos possua uma estratégia particular, muitos ainda possuem características comuns, a partir das quais pode ser realizada uma categorização em diferentes classes. Essas classes são definidas de acordo com o método de categorização utilizado e podem se basear, por exemplo, no tipo de uso de memória, no tipo de exploração da vizinhança, ou mesmo pelo número de soluções exploradas simultaneamente. Neste sentido, em [86] os algoritmos são classificados em metaheurísticas baseadas em população e metaheurísticas de solução única. Essa mesma estratégia de classificação é seguida no presente trabalho para apresentação das técnicas. As metaheurísticas classificadas como baseadas em população são ainda divididas em dois outros subgrupos: metaheurísticas relacionadas à computação evolucionária (Evo- 
lutionary Computation - EC) e metaheurísticas relacionadas à inteligência de enxame (Swarm Intelligence $-S I)$.

\section{- Metaheurísticas de Solução Única}

As técnicas classificadas como metaheurística de solução única, ou também chamadas de algoritmos de trajetória, se baseiam na modificação iterativa de uma única solução (ou de mais soluções, desde que de forma independente, como o caso de algoritmos paralelizados) realizando movimentos dentro de uma determinada vizinhança próxima à solução corrente e desenvolvendo uma trajetória ao longo do espaço de busca. A cada iteração do algoritmo, o movimento realizado é determinado seguindo a estratégia de busca empregada, que pode incluir mecanismos de diversidade com o objetivo de evitar o aprisionamento do algoritmo em ótimos locais. Os principais algoritmos pertencentes à categoria de metaheurísticas de solução única são TS, SA e o método GRASP.

O método SA é baseado na técnica de recozimento utilizado no tratamento de materiais sólidos, que consistem em aquecer o material até atingir altas temperaturas e lentamente diminuí-la a fim de se obter um sólido de estrutura cristalina de mínima energia. Nesse contexto, o algoritmo parte de uma única solução a uma dada temperatura inicial $T$ e, a cada iteração do algoritmo, uma nova solução é selecionada na vizinhança para se tornar a nova solução corrente até que se atinja o equilíbrio térmico. A nova solução será aceita como solução corrente com base no valor de sua energia e da temperatura atual. Caso haja uma redução da energia, a substituição é aceita com probabilidade igual a um, porém, caso haja um aumento, essa substituição se dará com certa probabilidade dependente de $T$, sendo essa probabilidade normalmente maior no início do processo onde a temperatura é elevada e menor conforme se dá o processo de resfriamento [86]. Segundo [73], essa probabilidade de aceitar soluções que representem uma piora da função objetivo é o que permite ao algoritmo evitar o aprisionamento em ótimos locais, sendo a eficiência do algoritmo dependente das temperaturas inicial e final, assim como da taxa de variação da mesma e do número de transições de estado feitas em cada temperatura (movimentos realizados até que se atinja o equilíbrio térmico).

Alguns exemplos de trabalhos que utilizam o método SA na solução do problema PET são [73], [74] e [75]. Em [73], é proposto um SA para a solução do 
problema PET estático, onde as transições são realizadas através da adição, subtração, ou troca de reforços entre dois ramos candidatos, sendo esses mecanismos utilizados de forma alternada em caso de não aprovação da substituição da solução corrente. Já em [74], é proposta uma versão do algoritmo discutido em [73] utilizando processamento paralelo no qual o número de operações de transição é dividido entre o número de processadores disponíveis, o que permite acelerar o processo de solução do problema. Em [75], por sua vez, utiliza-se um SA na solução do problema PET multiestágio com consideração da avaliação da energia esperada não suprida (EENS).

Outra técnica metaheurística de solução única muito utilizada na solução do problema PET é o algoritmo TS. Este algoritmo emprega em seu processo de busca mecanismos de memória que se baseiam na memória humana. Esses mecanismos impõem restrições ao processo, o que permite uma melhor exploração do espaço de busca, guiando a busca para espaços ainda não explorados, além de evitar aprisionamento em ótimos locais e repetição de ciclos [87]. As estruturas de memória utilizadas pelo algoritmo TS são normalmente utilizadas para armazenar soluções já visitadas e/ou propriedades das mesmas, de forma a proibir que essas soluções sejam revisitadas durante determinado período do processo de busca.

No TS, todas as restrições são armazenadas nas chamadas "listas tabu", as quais, do ponto de vista de estruturas de memória, podem ser tidas como uma memória de curto prazo, responsável por armazenar informações de soluções visitadas recentemente, de forma a evitar ciclos, ou uma memória de longo prazo, capaz de compreender informações de soluções de forma não tão imediata, mantendo um número maior de restrições e dando uma maior diversidade ao algoritmo. Esta estratégia permite ao TS explorar espaços ainda não visitados de maneira mais eficiente. Um tipo especial de memória de longo prazo, que pode também ser utilizada, é a memória de frequência, responsável por armazenar a frequência com que alguns atributos de soluções têm sido visitados. Ela permite ao processo evitar atributos visitados com frequência, ou priorizá-los, evitando atributos pouco visitados [86].

Em [76], é proposta a utilização de um algoritmo TS, sendo este empregado na solução de um problema PET estático a partir de um modelo de rede linear DC. Outros trabalhos também utilizam o método TS, como por exemplo [9], [29] e [77]. Em [9], é proposto um algoritmo TS para a solução do problema PET estáti- 
co, onde os conceitos básicos do TS são combinados com o uso de índices de sensibilidade para determinar os ramos a serem modificados durante sua trajetória. Já em [29], é proposto o uso do método TS no problema PET multiestágio considerando os custos das perdas de transmissão e de confiabilidade, relacionada ao custo de interrupção (LOLC). Neste trabalho, são utilizadas técnicas heurísticas como as do GRASP para construção de soluções iniciais de forma inteligente. Por fim, em [77], é proposto o uso de um algoritmo TS paralelizado, que permite explorar mais de uma solução simultaneamente, de forma similar ao proposto em [74]. Além disso, o algoritmo traz aprimoramentos baseados em outras técnicas de busca, como as técnicas metaheurísticas recozimento simulado e algoritmos genéti$\cos$.

Já o método GRASP se constitui de duas etapas: construção e busca local. Na primeira etapa, a cada iteração é adicionado um elemento a uma solução parcial do problema até que a mesma se torne viável. O elemento a receber a adição é escolhido de forma aleatória dentro de uma lista, chamada de lista de restrição de candidatos, a qual é composta por todos os elementos mais atrativos a serem adicionados ao sistema. Essa lista é atualizada de forma iterativa através de uma função "gulosa" (greedy), responsável por medir o benefício associado à adição de cada elemento e pode ser limitada por um parâmetro baseado no número total de elementos da lista, ou pela qualidade dos mesmos. Esse parâmetro determinará o quão "gulosa" será a busca. Na etapa seguinte, é realizado um processo de busca local na vizinhança da solução obtida na primeira etapa, de forma a obter uma solução melhor do que aquela encontrada anteriormente, visto que não é possível garantir a otimalidade da solução dentro de sua vizinhança.

Em [84], é utilizado o método GRASP na solução de um problema PET estático de longo prazo, onde a atratividade de cada elemento, utilizada para a formação da lista de restrição de candidatos, é baseada nos multiplicadores de Lagrange relacionados à susceptância das linhas de transmissão. Esses valores são obtidos através da solução de um problema de programação linear que tem como objetivo a minimização do corte de carga da rede. O fim da fase de construção se dá quando não existem mais cortes de carga no problema. Neste trabalho, após a fase de construção é utilizada uma técnica de remoção de reforços obsoletos de forma semelhante ao utilizado em [69]. A solução obtida após a aplicação da téc- 
nica de remoção é então submetida à etapa de busca local, que consiste, nesse caso, basicamente da troca de reforços entre ramos candidatos.

Já em [85], é usado um algoritmo que combina os conceitos do GRASP com a técnica Path Relinking, que consiste na exploração do espaço entre duas soluções de alta qualidade encontradas anteriormente, misturando os seus atributos na busca por melhores soluções. Após a fase de busca local do GRASP, é utilizada a técnica de Path Relinking com a solução corrente e uma solução escolhida de forma aleatória de uma lista de soluções de alta qualidade. Durante o processo de Path Relinking, os movimentos realizados são também determinados utilizando conceitos da fase de construção do GRASP, garantindo à técnica o conceito de aleatoriedade e diversidade.

\section{- Metaheurísticas baseadas em população}

Diferente das metaheurísticas de solução única, metaheurísticas baseadas em população exploram o espaço de soluções por meio de um conjunto de soluções diferentes, chamado de população, o que permite uma busca mais ampla pelo espaço de soluções. Durante o processo de otimização, pode haver, inclusive, uma interação entre as soluções. Segundo [86], dependendo da técnica utilizada para a movimentação das soluções dentro do espaço de busca, as metaheurísticas baseadas em população podem ser ainda divididas em dois grandes subgrupos: algoritmos relacionados à computação evolucionária (e.g., AIS, ES, GA e DE), que utilizam técnicas inspiradas na teoria da evolução biológica de Darwin; e algoritmos relacionados à inteligência de enxame (e.g., PSO e ACO), baseados no comportamento coletivo de agentes de um conjunto.

\section{- Metaheurísticas relacionadas à inteligência de enxame}

As técnicas metaheurísticas relacionadas à inteligência de enxame se baseiam no comportamento coletivo de um grupo de indivíduos em uma sociedade que interagem localmente entre si e com o ambiente que os cerca. Embora não possuam uma estrutura central de organização, pode-se perceber o surgimento de uma inteligência comunitária não observada em um único indivíduo [5] e [86]. Ou seja, embora um indivíduo por si só não possua a capacidade para realizar uma determinada tarefa, é possível que um conjunto de indivíduos operando coletivamente consigam atingir tal objetivo de forma otimizada. Dentre as metaheurísticas que 
fazem analogia a este tipo de comportamento estão as técnicas ACO, que se baseia no comportamento organizado de formigas em uma colônia, e o PSO, baseado no movimento organizado de um bando de pássaros e de cardumes de peixes.

A metaheurística ACO é baseada no comportamento coletivo de formigas de uma colônia quando na procura de comida. Buscando a melhor rota entre a colônia e a fonte de alimento, um conjunto inicial de formigas explora a vizinhança enquanto depositam ao longo do caminho uma substância conhecida como feromônio. Esse feromônio é responsável por guiar as formigas pelos caminhos já percorridos. Em geral, os caminhos mais favoráveis (mais curtos) tendem a ter uma maior taxa de feromônio depositado. Sendo assim, eles possuem uma maior probabilidade de serem escolhidos por outras formigas e de terem seu feromônio reforçado. Após um tempo, o caminho mais curto entre a colônia e a fonte de alimento será aquele que apresentar uma maior concentração da substância.

Em analogia ao problema PET, a cada iteração do algoritmo ACO, um conjunto de formigas (soluções) se move através do espaço de busca realizando movimentos aleatórios que consistem na adição de reforços aos ramos candidatos até que cada formiga corresponda a uma solução viável do problema. Neste sentido, cada ramo candidato é representado por uma opção de rota a ser escolhida, sendo que, para cada caminho escolhido (reforço adicionado) um incremento no nível de feromônio relativo àquele caminho é realizado. Ao final de cada iteração, as informações de cada indivíduo são compartilhadas entre o conjunto de forma a atualizar a informação relativa à quantidade de feromônio de cada ramo candidato, fazendo com que candidatos que possuam maior concentração da substância tenham uma maior probabilidade de serem reforçados em outros indivíduos na geração seguinte.

Um exemplo da aplicação da metaheurística ACO na solução do problema PET multiestágio pode ser visto em [44]. Neste trabalho, são considerados os custos de investimento e a confiabilidade da operação, esta última traduzida por meio do custo de interrupção (índice LOLC). A estratégia utilizada neste trabalho se baseia no algoritmo de Sistemas de Colônia de Formigas (Ant Colony System $A C S$ ), técnica pertencente à classe da metaheurística ACO. Nesta técnica, os movimentos realizados por cada formiga, chamados de transição, são guiados por informações heurísticas traduzidas por meio de multiplicadores de Lagrange obtidos através da solução de um problema de programação linear baseado em um 
modelo de fluxo de potência DC, utilizado na avaliação das soluções a cada reforço adicionado.

Já em [83], a metaheurística ACO é utilizada na solução do problema PET estático baseado em um modelo de rede DC, com consideração do critério de segurança "N-1". Os resultados obtidos pela ferramenta em dois sistemas testes de diferentes tamanhos são comparados com outras técnicas metaheurísticas como GA e TS em termos de qualidade de solução e esforço computacional.

Outra metaheurística baseada em inteligência de enxame é a técnica PSO. A técnica PSO é inspirada no movimento sincronizado de bando de pássaros e/ou de cardumes de peixes. Neste sistema, embora cada partícula se movimente independentemente, ou seja, baseado em seus próprios conhecimentos acumulados, eles também irão ao mesmo tempo seguir um indivíduo líder, o qual retém o melhor valor de aptidão. Dado que cada indivíduo possui um comportamento independente, a cada iteração do algoritmo é determinado entre os organismos do bando aquele com melhor aptidão que guiará o conjunto a partir de então, ajustando assim a sua trajetória. Normalmente, cada indivíduo de um bando é chamado de partícula e sua movimentação pelo espaço de busca é afetada por três fatores, sua própria velocidade, a melhor posição atingida por ele até o momento e a melhor posição atingida por todas as partículas [5].

Em [41], um algoritmo PSO aprimorado é utilizado na solução do problema PET multiestágio com modelo de rede DC e consideração do critério de segurança "N-1". O algoritmo traz aprimoramentos ao PSO básico, usando dois mecanismos de mutação com o objetivo de manter a diversidade das soluções durante as últimas iterações do algoritmo.

Já em [8], o algoritmo PSO é utilizado para a solução de um problema PET estático com modelagem de rede DC. Um algoritmo heurístico construtivo, baseado no algoritmo proposto por Garver [32], é proposto para determinar os ramos mais relevantes para o problema de forma a reduzir o espaço de busca de forma eficiente. Os ramos selecionados durante a solução do AHC são utilizados como informação heurística durante o processo de busca do PSO e as soluções obtidas utilizadas como trajetórias iniciais do algoritmo.

\section{- Metaheurísticas relacionadas à computação evolucionária}

As metaheurísticas baseadas em população relacionadas à classe de computação evolucionária se referem a um grupo de metaheurísticas que fazem uso de 
um conjunto de mecanismos inspirados na teoria da evolução de Darwin, tais como: seleção, mutação e cruzamento. Neste tipo de método, as soluções são normalmente chamadas de "indivíduos", os quais possuem a capacidade de se reproduzir. Cada iteração do algoritmo é dita como uma "geração", a qual é composta por uma seleção dos indivíduos mais aptos ao problema. Dentre as técnicas de otimização metaheurísticas mais comuns pertencentes a esta classificação, pode-se citar: AIS, ES, DE e GA.

A metaheurística AIS é baseada nos princípios de um sistema imunológico natural de combate aos patógenos invasores sem prévio conhecimento de sua estrutura, evoluindo anticorpos diversos a partir da seleção natural dos mais aptos a lidar com o antígeno invasor. A técnica AIS pode ser classificada em três categorias principais segundo [88]. Uma das estratégias mais utilizadas na aplicação da técnica AIS é a baseada na teoria da seleção clonal e maturação de afinidades. Neste sentido, os anticorpos com maior afinidade ao antígeno invasor são selecionados para se reproduzirem por meio de clonagem. Durante este processo, é realizada uma estratégia de maturação com aplicação de um mecanismo de hipermutação, de forma a aumentar a afinidade dos anticorpos ao antígeno. A nova geração de anticorpos é então selecionada tomando por base os melhores anticorpos resultantes do processo. Outras estratégias para a utilização da técnica AIS são ainda propostas e descritas com maiores detalhes em [86], [88] e [89].

Um exemplo da aplicação do método AIS para a solução do problema PET multiestágio com consideração das perdas ôhmicas pode ser encontrado em [31]. Neste trabalho é realizada uma comparação de desempenho entre as técnicas AIS e DE em dois sistemas: um sistema teste de pequeno porte e um subsistema de transmissão real. São ainda utilizadas informações heurísticas como as utilizadas no GRASP para construção de soluções iniciais, como realizado em [29]. Resultados neste trabalho apontam para um melhor desempenho da técnica AIS.

Já o método ES utiliza operadores de seleção e mutação para simular o processo de evolução de uma determinada população, com a vantagem de não necessitar de uma codificação para a representação de variáveis, uma vez que as mesmas são representadas por variáveis reais. Por meios da mutação, indivíduos da população corrente, denominados indivíduos pais, sofrem uma perturbação, que consiste na aplicação de mudanças em cada variável (gene) que compõe o indivíduo. Essas mudanças são dadas por uma distribuição normal. Esse mecanismo 
permite ao algoritmo a busca em diferentes regiões do espaço sem aprisionamentos em ótimos locais. Já por meio do operador de seleção, são selecionados os melhores indivíduos para formar a geração seguinte, o que é realizado com base na aptidão desses indivíduos. Nesse ponto, os principais algoritmos utilizados são: $(\mu+\lambda)$-ES, onde $\mu$ indivíduos pais geram $\lambda$ novos indivíduos filhos e os indivíduos que compõe a nova geração são selecionados do conjunto $(\mu+\lambda)$; e $(\mu, \lambda)$-ES, no qual os indivíduos que compõe a nova geração são selecionados somente entre os $\lambda$ indivíduos filhos criados [86].

Em [78] é possível verificar a utilização de um algoritmo do tipo $(\mu+\lambda)$-ES na solução do problema PET tendo em vista as mesmas considerações adotadas em [29]. O desempenho do algoritmo é validado através de testes realizados em dois sistemas, um sistema teste de pequeno porte e um subsistema brasileiro de transmissão.

A metaheurística ES é também utilizada em [30] na solução de um problema PET multiestágio utilizando o sistema Garver [32], onde é feita uma comparação dos resultados obtidos com e sem a consideração de um critério de segurança " $\mathrm{N}$ 1". É realizada ainda neste trabalho uma análise em termos de confiabilidade das soluções obtidas em ambos os casos, por meio dos índices de confiabilidade LOLC E LOLE.

Outra metaheurística muito utilizada é a DE. Esta técnica, assim como a técnica ES, simula um processo evolutivo através da aplicação de operadores evolutivos, tais como: cruzamento, mutação e seleção. A principal diferença entre a metaheurística DE e outras metaheurísticas como a ES, ou mesmo ao GA, que utilizam operadores semelhantes, reside no processo de mutação. Nele as perturbações geradas pelo operador não utilizam funções densidade de probabilidade, ao invés disso, a mutação se dá pela diferença calculada entre vetores selecionados aleatoriamente na população corrente.

Já para o operador de cruzamento, de forma geral, a cada geração são selecionados indivíduos pais entre os indivíduos da população corrente e os indivíduos gerados através da mutação. Estes indivíduos selecionados passam, então, pelo mecanismo de cruzamento para a formação de novos indivíduos filhos, que são formados pela combinação de atributos dos indivíduos pais. Por fim, o operador de seleção determina, com base na aptidão, se um novo indivíduo filho deverá 
substituir o correspondente indivíduo pai pertencente à população atual, que o criou, determinando assim uma nova geração.

Em [80], é proposta a utilização da metaheurística DE para a solução do problema PET com a utilização de um modelo de rede AC. Considera-se, neste trabalho, não somente os custos de expansão, mas também os requisitos de confiabilidade da rede a partir do índice de energia não suprida (EENS) e o bem estar social a partir da expectativa de perdas econômicas. Uma comparação entre as metaheurísticas DE, ES e GA é realizada através de testes em dois sistemas de transmissão de diferentes dimensões.

Já em [81], é proposto um algoritmo DE especializado para a solução do problema PET estático com modelagem de rede AC e inclusão de compensação de potência reativa. O título "especializado" dado a esta técnica se deve às estratégias propostas na inicialização da população, as quais são baseadas na informação de que em sistemas reais somente 10 a 30\% dos ramos candidatos serão selecionados para receber reforços e no operador de seleção, que visa à redução de problemas de fluxo de potência ótimo a serem realizados durante a avaliação das opções de solução.

Um algoritmo DE aprimorado é também proposto em [82] para a solução do problema PET em um ambiente de restruturação e descentralização do mercado de energia, sendo propostas modificações ao algoritmo em comparação com um algoritmo DE original. Uma das alterações propostas é a comparação do indivíduo filho gerado a partir da recombinação, não com o seu respectivo pai, mas com o indivíduo pai mais próximo a ele em termos de distância Euclidiana.

Por fim, a metaheurística GA, na qual o presente trabalho se baseia, pode também ser descrita como uma metaheurística baseada em população inspirada no processo de evolução de Darwin. Nesta técnica, o processo de evolução é simulado através da aplicação de operadores evolutivos de mutação, cruzamento e seleção. A metaheurística foi primeiramente proposta por John Holland [79] e desde então vem sendo utilizada em diversos trabalhos na literatura (em diversas áreas de conhecimento), sendo uma das técnicas de computação evolucionária mais conhecida e utilizada [86]. Alguns aspectos do algoritmo proposto por Holland vêm sendo adaptados de acordo com o tipo de problema que se deseja resolver, mas de maneira geral, a estrutura do algoritmo permanece a mesma. A técnica GA é baseada, assim como nas técnicas ES e DE, em operadores evolutivos, onde a 
cada geração, indivíduos pertencentes à população serão avaliados de acordo com sua aptidão e sofrerão a ação desses operadores. Os operadores genéticos que têm por objetivo modificar e recombinar informações contidas em cada indivíduo, a fim de criar novas opções de solução, permitindo assim explorar novas regiões do espaço de busca ainda não visitadas e evitar possíveis aprisionamentos em ótimos locais.

Durante o processo evolutivo de um GA, cada indivíduo é formado por um conjunto de parâmetros (genes) codificados por um vetor binário de $i$ bits, porém, dependendo do problema, outros métodos de codificação podem ser ainda utilizados como: codificação inteira, codificação decimal ou codificação real. Diversas são também as estratégias de cruzamento que podem ser utilizadas durante o processo de busca, porém, de forma geral, seu funcionamento se baseia na escolha de dois ou mais indivíduos pais na população corrente por meio de um mecanismo de seleção. A estratégia de cruzamento, quando empregada a dois pais selecionados, visa à geração de novos indivíduos, chamados de indivíduos filhos. Durante o processo de seleção dos indivíduos pais, aqueles indivíduos com maior aptidão possuem uma maior probabilidade de serem escolhidos. As estratégias mais comuns de seleção nesta etapa são as de seleção por roleta e seleção por torneio. Além disso, normalmente uma determinada probabilidade, denominada taxa de cruzamento, determina se ocorrerá ou não o cruzamento entre os indivíduos selecionados.

Após a aplicação do operador de cruzamento, cada indivíduo filho gerado poderá ainda, com certa probabilidade chamada de taxa de mutação, sofrer uma alteração em seus genes de acordo com uma regra determinada pela estratégia utilizada. Por fim, um mecanismo de seleção definirá os indivíduos que constituirão a próxima geração, existindo também aqui diversas estratégias que podem ser adotadas. Uma delas considera, por exemplo, a seleção dos melhores indivíduos em termos de aptidão entre os pais e filhos. Outras buscam garantir a diversidade na seleção desses indivíduos.

Na solução do problema PET, a metaheurística GA tem sido amplamente utilizada com as mais diversas características e estratégias. Em [55], por exemplo, é proposto um GA com codificação decimal, chamado de Algoritmo Genético Estendido, em que a população inicial do algoritmo é gerada a partir da solução de 
técnicas heurísticas como as utilizadas em Garver [32]. Além disso, a taxa de mutação do algoritmo é controlada por meios de técnicas de SA.

Já em [54], é proposta uma estratégia para a utilização da técnica GA na solução do problema PET com modelagem AC associada ao planejamento de potência reativa. Durante a etapa de planejamento da expansão da transmissão é utilizado um GA com codificação real, enquanto que na etapa de alocação de fontes de potência reativa é utilizado um modelo de GA com codificação binária. O método de seleção utilizado pelo GA com codificação real é a seleção por "ranqueamento", enquanto o operador de mutação modifica de forma dinâmica as informações dos indivíduos, conforme o algoritmo tende à convergência.

Um algoritmo GA contendo um conjunto de operadores evolutivos especializados é também proposto em [15] para a solução de um problema PET multiestágio. Neste algoritmo a população inicial é gerada de forma inteligente através da solução de um AHC.

Além disso, outros diversos trabalhos que utilizam técnicas básicas ou aprimoradas da metaheurística GA na solução de diferentes modelos e particularidades do problema PET podem ser citados. Em [10], uma curva limite de perda de carga é traçada a partir de soluções inviáveis encontradas por um GA a partir da qual se espera prever o custo de investimento de uma possível solução ótima para o problema. Já em [12], um GA com codificação binária é utilizado na solução de um problema PET multiestágio sob um cenário de mercado descentralizado de energia. Em [13], um GA é utilizado na solução de um PET multiestágio com modelagem AC, sendo utilizado neste algoritmo um mecanismo de seleção por roleta em que somente indivíduos que atendam a todas as restrições podem ser selecionados, independente da sua aptidão. Em [38], um GA especialista é utilizado na solução de um problema PET com restrições de segurança via critério " $\mathrm{N}$ 1”. Em [39], um GA aprimorado é utilizado na solução de um problema PET com a inclusão do critério de segurança "N-1", onde uma lista de contingências é atualizada a partir de um índice de desempenho (PI).

\section{4.}

\section{Conclusões}

A partir do que foi abordado neste capítulo é possível visualizar que, com o aumento da complexidade e das dificuldades inerentes ao problema PET, cada vez 
mais se faz necessário o uso de ferramentas robustas e capazes de oferecer um equilíbrio em termos de qualidade final das soluções e o custo computacional exigido. Neste sentido, dentre as diversas abordagens apresentadas para a solução do problema PET, principalmente no que tange ao planejamento de longo prazo e a sistemas reais de grande porte, onde as dimensões e as incertezas do problema podem torná-lo intratável, a combinação do modelo de rede DC e técnicas metaheurísticas de otimização se mostra como uma boa alternativa para a obtenção de soluções de boa qualidade em tempo computacional não proibitivo. Dessa forma, a presente dissertação propõe a utilização de uma ferramenta robusta e especializada, baseada na metaheurística GA, para a solução do problema PET estático de longo prazo. O modelo adotado para representação da rede é o modelo linear DC com a consideração das perdas ôhmicas do sistema de transmissão. Além disso, é considerado o atendimento do critério determinístico de segurança "N-1" na definição pela ferramenta proposta dos planos de expansão para a rede. Detalhes da formulação do problema e da ferramenta proposta serão apresentados no próximo capítulo desta dissertação. 


\section{3. Algoritmo Genético Especializado para Solução do Pro- blema PET}

\section{1. Introdução}

Neste capítulo são abordados os detalhes relativos à ferramenta proposta neste trabalho para solução do problema PET estático, denominada Algoritmo Genético Especializado (AGE-PET). Inicialmente, é apresentada a formulação matemática adotada para o problema e, em seguida, as particularidades da dinâmica de solução da ferramenta proposta são abordadas.

O AGE-PET proposto nesta dissertação é baseado na técnica metaheurística Algoritmo Genético, e visa evoluir um conjunto de planos de expansão de forma iterativa através da aplicação de operadores evolutivos aprimorados (especializados para o problema em questão). De forma geral, estes operadores utilizam informações heurísticas fundamentadas em informações de fluxo de potência da rede, como carregamento/sobrecarga de circuitos e corte de carga do sistema, traduzidas em forma de índices de sensibilidade. Com o emprego destes índices, a seleção de reforços considerados mais atrativos é priorizada, o que conduz o processo evolutivo inerente à ferramenta em direção a planos de expansão com boa qualidade. Esta estratégia visa fazer do AGE-PET uma ferramenta robusta e capaz de lidar com diferentes tipos de sistemas de transmissão, sendo capaz de encontrar um conjunto de soluções de boa qualidade até mesmo para sistemas reais e de grande porte.

\section{2.}

\section{Formulação do Problema}

A fim de se obter um bom equilíbrio entre a qualidade final das soluções e o custo computacional requerido para solução do problema, principalmente em estudos de planejamento de longo prazo, é adotado neste trabalho o modelo DC para 
solução do problema PET. Basicamente, o problema de otimização PET estático baseado em um modelo de rede DC pode ser formulado como:

$$
\begin{array}{lll}
\text { Min.: } & g(n)=\sum_{i j \in \Omega_{r c}} c_{i j}^{i n v} n_{i j}+\sum_{k \in \Omega_{b g}} c_{k}^{g} g_{k}+\sum_{m \in \Omega_{b c}} c_{m}^{r} r_{m} \\
\text { s.a.: } & & \\
& g+B \theta+r=d & \forall(i j) \in \Omega_{r} \\
& f_{i j}-B_{i j}\left(n_{i j}^{0}+n_{i j}\right) \theta_{i j}=0 & \forall(i j) \in \Omega_{r} \\
& \left|f_{i j}\right| \leq\left(n_{i j}^{0}+n_{i j}\right) f_{i j}^{\max } & \\
& g^{\text {min }} \leq g \leq g^{\max } & \forall(i j) \in \Omega_{r c} \\
& 0 \leq n_{i j} \leq n_{i j}^{\max } & \\
& 0 \leq r \leq d &
\end{array}
$$

sendo:

$g(n)$ - função objetivo do problema;

$n$ - vetor decisão do problema (plano de expansão);

$n_{i j}$ - componente do vetor $n$ que representa o número de reforços adicionados ao ramo candidato $i-j$;

$c_{i j}^{i n v}$ - custo de investimento ligado à adição de reforços no ramo candidato $i-j$, dado em \$;

$\Omega_{r c}$ - conjunto de ramos candidatos ao reforço da rede de transmissão;

$g_{k}$ - geração da barra $k$;

$c_{k}^{g}$ - custo de geração da barra $k$;

$\Omega_{b g}$ - conjunto de barras de geração;

$r_{m}$ - corte verificado na barra de carga $m$;

$c_{m}^{r}$ - custo do corte de carga na barra de carga $m$;

$\Omega_{b c}$ - conjunto de barras de carga;

$g$ - vetor de gerações;

$B$ - matriz de susceptância de rede;

$\theta$ - vetor de ângulos das tensões nodais;

$r$ - vetor de gerações fictícias referentes aos cortes de carga verificados para cada decisão de investimento $n$;

$d$ - vetor de demanda;

$f_{i j}$ - fluxo de potência ativa no ramo $i$-j;

$B_{i j}$ - componente da matriz de susceptância de rede relativo ao ramo $i-j$; 
$n_{i j}^{0}$ - número de circuitos existentes no ramo $i-j$, presentes na topologia base do sistema;

$\theta_{i j}$ - abertura angular entre as tensões das barras terminais $i$ e $j$;

$f_{i j}^{\max }$ - capacidade máxima de potência permitida ao circuito $i$-j;

$g^{\min }$ e $g^{\max }$ - vetores com limites mínimos e máximos de geração;

$n_{i j}^{\max }$ - limite máximo de reforços que pode ser adicionado ao ramo $i$-j candidato ao reforço;

$\Omega_{r}$ - conjunto de todos os ramos do sistema (existentes ou novos).

Apesar de ser considerado um modelo de rede linear, o modelo DC representa ainda um problema de programação não-linear inteira mista, isso se deve ao produto entre as variáveis de decisão do problema $n_{i j}$ e $\theta_{i j}$ presente na restrição (3.1c). Para contornar o problema da não linearidade, uma estratégia comum é a utilização de uma técnica inspirada na decomposição de Benders, que consiste no desacoplamento do problema proposto em (3.1) em dois subproblemas, denominados subproblemas de investimento e de operação [2], [7], [10] e [90]. De forma geral, o subproblema de investimento é responsável por identificar planos de expansão com baixo custo de investimento e que sejam capazes de atender ao critério de segurança adotado. Já o subproblema de operação é responsável por avaliar os planos de expansão identificados pelo subproblema de investimento sob o ponto de vista operacional, ou seja, verificação da existência de eventuais cortes de carga e de sobrecargas na rede. As informações obtidas por meio da solução do subproblema de operação são, por sua vez, utilizadas na solução do subproblema de investimento, sendo os dois subproblemas solucionados, portanto, de forma iterativa e alternada.

No caso desta dissertação, essa estratégia de decomposição do modelo DC é adotada para solução do problema PET. Para tanto, os planos de expansão são definidos a partir do processo evolutivo utilizado pela ferramenta AGE-PET proposta, e, a cada etapa do algoritmo, os planos são avaliados tanto do ponto de vista operacional quanto do ponto de vista de custo de investimento. Além disso, o subproblema de operação é adaptado para consideração das perdas ôhmicas de transmissão e para avaliação do critério determinístico de segurança "N-1". Maio- 
res detalhes sobre os subproblemas de investimento e de operação considerados são apresentados nas próximas subseções.

\subsection{1.}

\section{Subproblema de investimento}

O objetivo geral do problema PET é determinar os melhores planos de expansão que possam garantir o correto atendimento à demanda prevista em um determinado horizonte de estudo, estando o sistema de geração já planejado. O ideal é que esses planos permitam o atendimento da demanda, considerando, inclusive critérios de segurança, ao menor custo possível. Por isso, nesta dissertação, onde o critério de segurança determinístico "N-1" é adotado, o subproblema de investimento é definido como:

$$
\begin{aligned}
& \text { Min.: } \quad f(n)=\sum_{(i j) \in \Omega_{r c}} c_{i j} n_{i j}+\alpha_{i n v}\left(c c(n)+\sum_{c=1}^{n c}\left[c c i(n)_{c}+s c(n)_{c}\right]\right) \\
& \text { s.a.: } \quad 0 \leq n_{i j} \leq n_{i j}^{\max } \quad \forall(i j) \in \Omega_{r c}
\end{aligned}
$$

sendo $f(n)$ a função objetivo do problema; $\alpha_{i n v}$ se refere a uma penalização aplicada ao corte de carga da rede intacta $(\operatorname{cc}(n))$, ao corte de carga por ilhamento da rede decorrente da contingência $c\left(\operatorname{cci}(n)_{c}\right)$ e às sobrecargas decorrentes da contingência $c\left(\operatorname{sc}(n)_{c}\right)$, de forma a traduzir esses parâmetros em termos de custo e, por isso, é expressa em \$/MW; $n c$ é o número de contingências consideradas pelo critério de segurança utilizado.

A utilização do parâmetro $\alpha_{i n v}$ permite a inclusão no processo evolutivo de solução de planos de expansão inviáveis (infactíveis) do ponto de vista operacional, ou seja, de planos cuja configuração resultante da rede não atenda completamente ao critério de segurança adotado, ou que apresentem corte de carga na configuração de rede intacta do sistema. Essa estratégia aumenta a diversidade das soluções consideradas pelo algoritmo, principalmente durante etapas iniciais do processo evolutivo, permitindo uma melhor exploração do espaço de soluções. Contudo, pode-se perceber a partir da análise de (3.2) que indivíduos que não apresentam problemas de corte de carga e/ou sobrecarga dos circuitos, tendem a possuir um valor reduzido da função objetivo do problema em relação àqueles que 
não cumprem tais requisitos, fazendo com que a convergência do algoritmo se dê para planos de expansão viáveis e com custo de investimento reduzido.

\subsection{2.}

\section{Subproblema de Operação}

O subproblema de operação é o responsável por avaliar, a cada etapa do algoritmo, todo plano de expansão $n$ obtido ao longo do processo evolutivo, tanto em termos de operação com rede intacta, como de operação em contingência simples de qualquer um dos equipamentos da rede. O subproblema de operação é definido como:

$$
\text { Min.: } \quad p(n)=\sum_{k \in \Omega_{b g}} c_{k}^{g} g_{k}+\alpha_{o p} \sum_{m \in \Omega_{b c}} r_{m}
$$

s.a.:

$$
\begin{array}{ll}
g+B \theta+r=d+d_{f i c} & \\
\left|b_{i j} \theta_{i j}\right| \leq n_{i j}^{0} f_{i j}^{\max } & \forall(i j) \in \Omega_{r e} \\
\left|b_{i j} \theta_{i j}\right| \leq n_{i j} f_{i j}^{\max } & \forall(i j) \in \Omega_{r c} \\
g^{\min } \leq g \leq g^{\max } & \\
0 \leq r \leq d & \\
\theta_{b s w}=0 &
\end{array}
$$

sendo:

$p(n)$ - função objetivo referente ao subproblema de operação;

$\alpha_{o p}$ - penalização aplicada ao corte de carga, de valor elevado em relação ao custo de produção e, assim como $\alpha_{i n v}$, é expresso em \$/MW;

$d_{f i c}$ - vetor de demandas fictícias para representação das perdas na transmissão;

$b_{i j}$ - susceptância equivalente do ramo $i-j$;

$\Omega_{r e}$ - conjunto dos ramos que já possuem circuitos na topologia base da rede (ramos existentes);

$b s w$ - índice que representa a barra de referência angular para o sistema (barra swing);

\section{- Perdas Ôhmicas do Sistema de Transmissão}

A fim de se obter soluções mais robustas para o problema PET, uma correta representação do modelo de fluxo de potência ativa na rede se faz necessário, de 
forma a diminuir as discrepâncias aferidas entre um modelo de rede AC e o modelo de rede DC utilizado nesta dissertação. Dessa forma, a fim de se reduzir tais discrepâncias, as perdas ôhmicas de transmissão devem ser levadas em consideração e, para isso, a estratégia utilizada neste trabalho faz uso de um processo iterativo realizado durante a avaliação da rede em situação de rede intacta, conforme [5], [29], [30] e [31]. Neste caso, as perdas $P_{i j}^{\text {Perdas }}$ do ramo $i-j$ podem ser definidas como:

$$
P_{i j}^{\text {Perdas }}=g_{i j} \theta_{i j}^{2}
$$

onde $g_{i j}$ é a condutância equivalente do ramo $i$-j.

Para tanto, após a solução do subproblema de operação, definido em (3.3), é realizado o cálculo das perdas no ramo $i$-j segundo (3.4), utilizando o valor atual de abertura angular $\theta_{i j}$ obtido. Em seguida, cada uma das barras terminais a qual o ramo está conectado recebe metade do valor das perdas encontradas na forma de carga fictícia, para que então o subproblema de operação seja novamente resolvido, considerando agora os valores de $d_{f i c}$ atualizados. A fim de melhorar a aproximação dos valores calculados, todo o processo se repete mais uma vez, sendo o valor final encontrado aquele que também é considerado na análise de contingências.

\section{- Análise de Contingências}

Durante a avaliação do plano em condições de contingência (atendimento ao critério de segurança “ $\mathrm{N}-1$ ”), busca-se aferir o pleno atendimento à demanda após a consideração de uma contingência simples em cada um dos ramos ativos do sistema. Ou seja, após avaliação da rede intacta (com a atualização da demanda com base nas perdas ôhmicas calculadas), examina-se a retirada de um circuito pertencente a cada ramo ativo. Após a remoção do circuito, um problema de fluxo de potência linearizado (fluxo DC simples) é resolvido e o desempenho do sistema avaliado. Nesta dissertação, é considerado como ramo ativo, aquele ramo que possui pelo menos um circuito na rede atual sobe análise, seja este circuito pertencente à topologia base do sistema ou proveniente de reforço realizado durante o processo de solução do problema PET. Vale destacar, portanto, que na avaliação da rede sob o ponto de vista do critério de segurança "N-1", não é permitido o redes- 
pacho dos geradores em relação ao despacho ótimo identificado na situação de rede intacta.

É por meio da solução do subproblema de operação que se obtêm as informações de corte de carga e sobrecarga de equipamentos utilizados durante a avaliação dos planos de expansão pelo subproblema de investimento. O corte de carga de rede intacta $(c c(n))$, por exemplo, é calculado pelo somatório das componentes $r_{m}$ do vetor de geração fictícia. Por sua vez, as eventuais sobrecargas nos circuitos e os eventuais cortes de carga por ilhamento da rede, verificados a cada contingência $c$ considerada na avaliação do fluxo DC, são acumulados e compõem as componentes $s c(n)_{c}$ e $c c i(n)_{c}$ definidas. Nota-se que os únicos cortes de carga possíveis durante a avaliação de contingências são aqueles ocorridos por ilhamento da rede decorrente de uma contingência, ou seja, quando há a desconexão da barra de carga do sistema.

\section{3. \\ Representação das Soluções}

Durante o processo evolutivo do AGE-PET proposto neste trabalho, cada solução (plano de expansão) é chamada de indivíduo sendo representada por meio de um vetor composto por $n_{r c}$ posições (genes), relacionadas ao número de ramos candidatos ao reforço do sistema. Cada posição deste vetor é responsável por armazenar o número de reforços adicionados ao respectivo ramo candidato.

$\mathrm{Na}$ aplicação de uma ferramenta baseada na metaheurística GA, uma atenção especial deve ser dada à forma com que cada variável é codificada, podendo essa forma variar de acordo com o tipo de problema a ser estudado [38]. Dessa forma, dado a natureza discreta das decisões de investimento de um problema PET, uma estratégia bastante utilizada para a codificação das decisões de investimento, chamada codificação decimal, é empregada pelo AGE-PET. Na codificação decimal, conforme demonstrado em cada indivíduo na Figura 3.1, cada um dos genes armazena o número inteiro de reforços adicionados ao respectivo ramo candidato e corresponde a uma variável inteira, que pode variar de 0 (zero) a um valor máximo de reforços possíveis a serem adicionados em um único ramo candidato. 
Por fim, destaca-se que, durante o processo de solução do problema PET, a cada indivíduo avaliado pelos subproblemas de investimento e de operação, é atribuída uma aptidão igual ao valor da função objetivo definida em (3.2a).

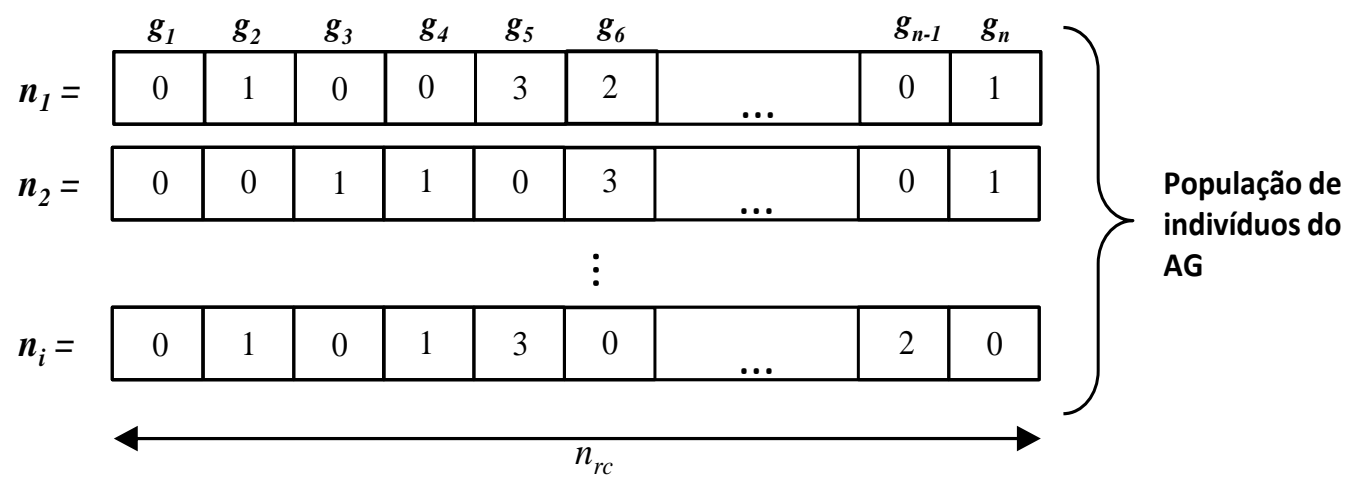

Figura 3.1 - Representação de uma população de indivíduos.

\section{4.}

\section{Dinâmica Evolutiva do AGE-PET}

A ferramenta AGE-PET proposta se caracteriza como uma metaheurística evolutiva especializada na solução do problema da expansão da transmissão. Mecanismos evolutivos básicos, avançados e específicos do problema, baseados na técnica metaheurística algoritmo genético, são utilizados durante o processo evolutivo para evolução de uma população de indivíduos (soluções). Informações heurísticas traduzidas na forma de índices de sensibilidade são integradas ao processo de forma a auxiliar os mecanismos na modificação dos indivíduos visando ao reforço dos ramos mais atrativos ao problema.

De forma geral, o processo evolutivo do AGE-PET consiste no desenvolvimento de um conjunto de execuções evolutivas (EE) que se baseiam na aplicação de mecanismos evolutivos: mecanismo de cruzamento, mecanismo de mutação, mecanismo de seleção, mecanismo de refinamento e mecanismo de lista tabu. Um fluxograma geral da ferramenta pode ser visto na Figura 3.2. Neste fluxograma, os passos pertencentes à região tracejada correspondem à EE no AGE-PET. A cada etapa de uma EE, os indivíduos da população corrente, e aqueles gerados pela aplicação dos mecanismos citados, são avaliados segundo a função objetivo definida em (3.2) sendo o valor obtido para essa função igual à aptidão do respectivo indivíduo. 
Durante o processo evolutivo do AGE-PET, são utilizados quatro conjuntos básicos de solução e dois conjuntos de reforços que são constantemente atualizados durante este processo, conforme se dá a aplicação de cada um dos mecanismos citados. Esses conjuntos são:

- $\Omega_{\mathrm{B} 15}$ : Conjunto responsável por armazenar os 15 (quinze) melhores indivíduos encontrados durante todo o processo evolutivo do AGE-PET;

- $\Omega_{\mathrm{IV}}$ : Conjunto responsável por armazenar os $N_{\mathrm{IV}}$ melhores indivíduos viáveis gerados a cada EE. Vale mais uma vez destacar que, são considerados viáveis no AGE-PET aqueles indivíduos cujos reforços correspondentes na rede permitem uma operação do sistema sem cortes de carga e/ou sobrecargas de equipamentos (ou seja, $c c(n), \operatorname{sc}(n)_{c} \mathrm{e}$ $\operatorname{cci}(n)_{c}$ com valores nulos);

- $\Omega_{\mathrm{POP}}$ : Conjunto responsável por armazenar os $N_{\mathrm{POP}}$ indivíduos pertencentes à população corrente de cada EE;

- $\Omega_{\mathrm{NOVO}}$ : Conjunto responsável por armazenar os novos indivíduos gerados a partir da aplicação dos mecanismos evolutivos propostos, a cada geração de cada EE;

- $\Omega_{\mathrm{LT}}$ : Conjunto responsável por armazenar os reforços definidos como tabu a cada geração de cada EE;

- $\Omega_{\mathrm{MZ}}$ : Conjunto responsável por armazenar os reforços não visitados durante $N_{G E R-L T}^{M A ́ X}$ gerações.

Os parâmetros $N_{\text {IV }}$ e $N_{\text {POP }}$ determinam o número máximo de indivíduos nos conjuntos $\Omega_{\mathrm{IV}}$ e $\Omega_{\text {POP }}$ respectivamente, e devem ser definidos pelo planejador no início do processo, assim como o critério de convergência do algoritmo, as taxas de cruzamento $\left(\alpha_{\mathrm{CR}}\right)$ e mutação $\left(\alpha_{\mathrm{MT}}\right)$ que estabelecem as probabilidades de aplicação de cada um dos respectivos mecanismos, e o número de gerações $\left(N_{G E R-L T}^{M A ́ x}\right)$ considerado para a atualização do conjunto $\Omega_{\mathrm{LT}}$. Neste trabalho a convergência de cada EE que compõe o AGE-PET se dá após um número máximo de gerações ( $N_{\text {MAX-GER }}$ ) ou pela estagnação do melhor indivíduo dos conjuntos $\Omega_{\text {IV }}$ e $\Omega_{\text {POP }}$ por um determinado número de gerações $\left(N_{\text {GER-EST }}\right)$. Já a convergência geral do algoritmo se dá após o desenvolvimento de um determinado número de EEs ( $\left.N_{\mathrm{MAX}-\mathrm{EE}}\right)$ definido pelo planejador. 


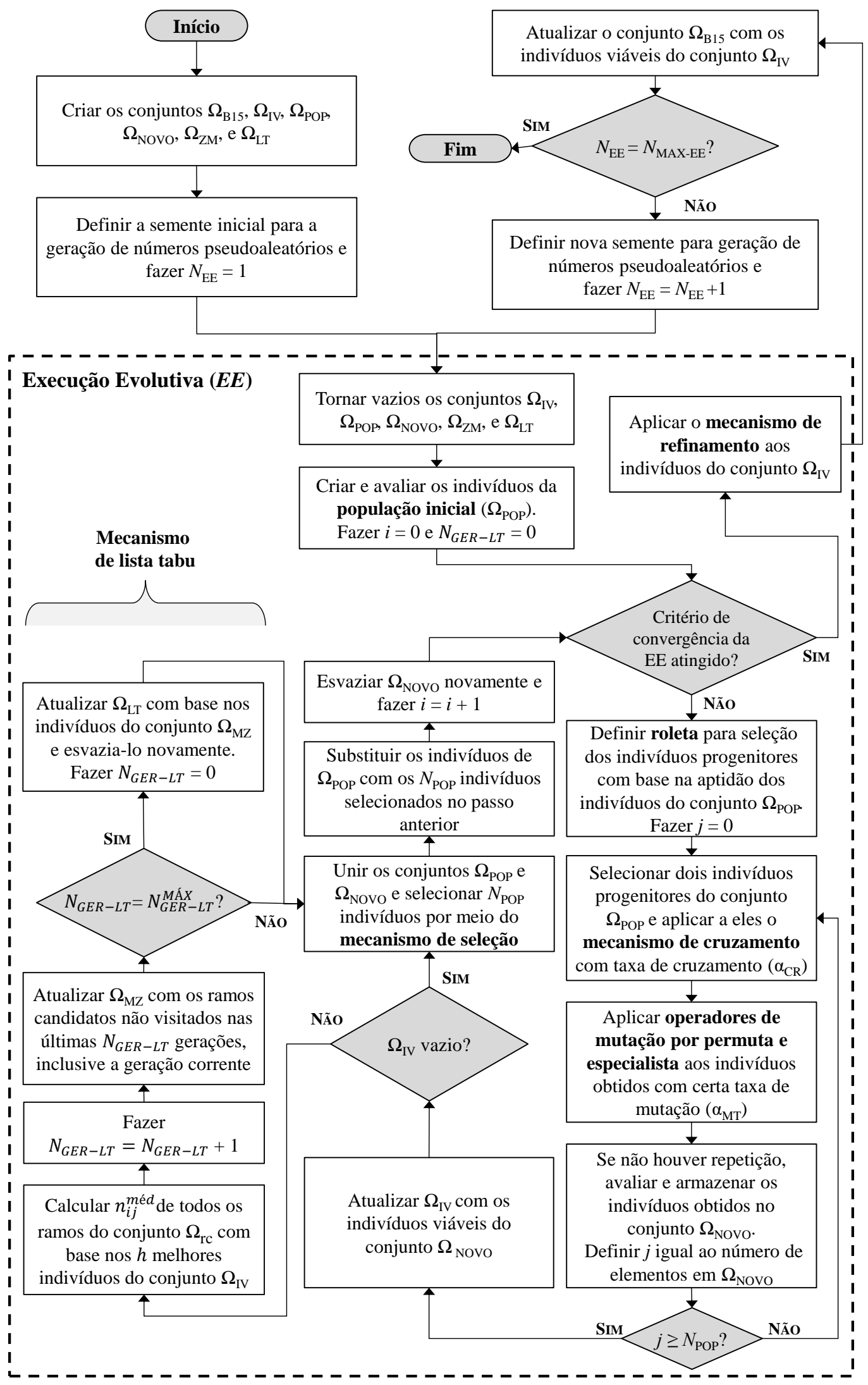

Figura 3.2 - Fluxograma da ferramenta AGE-PET. 
Os detalhes de cada mecanismo utilizado pelo AGE-PET, assim como dos índices de sensibilidade utilizados no aprimoramento de alguns desses mecanismos, são descritos a seguir.

\subsection{1.}

\section{Mecanismo de Cruzamento}

O mecanismo de cruzamento é equivalente ao operador evolutivo de cruzamento comum à técnica metaheurística Algoritmo Genético (GA). Ele é responsável pela criação de novos indivíduos a partir da recombinação de informações provindas de indivíduos selecionados na população de indivíduos corrente. Os indivíduos selecionados e envolvidos no processo de cruzamento são denominados indivíduos pais, enquanto aqueles gerados a partir da aplicação deste mecanismo são chamados de indivíduos filhos. A escolha dos indivíduos pais é realizada por meio do processo de roleta, conforme comumente realizado pelo operador de seleção por roleta da metaheurística GA [91]. Por meio desta estratégia, indivíduos da população corrente com melhores valores de aptidão, têm maiores chances de serem pais da próxima geração do processo evolutivo.

Nesta dissertação, o mecanismo de cruzamento utilizado durante o processo evolutivo do AGE-PET é um mecanismo básico, denominado mecanismo de cruzamento uniforme, que faz uso de uma máscara aleatória de bits para gerar dois novos indivíduos filhos $\left(n_{f 1}\right.$ e $\left.n_{f 2}\right)$, a partir da recombinação de dois indivíduos pais $\left(n_{p 1}\right.$ e $\left.n_{p 2}\right)$ selecionados na população corrente. A seleção dos indivíduos pais é realizada a por meio de uma roleta definida no início de cada geração do algoritmo com base nas aptidões dos indivíduos do conjunto $\Omega_{\mathrm{POP}}$, sendo que indivíduos com melhores valores de aptidão representam uma porção maior da roleta e por isso possuem uma maior probabilidade de serem escolhidos.

O cruzamento entre os indivíduos selecionados ocorre com certa probabilidade, chamada de taxa de cruzamento $\alpha_{\mathrm{CR}}$. No caso da decisão de aplicação desse mecanismo, uma máscara de bits de tamanho igual a $n_{r c}$ é gerada (i.e., vetor binário de tamanho $n_{r c}$ ). Cada indivíduo filho será formado, então, a partir dos indivíduos pais e com base nessa máscara a partir da seguinte lógica: 


$$
\begin{array}{ll}
n_{f 1, i}=\left\{\begin{array}{lr}
n_{p 1, i} & \text { se } M B_{i}=1 \\
n_{p 2, i} & \text { caso contrário }
\end{array}\right\} & \forall i=1,2, \ldots, n_{r c} \\
n_{f 2, i}=\left\{\begin{array}{lr}
n_{p 2, i} & \text { se } M B_{i}=1 \\
n_{p 1, i} & \text { caso contrário }
\end{array}\right\} & \forall i=1,2, \ldots, n_{r c}
\end{array}
$$

onde:

$n_{f j, i}$ - valor associado a $i$-ésima posição do vetor solução referente a cada indivíduo filho $j$ gerado;

$n_{p k, i}$ - valor associado a $i$-ésima posição do vetor solução referente a cada indivíduo pai $k$ selecionado;

$M B_{i}$ - valor associado a $i$-ésima posição da máscara de bits criada.

Cada indivíduo filho criado segue então para o emprego do mecanismo de mutação, porém, caso de acordo com a taxa de cruzamento definida não haja a aplicação do mecanismo de cruzamento, os indivíduos filhos seguem iguais aos seus progenitores para o emprego do mecanismo de mutação, ou seja, $n_{f 1}=n_{p 1} \mathrm{e}$ $n_{f 2}=n_{p 2}$.

\subsection{2. \\ Mecanismo de Mutação}

Assim como o mecanismo de cruzamento, o mecanismo de mutação é um mecanismo evolutivo baseado no operador de mutação pertencente à técnica GA. De forma geral, ele é responsável pela aplicação de modificações nos genes de cada indivíduo de forma aleatória, com base em funções densidade de probabilidade.

No AGE-PET, o processo de mutação é adaptado para solução especializada do problema PET. Basicamente, o mecanismo de mutação é composto por um conjunto de dois operadores específicos de mutação distintos, concebidos com base em três índices de sensibilidade, também utilizados em [2]. Esses índices traduzem necessidades da rede de transmissão obtidas a partir de informações do fluxo de potência da rede e são aplicados na definição dos operadores de mutação específicos do problema.

O primeiro índice traz informações sobre as necessidades do sistema de transmissão em condições de rede intacta, sendo calculado conforme (3.7) para 
todo ramo candidato durante o processo de solução do AGE-PET, exceto aqueles que conectam uma barra de carga ou geração inicialmente isolada ao sistema.

$$
\operatorname{Ind}_{c h-i j}=\frac{\left|\theta_{i j}\right|}{x_{i j} f_{i j}^{\max }}
$$

onde $x_{i j}$ é a reatância do circuito a ser adicionado ao ramo candidato $i-j$ e $f_{i j}^{\text {max }}$ corresponde à capacidade máxima de potência desse circuito.

$\mathrm{O}$ índice $\operatorname{Ind}_{c h-i j}$ calcula de forma hipotética, com base nos valores atuais da abertura angular das tensões nas barras terminais do ramo, qual seria o carregamento do novo circuito após a sua adição. Circuitos com valores elevados desse índice terão em princípio grande potencial para contribuir para uma melhor distribuição de potência ativa na rede, reduzindo as taxas de carregamento dos circuitos e por consequência as perdas ôhmicas da transmissão. Por outro lado, valores reduzidos deste índice para ramos já reforçados demonstram que o reforço adicionado pode ser pouco efetivo. Ou seja, que o reforço não contribui ativamente para uma melhor distribuição de potência ativa na rede, indicado que em caso da perda de reforço nesse ramo, os impactos resultantes no sistema seriam reduzidos.

O segundo e terceiro índices, por sua vez, trazem informações sobre as necessidades do sistema de transmissão em condição de contingência de um de seus equipamentos. Portanto, circuitos candidatos ao reforço com valores elevados desses índices terão, em princípio, um grande potencial para contribuir no atendimento ao critério de segurança. Estes índices são calculados para todo ramo ativo e candidato do problema, ou seja, os ramos novos do sistema, que ainda não possuem circuitos na rede e, portanto, considerados não ativos, não podem ser avaliados por meio desses índices.

De forma geral, o segundo índice visa mensurar para cada circuito, os impactos gerados a si mesmo em caso de contingência de outro ramo do sistema, ou seja, este índice é o responsável por acumular as sobrecargas ocorridas em um determinado ramo ativo e candidato $i$-j para cada uma das $n c$ contingências consideradas e, portanto, pode ser expresso por:

$$
\operatorname{Ind}_{s c-i j}^{\text {próprio }}=\sum_{c=1}^{n c} s c(n)_{c-i j}
$$


onde $s c(n)_{c-i j}$ é a sobrecarga observada no ramo candidato $i-j$ após a ocorrência de uma contingência $c$.

Por fim, o terceiro índice, ao contrário do que é proposto no caso anterior, visa mensurar o impacto de uma contingência $c$ ocorrida em determinado ramo $i-j$ em qualquer outro ramo ativo $k-m\left(s c(n)_{c-k m}\right)$, levando em conta ainda os cortes de carga por ilhamento decorrentes de tal contingência $\left(\operatorname{cci}(n)_{c}\right)$, caso haja. O terceiro índice é descrito por:

$$
\operatorname{Ind}_{s c-i j}^{\text {outros }}=\sum_{(k, m) \in \Omega_{r}^{a t i v o}} s c(n)_{c-k m}+c c i(n)_{c}
$$

onde $\Omega_{r}^{\text {ativo }}$ representa o conjunto de ramos ativos para cada indivíduo $n$.

Após emprego do mecanismo de mutação, conforme dinâmica da EE dentro do AGE-PET na Figura 3.2, todos os indivíduos resultantes são avaliados e, não sendo repetidos, são armazenados no conjunto $\Omega_{\text {Novo }}$.

Os operadores de mutação que compõem este mecanismo são denominados: operador de mutação por permuta (PerMut) e operador de mutação especialista (EspMut). De forma geral, a aplicação de cada um destes operadores a cada indivíduo filho gerado está condicionada a uma certa probabilidade, chamada de taxa de mutação $\left(\alpha_{\mathrm{MT}}\right)$. Portanto, dada esta probabilidade, podem ser aplicados a um mesmo indivíduo os dois operadores, somente um dos operadores, ou mesmo nenhum dos dois operadores. Neste último caso, o indivíduo sob ação do mecanismo de mutação no AGE-PET segue imutado, ou seja, idêntico à forma como foi gerado a partir da aplicação do mecanismo de cruzamento. Detalhes relativos a cada operador de mutação empregado pelo AGE-PET são discutidos a seguir.

\section{- Operador de Mutação por Permuta}

O operador de mutação por permuta (PerMut) se baseia na troca de material genético entre dois genes diferentes de um mesmo indivíduo, ou seja, na permuta de reforços entre ramos candidatos de um mesmo plano de expansão, sendo um reforço retirado de um dos genes e adicionado a outro. De forma geral, a seleção dos pares de genes sobre os quais será aplicada a permuta é realizada com base nos índices de sensibilidade já definidos, sendo que para cada índice é selecionado 
um par de genes, que são basicamente os ramos que apresentam o menor e o maior valor para o índice observado.

De maneira mais específica, dentre os ramos candidatos que já receberam pelo menos um reforço, o ramo que apresentar o menor valor para o índice observado será aquele que terá um reforço removido. Por outro lado, dentre os ramos aptos a receber reforços (que não atingiram o número máximo de reforços permitidos) aquele que apresentar o maior valor para o índice em questão receberá um novo reforço. Em ambos os casos, os ramos escolhidos para a permuta não poderão fazer parte do conjunto $\Omega_{\mathrm{LT}}$, ou seja, os ramos definidos como tabu para a geração corrente não participam do mecanismo de mutação por permuta.

Definido assim, o emprego do PerMut para cada um dos indivíduos gerados a partir do mecanismo de cruzamento é decidido com probabilidade igual a $\alpha_{\mathrm{MT}}$. Ou seja, com certa probabilidade $\alpha_{\mathrm{MT}}$, verifica-se se o indivíduo sofrerá ou não perturbação gerada pelo operador PerMut. Em caso positivo, três novos indivíduos serão criados a partir da seleção e permuta de um par de genes selecionados a partir de cada um dos três índices de sensibilidade definidos. Esses indivíduos seguirão então para a aplicação do operador de mutação especialista. Por outro lado, caso seja decidido pela não aplicação do operador (de acordo com a probabilidade $\alpha_{\mathrm{MT}}$ ), os indivíduos gerados pelo cruzamento seguirão então imutados para a aplicação do operador de mutação especialista.

\section{- Operador de Mutação Especialista}

Os indivíduos gerados a partir da aplicação do operador de mutação por permuta (mutados ou não) são encaminhados ainda para a aplicação do operador de mutação especialista (EspMut). Com este novo operador, para cada um dos indivíduos será determinado, de acordo com a taxa de mutação $\alpha_{\mathrm{MT}}$, se cada um de seus genes sofrerá ou não as perturbações geradas pelo EspMut. Neste caso, para cada gene de um indivíduo é realizado um sorteio que definirá, com probabilidade $\alpha_{\mathrm{MT}}$, se o mesmo será ou não mutado. Em caso positivo, esse gene deverá então receber um incremento ou a subtração de um reforço, respeitando-se os limites máximo e mínimo permitidos. A decisão quanto à adição ou à subtração de reforços é baseada, respectivamente, nas taxas de adição $\left(\alpha_{a d i}\right)$ e subtração de reforços $\left(\alpha_{\text {sub }}\right)$, sendo $\alpha_{a d i}+\alpha_{\text {sub }}=1$. Para cada ramo candidato ao reforço do 
sistema, essas taxas são calculadas com base na média ponderada dos três índices de sensibilidade calculados. Para o ramo candidato $i$-j, relacionado ao respectivo gene, as taxas são dadas por:

$$
\begin{gathered}
\alpha_{a d i-i j}=\frac{P_{1} x \operatorname{Ind} d_{c h-i j}+P_{2} x \operatorname{Ind} d_{s c-i j}^{\text {próprio }}+P_{3} x \operatorname{Ind} d_{s c-i j}^{\text {outros }}}{P_{1}+P_{2}+P_{3}} \\
\alpha_{s u b-i j}=1-\alpha_{a d i-i j}
\end{gathered}
$$

onde $P_{1}, P_{2}$ e $P_{3}$, são os pesos dados a cada um dos índices na formação da taxa de adição e devem ser definidos pelo planejador ao início do processo evolutivo. Vale ressaltar que, tanto na aplicação do operador de mutação especialista quanto na aplicação do operador por permuta, os índices de sensibilidade são normalizados para os ramos candidatos ao reforço do sistema, o que viabiliza o emprego dos mesmos na forma descrita nas Equações (3.10) e (3.11).

Basicamente, ramos candidatos que apresentem maiores valores de carregamento em condição de rede intacta e/ou sobrecarga em caso de contingências apresentam maior probabilidade de receberem um reforço. Por outro lado, aqueles ramos candidatos ao reforço que apresentem valores reduzidos dos índices de sensibilidade terão maior probabilidade de subtração de reforços. Para o caso de ramos candidatos que não possam ser avaliados por qualquer um dos índices de sensibilidade são consideradas taxas de adição e de subtração fixas a serem determinadas pelo planejador (e.g., $\alpha_{a d i-i j}=70 \%$ e $\alpha_{s u b-i j}=30 \%$ ). Observa-se que, para o caso de ramos em que o valor do índice $\operatorname{Ind}_{c h-i j}$ não pode ser calculado, seu valor é considerado igual ao valor da taxa de adição, podendo, dessa forma, o ramo ser avaliado também durante a etapa do operador de mutação por permuta. Além disso, é importante frisar que durante a aplicação do operador de mutação especialista, os ramos candidatos considerados como tabu também são passíveis de serem mutados.

De forma geral, dadas as características de aplicação do operador PerMut, cada indivíduo gerado por meio da aplicação do mecanismo de cruzamento pode gerar até três novos indivíduos (um a partir de cada índice de sensibilidade) que seguirão então para a aplicação do operador especialista. Neste caso, após a aplicação do operador EspMut, somente o indivíduo mutado que possuir a melhor 
aptidão é selecionado para seguir no processo evolutivo. Esta dinâmica é ilustrada na Figura 3.3.

Destaca-se que, após a aplicação do operador PerMut, a configuração resultante da rede de transmissão deve apresentar uma redistribuição do fluxo de potência na rede, o que alteraria os valores calculados para os índices de sensibilidade. Porém, a fim de evitar um crescente número de problemas de programação linear a ser solucionados (subproblema de operação), o que aumentaria consideravelmente o tempo de processamento do algoritmo, não é realizada uma nova avaliação das soluções após o emprego do PerMut. Portanto, os valores dos índices considerados durante a aplicação do operador EspMut seguem iguais aos utilizados no emprego do operador PerMut.

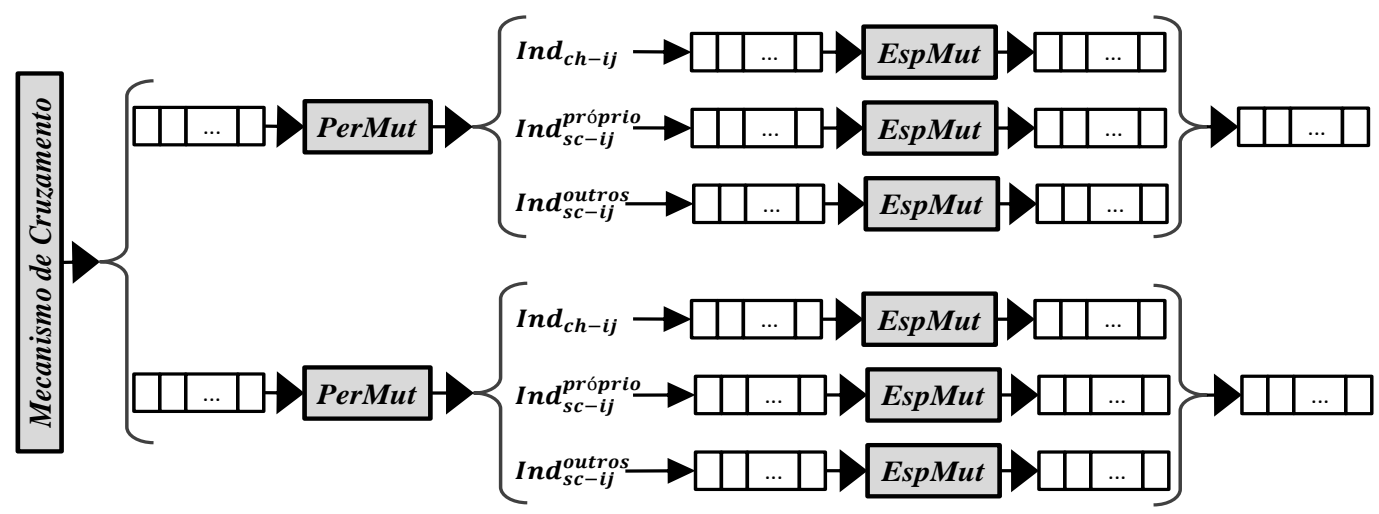

Figura 3.3 - Mecanismo de Mutação da ferramenta AGE-PET.

Vale destacar ainda que, uma situação comum que se encontra em sistemas de transmissão é a consideração da construção de barras de passagem, ou seja, que não apresentam conexão direta a uma fonte geradora ou à carga. Neste caso, ramos que fazem a interligação destas barras ao sistema devem receber uma atenção especial, a fim de se evitar que a mesma se torne uma barra terminal, não trazendo benefícios ao sistema. Para isso, a adição de ramos que fazem a conexão de barras de passagem deve ser realizada em pares, de forma a realizar a interligação da barra pelos dois lados, fechando assim a malha de transmissão, o que caracteriza uma correta conexão da barra ao sistema. De forma semelhante, uma atenção especial deverá ser dada também à remoção de reforços responsáveis por este tipo de conexão. Sendo assim, dada a natureza pontual e aleatória do mecanismo de mutação, após a aplicação das perturbações em cada gene, uma estratégia de veri- 
ficação/adaptação é aplicada à solução gerada de forma a construir ou remover os reforços necessários para que não haja barras de passagem terminal no sistema.

Em relação à dinâmica da EE ilustrada na Figura 3.2, o ciclo de aplicação dos mecanismos de cruzamento e de mutação se repete até que o conjunto $\Omega_{\text {NOVo }}$ esteja completo, ou seja, com número de indivíduos maior ou igual a $N_{\text {POP. }}$ Em seguida, os indivíduos do conjunto $\Omega_{\mathrm{NOVO}}$ e os indivíduos de $\Omega_{\mathrm{POP}}$ serão encaminhados para a aplicação do mecanismo de seleção.

\subsection{3. \\ Mecanismo de Seleção}

Para definiçãa das $N_{\text {POP }}$ soluções que devem seguir pelo processo evolutivo do AGE-PET (nova população de indivíduos), três diferentes estratégias de seleção podem ser empregadas ao conjunto de solução formado pela população corrente $\Omega_{\mathrm{POP}}$ e por $\Omega_{\mathrm{NOVO}}$ durante uma EE: estratégias de seleção por elitismo, por torneio e por "clusterização".

A primeira estratégia de seleção (seleção por elitismo) tem por objetivo preservar os indivíduos mais aptos de cada população durante o processo de seleção, tendo em vista que esses indivíduos carregam informações genéticas relevantes para a solução do problema. Esta estratégia consiste em transferir de forma direta para a população da nova geração um número $N_{\mathrm{EL}}$ dos indivíduos mais aptos entre os indivíduos dos conjuntos $\Omega_{\mathrm{NOVO}}$ e $\Omega_{\mathrm{POP}}$. O valor de $N_{\mathrm{EL}}$ corresponde a uma porcentagem de $N_{\text {POP }}$ e é definida pelo planejador. Portanto, no mecanismo de seleção, primeiramente é empregada a estratégia de elitismo. Dessa forma, a nova população será sempre formada por $N_{\mathrm{EL}}$ indivíduos selecionados por meios da etapa de elitismo. Visando garantir uma certa diversidade de soluções neste processo, os $N_{\mathrm{POP}}-N_{\mathrm{EL}}$ indivíduos restantes são selecionados por meio da estratégia de seleção por torneio ou pela estratégia de seleção por clusterização. Estudos de desempenho do AGE-PET relacionados ao emprego de cada uma dessas possibilidades são analisados no Capítulo 4.

A estratégia de seleção por torneio se baseia, como sugere o nome, na realização de pequenos "torneios" entre os indivíduos de um dado conjunto de soluções. Neste torneio, é selecionado aleatoriamente um determinado número de indivíduos que, com base nas suas aptidões, competem entre si para seguir para a próxima geração. O vencedor é aquele que possuir o melhor valor de aptidão den- 
tre os indivíduos selecionados. Esse processo permite a seleção de indivíduos com melhores valores de aptidão e, ao mesmo tempo, visa à manutenção da diversidade populacional. O processo de torneios se repete até que uma nova população de indivíduos, com $N_{\text {POP }}$ elementos, seja formada.

Já a estratégia de seleção por clusterização tem como intuito de aprimorar o desempenho da ferramenta AGE-PET, principalmente, na solução do problema PET para sistemas reais de grande porte. Neste caso, é utilizado o algoritmo $K$ Means [92], para realizar a classificação dos indivíduos dos conjuntos $\Omega_{\mathrm{NOVO}} \mathrm{e}$ $\Omega_{\text {POP }}$ por meio de um critério de similaridade, medida através da distância Euclidiana. Basicamente, os indivíduos desses conjuntos são assim distribuídos em $N_{\text {POP }}-N_{\text {EL }}$ classes, onde os melhores indivíduos de cada classe serão selecionados para compor a nova população corrente. Sendo assim, junto com os $N_{\mathrm{EL}}$ indivíduos selecionados pela estratégia de elitismo, a nova população é formada por $N_{\text {POP indivíduos. }}$

\subsection{4. \\ Mecanismo de Refinamento}

O mecanismo de refinamento é uma estratégia avançada aplicada ao final de cada EE aos indivíduos viáveis do conjunto $\Omega_{\mathrm{IV}}$. Este mecanismo é baseado na técnica utilizada em [69], onde após a convergência do algoritmo, os reforços de um plano de expansão são ordenados e removidos, um a um, sendo verificada a viabilidade do plano após cada remoção. Isso se deve ao fato de que, os indivíduos podem apresentar reforços desnecessários ao final do processo evolutivo. Em [93] este mesmo mecanismo é também utilizado durante o processo evolutivo de um algoritmo genético utilizado para a solução do problema PET.

Desta forma, após a convergência de cada EE, o mecanismo de refinamento realiza a remoção de reforços ordenados por ordem decrescente de custo de investimento, para cada indivíduo do conjunto $\Omega_{\mathrm{IV}}$, verificando a viabilidade do sistema dos indivíduos resultantes de cada remoção até que todos os ramos adicionados tenham sido testados. Caso a remoção de um reforço resulte na geração de um novo indivíduo viável ainda não identificado, o mesmo é adicionado ao conjunto $\Omega_{\mathrm{IV}}$ para que também seja submetido à aplicação do mecanismo de refinamento. Neste caso, depois de finalizada a análise do indivíduo original, este é então des- 
cartado, para que não se mantenham indivíduos com conjunto de reforços semelhantes. Ou seja, indivíduos que possuam um subconjunto de reforços pertencentes à outra solução viável de melhor aptidão são desconsiderados do conjunto de soluções finais do AGE-PET.

De forma a reduzir o custo computacional requerido por este mecanismo, visto o grande número de PL's a serem resolvidos na avaliação de cada indivíduo resultante, caso a remoção de um reforço venha a ocasionar corte de carga em situação de operação com rede intacta no plano $n_{v}$, este reforço não deverá ser mais retirado durante a aplicação do mecanismo de refinamento a indivíduos viáveis gerados a partir da remoção de outros reforços de $n_{v}$.

\subsection{5.}

\section{Mecanismo de Lista Tabu}

A lista tabu é um mecanismo de memória aplicado na utilização da metaheurística de TS (Tabu Search) e visa impor novas restrições ao processo de busca para permitir uma melhor exploração do espaço de soluções. Neste sentido, a aplicação de uma lista tabu no presente trabalho foi pensada de forma a aprimorar a etapa de busca realizada pelo operador de mutação por permuta da ferramenta AGE-PET. Esta estratégia é baseada na utilização de uma memória de frequência, onde as restrições relativas aos circuitos candidatos ao reforço são definidas com base na frequência de visitação dos atributos de uma solução.

Dessa forma, a lista tabu implementada nesta dissertação é baseada nos $h$ melhores indivíduos do conjunto $\Omega_{\mathrm{IV}}$, sendo que a definição dos ramos considerados tabu se dá com base na frequência com que um determinado ramo candidato é visitado ao longo de um determinado número $\left(N_{G E R-L T}^{M A ́ x}\right)$ de gerações. Ou seja, após a consolidação dos indivíduos do conjunto $\Omega_{\mathrm{IV}}$, é calculada, a cada geração, a média dos reforços adicionados a cada ramo candidato ao longo dos indivíduos analisados de forma a se determinar os ramos não visitados pela ferramenta, conforme Equação (3.12).

$$
n_{i j}^{\text {méd }}=\operatorname{Round}\left[\frac{\sum_{k=1}^{h} n_{i j}^{k}}{h}\right] \quad k \in \Omega_{\mathrm{IV}}, \forall(i j) \in \Omega_{r c}
$$

onde: $n_{i j}^{\text {méd }}$ é a média dos reforços adicionados ao ramo $i-j$ ao longo dos $h$ indivíduos analisados; $n_{i j}^{k}$ é o número de reforços adicionados ao ramo $i$-j para um de- 
terminado indivíduo $k$; e Round[.] é a função de arredondamento do valor da média calculada, retornando o valor inteiro mais próximo do valor da média calculada.

Os ramos candidatos, cuja média calculada a partir de (3.12) for igual a zero, são armazenados no conjunto $\Omega_{\mathrm{MZ}}$, inicialmente vazio. A partir da inicialização do conjunto $\Omega_{\mathrm{MZ}}$ o mesmo será atualizado a cada geração de uma EE de forma que, caso um dos ramos atualmente contidos no conjunto passe a ter média diferente de zero, o mesmo será removido, permanecendo somente aqueles ramos não visitados em nenhuma das gerações analisadas.

Ao final de $N_{G E R-L T}^{M A ́ X}$ gerações, a lista tabu é então criada com base no conjunto de ramos remanescentes em $\Omega_{\mathrm{MZ}}$, sendo a mesma formada hora pelos ramos não visitados e presentes no conjunto, hora pelos ramos já visitados e que não pertencem ao conjunto $\Omega_{\mathrm{MZ}}$. Os ramos que irão compor a lista tabu são então armazenados no conjunto $\Omega_{\mathrm{LT}}$, sendo o conjunto $\Omega_{\mathrm{MZ}}$ novamente esvaziado. Em seguida, é iniciado um novo processo a partir da próxima geração. Um fluxograma simplificado do processo de criação da lista tabu é demonstrado na Figura 3.2.

\section{5. Considerações Finais do AGE-PET}

Durante a aplicação da ferramenta AGE-PET, a cada EE, os mecanismos evolutivos apresentados nas seções anteriores são aplicados de forma a evoluir, de forma gradual e a partir de uma população inicial, um conjunto (população) de indivíduos, movimentando-os através do espaço de busca e guiando-os em direção de soluções de boa qualidade para o problema PET. Mais alguns detalhes importantes, relativos à metodologia AGE-PET, cujo fluxograma é apresentado na Figura 3.2, são aqui discutidos.

Primeiramente, os conjuntos $\Omega_{\mathrm{B} 15}, \Omega_{\mathrm{IV}}, \Omega_{\mathrm{POP}}, \Omega_{\mathrm{NOVO}}, \Omega_{\mathrm{MZ}}$ e $\Omega_{\mathrm{LT}}$ são criados inicialmente vazios. Os conjuntos $\Omega_{\mathrm{IV}}$ e $\Omega_{\mathrm{POP}}$ têm seus tamanhos definidos pelo planejador e iguais, respectivamente, a $N_{\text {IV }}$ e $N_{\text {POP. }}$ Nesta etapa também é definido o valor inicial da semente para a geração de números pseudoaleatórios, utilizado durante o desenvolvimento de cada EE na dinâmica de solução do AGEPET. 
A partir daí, para cada nova execução evolutiva (EE) do AGE-PET, são então gerados os $N_{\mathrm{POP}}$ indivíduos da população inicial, sendo que, cada gene do indivíduo deverá receber um número de reforços determinado de forma pseudoaleatória. Na definição deste número de reforços para cada gene, é considerado que, com 5\% de probabilidade, o gene deverá receber dois reforços; com 10\% de probabilidade, o gene receberá um reforço; e com $85 \%$ de probabilidade, o gene não receberá qualquer reforço. As probabilidades de adição de reforços foram assim ajustadas com o objetivo de gerar indivíduos com um número limitado de reforços em sua etapa inicial, para que não apresentem um elevado custo de investimento. Dessa forma, a partir da estratégia adotada, é esperado que os indivíduos gerados apresentem um número médio aproximado de 0,2 reforços por gene. Ou seja, um sistema hipotético que apresente um número total de 40 (quarenta) ramos candidatos ao reforço, deverá apresentar, em média, indivíduos da população inicial compostos por 8 (oito) reforços, que de forma geral não garantem a viabilidade da solução. Ao final do processo de geração, os $N_{\mathrm{POP}}$ indivíduos serão avaliados de acordo com os subproblemas de investimento e de operação e armazenados em $\Omega_{\mathrm{POP}}$.

Dada a criação da população inicial, o processo evolutivo/iterativo de gerações dentro de cada EE se inicia através da aplicação dos mecanismos de cruzamento e de mutação, sendo que os indivíduos resultantes armazenados no conjunto de indivíduos $\Omega_{\text {Novo }}$. Esse processo se repete até que o número de indivíduos neste conjunto se iguale a de indivíduos do conjunto $\Omega_{\text {POP }}$ (ou seja, $N_{\text {POP }}$ ).

Consecutivamente, o conjunto de indivíduos viáveis $\left(\Omega_{\mathrm{IV}}\right)$ identificados durante a $\mathrm{EE}$ deve ser atualizado a partir dos novos indivíduos viáveis obtidos do conjunto $\Omega_{\text {Novo }}$. Durante este processo, além do cuidado de não se selecionar indivíduos repetidos, novos indivíduos identificados formados por um conjunto de reforços equivalentes a um subconjunto de reforços de uma ou mais soluções viáveis já pertencentes ao $\Omega_{\mathrm{IV}}$, ou vice-versa, devem ser avaliados de forma que, somente aquele com melhor valor de aptidão dentre todos os indivíduos semelhantes permanecerá no conjunto.

Após a identificação do primeiro indivíduo viável, inicia-se o processo de construção da lista tabu, conforme descrito na subseção 3.4.5 desta dissertação. Em seguida, os indivíduos dos conjuntos $\Omega_{\mathrm{POP}}$ e $\Omega_{\mathrm{NOVO}}$ seguem juntos para a aplicação do mecanismo de seleção, que substituirá os indivíduos de $\Omega_{\mathrm{POP}}$ por 


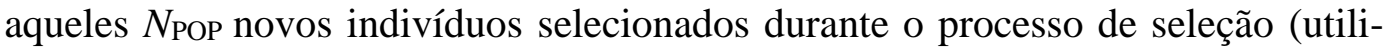
zando as estratégias de seleção por torneio ou por clusterização, combinadas à técnica de seleção por elitismo).

A aplicação dos mecanismos evolutivos propostos se dá até que o critério de convergência da EE seja atingido, ou seja, até que se atinja um determinado nú-

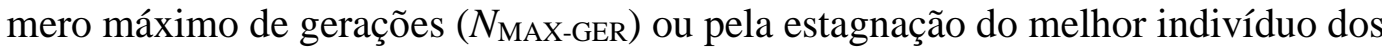
conjuntos $\Omega_{\mathrm{IV}}$ e $\Omega_{\mathrm{POP}}$ por um determinado número de gerações $\left(N_{\mathrm{GER}-\mathrm{EST}}\right)$.

Após a convergência de cada EE, é aplicado o mecanismo de refinamento aos indivíduos do conjunto $\Omega_{\mathrm{IV}}$ e, com base nos indivíduos resultantes, o conjunto dos quinze melhores indivíduos viáveis encontrados em todas as EEs $\left(\Omega_{\mathrm{B} 15}\right)$ é atualizado. Por fim, o algoritmo AGE-PET converge após o desenvolvimento de um número máximo ( $\left.N_{\mathrm{MAX}-\mathrm{EE}}\right)$ de EEs, definido pelo planejador.

\section{6.}

\section{Conclusões}

Neste capítulo é apresentada em detalhes a metodologia de otimização do algoritmo genético especializado (AGE-PET). A ferramenta é proposta no presente trabalho para solução do problema PET estático de longo prazo. A formulação do problema é realizada a partir do modelo DC da rede do sistema, com a inclusão das perdas ôhmicas. Além disso, é considerado o atendimento ao critério determinístico de segurança "N-1".

O emprego de informações heurísticas baseadas nas informações de fluxo de potência e o desenvolvimento de execuções evolucionárias com estratégias especializadas para solução do problema PET, tornam o AGE-PET uma ferramenta robusta e capaz de lidar com diferentes tipos de sistemas de transmissão, sendo capaz de encontrar um conjunto final de soluções de boa qualidade até mesmo para sistemas reais e de grande porte. Isso permite ao planejador dispor de um maior número de alternativas de expansão de boa qualidade, de modo a lidar de forma mais apropriada com as questões relacionadas ao problema PET não consideradas em sua modelagem. O desempenho da ferramenta proposta é avaliado no próximo capítulo. 


\section{4. \\ Resultados e Discussões}

\section{1. Introdução}

Os benefícios inerentes ao emprego da ferramenta proposta (AGE-PET) nesta dissertação para solução do problema PET são avaliados por meio de testes realizados com três diferentes sistemas de potência: sistema IEEE-RTS [94], de 24 barras; configuração do Sistema Sul Brasileiro (SSB) [67] do ano de 1980, de 46 barras; e um sistema equivalente mais atual da região geoelétrica sul do Brasil, denominado Sistema Geoelétrico Sul do Brasil (SGSB), com 242 barras. Para o SGSB, cuja rede equivalente se refere ao ano de 2017, o problema PET é solucionado para dois diferentes cenários de carga e geração, definidos para os períodos de menor e maior incidência de chuvas na região norte do país para o ano de 2025 . Estes sistemas apresentam dimensões e características distintas entre si, sendo que os dois primeiros (i.e., IEEE-RTS e SSB), são amplamente empregados na literatura para realização de estudos do planejamento da transmissão, sendo o SGSB um sistema real de grande porte e também estudado em [2].

Ao longo deste capítulo são apresentados os detalhes relativos ao emprego do AGE-PET e as análises de desempenho estatístico provenientes dos resultados obtidos em todos os testes realizados.

\section{2. \\ Parametrização do AGE-PET}

Com o objetivo de verificar a robustez do algoritmo AGE-PET, os mesmos ajustes de seus parâmetros são considerados para realização dos testes com os três sistemas de transmissão sob estudo neste trabalho. De forma geral, são realizados testes com dois diferentes tamanhos de população (i.e., $N_{\mathrm{POP}}=600$ e $N_{\mathrm{POP}}=800$ indivíduos) definidos de forma que soluções de boa qualidade sejam identificadas em todos os três sistemas avaliados a partir de um único ajuste de parâmetros. Os demais parâmetros são definidos como: $N_{\mathrm{IV}}=50$ indivíduos; as taxas de cruza- 
mento e mutação iguais a $65 \%$ e $8 \%$, respectivamente; para o fator de penalização $\alpha_{i n v}$ foi considerado o valor de $10^{6} \mathrm{R} \$ / \mathrm{MW}$; a convergência do algoritmo AGEPET se dá após o desenvolvimento de um número máximo de 5 EEs $\left(N_{\mathrm{MAX}-\mathrm{EE}}=\right.$ 5), enquanto que a convergência de cada EE dentro do AGE-PET (Figura 3.2) se dá após a realização de um número máximo de 500 gerações $\left(N_{\text {MAX-GER }}=500\right)$ ou pela estagnação do melhor indivíduo dos conjuntos $\Omega_{\mathrm{IV}}$ e $\Omega_{\mathrm{POP}}$ por 15 gerações consecutivas $\left(N_{\mathrm{GER}-\mathrm{EST}}=15\right)$, o que ocorrer primeiro; os pesos dados a cada índice de sensibilidade no cálculo das taxas de adição de cada ramo, conforme definido na Subseção 3.4.2, são definidos como $P_{1}=1$ e $P_{2}=P_{3}=2$ (ou seja, os índices relacionados às sobrecargas e cortes observados na análise de contingências dos circuitos de transmissão são priorizados em relação ao índice obtido pelo carregamento observado na operação com rede intacta do sistema). Ainda em relação aos testes realizados, para cada EE, a lista tabu é atualizada a cada 9 gerações $\left(N_{G E R-L T}^{M A ́ X}=9\right)$ após a identificação do primeiro indivíduo viável, com base nos 10 melhores indivíduos do conjunto $\Omega_{\mathrm{IV}}$ (i.e. $h=10$ ); enquanto o mecanismo de seleção utiliza uma seleção por elitismo de $80 \%$ (i.e., $N_{\mathrm{EL}}=80 \%$ de $N_{\mathrm{POP}}$ ). Em resumo, durante a aplicação da ferramenta AGE-PET, é inicialmente ajustado um total de 14 parâmetros conforme representado na Tabela 4.1.

Tabela 4.1 - Parâmetros utilizados na implementação do AGE-PET

\begin{tabular}{|l|lc|}
\hline Parâmetro & \multicolumn{1}{|c|}{ Descrição } & Valor \\
\hline \hline$N_{\mathrm{POP}}$ & Número de indivíduos da população $\left(\Omega_{\mathrm{POP}}\right)$ & $600 / 800$ \\
\hline$N_{\mathrm{IV}}$ & Número máximo de indivíduos viáveis no conjunto $\Omega_{\mathrm{IV}}$ & 50 \\
\hline$\alpha_{\mathrm{CR}}$ & Taxa de cruzamento & $65 \%$ \\
\hline$\alpha_{\mathrm{MT}}$ & Taxa de mutação & $8 \%$ \\
\hline$\alpha_{i n v}$ & Fator de penalização (R\$/MW) & $10^{6}$ \\
\hline$N_{\mathrm{MAX}-\mathrm{EE}}$ & Número máximo de execuções evolutivas & 5 \\
\hline$N_{\mathrm{MAX}-\mathrm{GER}}$ & Número máximo de gerações & 500 \\
\hline$N_{\mathrm{GER}-\mathrm{EST}}$ & $\begin{array}{l}\text { Número máximo de gerações com estagnação do melhor indi- } \\
\text { víduo }\end{array}$ & 15 \\
\hline$P_{1}$ & Peso dado para o índice $I n d_{c h-i j}$ & 1 \\
\hline$P_{2}$ & Peso dado para o índice $I n d_{s c-i j}^{\text {próprio }}$ & 2 \\
\hline$P_{3}$ & Peso dado para o índice $I n d_{s c-i j}^{\text {outros }}$ & 2 \\
\hline$N_{G E R-L T}^{M A ́ x}$ & Número máximo de gerações para atualização da Lista Tabu & 9 \\
\hline$h$ & $\begin{array}{l}\text { Número máximo de indivíduos considerados para identificação } \\
\text { de ramos tabus }\end{array}$ & 10 \\
\hline$N_{\mathrm{EL}}$ & Porcentagem de elitismo & $80 \%$ \\
\hline
\end{tabular}


Por fim, todas as rotinas do algoritmo AGE-PET foram desenvolvidas em linguagem C\#.NET, com exceção da biblioteca GLPK, utilizada na solução dos problemas de programação linear via método simplex, implementada através de linguagem $\mathrm{C}++$ e da biblioteca utilizada na análise de contingência da rede de transmissão implementada em linguagem FORTRAN. Todos os testes foram realizados utilizando um processador Intel Xeon de $3.5 \mathrm{GHz}$.

\section{3. Índices de Desempenho}

Visto que a ferramenta AGE-PET configura uma técnica de otimização estocástica, seu desempenho é avaliado neste trabalho por meio de cinco índices estatísticos, calculados para cada teste realizado com o algoritmo. Estes índices são calculados com base nas soluções que compõem o conjunto $\Omega_{\mathrm{B} 15}$ obtido após a convergência da ferramenta a partir de um determinado número de aplicações (rodadas) do algoritmo apresentado na Figura 3.2. A cada nova rodada do algoritmo, uma diferente semente inicial para o processo é considerada. Os índices propostos para análise estatística de desempenho são definidos como:

- $\quad R_{\text {Best }}=$ Quantidade de rodadas do algoritmo que identificaram soluções melhores ou iguais à melhor solução conhecida para o problema;

- $\quad N_{\text {Top10 }}=$ Quantidade média de soluções identificadas que pertencem ao conjunto das 10 melhores soluções conhecidas para o problema (Top10) ou que possuem melhor investimento;

- $\quad T_{\mathrm{M}}$ : Tempo médio demandado por rodada do algoritmo;

- $D_{\text {Best: }}$ Desvio percentual médio apresentado entre o melhor investimento encontrado em cada rodada do algoritmo e o investimento do melhor plano de expansão conhecido;

- $D_{10 \text { Best: }}$ Desvio percentual médio apresentado pelos investimentos das 10 melhores soluções identificadas em cada rodada do algoritmo e o melhor investimento conhecido.

A partir da análise dos índices estatísticos propostos é possível quantificar de forma consistente o desempenho do algoritmo, sendo reduzidas as consequên- 
cias impostas pela sua natureza estocástica. De forma geral, o desempenho é analisado tanto em termos de qualidade do conjunto final de soluções encontradas quanto em relação ao custo computacional requerido para solução do problema.

\section{4. \\ Resultados - IEEE-RTS}

Comumente utilizado em estudos de planejamento da expansão da transmissão, o sistema IEEE-RTS [94] possui em sua topologia base 38 circuitos distribuídos em 34 ramos existentes e um total de 24 barras. O diagrama do sistema pode ser visto na Figura 4.1. Os valores de demanda total e de capacidade de geração seguem as premissas propostas em [95]. Neste caso, seus respectivos patamares são expandidos em três vezes seus valores originais ao final do horizonte de estudo, sendo mantidos os respectivos fatores de participação das barras de geração do sistema. Ou seja, o sistema apresenta para o ano horizonte de planejamento uma carga pico de $8.550 \mathrm{MW}$ e uma capacidade de geração total de 10.215MW.

Para a solução do problema de programação linear gerado a partir do subproblema de operação (Subseção 3.2.2) durante o processo evolutivo do AGEPET foi considerada uma ordem prioritária de despacho que representa os custos de geração $c_{k}^{g}$ de cada unidade geradora. Foi definido, ainda, um total de 41 ramos candidatos à expansão, sendo 34 ramos existentes na topologia base do sistema $\mathrm{e}$ sete novos ramos inicialmente vazios (sem circuitos). Na solução do problema PET para o sistema IEEE-RTS, cada um dos 41 ramos candidatos pode receber um número máximo de 3 reforços $\left(n_{i j}^{\max }=3\right)$. Para esse sistema, destaca-se ainda que todos os ramos ativos do sistema são considerados durante a avaliação do plano em condições de contingência. Ou seja, durante o processo de solução do AGE-PET, para cada solução avaliada um mínimo de 34 e um máximo de 41 contingências simples são analisados. As informações referentes aos dados de barra, assim como as referentes a ramos candidatos do sistema estão apresentados, respectivamente, na Tabela A.1 e na Tabela A.2 do Anexo A desta dissertação. 


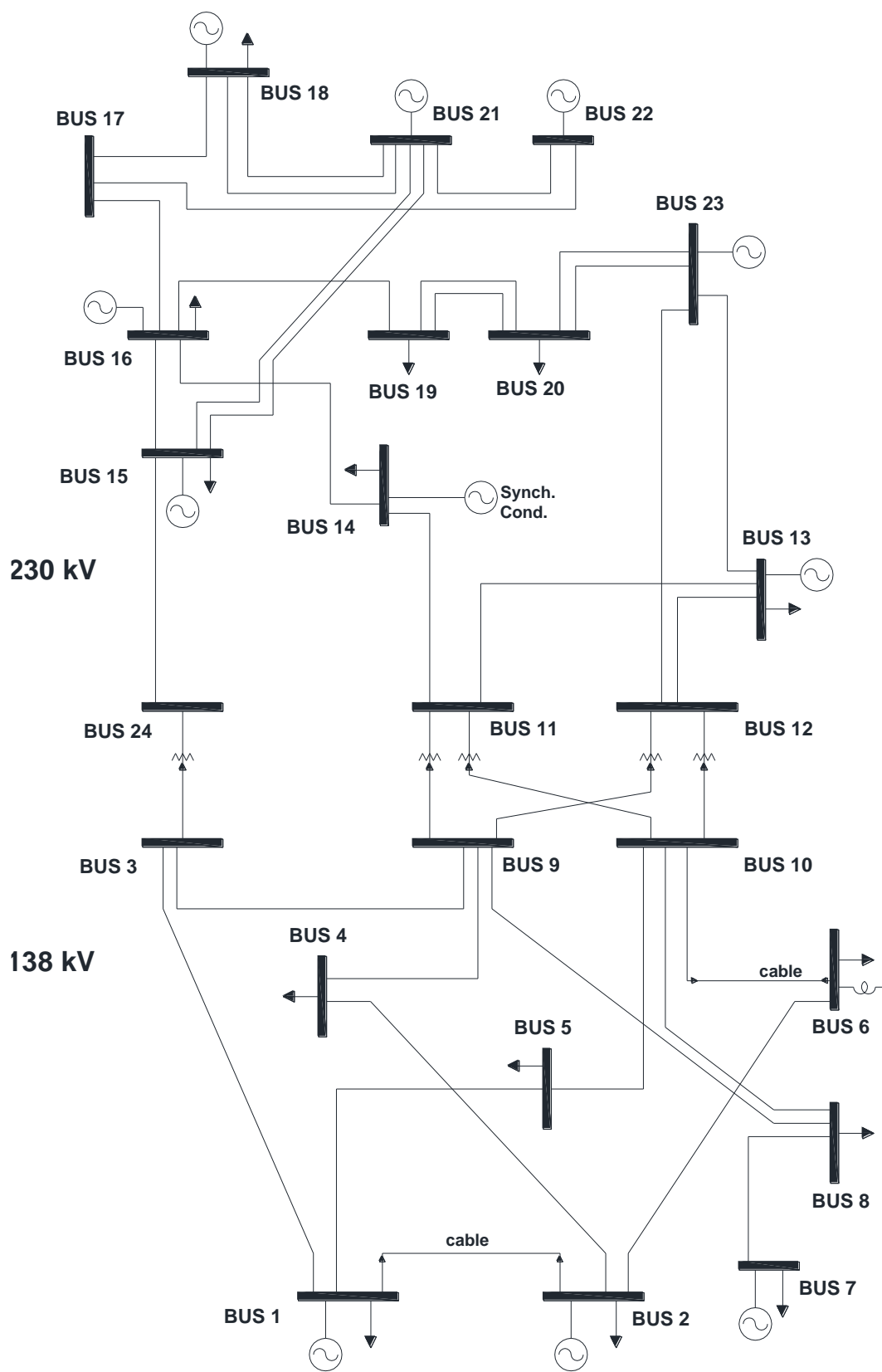

Figura 4.1 - Diagrama Unifilar do Sistema IEEE-RTS. Adaptado de [94].

Em todos os testes realizados com o sistema IEEE-RTS, o menor investimento conhecido é de 681,00 milhões de unidades monetárias (\$), sendo a solução correspondente constituída de um total de 17 reforços distribuídos em 10 ramos candidatos. A configuração da rede de transmissão resultante deste plano apresenta um valor total de perdas ativas de 138,90 MW. O conjunto das 10 melhores soluções identificadas para este sistema (Top10-IEEE-RTS) apresenta 10 diferentes soluções em termos do conjunto de reforços, porém com o mesmo valor de 
investimento (681,00 milhões de \$). Os detalhes relativos ao Top10 para este sistema podem ser vistos na Tabela 4.2.

Tabela 4.2 - Conjunto das 10 melhores soluções conhecidas - Top10-IEEE-RTS.

\begin{tabular}{|c|c|c|c|c|c|}
\hline Plano & $\begin{array}{c}\text { Investimento } \\
\left(10^{6} \times \$\right) \\
\end{array}$ & $\begin{array}{c}\text { Perdas } \\
\text { (MW) } \\
\end{array}$ & $\begin{array}{l}\text { Total de } \\
\text { Reforços } \\
\end{array}$ & $\begin{array}{c}\text { Ramos } \\
\text { Reforçados } \\
\end{array}$ & Reforços \\
\hline 1 & 681,00 & 138,90 & 17 & 10 & $\begin{array}{c}n_{01-05}=1 ; n_{02-04}=1 ; n_{03-09}=2 ; \\
n_{06-10}=2 ; n_{07-08}=3 ; n_{09-12}=1 ; \\
n_{10-12}=2 ; n_{12-13}=2 ; n_{20-23}=1 ; \\
n_{14-23}=2\end{array}$ \\
\hline 2 & 681,00 & 138,98 & 17 & 12 & $\begin{array}{l}n_{01-05}=1 ; n_{02-04}=1 ; n_{03-09}=2 ; \\
n_{06-10}=2 ; n_{07-08}=3 ; n_{09-12}=1 ; \\
n_{10-11}=1 ; n_{10-12}=1 ; n_{11-13}=1 ; \\
n_{12-13}=1 ; n_{20-23}=1 ; n_{14-23}=2\end{array}$ \\
\hline 3 & 681,00 & 139,01 & 17 & 11 & $\begin{array}{c}n_{01-05}=1 ; n_{02-04}=1 ; n_{03-09}=2 ; \\
n_{06-10}=2 ; n_{07-08}=3 ; n_{09-11}=1 ; \\
n_{10-12}=2 ; n_{11-13}=1 ; n_{12-13}=1 ; \\
\quad n_{20-23}=1 ; n_{14-23}=2\end{array}$ \\
\hline 4 & 681,00 & 139,18 & 17 & 10 & $\begin{array}{c}n_{01-05}=1 ; n_{02-04}=1 ; n_{03-09}=2 ; \\
n_{06-10}=2 ; n_{07-08}=3 ; n_{09-11}=1 ; \\
n_{10-11}=2 ; n_{11-13}=2 ; n_{20-23}=1 ; \\
n_{14-23}=2\end{array}$ \\
\hline 5 & 681,00 & 139,20 & 17 & 11 & $\begin{aligned} n_{01-05} & =1 ; n_{02-04}=1 ; n_{03-09}=2 ; \\
n_{06-10}=2 ; & n_{07-08}=3 ; n_{09-11}=1 ; \\
n_{10-11} & =1 ; n_{10-12}=1 ; n_{11-13}=2 ; \\
& n_{20-23}=1 ; n_{14-23}=2\end{aligned}$ \\
\hline 6 & 681,00 & 139,21 & 17 & 10 & $\begin{aligned} n_{01-05} & =1 ; n_{02-04}=1 ; n_{03-09}=2 ; \\
n_{06-10}=2 ; & n_{07-08}=3 ; n_{09-12}=1 ; \\
n_{10-11}=2 ; & n_{11-13}=2 ; n_{20-23}=1 ; \\
& n_{14-23}=2\end{aligned}$ \\
\hline 7 & 681,00 & 139,39 & 17 & 12 & $\begin{aligned} n_{01-05}=1 ; & n_{02-04}=1 ; n_{03-09}=2 ; \\
n_{06-10}=2 ; & n_{07-08}=3 ; n_{09-11}=1 ; \\
n_{10-11}=1 ; & n_{10-12}=1 ; n_{11-13}=1 ; \\
n_{12-13}=1 ; & n_{20-23}=1 ; n_{14-23}=2\end{aligned}$ \\
\hline 8 & 681,00 & 139,47 & 17 & 11 & $\begin{array}{c}n_{01-05}=1 ; n_{02-04}=1 ; n_{03-09}=2 ; \\
n_{06-10}=2 ; n_{07-08}=3 ; n_{09-12}=1 ; \\
n_{10-11}=2 ; n_{11-13}=1 ; n_{12-13}=1 ; \\
\quad n_{20-23}=1 ; n_{14-23}=2\end{array}$ \\
\hline 9 & 681,00 & 139,83 & 17 & 11 & $\begin{array}{c}n_{01-05}=1 ; n_{02-04}=1 ; n_{03-09}=2 ; \\
n_{06-10}=2 ; n_{07-08}=3 ; n_{09-12}=1 ; \\
n_{10-11}=1 ; n_{10-12}=1 ; n_{12-13}=2 ; \\
\quad n_{20-23}=1 ; n_{14-23}=2\end{array}$ \\
\hline 10 & 681,00 & 139,91 & 17 & 10 & $\begin{array}{c}n_{01-05}=1 ; n_{02-04}=1 ; n_{03-09}=2 ; \\
n_{06-10}=2 ; n_{07-08}=3 ; n_{09-11}=1 ; \\
n_{10-12}=2 ; n_{12-13}=2 ; n_{20-23}=1 ; \\
n_{14-23}=2\end{array}$ \\
\hline
\end{tabular}

Para a análise de desempenho, para cada um dos tamanhos de população e para cada mecanismo de seleção proposto na Subseção 3.4.3 foram realizadas 10 rodadas do algoritmo AGE-PET, cada uma desenvolvendo um total de 5 execuções evolutivas $\left(N_{\text {MAX-EE }}=5\right)$, conforme definido na Figura 3.2. Os índices de 
desempenho estatístico propostos são então calculados para o conjunto das 15 melhores soluções identificadas $\left(\Omega_{\mathrm{B} 15}\right)$ obtido após convergência em cada rodada de 5 EEs. Portanto, dado que todas as soluções que compõe o conjunto das 10 melhores soluções conhecidas para o sistema IEEE-RTS possuem o mesmo valor de investimento (681,00 milhões de \$), o mínimo valor esperado para o índice

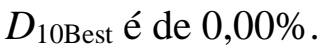

Por fim, em relação aos testes destaca-se, ainda que, no emprego do AGEPET para solução do planejamento da rede de transmissão para o sistema IEEERTS, todos os ramos candidatos podem ser avaliados pelos índices de sensibilidade propostos na Subseção 3.4.2, não havendo necessidade da definição da taxa de adição $\left(\alpha_{a d i}\right)$ quando aplicado o mecanismo de Mutação Especialista (EspMut).

$\mathrm{Na}$ Tabela 4.3 são apresentados os índices de desempenho estatístico calculados a partir dos resultados obtidos pela ferramenta AGE-PET para dois diferentes testes realizados com o sistema IEEE-RTS, Testes A.1 e A.2. Para definição destes testes, são considerados dois diferentes tamanhos de população, $N_{\mathrm{POP}}=600$ e $N_{\text {POP }}=800$, respectivamente, sendo os demais parâmetros definidos conforme Seção 4.2. Para estes testes, foi considerada a aplicação do mecanismo de seleção por torneio, combinado à seleção por elitismo de $80 \%$ (i.e., $N_{\mathrm{EL}}=80 \%$ de $N_{\mathrm{POP}}$ ). Vale lembrar que cada uma das 10 rodadas do AGE-PET corresponde à execução de 5 EEs $\left(N_{\mathrm{MAX}-\mathrm{EE}}=5\right)$.

Tabela 4.3 - Índices de desempenho para IEEE-RTS - Seleção por torneio.

\begin{tabular}{|c|c|c|c|c|c|c|}
\hline Teste & $\boldsymbol{N}_{\text {POP }}$ & $\boldsymbol{R}_{\text {Best }}$ & $\boldsymbol{N}_{\text {Top10 }}$ & $\boldsymbol{T}_{\mathbf{M}}(\mathbf{m i n})$ & $\boldsymbol{D}_{\text {Best }}(\boldsymbol{\%})$ & $\boldsymbol{D}_{\text {10Best }}(\boldsymbol{\%})$ \\
\hline \hline A.1 & 600 & 10,00 & 9,80 & 13,08 & 0,00 & 0,05 \\
\hline $\mathbf{A . 2}$ & 800 & 10,00 & 9,90 & 16,19 & 0,00 & 0,02 \\
\hline
\end{tabular}

É possível verificar um bom desempenho do AGE-PET a partir dos resultados da Tabela 4.3. No teste realizado para $N_{\mathrm{POP}}=600$ (Teste A.1), por exemplo, uma análise do índice $N_{\text {Top10 }}$ mostra que, em média, a ferramenta é capaz de identificar em cada rodada 9,8 das 10 melhores soluções conhecidas para o sistema. Já nos testes realizados para $N_{\mathrm{POP}}=800$ (Teste A.2), esse índice apresenta um valor ainda maior, onde em média, a ferramenta é capaz de identificar em cada rodada 9,9 das 10 melhores soluções conhecidas para o problema. Contudo, ainda que na média nem todas as rodadas tenham sido capazes de identificar todas as 10 melhores soluções conhecidas (Top10-IEEE-RTS), foi verificado que a pior rodada em 
ambos os testes foi ainda capaz de identificar 9 dessas soluções. Foi verificado, ainda, que quando uma rodada não foi capaz de identificar todas as soluções do Top10-IEEE-RTS, a média dos investimentos das 10 melhores soluções identificadas (i.e., 10 melhores soluções do conjunto $\Omega_{\mathrm{B} 15}$ ) é apenas $0,23 \%$ maior que o melhor conhecido (681,00 milhões de \$). Por outro lado, em 17 das 20 rodadas realizadas o Top10-IEEE-RTS foi completamente identificado.

De forma geral, verificou-se, ainda, que dentre as rodadas realizadas no Teste A.1, somente duas rodadas não foram capazes de identificar todas as soluções do Top10-IEEE-RTS, definindo para o índice $D_{10 \text { Best }}$ um valor igual a $0,05 \%$. Ou seja, estima-se que para o Teste A.1, considerando-se os parâmetros do AGE-PET adotados nesta dissertação, em uma única rodada do algoritmo a média do investimento das 10 melhores soluções identificadas seja apenas 0,05\% maior que o valor do melhor investimento conhecido. Já com o aumento do tamanho populacional para 800 indivíduos (Teste A.2), verifica-se que o valor do índice $D_{10 \text { Best }}$ é ainda menor, com valor de $0,02 \%$.

Além disso, uma ênfase especial pode ser dada ainda aos desempenhos atingidos pelos índices $R_{\text {Best }}$ e $D_{\text {Best, }}$ que apresentam, para ambos os testes, os seus melhores valores esperados (i.e., 10.00 e $0.00 \%$, respectivamente). Isso indica que, em cada rodada do AGE-PET, a ferramenta foi capaz de identificar a melhor solução conhecida para o problema.

Em termos de tempo médio de execução $\left(T_{\mathrm{M}}\right)$, estima-se que o algoritmo demanda, em média, 13,08 minutos até a sua convergência quando considerado uma população de 600 indivíduos (Teste A.1). Já quando considerado um tamanho populacional de 800 indivíduos (Teste A.2), observa-se um aumento médio de $23,78 \%$ no tempo demandado $\left(T_{\mathrm{M}}=16,19\right.$ minutos). Esse aumento já era esperado e pode ser explicado pelo maior número de indivíduos gerados e avaliados a cada etapa do processo evolutivo do AGE-PET, o que resulta em um maior custo computacional requerido.

Ainda em termos de desempenho do AGE-PET, é possível analisar a qualidade do conjunto final de soluções obtidos ao final de cada EE desenvolvida em todas as 10 rodadas realizadas para cada teste. Neste sentido, a Figura 4.2 apresenta dois diagramas de caixa (boxplot) construidos a partir da análise das 10 melhores soluções do conjunto $\Omega_{\mathrm{IV}}$ obtidas ao final de cada uma das 50 EEs (i.e., 10 rodadas de 5 EEs) realizadas em cada um dos testes, o que totaliza, portanto, 
500 indivíduos. Este gráfico apresenta o desvio percentual dado por cada uma dessas soluções em relação ao melhor investimento conhecido para o sistema.

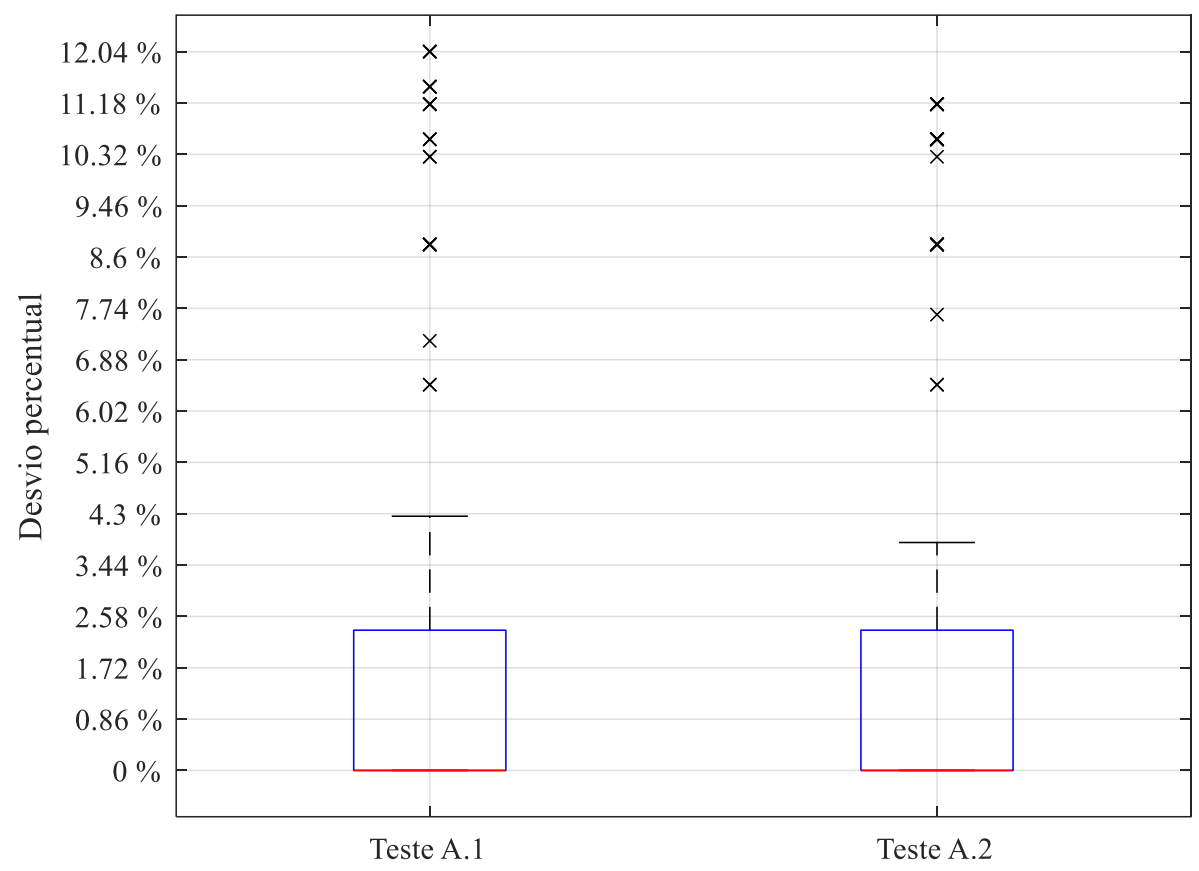

Figura 4.2 - Desvio percentual entre os melhores indivíduos de cada EE e o melhor investimento conhecido para o sistema IEEE-RTS - Seleção por torneio.

De forma geral, os diagramas da Figura 4.2 apresentam uma alta recorrência de planos de expansão de boa qualidade, com alta concentração (50\%) de soluções próximas ao valor mínimo de $0,00 \%$ em ambos os testes realizados. Além disso, é possível ainda verificar que, para ambos os tamanhos de população considerados, pelo menos $75 \%$ das soluções analisadas apresentam desvios percentuais menores ou iguais a 2,35\% (quartil superior). Verifica-se também que a média dos investimentos das soluções analisadas apresenta desvio percentual igual a 1,33\% e $1,19 \%$ para $N_{\mathrm{POP}}=600$ e $N_{\mathrm{POP}}=800$, respectivamente. Este resultado confirma o bom desempenho do algoritmo AGE-PET em termos de qualidade do conjunto final de soluções para o sistema em questão.

Além dos testes realizados utilizando-se o mecanismo de seleção por torneio, dois novos testes (A.3 e A.4) foram realizados com o sistema IEEE-RTS aplicando-se o mecanismo de seleção por clusterização, também combinado à seleção por elitismo de $80 \%$. Os demais parâmetros do AGE-PET foram considerados idênticos àqueles aplicados nos Testes A.1 e A.2. Os resultados, em termos 
de índices de desempenho estatístico obtidos para os Testes A.3 e A.4, são apresentados na Tabela 4.4 .

Tabela 4.4 - Índices de desempenho para IEEE-RTS - Seleção por clusterização.

\begin{tabular}{|c|c|c|c|c|c|c|}
\hline Teste & $\boldsymbol{N}_{\text {POP }}$ & $\boldsymbol{R}_{\text {Best }}$ & $\boldsymbol{N}_{\text {Top10 }}$ & $\boldsymbol{T}_{\mathbf{M}}(\mathbf{m i n})$ & $\boldsymbol{D}_{\text {Best }}(\boldsymbol{\%})$ & $\boldsymbol{D}_{\mathbf{1 0 B e s t}}(\boldsymbol{\%})$ \\
\hline \hline $\mathbf{A . 3}$ & 600 & 10,00 & 9,50 & 11,60 & 0,00 & 0,12 \\
\hline $\mathbf{A . 4}$ & 800 & 10,00 & 10,00 & 14,87 & 0,00 & 0,00 \\
\hline
\end{tabular}

De forma geral, verifica-se também um excelente desempenho da ferramenta para os Testes A.3 e A.4. Enquanto que para o Teste A.3 a ferramenta é capaz de identificar, em média, 9,5 das soluções do Top10-IEEE-RTS (i.e., $N_{\text {Top10 }}=$ 9,5), para o Teste A.4 essa média sobe para $10\left(N_{\text {Top10 }}=10\right)$. Ou seja, no Teste A.4, o Top10-IEEE-RTS foi completamente identificado em cada rodada isolada da ferramenta.

O menor valor verificado para o índice $N_{\text {Top10 }}$ no Teste A. 3 em relação ao Teste A.1, que considera o mesmo tamanho de população, reflete também um menor desempenho em termos do índice $D_{10 \text { Best }}$, cujo valor é igual a $0,12 \%$. Contudo, a rodada que identificou o menor número de soluções do Top10-IEEE-RTS no Teste A.3 foi ainda capaz de identificar 8 das 10 soluções desse conjunto. Nesta rodada, a média dos investimentos das 10 melhores soluções identificadas apresenta um desvio de apenas $0,47 \%$ em relação ao menor investimento conhecido.

Já para o Teste A.4, o qual considera $N_{\mathrm{POP}}=800$, o aumento no valor do índice $N_{\text {Top10 }}$ quando comparado ao Teste A.2, leva o índice $D_{10 \text { Best }}$ a atingir seu desempenho máximo esperado $\left(D_{10 \text { Best }}=0,00 \%\right)$. Ou seja, o Top10-IEEE-RTS foi completamente identificado em todas as rodadas do Teste A.4.

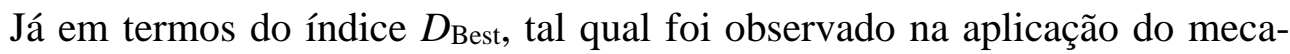
nismo de seleção por torneio (Testes A.1 e A.2), todas as rodadas dos Testes A.3 e A.4 foram capazes de identificar a melhor solução conhecida para o sistema. Tal constatação é confirmada pelo índice $R_{\text {Best, }}$ que é igual a 10 para os dois testes.

Em termos do tempo médio de execução $\left(T_{\mathrm{M}}\right)$, é possível notar reduções de $11,31 \%$ e 8,15\% dos Testes A.3 e A.4 em relação aos Testes A.1 e A.2, respectivamente. Ou seja, com emprego da seleção por clusterização, um menor tempo computacional de execução é demandado em relação ao emprego da seleção por torneio. 
O bom desempenho em termos de conjunto final de soluções de cada uma das EEs desenvolvida pela ferramenta AGE-PET com a aplicação da estratégia de clusterização pode também ser verificado por meio de diagramas de caixa (boxplot) conforme apresentado na Figura 4.3. De forma geral, verifica-se que o desvio percentual de investimento da maior parte das 500 soluções obtidas em cada teste se concentra próximo ao limite inferior de $0,0 \%$.

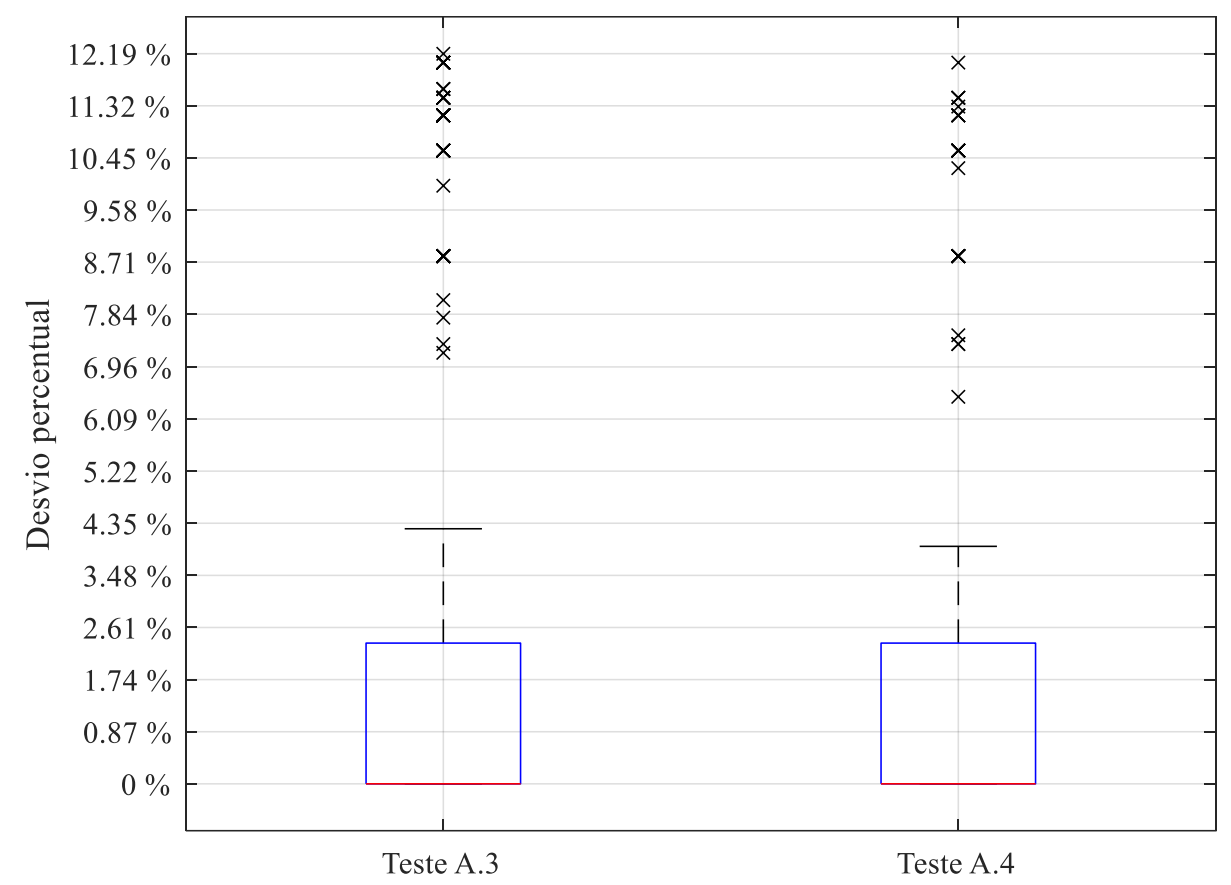

Figura 4.3 - Desvio percentual entre os melhores indivíduos de cada EE e o melhor investimento conhecido para o sistema IEEE-RTS - Seleção por clusterização.

Por fim, a partir dos resultados apresentados na Tabela 4.3 e na Tabela 4.4, é possível verificar que, para o sistema IEEE-RTS, o emprego da estratégia de diversidade considerada pelo mecanismo de seleção por clusterização manteve desempenho semelhante àquele observado no emprego da ferramenta com a aplicação do mecanismo de seleção por torneio, sendo mais perceptível apenas a pequena redução do tempo médio de execução $\left(T_{M}\right)$. Mas, de forma geral, o AGE-PET apresentou excelentes desempenhos em todos os quatros testes realizados com o sistema IEEE-RTS. 


\section{5.}

Resultados - SSB

O Sistema Sul Brasileiro (SSB) [67], cuja rede refere-se ao ano de 1980, corresponde a outro sistema comumente utilizado no estudo do planejamento da expansão da transmissão. Este sistema possui em sua topologia base um total de 46 barras, das quais 11 são inicialmente isoladas da rede, sendo 2 barras de geração e 9 barras de passagem. Além disso, o sistema SSB possui ainda 62 circuitos distribuídos em 47 ramos existentes. Um diagrama simplificado do sistema pode ser visto na Figura 4.4.

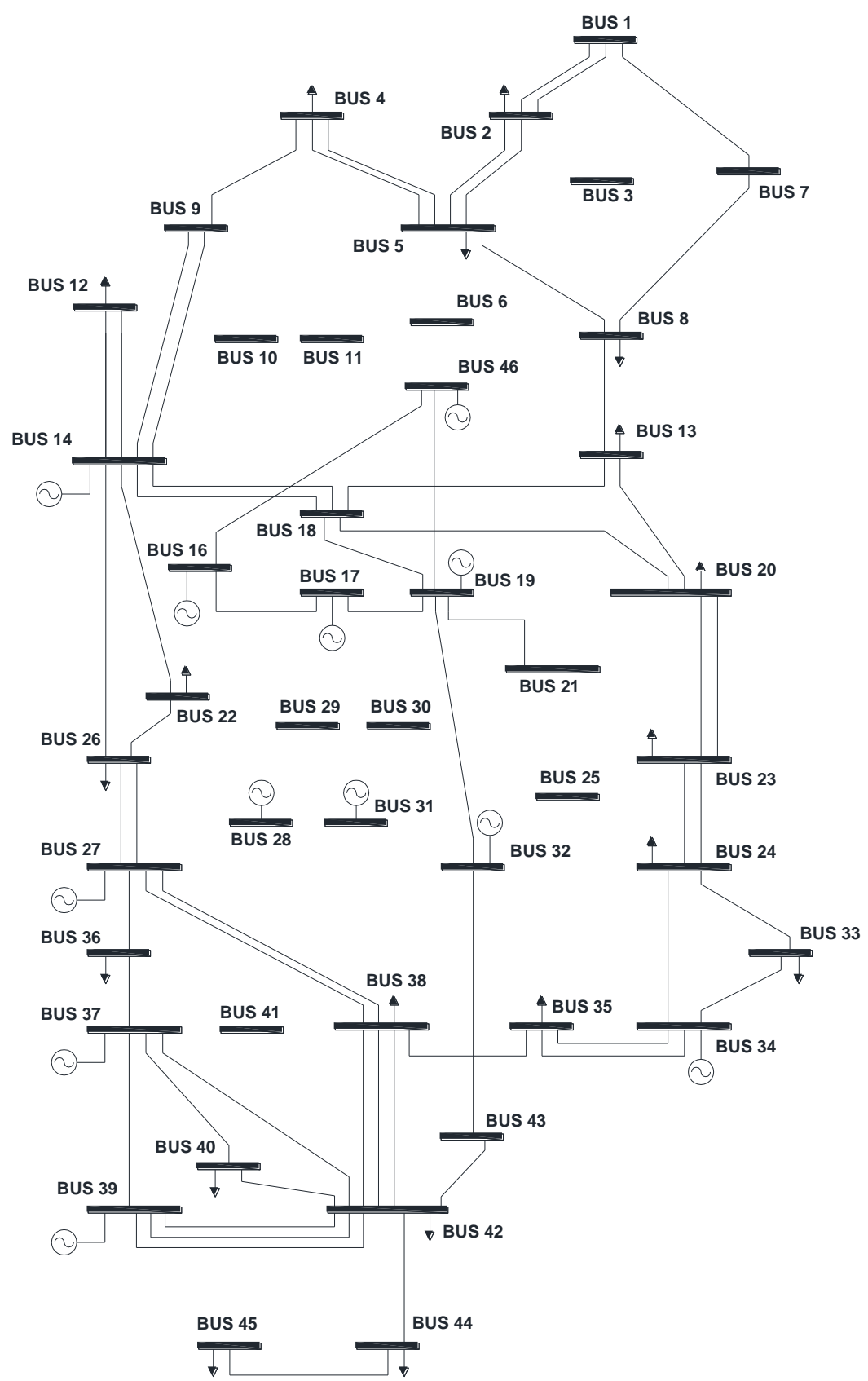

Figura 4.4 - Diagrama Unifilar Sistema Sul Brasileiro (SSB). Adaptado de [67]. 
No estudo de planejamento da expansão da transmissão para o SSB, o que é realizado considerando o ano horizonte de 1990, são definidos como candidatos ao reforço 79 ramos do sistema, dos quais 32 são ramos novos (i.e., não possuem circuitos na topologia base). Cada um desses ramos candidatos ao reforço pode receber um número máximo de 3 reforços $\left(n_{i j}^{\max }=3\right)$ na solução do problema PET. Para este sistema, assim como realizado para o sistema IEEE-RTS, todos os ramos ativos do sistema são considerados durante a avaliação do plano em condições de contingência. Sendo analisados, portanto, um mínimo de 47 e um máximo de 79 contingências simples para cada solução avaliada durante o processo de solução. Os dados de barra, com a ordem de despacho adotada na realização dos testes para os custos de geração, estão descritos na Tabela B.1. Já os dados referentes aos ramos candidatos do sistema estão dispostos na Tabela B.2. Estas duas tabelas estão presentes no Anexo B desta dissertação.

Para todos os testes realizado com o sistema SSB, os quais são analisados na presente seção, o investimento da melhor solução identificada é de 239,021 milhões de \$. Essa solução é constituída por um total de 22 reforços distribuidos em 14 ramos candidatos e possui um valor total de perdas ativas de 184,78 MW. O investimento médio verificado para as 10 melhores soluções identificadas para o SSB (Top10-SSB), apresentadas na Tabela 4.5, é igual a 243,13 milhões de \$, o que representa um desvio de $1,72 \%$ em relação ao melhor investimento identificado (239,021 milhões de \$), sendo este, portanto, o menor valor esperado para o índice de desempenho estatístico $D_{10 \text { Best. }}$

Os parâmetros dos testes realizados com o sistema SSB foram definidos idênticos àqueles considerados para o sistema IEEE-RTS. De forma geral, dois diferentes tamanhos de populção $\left(N_{\mathrm{POP}}=600\right.$ e $\left.N_{\mathrm{POP}}=800\right)$ foram considerados para cada estratégia de seleção analisada (seleção por terneio e por clusterização combinadas à seleção por elitismo com $N_{\mathrm{EL}}=80 \%$ de $\left.N_{\mathrm{POP}}\right)$. Para cada teste, foram considerdas 10 rodadas do AGE-PET com $N_{\mathrm{MAX}-\mathrm{EE}}=5$, ou seja, 5 EEs por rodada do algoritmo da Figura 3.2.

Para o sistema SSB, três ramos candidatos não podem ser inicialmente avaliados pelos índices de sensibilidade, sendo estes ramos responsáveis pela interligação da rede às duas barras de geração inicialmente isoladas. Portanto, foram consideradas para esses ramos, no emprego da mutação, uma taxa de adição $\alpha_{a d i}=$ $70 \%$ e taxa de subtração $\alpha_{s u b}=30 \%$. 
Tabela 4.5 - Conjunto das 10 melhores soluções conhecidas - Top10-SSB

\begin{tabular}{|c|c|c|c|c|c|}
\hline Plano & $\begin{array}{c}\text { Investimento } \\
\left(10^{6} \times \$\right)\end{array}$ & $\begin{array}{c}\text { Perdas } \\
\text { (MW) }\end{array}$ & $\begin{array}{l}\text { Total de } \\
\text { Reforços } \\
\end{array}$ & $\begin{array}{c}\text { Ramos } \\
\text { Reforçados }\end{array}$ & Reforços \\
\hline 1 & 239,021 & 184,78 & 22 & 14 & $\begin{array}{c}n_{02-05}=1 ; n_{12-14}=1 ; n_{19-21}=1 ; \\
n_{20-23}=2 ; n_{24-33}=1 ; n_{33-34}=1 ; \\
n_{32-43}=1 ; n_{42-44}=1 ; n_{44-45}=1 ; \\
n_{20-21}=3 ; n_{42-43}=3 ; n_{46-06}=2 ; \\
\quad n_{31-32}=1 ; n_{05-06}=2\end{array}$ \\
\hline 2 & 239,425 & 185,03 & 22 & 14 & $\begin{array}{l}n_{02-05}=1 ; n_{12-14}=1 ; n_{19-21}=1 ; \\
n_{20-23}=2 ; n_{24-33}=1 ; n_{33-34}=1 ; \\
n_{40-42}=1 ; n_{32-43}=1 ; n_{20-21}=3 ; \\
n_{42-43}=3 ; n_{46-06}=2 ; n_{31-32}=1 ; \\
\quad n_{40-45}=1 ; n_{05-06}=3\end{array}$ \\
\hline 3 & 240,233 & 181,11 & 22 & 14 & $\begin{array}{l}n_{02-05}=1 ; n_{12-14}=1 ; n_{19-21}=1 ; \\
n_{20-23}=2 ; n_{24-34}=1 ; n_{33-34}=1 ; \\
n_{32-43}=1 ; n_{42-44}=1 ; n_{44-45}=1 ; \\
n_{20-21}=3 ; n_{42-43}=3 ; n_{46-06}=2 ; \\
\quad n_{31-32}=1 ; n_{05-06}=3\end{array}$ \\
\hline 4 & 240,637 & 181,36 & 22 & 14 & $\begin{array}{l}n_{02-05}=1 ; n_{12-14}=1 ; n_{19-21}=1 ; \\
n_{20-23}=2 ; n_{24-34}=1 ; n_{33-34}=1 ; \\
n_{40-42}=1 ; n_{32-43}=1 ; n_{20-21}=3 ; \\
n_{42-43}=3 ; n_{46-06}=2 ; n_{31-32}=1 ; \\
\quad n_{40-45}=1 ; n_{05-06}=3\end{array}$ \\
\hline 5 & 242,556 & 181,90 & 22 & 13 & $\begin{array}{c}n_{02-05}=1 ; n_{12-14}=1 ; n_{19-21}=1 ; \\
n_{20-23}=2 ; n_{24-34}=2 ; n_{32-43}=1 ; \\
n_{42-44}=1 ; n_{44-45}=1 ; n_{20-21}=3 ; \\
n_{42-43}=3 ; n_{46-06}=2 ; n_{31-32}=1 ; \\
n_{05-06}=3\end{array}$ \\
\hline 6 & 242,960 & 182,15 & 22 & 13 & $\begin{aligned} n_{02-05} & =1 ; n_{12-14}=1 ; n_{19-21}=1 ; \\
n_{20-23}=2 ; & n_{24-34}=2 ; n_{40-42}=1 ; \\
n_{32-43}=1 ; & n_{20-21}=3 ; n_{42-43}=3 ; \\
n_{46-06}=2 ; & n_{31-32}=1 ; n_{40-45}=1 ; \\
n_{05-06} & =3\end{aligned}$ \\
\hline 7 & 245,087 & 176,04 & 23 & 15 & $\begin{array}{l}n_{02-05}=1 ; n_{12-14}=1 ; n_{19-21}=1 ; \\
n_{20-23}=2 ; n_{24-34}=1 ; n_{33-34}=1 ; \\
n_{37-39}=1 ; n_{37-40}=1 ; n_{32-43}=1 ; \\
n_{20-21}=3 ; n_{42-43}=3 ; n_{46-06}=2 ; \\
n_{31-32}=1 ; n_{40-45}=1 ; n_{05-06}=3\end{array}$ \\
\hline 8 & 246,456 & 179,11 & 24 & 15 & $\begin{array}{l}n_{02-05}=2 ; n_{12-14}=1 ; n_{19-21}=1 ; \\
n_{20-23}=2 ; n_{24-33}=1 ; n_{33-34}=1 ; \\
n_{37-39}=1 ; n_{37-40}=1 ; n_{32-43}=1 ; \\
n_{20-21}=3 ; n_{42-43}=3 ; n_{46-06}=2 ; \\
n_{31-32}=1 ; n_{40-45}=1 ; n_{05-06}=3\end{array}$ \\
\hline 9 & 247,410 & 176,84 & 23 & 14 & $\begin{array}{c}n_{02-05}=1 ; n_{12-14}=1 ; n_{19-21}=1 ; \\
n_{20-23}=2 ; n_{24-34}=2 ; n_{37-39}=1 ; \\
n_{37-40}=1 ; n_{32-43}=1 ; n_{20-21}=3 ; \\
n_{42-43}=3 ; n_{46-06}=2 ; n_{31-32}=2 ; \\
\quad n_{40-45}=1 ; n_{05-06}=3\end{array}$ \\
\hline 10 & 247,466 & 179,25 & 24 & 16 & $\begin{array}{c}n_{02-05}=1 ; n_{12-14}=1 ; n_{19-21}=1 ; \\
n_{20-23}=2 ; n_{24-33}=1 ; n_{33-34}=1 ; \\
n_{34-35}=1 ; n_{37-39}=1 ; n_{37-40}=1 ; \\
n_{32-43}=1 ; n_{20-21}=3 ; n_{42-43}=3 ; \\
n_{46-06}=2 ; n_{31-32}=1 ; n_{40-45}=1 ; \\
n_{05-06}=3\end{array}$ \\
\hline
\end{tabular}


Vale resaltar que, após a adição de reforços que conectem as barras isoladas à rede, sejam elas de geração/carga ou de passagem, o ramo candidato passa também a ser considerado um ramo existente e, portanto, avaliado normalmente por todos os índices de sensibilidade, tendo suas taxas de adição e subtração calculadas conforme definido na Subseção 3.4.2.

A Tabela 4.6 apresenta os resultados da ferramenta AGE-PET para o SSB considerando a aplicação do mecanismo de seleção por torneio, sendo definidos dois testes (B.1 e B.2) para os dois tamanhos de população considerados. Apesar deste sistema possuir maior dimensão quando comparado ao sistema IEEE-RTS, constata-se o bom desempenho da ferramenta em relação aos mesmos ajustes de parâmetros do AGE-PET utilizados. Como exemplo, pode-se citar os elevados valores do índice $R_{\text {Best }}$ o qual atingiu seu valor máximo em ambos os testes realizados $\left(R_{\text {Best }}=10\right)$. Ou seja, todas as rodadas foram capazes de identificar o menor investimento conhecido para o sistema. Essa informação pode ser também evidenciada pelo valor do índice $D_{\text {Best }}$, o qual indica um desvio percentual de $0,0 \%$ entre o melhor investimento encontrado e o melhor investimento conhecido para o SSB.

Tabela 4.6 - Índices de desempenho para o SSB - Seleção por torneio.

\begin{tabular}{|c|c|c|c|c|c|c|}
\hline Teste & $\boldsymbol{N}_{\text {POP }}$ & $\boldsymbol{R}_{\text {Best }}$ & $\boldsymbol{N}_{\text {Top10 }}$ & $\boldsymbol{T}_{\mathbf{M}}(\mathbf{m i n})$ & $\boldsymbol{D}_{\text {Best }}$ (\%) & $\boldsymbol{D}_{\text {10Best }}$ (\%) \\
\hline \hline B.1 & 600 & 10,00 & 8,90 & 31,73 & 0,00 & 1,92 \\
\hline B.2 & 800 & 10,00 & 9,40 & 42,48 & 0,00 & 1,82 \\
\hline
\end{tabular}

Destaca-se, também, o bom desempenho da ferramenta no que se refere ao índice $D_{10 \mathrm{Best}}$, o qual apresentou valores iguais a 1,92 e $1,82 \%$ para os Testes B.1 e B.2, respectivamente, valores bem próximos do mínimo esperado de 1,72\%. Esses valores do índice $D_{10 B e s t}$ evidenciam a qualidade do algoritmo em termos do conjunto final de soluções identificado em cada rodada. Para os dois testes, um mínimo de 8 soluções do Top10-SSB é identificado. Neste sentido, os valores do

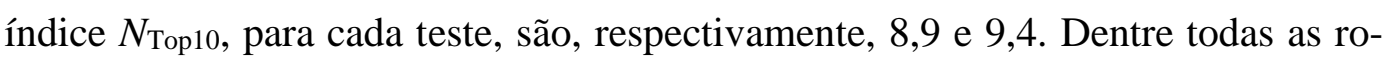
dadas analisadas, a que apresentou o pior desempenho em termos do desvio percentual médio das 10 melhores soluções identificadas em relação ao melhor investimento conhecido para o SSB apresentou valor igual a 2,28\%. Neste caso, o maior investimento identificado dentre as 10 melhores soluções desta rodada é formado por um total de 22 reforços e possui investimento de \$254,144 milhões com perdas ativas de 179,294 MW. 
Em termos do índice $T_{\mathrm{M}}$, verifica-se um aumento de, aproximadamente, $34 \%$ do Teste B.1 para o Teste B.2, com ganhos médios de $5.62 \%$ e 5,21\%, respectivamente, para os índices $N_{\text {Top10 }}$ e $D_{10 \text { Best. }}$

Em relação à qualidade final das soluções de cada execução evolutiva realizada, os diagramas de caixa apresentados na Figura 4.5 demonstram o bom desempenho do AGE-PET parar os Testes B.1 e B.2. Estes diagramas foram construídos, assim como nos testes para o sistema IEEE-RTS, observando as 10 melhores soluções obtidas ao final de cada uma das 50 EEs realizadas (10 rodadas de 5 EEs) em cada teste. Destaque pode ser dado ao Teste B.2, com $N_{\text {POP }}=800$, em que $50 \%$ (segundo quartil) de todas as soluções identificadas possuem desvio percentual menor ou igual a $1,65 \%$ em relação ao melhor investimento identificado para o sistema. Isso significa dizer que, pelo menos $50 \%$ das soluções identificadas possuem valor de investimento menor ou igual ao sexto melhor investimento das soluções do Top10-SSB (Tabela 4.5). O investimento avaliado para este plano de expansão apresenta valor igual \$242,96 milhões. Contudo, uma boa qualidade das soluções finais de cada execução evolutiva do AGE-PET é também verificada para o Teste B.1, onde pelo menos $50 \%$ das soluções apresentam desvio percentual menor ou igual ao desvio apresentado entre o investimento da sétima melhor solução e o investimento da melhor solução conhecida, ou seja, menor ou igual a 2,54\%.

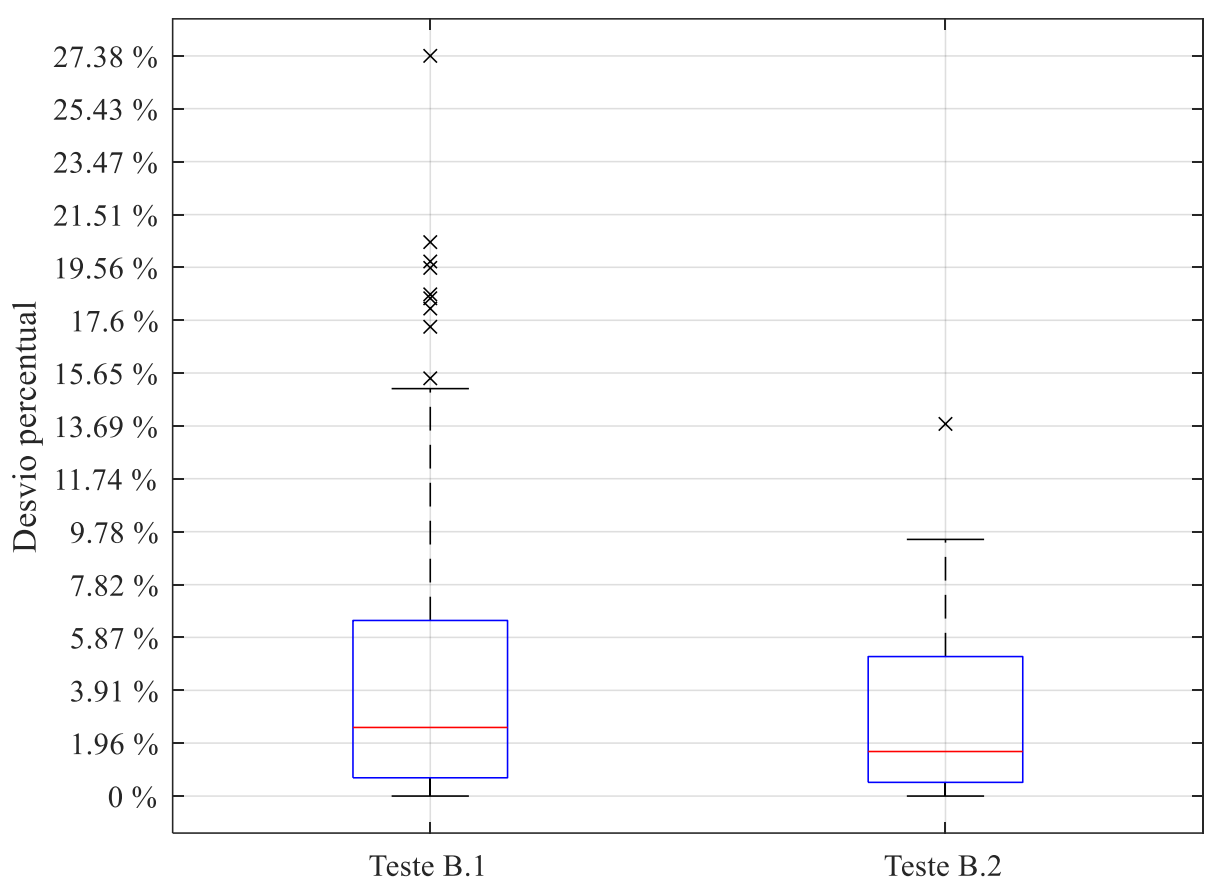

Figura 4.5 - Desvio percentual entre os melhores indivíduos de cada EE e o melhor investimento conhecido para o sistema SSB - Seleção por torneio. 
Para os testes considerando o emprego do mecanismo de seleção por clusterização combinado à seleção por elitismo, Testes B.3 e B.4, os resultados obtidos estão apresentados na Tabela 4.7. Em termos gerais, a aplicação deste mecanismo em relação à seleção por torneio acarretou em uma pequena degradação dos índices de desempenho avaliados, com exceção do tempo médio de execução $\left(T_{\mathrm{M}}\right)$, o qual apresentou uma melhora média de 14,4\% quando comparado aos tempos médios gastos pelos Testes B.1 e B.2. Apesar disso, a ferramenta apresenta ainda um alto desempenho na solução do problema PET em relação aos parâmetros considerados.

Tabela 4.7 - Índices de desempenho para o SSB - Seleção por clusterização.

\begin{tabular}{|c|c|c|c|c|c|c|}
\hline Teste & $\boldsymbol{N}_{\text {POP }}$ & $\boldsymbol{R}_{\text {Best }}$ & $\boldsymbol{N}_{\text {Top10 }}$ & $\boldsymbol{T}_{\mathbf{M}}(\mathbf{m i n})$ & $\boldsymbol{D}_{\text {Best }}(\boldsymbol{\%})$ & $\boldsymbol{D}_{\text {10Best }}(\boldsymbol{\%})$ \\
\hline \hline B.3 & 600 & 9,00 & 8,70 & 27,02 & 0,02 & 2,00 \\
\hline B.4 & 800 & 8,00 & 8,70 & 36,55 & 0,03 & 2,00 \\
\hline
\end{tabular}

Em termos do índice $R_{\text {Best }}$, somente três das vinte rodadas realizadas para os dois testes (B.3 e B.4) não foram capazes de identificar a melhor solução conhecida para o sistema, sendo uma dessas rodadas pertencente ao Teste B.3 e duas pertencentes ao Teste B.4. Nesse caso, todas as três rodadas foram capazes de identificar o mesmo indivíduo, o qual apresenta um desvio percentual de apenas $0,17 \%$ em relação ao melhor indivíduo conhecido. Observadas tais características, estima-se que, em termos do índice $D_{\text {Best, }}$ seja esperado um desvio de apenas $0,02 \%$ para $N_{\text {POP }}=600\left(\right.$ Testes B.3) e $0,03 \%$ para $N_{\text {POP }}=800($ Testes B.4 $)$.

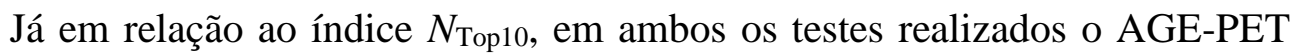
foi capaz de identificar 8,7 das 10 soluções do Top10-SSB. Esse resultado representa uma redução de $2,25 \%$ e 7,45\% em relação aos valores encontrados nos Testes B.1 e B.2, respectivamente. Entretanto, a pior de todas as rodadas foi ainda capaz de identificar 7 soluções do Top10-SSB para o SSB, sendo eles os Planos 2, 3, 4, 5, 6, 7 e 9 da Tabela 4.5.

Ainda em termos de qualidade do conjunto final das soluções, os Testes B.3 e B.4 apresentam o mesmo valor para o índice $D_{10 \mathrm{Best}}$, onde a média dos investimentos das 10 melhores soluções apresenta valor apenas 2,00\% maior do que o da melhor solução identificada para este sistema. Aplicando a lógica de cálculo do índice $D_{10 \text { Best }}$ às dez melhores soluções finais de cada rodada, verifica-se ainda que as três piores rodadas apresentam valores de 2,50\%, 2,43\% e 2,23\%. De for- 
ma geral, são valores reduzidos, que indicam bom desempenho do AGE-PET mesmo para essas rodadas.

Tendo em vista a degradação dos valores dos índices de desempenho da ferramenta quando da utilização do mecanismo de seleção por clusterização para o SSB em comparação com os testes que empregaram a seleção por torneio, foram repetidos os testes B.3 e B.4 adotando-se um aumento do número máximo de EEs para $N_{\text {MAX-EE }}=10$. Ou seja, cada rodada nestes novos testes equivale à execução de 10 EEs. Os resultados obtidos para estes testes, denominados Testes B.5 e B.6, estão presentes na Tabela 4.8 .

Tabela 4.8 - Índices de desempenho para o SSB e $N_{\text {MAX-EE }}=10$ - Seleção por clusterização.

\begin{tabular}{|c|c|c|c|c|c|c|}
\hline Teste & $\boldsymbol{N}_{\text {POP }}$ & $\boldsymbol{R}_{\text {Best }}$ & $\boldsymbol{N}_{\text {Top10 }}$ & $\boldsymbol{T}_{\mathbf{M}}(\mathbf{m i n})$ & $\boldsymbol{D}_{\text {Best }}$ (\%) & $\boldsymbol{D}_{\text {10Best }}(\boldsymbol{\%})$ \\
\hline \hline B.5 & 600 & 10,00 & 9,70 & 55,09 & 0,00 & 1,77 \\
\hline B.6 & 800 & 10,00 & 9,10 & 72,27 & 0,00 & 1,86 \\
\hline
\end{tabular}

Verifica-se que com o aumento do número máximo de execuções evolucionárias (EEs) a cada rodada há também, como esperado, um aumento no tempo médio de execução proporcional a esta variação. Dessa forma, para ambos os testes, os valores verificados do índice $T_{\mathrm{M}}$ são aproximadamente duas vezes maiores do que aqueles observados com $N_{\mathrm{MAX} \text {-EE }}=5$ (Tabela 4.7). Entretanto, em relação à qualidade do conjunto final de soluções identificadas, é possível verificar uma melhora significativa, com redução, por exemplo, de 11,65\% no valor do índice

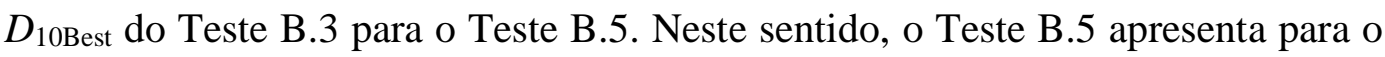
índice $D_{10 \text { Best }}$ uma diferença de apenas 0,05 pontos percentuais em relação ao menor resultado esperado, que é de 1,72\% para o sistema SSB. Quanto ao teste com $N_{\text {POP }}=800$ (Teste B.6), a redução observada para o índice $D_{10 \text { Best }}$ é de $7,00 \%$ quando comparado ao Teste B.4, com $N_{\mathrm{POP}}=800$ e $N_{\mathrm{MAX}-\mathrm{EE}}=5$.

Ainda em relação à qualidade do conjunto final de soluções, verifica-se também uma melhora no desempenho da ferramenta em termos do índice $N_{\text {Top10 }}$. Com o aumento do número máximo de execuções evolutivas, o índice $N_{\text {Top10 }}$ atingiu valores $11,49 \%$ e 4,60\% maiores que os valores observados na Tabela 4.7 para os Testes B.3 e B.4, respectivamente. Ou seja, em média, uma rodada da ferramenta encontra 9,70 das 10 soluções do Top10-SSB (Tabela 4.5) quando considerado uma população de 600 indivíduos, e 9,10 quando considerado um aumento da população para 800 indivíduos. Já em termos de qualidade do melhor indivíduo 
identificado, nos Testes B.5 e B.6 a ferramenta foi capaz de identificar o melhor indivíduo conhecido em todas as rodadas, atingindo o máximo desempenho para os índices $R_{\text {Best }}$ e $D_{\text {Best }}$.

Vale ressaltar que, o aumento do número máximo de execuções evolutivas ( $\left.N_{\text {MAX-EE}}\right)$ não é condição suficiente para o aumento do desempenho da ferramenta, sendo necessária ainda uma boa qualidade das soluções identificadas a cada EE. Ou seja, considerando que cada execução evolutiva é capaz de fornecer, com alta probabilidade, planos de expansão de boa qualidade, um aumento do número máximo de execuções poderá se tornar então uma estratégia efetiva para o aprimoramento do desempenho do algoritmo.

Neste sentido, verifica-se por meio de análise da Figura 4.6 o desempenho da ferramenta em termos do conjunto das 10 melhores soluções identificadas ao final de cada EE em cada uma das rodadas. Os gráficos da Figura 4.6 correspondem a histogramas com a função densidade de probabilidade das soluções analisadas para os Testes B.5 e B.6 em termos do desvio percentual apresentado entre cada amostra e o menor investimento conhecido.
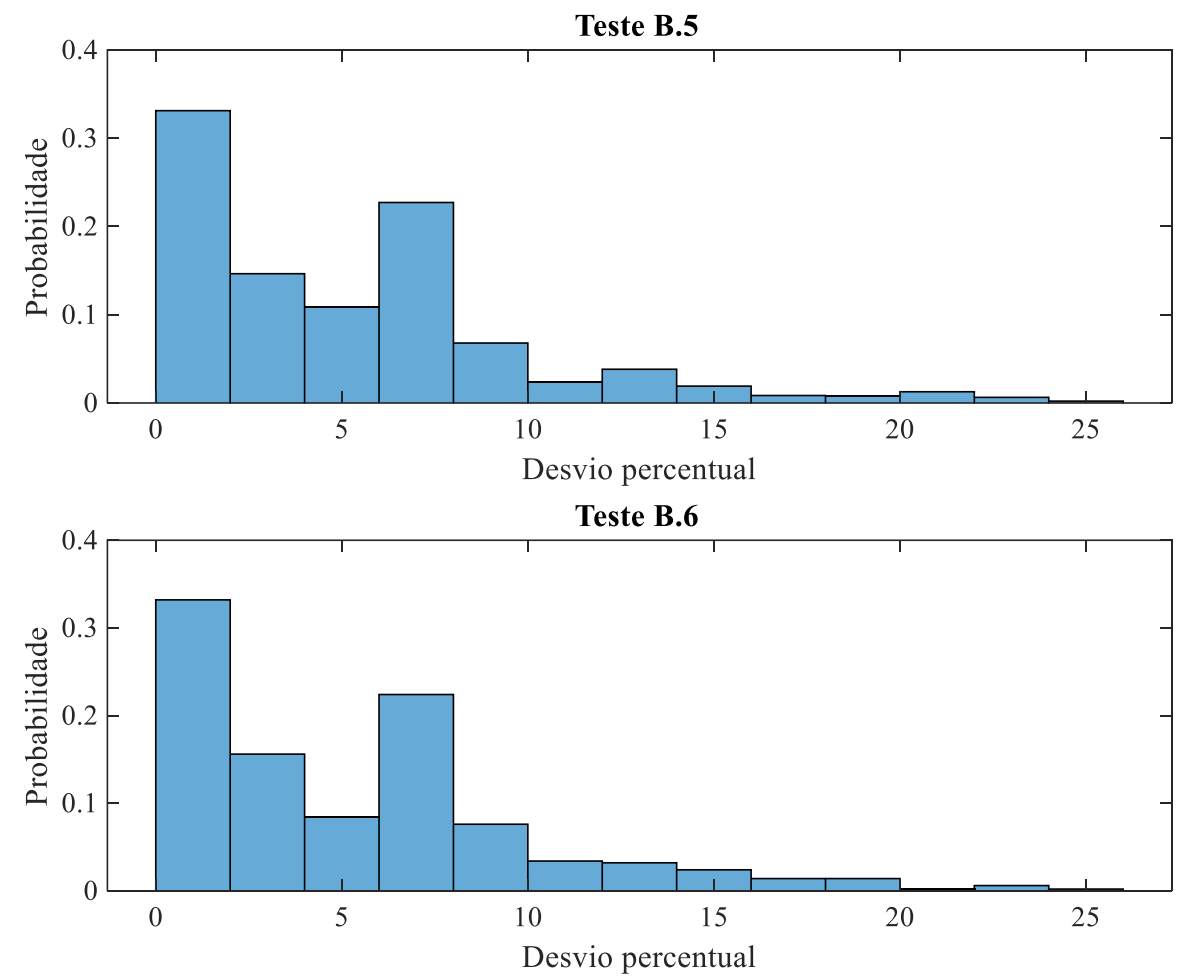

Figura 4.6 - Histogramas de probabilidade dos desvios percentuais verificados para o sistema SSB - Seleção por clusterização. 
É possível observar um comportamento quase idêntico entre os dois histogramas da Figura 4.6. De forma geral, há uma probabilidade de aproximadamente $33 \%$ das soluções possuírem desvio percentual entre 0,00 e 2,00\% em relação ao melhor plano da Tabela 4.5. Em termos de probabilidade acumulada, há em torno de $47 \%$ de chance dos planos identificados apresentem um desvio percentual menor ou igual a $4 \%$. Ou seja, dado que o desvio percentual do investimento pertencente à décima melhor solução conhecida (solução 10 do Top10-SSB) em relação ao melhor plano é de 3,53\%, espera-se que em uma execução evolutiva aproximadamente $47 \%$ das 10 melhores soluções encontradas sejam soluções do Top10SSB (Tabela 4.5).

\section{6. \\ Resultados - SGSB}

O Sistema Geoelétrico Sul do Brasil (SGSB), proposto em [2], é um equivalente criado a partir de um sistema atual, do ano de 2017, formado por linhas de transmissão e subestações de $230 \mathrm{kV}$ e $500 \mathrm{kV}$ pertencentes à rede básica da região geoelétrica Sul do Brasil. Este sistema equivalente possui em sua topologia base um total de 242 barras e 467 circuitos, os quais são distribuídos em 345 ramos existentes. Para o estudo de planejamento da transmissão, cujo ano horizonte é 2025, são considerados como candidatos ao reforço um total de 108 ramos, sendo 83 ramos já existentes e 25 ramos novos. Cada ramo candidato pode receber até 2 reforços $\left(n_{i j}^{\max }=2\right)$. Para este sistema definiu-se que 38 dos 345 ramos da topologia base do sistema não sofrem contingência durante a avaliação do critério de segurança da rede. Esses ramos são responsáveis pela interligação de barras terminais de carga e/ou geração ao sistema e, portanto, o reforço para atendimento ao critério "N-1" não precisa ser definido por meio de ferramentas de otimização. Dessa forma, durante o processo de solução do AGE-PET, para cada solução avaliada um mínimo de 307 e um máximo de 332 (307 ramos existentes mais 25 ramos novos) contingências simples são analisados.

Para o SGSB, o problema PET é solucionado considerando dois diferentes cenários de carga e geração para o ano de 2025, definidos com base no regime hidrológico na região norte do Brasil. O primeiro cenário, denominado Norte Úmido, corresponde a uma condição de operação em que há maior incidência de chuvas na região norte do país, sendo essa região considerada exportadora de 
energia. Neste cenário, os valores de demanda total e capacidade máxima de geração são, respectivamente, de 15.001,6 MW e 15.049MW. Em contrapartida, no segundo cenário, denominado Norte Seco, a região norte do Brasil se comporta como importadora de energia elétrica, com incidência de chuvas mais desfavoráveis. No cenário Norte Seco, a capacidade de geração e o valor total de demanda são iguais, respectivamente, a 18.944,4 MW e 18.527,6 MW.

Todos os dados de barra, ramos existentes e candidatos do SGSB estão definidos em [2] e encontram-se também reproduzidos na Tabela C.1, Tabela C.2 e Tabela C.3 no Anexo C desta dissertação.

Tendo em vista as dimensões do sistema, o qual é tido como um sistema de grande porte, foi considerado um número menor de rodadas nos testes realizados com o SGSB em relação aos testes realizados anteriormente para os sistemas IEEE-RTS e SSB. Para o SGSB foram realizadas, para cada teste, 6 rodadas, sendo em cada rodada $N_{\mathrm{MAX}-\mathrm{EE}}=5$. Todos os demais parâmetros da ferramenta AGEPET foram considerados inalterados em relação aos parâmetros utilizados para o sistema IEEE-RTS e SSB. A única exceção é com relação ao critério de parada definido pela estagnação $\left(N_{\mathrm{GER}-\mathrm{EST}}\right)$ dos melhores indivíduos dentro de cada execução evolutiva (EE) da ferramenta. Para este parâmetro, nos testes realizados para o cenário Norte Seco (cenário que resulta em um problema de otimização com maior nível de dificuldade de solução), variou-se o valor máximo de 15 gerações $\left(N_{\mathrm{GER} \text {-EST }}=15\right)$ consecutivas para $N_{\mathrm{GER} \text {-EST }}=30$. Nas subseções a seguir são apresentados e analisados os resultados obtidos para o SGSB considerando os dois cenários de estudo.

\subsection{1.}

\section{Cenário Norte Úmido}

Para o cenário Norte Úmido, a melhor solução identificada em todos os testes realizados possui um investimento de 385,819 milhões de $\mathrm{R} \$$, sendo constituída por um total de 9 reforços distribuídos em 7 ramos candidatos. A configuração resultante da rede para este cenário apresenta um valor total de perdas ativas igual a 423,846 MW. Detalhes sobre as 10 melhores soluções identificadas para este cenário, conjunto aqui denominado como Top10-Norte Úmido, podem ser verificados na Tabela 4.9. 
Tabela 4.9 - Top10 para o cenário Norte Úmido do sistema SGSB

\begin{tabular}{|c|c|c|c|c|c|}
\hline Plano & $\begin{array}{c}\text { Investimento } \\
\left(10^{6} \times \mathbf{R} \$\right) \\
\end{array}$ & \begin{tabular}{|c}
$\begin{array}{c}\text { Perdas } \\
\text { (MW) }\end{array}$ \\
\end{tabular} & $\begin{array}{l}\text { Total de } \\
\text { Reforços } \\
\end{array}$ & $\begin{array}{c}\text { Ramos } \\
\text { Reforçados }\end{array}$ & Reforços \\
\hline 1 & 385,819 & 423,850 & 9 & 7 & $\begin{array}{c}n_{7980-7794}=2 ; n_{38857-7771}=1 ; \\
n_{7922-9265}=2 ; n_{6715-7042}=1 ; \\
n_{6649-6626}=1 ; n_{7755-38857}=1 ; \\
n_{7304-9180}=1 ;\end{array}$ \\
\hline 2 & 389,911 & 423,840 & 9 & 7 & $\begin{array}{c}n_{7980-7794}=2 ; n_{38857-7771}=1 ; \\
n_{7922-9265}=2 ; n_{6651-7042}=1 ; \\
n_{6649-6626}=1 ; n_{7755-38857}=1 ; \\
n_{7304-9180}=1 ;\end{array}$ \\
\hline 3 & 405,373 & 421,370 & 9 & 7 & $\begin{array}{c}n_{7980-7794}=2 ; n_{38857-4290}=1 ; \\
n_{7922-9265}=2 ; n_{6715-7042}=1 ; \\
n_{6649-6626}=1 ; n_{7755-38857}=1 ; \\
n_{7304-9180}=1 ;\end{array}$ \\
\hline 4 & 409,465 & 421,370 & 9 & 7 & $\begin{array}{c}n_{7980-7794}=2 ; n_{38857-4290}=1 ; \\
n_{7922-9265}=2 ; n_{6651-7042}=1 ; \\
n_{6649-6626}=1 ; n_{7755-38857}=1 ; \\
n_{7304-9180}=1 ;\end{array}$ \\
\hline 5 & 409,798 & 424,710 & 9 & 7 & $\begin{array}{c}n_{7980-7794}=2 ; n_{38857-39850}=1 ; \\
n_{38857-7771}=1 ; n_{7922-9265}=2 ; \\
n_{6715-7042}=1 ; n_{6649-6626}=1 ; \\
n_{7304-9180}=1 ;\end{array}$ \\
\hline 6 & 413,890 & 424,700 & 9 & 7 & $\begin{array}{c}n_{7980-7794}=2 ; n_{38857-39850}=1 ; \\
n_{38857-7771}=1 ; n_{7922-9265}=2 ; \\
n_{6651-7042}=1 ; n_{6649-6626}=1 ; \\
n_{7304-9180}=1 ;\end{array}$ \\
\hline 7 & 414,504 & 423,920 & 9 & 7 & $\begin{array}{c}n_{7980-7794}=2 ; n_{38857-7771}=1 ; \\
n_{7922-9265}=2 ; n_{9290-7812}=1 ; \\
n_{6715-7042}=1 ; n_{6649-6626}=1 ; \\
n_{7755-38857}=1 ;\end{array}$ \\
\hline 8 & 418,596 & 423,920 & 9 & 7 & $\begin{array}{c}n_{7980-7794}=2 ; n_{38857-7771}=1 ; \\
n_{7922-9265}=2 ; n_{9290-7812}=1 ; \\
n_{6651-7042}=1 ; n_{6649-6626}=1 ; \\
n_{7755-38857}=1 ;\end{array}$ \\
\hline 9 & 424,576 & 423,880 & 9 & 8 & $\begin{array}{l}n_{7980-7794}=1 ; n_{38857-7771}=1 ; \\
n_{7739-7794}=2 ; n_{7922-9265}=2 ; \\
n_{6715-7042}=1 ; n_{6649-6626}=1 ; \\
n_{7755-38857}=1 ; n_{7304-9180}=1 ;\end{array}$ \\
\hline 10 & 428,668 & 423,870 & 9 & 8 & $\begin{array}{l}n_{7980-7794}=1 ; n_{38857-7771}=1 ; \\
n_{7739-7794}=2 ; n_{7922-9265}=2 ; \\
n_{6651-7042}=1 ; n_{6649-6626}=1 ; \\
n_{7755-38857}=1 ; n_{7304-9180}=1 ;\end{array}$ \\
\hline
\end{tabular}

O investimento médio verificado para o Top10-Norte Úmido é de 410,06 milhões de R\$, o que representa um desvio percentual de 6,28\% em relação ao melhor investimento apresentado, sendo este, portanto, o valor mínimo esperado para o índice $D_{10 \text { Best }}$ nos testes realizados com o cenário Norte Úmido. É importante destacar que o conjunto Top10-Norte Úmido é idêntico ao conjunto das 10 
melhores soluções identificadas pela referência [2], onde o sistema SGSB é proposto.

A Tabela 4.10 apresenta os resultados obtidos para o cenário Norte Úmido a partir de dois testes com diferentes tamanhos de população $\left(N_{\mathrm{POP}}=600\right.$ e $N_{\mathrm{POP}}=$ 800) e aplicação do mecanismo de seleção por torneio. Para estes testes (C.1 e C.2), considerou-se, assim como nos testes realizados para o sistema IEEE e SSB, um elitismo de $80 \%$ (i.e., $N_{\mathrm{EL}}=80 \%$ de $N_{\mathrm{POP}}$ ) durante a aplicação do mecanismo de seleção.

Tabela 4.10 - Índices de desempenho com cenário Norte Úmido do sistema SGSB - Seleção por torneio.

\begin{tabular}{|c|c|c|c|c|c|c|}
\hline Teste & $\boldsymbol{N}_{\text {POP }}$ & $\boldsymbol{R}_{\text {Best }}$ & $\boldsymbol{N}_{\text {Top10 }}$ & $\boldsymbol{T}_{\mathbf{M}}(\mathbf{m i n})$ & $\boldsymbol{D}_{\text {Best }}(\boldsymbol{\%})$ & $\boldsymbol{D}_{\text {10Best }}(\boldsymbol{\%})$ \\
\hline \hline C.1 & 600 & 6,00 & 9,83 & 12,18 & 0,00 & 6,37 \\
\hline C.2 & 800 & 6,00 & 10,00 & 15,50 & 0,00 & 6,28 \\
\hline
\end{tabular}

Verifica-se, a partir dos resultados apresentados da Tabela 4.10, um bom desempenho estatístico da ferramenta AGE-PET na solução do problema PET para o cenário Norte Úmido do sistema SGSB. Para este cenário somente uma rodada do Teste C.1 não foi capaz de identificar todas as 10 melhores soluções conhecidas, o que levou a ferramenta não atingir o máximo desempenho para o índice $N_{\text {Top10, }}$, diferente do que foi verificado para o Teste C.2. Apesar disso, essa rodada do Teste C.1 foi ainda capaz de identificar 9 das soluções do Top10-Norte Úmido, incluindo a melhor solução conhecida, resultando, portanto, em $D_{\text {Best }}=0,00 \%$. Além disso, o décimo melhor plano identificado nesta rodada apresenta valor de investimento de 429,352 milhões de $\mathrm{R} \$$, valor muito próximo à décima solução do Top10-Norte Úmido (Tabela 4.9). Em termos de $D_{10 \text { Best, }}$ os dois testes (C.1 e C.2) apresentaram excelentes valores, sendo que no segundo teste o valor mínimo para o índice foi atingido.

Em relação ao índice de desempenho $R_{\text {Best, }}$ verifica-se que, tanto para o Teste C. 1 quanto para o Teste C.2, todas as 6 rodadas do AGE-PET foram capazes de identificar, o melhor investimento do conjunto Top10-Norte Úmido.

Em termos de tempo de execução (índice $T_{\mathrm{M}}$ ), estima-se que o algoritmo demore em média 12,18 minutos para a convergência em uma rodada do Teste C.1, e 15,5 minutos em uma rodada do Teste C.2, valores relativamente reduzidos, dado que o SGSB se trata de um sistema real de grande porte. A razão deste comportamento está associada às condições favoráveis de operação e o reduzido nú- 
mero de reforços necessários para a construção de planos viáveis no cenário Norte Úmido. Essas premissas fazem com que seja necessária uma quantidade menor de gerações até que se atinja a convergência de uma única $E E$ dentro de cada rodada do AGE-PET e, portanto, um menor tempo de execução do algoritmo.

Em termos da qualidade do conjunto final de soluções identificadas a cada EE, a Figura 4.7 apresenta os diagramas de caixa (boxplot) construídos a partir das 10 melhores soluções identificada em cada EE isolada do AGE-PET para cada teste realizado. Portanto, um total de 30 EEs (6 rodadas de 5 EEs) fornece as 300 soluções para construção dos diagramas em cada teste. Nestes diagramas, é possível verificar uma alta dispersão dos planos observados. Porém, visto que os planos que compõe o conjunto Top10-Norte Úmido apresentam elevados valores de desvio em relação à melhor solução dentre elas (conforme apresentado na Tabela 4.9) este comportamento já era esperado. Para o Teste C.1, por exemplo, pelo menos $75 \%$ das soluções encontradas apresenta um desvio percentual de $11,11 \%$ em relação a melhor solução conhecida. Esse resultado equivale a dizer que pelo menos $75 \%$ dos planos identificados no cenário Norte Úmido para o Teste C.1 apresentam investimento menor ou igual a décima melhor solução conhecida.

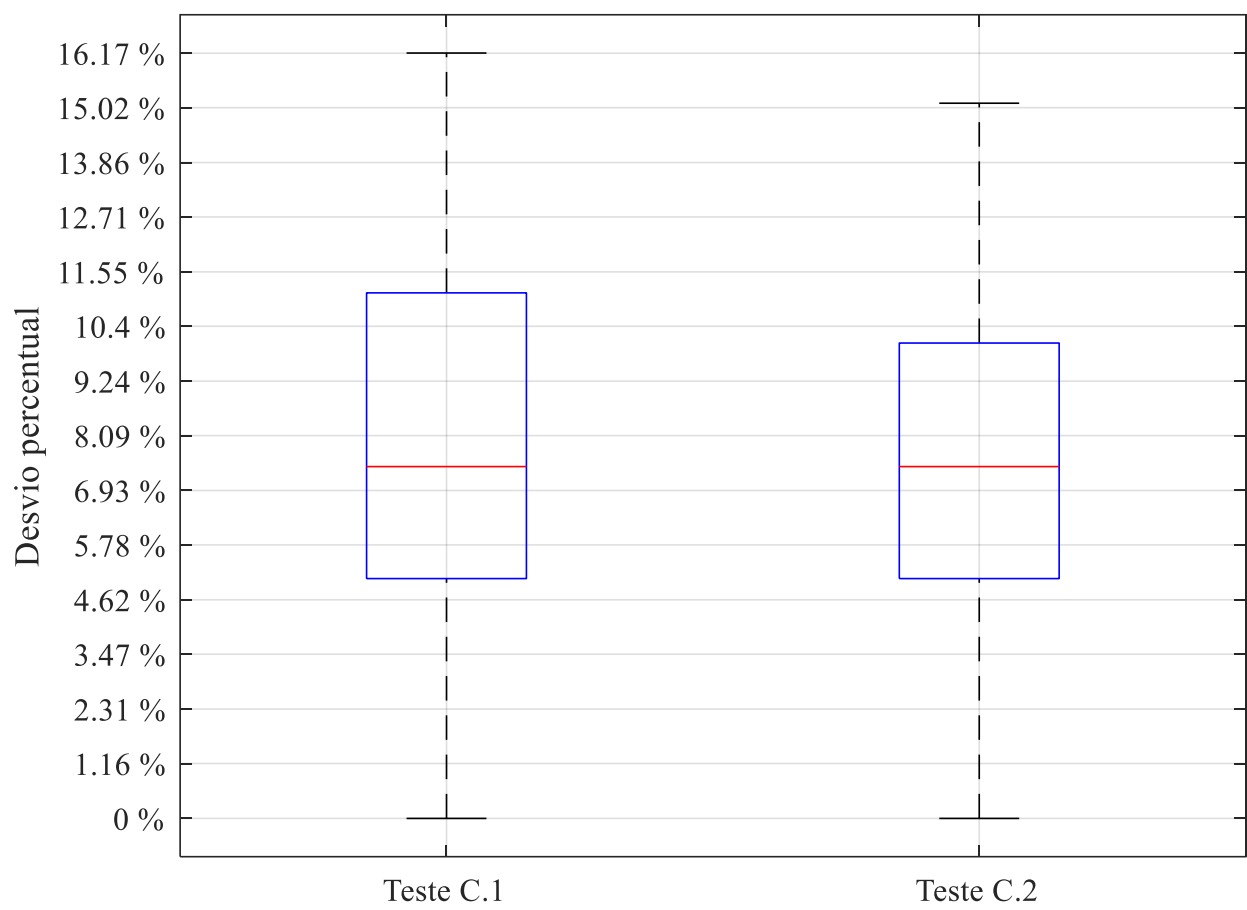

Figura 4.7 - Desvio percentual entre os melhores indivíduos de cada EE e o melhor investimento conhecido para o cenário Norte Úmido do sistema SGSB - Seleção por torneio. 
De forma análoga, para o Teste C.2, 75\% das soluções avaliadas possuem desvio percentual menor ou igual a $10,05 \%$, sendo menor ou igual ao nono melhor plano de expansão conhecido (solução 9 do Top10-Norte Úmido). Ademais, ambos os testes apresentam o mesmo desempenho em termos do primeiro e segundo quartis, os quais apresentam respectivamente os valores de 5,07\% e 7,43\%. Além disso, vale ressaltar que em ambos os testes (Teste C.1 e C.2), todas as 30 execuções evolutivas foram capazes de encontrar a melhor solução conhecida $(385,819$ milhões de $\mathrm{R} \$$ ).

Tal qual foi feito para os sistemas IEEE e SSB, novos testes foram realizados para o cenário Norte Úmido do SGSB considerando-se a aplicação do mecanismo de seleção por clusterização combinada à seleção por elitismo. Os resultados destes novos testes (C.3 e C.4) estão descritos na Tabela 4.11.

Tabela 4.11 - Índices de desempenho com cenário Norte Úmido do sistema SGSB - Seleção por clusterização.

\begin{tabular}{|c|c|c|c|c|c|c|}
\hline Teste & $\boldsymbol{N}_{\text {POP }}$ & $\boldsymbol{R}_{\text {Best }}$ & $\boldsymbol{N}_{\text {Top10 }}$ & $\boldsymbol{T}_{\mathbf{M}}(\mathbf{m i n})$ & $\boldsymbol{D}_{\text {Best }}(\boldsymbol{\%})$ & $\boldsymbol{D}_{\text {10Best }}(\boldsymbol{\%})$ \\
\hline \hline C.3 & 600 & 6,00 & 10,00 & 9,88 & 0,00 & 6,28 \\
\hline C.4 & 800 & 6,00 & 10,00 & 12,78 & 0,00 & 6,28 \\
\hline
\end{tabular}

A partir dos resultados apresentados na Tabela 4.11, é possível também verificar um excelente desempenho da ferramenta AGE-PET na solução do problema PET para o cenário Norte Úmido com mecanismo de seleção por clusterização. Para os parâmetros estabelecidos, a ferramenta foi capaz de atingir, em ambos os testes, o desempenho máximo esperado para todos os índices estatísticos analisados (excluído o índice $T_{\mathrm{M}}$ que, por sua natureza, não possui limite de desempenho definido).

Para o índice $T_{\mathrm{M}}$, observa-se que com um tamanho populacional de 600 indivíduos (Teste C.3) cada rodada demora em média 9,88 minutos até atingir a convergência. Já para uma população de 800 indivíduos (Teste C.4) esse tempo sofre um aumento de 29,37\%, atingindo a convergência após, em média, 12,78 minutos. Esses resultados representam uma redução média de 18,2\% em relação aos resultados apresentados para os Testes C.1 e C.2. Mais uma vez, verifica-se que o emprego da seleção por clusterização demanda menor tempo computacional que a seleção por torneio, sendo considerados idênticos os demais parâmetros da ferramenta AGE-PET. 
Em termos da qualidade do conjunto final de soluções de cada EE, a ferramenta AGE-PET com a aplicação do mecanismo de seleção por clusterização apresenta desempenho quase idêntico ao apresentado pelo mecanismo de seleção por torneio. Em termos de quartis, para as 300 soluções geradas em 30 EEs (6 rodadas de 5 EEs cada), a única diferença se encontra no valor apresentado para o segundo quartil do Teste C.4, o qual sofreu uma redução de $2,15 \%$ em relação ao valor apresentado pelo Teste C.2.

Além disso, diferenças podem também ser verificadas no desvio percentual médio de cada um dos testes analisados. Para o Teste C.3 o desvio percentual médio de todas as 300 soluções analisadas apresentou um valor de 7,31\%, representando uma redução de 1,08\% em relação ao desvio médio apresentado pelo Teste C.1, que considera o mesmo tamanho de população. Já em relação aos Testes C.2 e C.4, essa redução foi de 2,55\%, onde o Teste C.4 apresenta um valor de desvio percentual médio de $6,86 \%$, valor bem próximo do mínimo esperado de $6,28 \%$.

\subsection{2. Cenário Norte Seco}

O cenário Norte Seco representa uma condição mais desfavorável de operação para a região geoelétrica sul do Brasil se comparado ao cenário Norte Úmido, incorrendo, portanto, em um problema de otimização mais complexo de ser solucionado. Conforme apresentado na referência [2], onde foi definido este sistema teste, a melhor solução conhecida para este cenário é constituída por um total de 22 reforços distribuídos em 19 ramos candidatos. De forma geral, verifica-se que um conjunto maior de reforços é necessário para o atendimento dos critérios operativos definidos na solução do problema PET para este caso. Essa melhor solução apresenta um investimento total de 833,442 milhões de $\mathrm{R} \$$ e resulta, para a rede de transmissão, em um montante igual a 602,82 MW de perdas ôhmicas.

O investimento médio verificado para as 10 melhores soluções identificadas e apresentadas em [2] é de 843,07 milhões de R\$, sendo este conjunto aqui definido como Top10 [2]-Norte Seco. A média destes investimentos implica em um valor mínimo esperado para o índice $D_{10 \text { Best }}$ de $1,16 \%$. Cada uma das soluções que compõem o conjunto Top10 [2]-Norte Seco possui, assim como a melhor solução conhecida, um total de 22 reforços distribuídos em 19 ramos candidatos, conforme observado na Tabela 4.12 . 
Tabela 4.12 - Top10 [2] para o cenário Norte Seco do sistema SGSB

\begin{tabular}{|c|c|c|c|c|c|}
\hline Plano & $\begin{array}{c}\text { Investimento } \\
\left(10^{6} \times \mathbf{R} \$\right) \\
\end{array}$ & $\begin{array}{c}\text { Perdas } \\
\text { (MW) } \\
\end{array}$ & $\begin{array}{l}\text { Total de } \\
\text { Reforços } \\
\end{array}$ & $\begin{array}{c}\text { Ramos } \\
\text { Reforçados }\end{array}$ & Reforços \\
\hline 1 & 833,442 & 602,82 & 22 & 19 & $\begin{array}{c}n_{6754-6602}=2 ; n_{7749-7024}=1 ; \\
n_{7903-7731}=2 ; n_{7980-7794}=2 ; \\
n_{33857-4290}=1 ; n_{7024-6763}=1 ; \\
n_{47120-9261}=1 ; n_{7922-9265}=1 ; \\
n_{7763-6651}=1 ; n_{7762-7763}=1 ; \\
n_{6754-6601}=1 ; n_{6651-6688}=1 ; \\
n_{9208-9209}=1 ; n_{7734-7731}=1 ; \\
n_{6715-7042}=1 ; n_{6619-7739}=1 ; \\
n_{7824-7823}=1 ; n_{6649-6626}=1 ; \\
n_{77755-38857}=1 ;\end{array}$ \\
\hline 2 & 836,511 & 602,01 & 22 & 19 & $\begin{array}{c}n_{6754-6602}=2 ; n_{7749-7024}=1 ; \\
n_{7903-7731}=2 ; n_{7980-7794}=2 ; \\
n_{33857-4290}=1 ; n_{7024-6763}=1 ; \\
n_{47120-9261}=1 ; n_{7922-9265}=1 ; \\
n_{7763-6651}=1 ; n_{9110-9208}=1 ; \\
n_{7762-7763}=1 ; n_{6754-6601}=1 ; \\
n_{6651-6688}=1 ; n_{7734-7731}=1 ; \\
n_{6715-7042}=1 ; n_{6619-7739}=1 ; \\
n_{7824-7823}=1 ; n_{6649-6626}=1 ; \\
n_{7755-38857}=1 ;\end{array}$ \\
\hline 3 & 837,534 & 603,13 & 22 & 19 & $\begin{aligned} & n_{6754-6602}=2 ; n_{7749-7024}=1 ; \\
& n_{7903-7731}=2 ; n_{7980-7794}=2 ; \\
& n_{33857-4290}=1 ; n_{7024-6763}=1 ; \\
& n_{47120-9261}=1 ; n_{7922-9265}=1 ; \\
& n_{7763-6651}=1 ; n_{7762-7763}=1 ; \\
& n_{6754-6601}=1 ; n_{6651-6688}=1 ; \\
& n_{9208-9209}=1 ; n_{7734-7731}=1 ; \\
& n_{6651-7042}=1 ; n_{6619-7739}=1 ; \\
& n_{7824-7823}=1 ; n_{6649-6626}=1 ; \\
& n_{77755-38857}=1 ;\end{aligned}$ \\
\hline 4 & 840,603 & 602,33 & 22 & 19 & $\begin{array}{c}n_{6754-6602}=2 ; n_{7749-7024}=1 ; \\
n_{7903-7731}=2 ; n_{7980-7794}=2 ; \\
n_{33857-4290}=1 ; n_{7024-6763}=1 ; \\
n_{47120-9261}=1 ; n_{7922-9265}=1 ; \\
n_{7763-6651}=1 ; n_{9110-9208}=1 ; \\
n_{7762-7763}=1 ; n_{6754-6601}=1 ; \\
n_{6651-6688}=1 ; n_{7734-7731}=1 ; \\
n_{6651-7042}=1 ; n_{6619-7739}=1 ; \\
n_{7824-7823}=1 ; n_{6649-6626}=1 ; \\
n_{77755-38857}=1 ;\end{array}$ \\
\hline 5 & 842,526 & 602,05 & 22 & 19 & $\begin{aligned} & n_{6754-6602}=2 ; n_{7749-7024}=1 ; \\
& n_{7903-7731}=2 ; n_{7980-7794}=2 ; \\
& n_{33857-4290}=1 ; n_{7024-6763}=1 ; \\
& n_{47120-9261}=1 ; n_{7922-9265}=1 ; \\
& n_{7763-6651}=1 ; n_{7762-7763}=1 ; \\
& n_{6754-6601}=1 ; n_{6651-6688}=1 ; \\
& n_{9208-9209}=1 ; n_{7734-7731}=1 ; \\
& n_{6715-7042}=1 ; n_{6619-7739}=1 ; \\
& n_{6649-6626}=1 ; n_{7755-38857}=1 ; \\
& n_{77743-7823}=1 ;\end{aligned}$ \\
\hline
\end{tabular}

(continua) 
(conclusão da Tabela 4.12)

\begin{tabular}{|c|c|c|c|c|c|}
\hline Plano & $\begin{array}{c}\text { Investimento } \\
\left(10^{6} \times \mathbf{R} \$\right) \\
\end{array}$ & $\begin{array}{l}\text { Perdas } \\
\text { (MW) } \\
\end{array}$ & $\begin{array}{l}\text { Total de } \\
\text { Reforços } \\
\end{array}$ & $\begin{array}{c}\text { Ramos } \\
\text { Reforçados }\end{array}$ & Reforços \\
\hline 6 & 845,595 & 601,24 & 22 & 19 & $\begin{array}{c}n_{6754-6602}=2 ; n_{7749-7024}=1 ; \\
n_{7903-7731}=2 ; n_{7980-7794}=2 ; \\
n_{33857-4290}=1 ; n_{7024-6763}=1 ; \\
n_{47120-9261}=1 ; n_{7922-9265}=1 ; \\
n_{7763-6651}=1 ; n_{9110-9208}=1 ; \\
n_{7762-7763}=1 ; n_{6754-6601}=1 ; \\
n_{6651-6688}=1 ; n_{7734-7731}=1 ; \\
n_{6715-7042}=1 ; n_{6619-7739}=1 ; \\
n_{6649-6626}=1 ; n_{7755-38857}=1 ; \\
n_{77443-7823}=1 ;\end{array}$ \\
\hline 7 & 846,618 & 602,37 & 22 & 19 & $\begin{array}{c}n_{6754-6602}=2 ; n_{7749-7024}=1 ; \\
n_{7903-7731}=2 ; n_{7980-7794}=2 ; \\
n_{33857-4290}=1 ; n_{7024-6763}=1 ; \\
n_{47120-9261}=1 ; n_{7922-9265}=1 ; \\
n_{7763-6651}=1 ; n_{7762-7763}=1 ; \\
n_{6754-6601}=1 ; n_{6651-6688}=1 ; \\
n_{9208-9209}=1 ; n_{7734-7731}=1 ; \\
n_{6651-7042}=1 ; n_{6619-7739}=1 ; \\
n_{6649-6626}=1 ; n_{7755-38857}=1 ; \\
n_{77443-7823}=1 ;\end{array}$ \\
\hline 8 & 847,559 & 602,38 & 22 & 19 & $\begin{array}{c}n_{6754-6602}=2 ; n_{7749-7024}=1 ; \\
n_{7903-7731}=2 ; n_{7980-7794}=2 ; \\
n_{33857-4290}=1 ; n_{7024-6763}=1 ; \\
n_{47120-9261}=1 ; n_{7922-9265}=1 ; \\
n_{7763-6651}=1 ; n_{7762-7763}=1 ; \\
n_{6754-6601}=1 ; n_{6715-6688}=1 ; \\
n_{9208-9209}=1 ; n_{7734-7731}=1 ; \\
n_{6651-7042}=1 ; n_{6619-7739}=1 ; \\
n_{7824-7823}=1 ; n_{6649-6626}=1 ; \\
n_{77555-38857}=1 ;\end{array}$ \\
\hline 9 & 849,687 & 601,56 & 22 & 19 & $\begin{array}{c}n_{6754-6602}=2 ; n_{7749-7024}=1 ; \\
n_{7903-7731}=2 ; n_{7980-7794}=2 ; \\
n_{33857-4290}=1 ; n_{7024-6763}=1 ; \\
n_{47120-9261}=1 ; n_{7922-9265}=1 ; \\
n_{7763-6651}=1 ; n_{9110-9208}=1 ; \\
n_{7762-7763}=1 ; n_{6651-6688}=1 ; \\
n_{6754-7763}=1 ; n_{7734-7731}=1 ; \\
n_{6715-7042}=1 ; n_{6619-7739}=1 ; \\
n_{7824-7823}=1 ; n_{6649-6626}=1 ; \\
n_{77755-38857}=1 ;\end{array}$ \\
\hline 10 & 850,628 & 601,58 & 22 & 19 & $\begin{array}{c}n_{6754-6602}=2 ; n_{7749-7024}=1 ; \\
n_{7903-7731}=2 ; n_{7980-7794}=2 ; \\
n_{33857-4290}=1 ; n_{7024-6763}=1 ; \\
n_{47120-9261}=1 ; n_{7922-9265}=1 ; \\
n_{7763-6651}=1 ; n_{9110-9208}=1 ; \\
n_{7762-7763}=1 ; n_{6754-6601}=1 ; \\
n_{6715-6688}=1 ; n_{7734-7731}=1 ; \\
n_{6651-7042}=1 ; n_{6619-7739}=1 ; \\
n_{7824-7823}=1 ; n_{66499-6626}=1 ; \\
n_{77555-38857}=1 ;\end{array}$ \\
\hline
\end{tabular}


Na Tabela 4.13 estão apresentados os índices de desempenho estatístico calculados para os testes com o cenário Norte Seco do SGSB relativos ao emprego da ferramenta AGE-PET com utilização do mecanismo de seleção por torneio. Estes índices foram calculados com base no conjunto Top10 [2]-Norte Seco. Vale destacar que, na realização dos testes com este cenário, foram mantidos os parâmetros considerados durante a realização dos testes com os demais sistemas, com

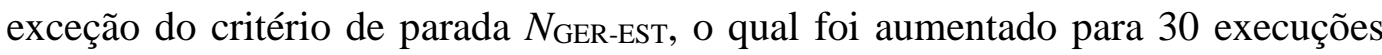
consecutivas, dada a maior complexidade de solução deste novo problema.

Tabela 4.13 - Índices de desempenho com cenário Norte Seco do sistema SGSB - Seleção por torneio.

\begin{tabular}{|c|c|c|c|c|c|c|}
\hline Teste & $\boldsymbol{N}_{\text {POP }}$ & $\boldsymbol{R}_{\text {Best }}$ & $\boldsymbol{N}_{\text {Top10 }}$ & $\boldsymbol{T}_{\mathbf{M}}(\mathbf{m i n})$ & $\boldsymbol{D}_{\text {Best }}(\boldsymbol{\%})$ & $\boldsymbol{D}_{\text {10Best }}(\boldsymbol{\%})$ \\
\hline \hline D.1 & 600 & 0,00 & 0,00 & 34,76 & 11,90 & 13,22 \\
\hline D.2 & 800 & 0,00 & 0,17 & 47,12 & 10,26 & 12,56 \\
\hline
\end{tabular}

É possível verificar, a partir dos resultados apresentados na Tabela 4.13, que a ferramenta proposta apresentou dificuldades em lidar com a maior complexidade apresentada pelo cenário Norte Seco, incorrendo em um desempenho reduzido em relação ao conjunto Top10 [2]-Norte Seco. Em média, os Testes D.1 e D.2 realizados com a aplicação do mecanismo de seleção por torneio apresentam valores do índice $D_{10 \text { Best }}$ onze vezes maiores que o mínimo valor esperado de $1,16 \%$.

De acordo com os resultados da Tabela 4.13, é possível verificar que nos dois testes (D.1 e D.2), nenhuma das rodadas foi capaz de identificar a melhor solução conhecida, o que em termos de índice de desempenho é representado por $R_{\text {Best }}=0$. Além disso, dentre todas as rodadas realizadas, somente uma rodada pertencente ao Teste D.2 foi capaz de identificar algum dos planos do conjunto Top10 [2]-Norte Seco apresentado na Tabela 4.12. Neste caso, o plano identificado foi o décimo melhor plano desse conjunto, o qual apresenta desvio percentual de 2,06\% em relação ao melhor investimento conhecido. Já no Teste D.1, o AGEPET não identificou soluções do conjunto Top10 [2]-Norte Seco em nenhuma das 6 rodadas.

Foram também realizados para o cenário Norte Seco, testes com o AGEPET considerando o emprego do mecanismo de seleção por clusterização combinado à seleção por elitismo, tal qual realizado para os demais estudos apresenta- 
dos nesta dissertação. Os resultados identificados para estes novos testes, denominados Testes D.3 e D.4, estão apresentados na Tabela 4.14.

Tabela 4.14 - Índices de desempenho com cenário Norte Seco do sistema SGSB - Seleção por clusterização.

\begin{tabular}{|c|c|c|c|c|c|c|}
\hline Teste & $\boldsymbol{N}_{\text {POP }}$ & $\boldsymbol{R}_{\text {Best }}$ & $\boldsymbol{N}_{\text {Top10 }}$ & $\boldsymbol{T}_{\mathbf{M}}(\mathbf{m i n})$ & $\boldsymbol{D}_{\text {Best }}(\boldsymbol{\%})$ & $\boldsymbol{D}_{\mathbf{1 0 B e s t}}(\boldsymbol{\%})$ \\
\hline \hline D.3 & 600 & 1,00 & 1,50 & 31,31 & 9,59 & 11,22 \\
\hline $\mathbf{D . 4}$ & 800 & 1,00 & 1,83 & 39,95 & 8,70 & 10,04 \\
\hline
\end{tabular}

É possível observar a partir dos resultados apresentados na Tabela 4.14 que, apesar do AGE-PET não apresentar ainda uma qualidade de desempenho igual à exibida na solução do problema de planejamento da expansão para os casos anteriores, há uma melhora significativa nos resultados dos Testes D.3 e D.4 se comparados aos Testes D.1 e D.2. Um exemplo dessa melhora pode ser visto na redução de $19,44 \%$ e $15,24 \%$, respectivamente, dos valores apresentados para o índice $D_{\text {Best }}$, com os Testes D.3 e D.4 em relação aos Testes D.1 e D.2. Além disso, verifica-se uma redução de $9,94 \%$ e $15,21 \%$ nos tempos médios de execução ( $\left.T_{\mathrm{M}}\right)$ do algoritmo para estes mesmos testes.

O índice $D_{10 \mathrm{Best}}$, que apesar de corresponder para os Testes D.3 e D.4 a valores ainda elevados em relação ao mínimo esperado de 1,16\%, apresentou um ganho médio de desempenho de aproximadamente 17,6\% em relação aos Testes D.1 e D.2. O índice $N_{\text {Top10 }}$ apresenta uma melhora significativa, apontado uma capacidade da ferramenta de identificar, em média para todas as rodadas, 1,5 e 1,83 soluções iguais ou melhores que os planos do conjunto Top10 [2]-Norte Seco (Tabela 4.12) para os Testes D.3 e D.4, respectivamente.

Para o caso destes dois novos testes, um importante resultado foi obtido em relação ao conjunto de melhores soluções identificadas pelo AGE-PET. Em uma execução evolutiva (EE) dentro das rodadas de cada um dos Testes D.3 e D.4, soluções melhores que aquelas identificadas em [2] e apresentadas na Tabela 4.12 foram obtidas. Essas soluções são apresentadas na Tabela 4.15 e Tabela 4.16 respectivamente, para os Testes D.3 e D.4.

De forma geral, verifica-se que os Testes D.3 e D.4 foram capazes de identificar cada um e isoladamente, 6 soluções melhores que aquelas do conjunto Top10 [2]-Norte Seco apresentado na Tabela 4.12. Juntas, as soluções dessas duas tabelas formam um novo Top10 para o cenário Norte Seco que contém 7 soluções com melhores investimentos que aquelas verificadas no Top10 [2]-Norte Seco. 
Tabela 4.15 - Melhores soluções identificadas no Teste D.3 para o cenário Norte Seco do sistema SGSB - Seleção por clusterização

\begin{tabular}{|c|c|c|c|c|}
\hline Plano & $\begin{array}{c}\text { Investimento } \\
(\mathbf{1 0} \times \mathbf{~} \mathbf{R} \mathbf{)}\end{array}$ & $\begin{array}{c}\text { Perdas } \\
\text { Ativas (MW) }\end{array}$ & $\begin{array}{c}\text { Total de } \\
\text { Reforços }\end{array}$ & $\begin{array}{c}\text { Total de Ramos } \\
\text { Reforçados }\end{array}$ \\
\hline \hline 1 & 816,957 & 602,536 & 22 & 19 \\
\hline 2 & 817,980 & 603,656 & 22 & 19 \\
\hline 3 & 821,049 & 602,852 & 22 & 19 \\
\hline 4 & 826,041 & 601,769 & 22 & 19 \\
\hline 5 & 827,064 & 602,891 & 22 & 19 \\
\hline 6 & 830,133 & 602,084 & 22 & 19 \\
\hline 7 & 840,603 & 602,326 & 22 & 19 \\
\hline 8 & 843,310 & 600,418 & 22 & 19 \\
\hline 9 & 846,618 & 602,365 & 22 & 19 \\
\hline 10 & 932,583 & 563,920 & 20 & 17 \\
\hline
\end{tabular}

Tabela 4.16 - Melhores soluções identificadas no Teste D.4 para o cenário Norte Seco do sistema SGSB - Seleção por clusterização

\begin{tabular}{|c|c|c|c|c|}
\hline Plano & $\begin{array}{c}\text { Investimento } \\
\left(\mathbf{1 0}^{\mathbf{6}} \times \mathbf{R} \mathbf{\text { }}\right)\end{array}$ & $\begin{array}{c}\text { Perdas } \\
\text { Ativas }(\mathbf{M W})\end{array}$ & $\begin{array}{c}\text { Total de } \\
\text { Reforços }\end{array}$ & $\begin{array}{c}\text { Total de Ramos } \\
\text { Reforçados }\end{array}$ \\
\hline \hline 1 & 813,888 & 603,340 & 22 & 19 \\
\hline 2 & 816,957 & 602,536 & 22 & 19 \\
\hline 3 & 817,980 & 603,656 & 22 & 19 \\
\hline 4 & 821,049 & 602,852 & 22 & 19 \\
\hline 5 & 826,041 & 601,769 & 22 & 19 \\
\hline 6 & 830,133 & 600,871 & 22 & 19 \\
\hline 7 & 836,511 & 602,011 & 22 & 19 \\
\hline 8 & 838,767 & 601,171 & 22 & 19 \\
\hline 9 & 840,603 & 602,326 & 22 & 19 \\
\hline 10 & 842,859 & 601,486 & 22 & 19 \\
\hline
\end{tabular}

Este novo conjunto, denominado Top10-Norte Seco, é apresentado na Tabela 4.17. O investimento médio verificado para essas soluções é de 826,06 milhões de $\mathrm{R} \$$, o que representa um desvio percentual de 1,49\% em relação à nova melhor solução do conjunto. Além disso, todos os planos deste conjunto são constituídos por 22 reforços distribuídos em 19 ramos candidatos ao reforço do sistema.

As rodadas dos Testes D.3 e D.4 que identificaram essas melhores soluções apresentam valores negativos de desvio entre o investimento da melhor solução identificada e o investimento da melhor solução até então conhecida para o problema (melhor solução do Top10 [2]-Norte Seco), o que contribui para a melhora dos índices de desempenho apresentados na Tabela 4.14 quando comparados aos resultados da Tabela 4.13 . 
Tabela 4.17 - Novo Top10 para o Cenário Norte Seco do SGSB.

\begin{tabular}{|c|c|c|c|c|}
\hline Plano & $\begin{array}{c}\text { Investimento } \\
(\mathbf{1 0} \times \mathbf{~} \times \mathbf{R} \mathbf{)})\end{array}$ & $\begin{array}{c}\text { Perdas } \\
\text { Ativas }(\mathbf{M W})\end{array}$ & $\begin{array}{c}\text { Total de } \\
\text { Reforços }\end{array}$ & $\begin{array}{c}\text { Total de Ramos } \\
\text { Reforçados }\end{array}$ \\
\hline \hline 1 & 813,888 & 603,34 & 22 & 19 \\
\hline 2 & 816,957 & 602,54 & 22 & 19 \\
\hline 3 & 817,980 & 603,66 & 22 & 19 \\
\hline 4 & 821,049 & 602,85 & 22 & 19 \\
\hline 5 & 826,041 & 601,77 & 22 & 19 \\
\hline 6 & 827,064 & 602,89 & 22 & 19 \\
\hline 7 & 830,133 & 602,08 & 22 & 19 \\
\hline 8 & 833,442 & 602,82 & 22 & 19 \\
\hline 9 & 836,511 & 602,01 & 22 & 19 \\
\hline 10 & 837,534 & 603,13 & 22 & 19 \\
\hline
\end{tabular}

Ademais, em termos da qualidade do conjunto das melhores soluções finais identificadas, verificou-se que ambas as rodadas apresentam isoladamente valores de desvio percentual médio bem abaixo do mínimo valor esperado de $1,16 \%$. Para a melhor rodada do Teste D.4, por exemplo, o desvio percentual médio em relação a melhor solução conhecida apresenta valor de $-0,60 \%$. Ou seja, a média dos investimentos das 10 melhores soluções identificadas é ainda menor do que a melhor solução até então conhecida de investimento. Já para a melhor rodada do Teste D.3, esse valor de desvio é positivo e igual a $0,81 \%$. Isso significa, que a média de investimentos das 10 melhores soluções identificadas nessa rodada é ainda menor do que o quarto melhor investimento conhecido.

Por fim, destaca-se que, após solução isolada de cada cenário para o sistema SGSB, as melhores soluções obtidas em cada caso podem ser combinadas a fim de se identificar uma solução única global para o sistema. De forma geral, em uma etapa posterior de planejamento, os reforços que compõem as soluções identificadas nos dois cenários podem ser sobrepostos e a solução global pode ser definida como o resultado de um "refinamento" dos planos resultantes. Esse refinamento visa à eliminação de reforços desnecessários para o atendimento global de operação, uma vez que os reforços adicionados à rede de transmissão para o atendimento de um dos cenários contribuem também para o atendimento do outro. Tal estratégia pode ser verificada em [2]. 


\section{7.}

\section{AGE-PET versus Algoritmo Genético Básico}

A fim de investigar com mais detalhes os benefícios inerentes ao emprego do AGE-PET proposto neste trabalho, seu desempenho foi ainda comparado ao desempenho apresentado por uma versão básica do algoritmo genético (GA), aqui denominado GAB. Basicamente, essa versão básica do GA não faz uso de quaisquer informações heurísticas relacionadas ao problema PET. A análise comparativa entre as duas ferramentas é apresentada nesta seção.

De forma geral, o algoritmo do GAB foi implementado seguindo as mesmas premissas, em termos de estrutura das execuções evolutivas (EEs), que o algoritmo do AGE-PET apresentado na Figura 3.2. As diferenças básicas entre o GAB e o AGE-PET ficam por conta da implementação dos operadores de mutação e da estratégia de seleção de indivíduos que seguem pelo processo evolutivo. Além disso, no GAB não são utilizados os mecanismos de refinamento e "lista tabu" definidos para o AGE-PET.

Sendo assim, em cada EE do algoritmo GAB, após a aplicação do mecanismo de cruzamento, aplica-se somente um mecanismo básico de mutação, que possui estrutura semelhante àquela do operador EspMut proposto na Subseção 3.4.2. No mecanismo básico de mutação do GAB, cada ramo candidato ao reforço tem igual probabilidade de ter um reforço adicionado ou removido (i.e., $\alpha_{a d i}=\alpha_{s u b}=$ $50 \%$ ), sendo estas probabilidades mantidas fixas ao longo de todo o processo de solução do problema PET.

Após a aplicação do mecanismo básico de mutação, a cada geração de uma EE, a nova população é formada a partir da seleção dos $N_{\text {POP }}$ indivíduos mais aptos entre indivíduos pais $\left(\Omega_{\mathrm{POP}}\right)$ e filhos gerados $\left(\Omega_{\mathrm{NOVO}}\right)$. Ou seja, considera-se para o GAB uma estratégia de seleção por elitismo de $100 \%\left(N_{\mathrm{EL}}=N_{\mathrm{POP}}\right)$. Considera-se ainda que a forma como se dá a geração da população inicial do GAB é idêntica à do AGE-PET, descrita na Seção 3.5.

Para realizar a análise comparativa, testes foram realizados empregando a ferramenta GAB para cada um dos três sistemas estudados neste trabalho. Para os sistemas IEEE-RTS e SSB, foram mantidos no emprego do GAB os mesmos parâmetros utilizados nos testes realizados para o AGE-PET e que são comuns às duas ferramentas. Já para o SGSB, sistema que apresenta maior complexidade de 
solução para o problema PET, foram considerados para os dois cenários avaliados os mesmos parâmetros utilizados em [2], trabalho onde este sistema foi proposto. Neste último caso, para efeitos de convergência de uma $\mathrm{EE}$ do GAB, foram considerados os critérios de estagnação do melhor indivíduo do conjunto $\Omega_{\mathrm{IV}}$ por 60 gerações consecutivas (i.e., $N_{\text {GER-EST }}=60$ ) para os testes com $N_{\text {POP }}=600$ (Testes GAB.5 e GAB.7) e de 80 gerações (i.e., $N_{\text {GER-EST }}=80$ ) para os testes realizados com $N_{\mathrm{POP}}=800$ (Teste GAB.6 e GAB.8). Além disso, a fim de garantir uma comparação consistente entre as ferramentas, o mesmo número de execuções evolutivas $\left(N_{\text {MAX-EE }}=5\right)$ foi considerado na aplicação de cada teste realizado para o GAB e para o AGE-PET.

Para o sistema IEEE-RTS, os resultados, em termos dos índices de desempenho estatístico, obtidos via algoritmo GAB nos dois testes realizados (Testes GAB.1 e GAB.2), estão apresentados na Tabela 4.18 a seguir.

Tabela 4.18 - Índices de desempenho para IEEE-RTS com algoritmo GAB.

\begin{tabular}{|c|c|c|c|c|c|c|}
\hline Teste & $\boldsymbol{N}_{\text {POP }}$ & $\boldsymbol{R}_{\text {Best }}$ & $\boldsymbol{N}_{\text {Top10 }}$ & $\boldsymbol{T}_{\mathbf{M}}(\mathbf{m i n})$ & $\boldsymbol{D}_{\text {Best }}$ (\%) & $\boldsymbol{D}_{\text {10Best }}$ (\%) \\
\hline \hline GAB.1 & 600 & 10,00 & 4,00 & 6,70 & 0,00 & 1,18 \\
\hline GAB.2 & 800 & 9,00 & 2,60 & 9,52 & 0,24 & 1,94 \\
\hline
\end{tabular}

Quando comparados aos resultados obtidos pelo AGE-PET (Tabela 4.3 e Tabela 4.4), verifica-se na Tabela 4.18 uma deterioração significativa de desempenho. No Teste GAB.1, por exemplo, de acordo com o índice $N_{\text {Top10, o GAB foi }}$ capaz, em média, de encontrar em cada rodada apenas 4 das 10 melhores soluções conhecidas para o problema (Top10-IEEE-RTS), o que representa uma redução de $57,89 \%$ em relação ao menor valor identificado pela ferramenta AGE-PET ( $N_{\text {Top10 }}$

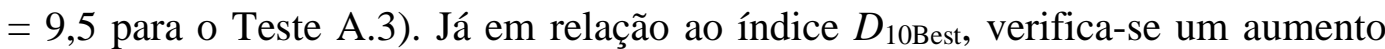
médio significativo de 32,84 vezes para os Testes GAB.1 e GAB.2 em relação aos Testes de A.1 a A.4.

O único índice a apresentar melhora de desempenho foi o tempo médio de execução $\left(T_{\mathrm{M}}\right)$, o qual apresentou melhoras de $42,24 \%$ e $35,98 \%$, respectivamente, para os Testes GAB.1 e GAB.2, em relação aos testes realizados com a ferramenta AGE-PET com seleção por clusterização (Testes A.3 e A.4). Esta última constatação pode ser justificada pelo fato de que, com o emprego dos operadores específicos e avançados pelo AGE-PET, há um aumento do número de indivíduos gera- 
dos e avaliados a cada geração, acarretando, dessa forma, em um maior custo computacional exigido.

Desempenho análogo pode ser verificado pelo emprego do GAB na solução do problema PET para o sistema SSB, cujos resultados em termos de índices de desempenho estatístico estão dispostos na Tabela 4.19.

Tabela 4.19 - Índices de desempenho para o SSB com algoritmo GAB.

\begin{tabular}{|c|c|c|c|c|c|c|}
\hline Teste & $\boldsymbol{N}_{\text {POP }}$ & $\boldsymbol{R}_{\text {Best }}$ & $\boldsymbol{N}_{\text {Top10 }}$ & $\boldsymbol{T}_{\mathbf{M}}(\mathbf{m i n})$ & $\boldsymbol{D}_{\text {Best }}(\boldsymbol{\%})$ & $\boldsymbol{D}_{\text {10Best }}(\boldsymbol{\%})$ \\
\hline \hline GAB.3 & 600 & 1,00 & 1,10 & 24,21 & 5,55 & 8,81 \\
\hline GAB.4 & 800 & 0,00 & 1,00 & 29,93 & 5,61 & 9,40 \\
\hline
\end{tabular}

Se comparados os resultados obtidos pelas duas ferramentas para os testes realizados com o sistema SSB (Tabela 4.6, Tabela 4.7 e Tabela 4.8 para o AGEPET e Tabela 4.19 para o GAB), é possível verificar novamente que o desempenho apresentado pelo AGE-PET é, em geral, superior ao do GAB. Novamente, a exceção se dá para o índice $T_{\mathrm{M}}$, o qual apresenta uma melhora média de $38,74 \%$ para os testes realizados com o GAB (Testes GAB.3 a GAB.4) em relação a todos os testes realizados com o AGE-PET (Testes de B.1 a B.6). Essa melhora é explicada também pelo aumento do número de indivíduos gerados e avaliados no AGE-PET de acordo com seus operadores específicos e avançados.

Já em relação aos demais índices, destaque pode ser dado aos reduzidos valores dos índices $R_{\text {Best }}$ e $N_{\text {Top10 }}$ atingidos pela ferramenta GAB. Enquanto o AGEPET é capaz de identificar em todas as rodadas o melhor investimento conhecido em 4 dos 6 testes realizados (Testes B.1, B.2, B.5 e B.6), o GAB só identifica a melhor solução conhecida para o problema e uma rodada de um de seus testes (Teste GAB.3). Além disso, das 10 melhores soluções conhecidas para o sistema SSB (Top10-SSB), o GAB é capaz de identificar, em média, somente 1,05 dessas soluções. Essa média é muito superior para o AGE-PET, que identifica por rodada para os Testes de B.1 a B.6 uma média de 9,08 das soluções do Top10-SSB.

Já para o SGSB, quando considerado o cenário Norte Úmido, por se tratar de um sistema cujo problema de otimização apresenta menor complexidade de solução, é possível verificar desempenhos semelhantes entre as ferramentas GAB e AGE-PET. Os índices de desempenho apresentados pelos testes com este cenário, obtidos via algoritmo GAB, estão presentes na Tabela 4.20. Vale ressaltar, que nos testes realizados com a ferramenta $\mathrm{GAB}$, foi considerado um critério de 
convergência pelo menos 4 vezes maior em cada EE do algoritmo que aquele considerado pelo AGE-PET neste trabalho, o que definiu para o índice $D_{10 B e s t}$ valores ligeiramente inferiores àqueles verificados nos testes do AGE-PET, em média, para todos os testes, $1,91 \%$ vezes menores. Por outro lado, dado o aumento do critério de convergência, verifica-se que os tempos computacionais médios (índice $T_{\mathrm{M}}$ ) apresentados pelos Testes GAB.5 e GAB.6 são apresentados em horas na Tabela 4.20, sendo, em média, 17,52 vezes maiores que aqueles verificados para os Testes de C. 1 a C.4 realizados com o AGE-PET. Portanto, verifica-se que a ligeira melhora do índice $D_{10 B e s t}$ nos testes do GBA só é obtida mediante uma deterioração muito significativa do índice $T_{\mathrm{M}}$.

Tabela 4.20 - Índices de desempenho para o cenário Norte Úmido do SGSB com algoritmo GAB.

\begin{tabular}{|c|c|c|c|c|c|c|}
\hline Teste & $\boldsymbol{N}_{\text {POP }}$ & $\boldsymbol{R}_{\text {Best }}$ & $\boldsymbol{N}_{\text {Top10 }}$ & $\boldsymbol{T}_{\mathbf{M}}(\mathbf{h})$ & $\boldsymbol{D}_{\text {Best }}(\boldsymbol{\%})$ & $\boldsymbol{D}_{\text {10Best }}(\boldsymbol{\%})$ \\
\hline \hline GAB.5 & 600 & 6,00 & 10,00 & 3,83 & 0,00 & 5,14 \\
\hline GAB.6 & 800 & 6,00 & 9,17 & 3,52 & 0,00 & 5,02 \\
\hline
\end{tabular}

Para o cenário Norte Seco do sistema SGSB, que representa um problema de otimização com maior nível de dificuldade de solução, é verificado que, mesmo com o considerável aumento do critério de convergência em cada EE do algoritmo, a ferramenta GAB apresenta desempenho muito inferior ao que é verificado para o AGE-PET. Com este cenário, os resultados obtidos pelo emprego do GAB são apresentados na Tabela 4.21.

Tabela 4.21 - Índices de desempenho para o cenário Norte Seco do SGSB com algoritmo GAB

\begin{tabular}{|c|c|c|c|c|c|c|}
\hline Teste & $\boldsymbol{N}_{\text {POP }}$ & $\boldsymbol{R}_{\text {Best }}$ & $\boldsymbol{N}_{\text {Top10 }}$ & $\boldsymbol{T}_{\mathbf{M}}(\mathbf{h})$ & $\boldsymbol{D}_{\text {Best }}$ (\%) & $\boldsymbol{D}_{\text {10Best }}(\boldsymbol{\%})$ \\
\hline \hline GAB.7 & 600 & 0,00 & 0,00 & 8,41 & 14,66 & 17,69 \\
\hline GAB.8 & 800 & 0,00 & 0,00 & 14,57 & 12,80 & 14,32 \\
\hline
\end{tabular}

De forma geral, verifica-se pelos resultados dos índices $R_{\text {Best }}$ e $N_{\text {Top10 }}$ apresentados na Tabela 4.21 que o GAB não foi capaz de identificar, em nenhum dos dois testes realizados (Testes GAB.7 e GAB.8), nenhuma das soluções que compõem o conjunto Top10 [2]-Norte Seco, sendo este o conjunto que contém as 10 melhores soluções apresentadas por [2]. Já o AGE-PET, conforme pode ser verificado pela Tabela 4.17, foi capaz de identificar 7 soluções ainda melhores que as deste conjunto. 
Além disso, quando comparados com os Testes de D.1 a D5, realizados para o cenário Norte Seco via AGE-PET, pode-se verificar que os Testes GBA.7 e GBA.8 apresentam aumentos médios de $35,77 \%$ e $36,10 \%$ para os índices $D_{10 B e s t}$ e $D_{\text {Best, }}$ respectivamente. Por fim, destaca-se que, assim como verificado para o cenário Norte Úmido, o aumento do critério de convergência considerado nos testes realizados com o GAB, levou a um crescimento elevado do tempo computacional médio requerido em cada rodada da ferramenta. Em média, o índice $T_{\mathrm{M}}$ é 18 vezes maior para os testes com o GAB que para os testes que empregam o algoritmo AGE-PET proposto neste trabalho.

\section{8.}

\section{Conclusões}

São apresentados neste capítulo os resultados obtidos a partir da aplicação da ferramenta AGE-PET na solução do problema PET estático de longo prazo, para três diferentes sistemas elétricos de potência. Os resultados aqui apresentados são sistematicamente analisados ao longo do capítulo, sendo o desempenho da ferramenta proposta verificado por meio de índices estatísticos, calculados com base na realização de diferentes rodadas (execuções) de seu algoritmo.

Especificamente em relação às estratégias e mecanismos evolutivos que compõem a ferramenta AGE-PE, foi possível observar a partir dos estudos realizados que o emprego da estratégia de seleção por clusterização exigiu em todos os testes realizados um custo computacional reduzido em relação à estratégia de seleção por torneio, isso quando considerado o mesmo ajuste de parâmetros da ferramenta. Essa redução do custo computacional se deve principalmente ao menor número de avaliações realizadas por esta estratégia quando comparada à estratégia de seleção por torneio. Porém em termos de qualidade das soluções, mostrou desempenho ligeiramente inferior na solução de sistemas de pequeno porte (IEEE e SSB). Por outro lado, nos testes com o sistema de maior porte, o emprego da estratégia de seleção por clusterização apresentou um desempenho acima daquele verificado pela aplicação da estratégia de seleção por torneio, mostrando-se essencial na obtenção dos melhores planos de expansão para o sistema.

De forma geral, a partir dos resultados obtidos, é possível verificar um bom nível de robustez do AGE-PET em termos de ajuste de seus parâmetros. Em geral, planos de expansão de boa qualidade podem ser obtidos pela ferramenta proposta 
para diferentes tipos de sistemas mesmo sem a necessidade de grandes ajustes dos parâmetros. O bom desempenho apresentado pelo AGE-PET foi corroborado por um estudo comparativo realizado com emprego de uma versão básica da metaheurística algoritmo genético. Neste estudo, foi possível verificar que o emprego de informações heurísticas relacionadas ao problema, que permitem denominar a ferramenta como "especializada", foram essenciais para a qualidade final dos resultados obtidos pelo AGE-PET. 


\section{5. \\ Conclusões e Trabalhos Futuros}

\section{1. Conclusões}

É proposta nesta dissertação de mestrado uma nova ferramenta de otimização especializada na solução do problema PET estático de longo prazo, a qual é construída a partir da metaheurística Algoritmo Genético. A ferramenta proposta é denominada Algoritmo Genético Especializado (AGE-PET). De forma geral, o AGE-PET visa à evolução de um conjunto de soluções (população de indivíduos) para o problema de forma iterativa, em direção a planos de ótima qualidade. Informações heurísticas atualizadas com base no carregamento de circuitos da rede de transmissão, bem como eventuais sobrecargas e cortes de carga verificados em uma etapa de análise de contingências da rede, são incorporadas aos mecanismos evolutivos que compõem o AGE-PET. Essas informações são traduzidas por meio de índices de sensibilidade que visam ao auxílio na seleção de reforços mais atrativos para o sistema.

Durante o processo evolutivo da ferramenta, considera-se a implementação de um modelo linear de rede DC com inclusão das perdas ôhmicas na transmissão e o atendimento ao critério determinístico de segurança "N-1", visando lidar de maneira eficiente com as incertezas inerentes ao problema PET, garantindo um equilíbrio entre a qualidade das soluções identificadas (do ponto de vista dos custos envolvidos e do desempenho operativo do sistema) e o custo computacional exigido pela ferramenta de otimização.

A avaliação do desempenho do AGE-PET é realizada a partir de índices estatísticos, calculados a partir de diversas rodadas da ferramenta com diferentes sementes para a geração de números pseudoaleatórios. Esses índices são calculados com base no conjunto das melhores soluções identificadas após a convergência do algoritmo e visam quantificar de forma consistente os benefícios inerentes ao emprego do AGE-PET, sendo assim reduzidas as consequências impostas por sua natureza estocástica. 
Três sistemas de potência com diferentes características são utilizados na avaliação da ferramenta proposta, sendo dois sistemas de menor porte amplamente empregados na literatura para o estudo do planejamento da transmissão, e um sistema real de grande porte, criado a partir de um subsistema atual pertencente à rede básica da região geoelétrica Sul do Brasil. Para este último sistema, dois cenários de geração e carga, obtidos a partir de duas diferentes condições hidrológicas do país, são avaliados.

A partir dos resultados apresentados pelo AGE-PET para os três sistemas avaliados, é possível verificar o excelente desempenho e robustez da ferramenta na solução do problema PET, não somente em relação à qualidade dos planos identificados, como também em relação aos ajustes de parâmetros. Mesmo frente às diferentes dimensões e características dos problemas estudados, a ferramenta foi capaz de identificar, com basicamente um único conjunto de parâmetros, bons conjuntos de soluções para todos os sistemas.

Por fim, destaca-se o desempenho superior apresentado pelo AGE-PET em relação aos resultados apresentados por uma versão básica da metaheurística algoritmo genético. Por meio da análise comparativa realizada entre as duas ferramentas, é possível verificar que as estratégias especializadas, concebidas para a definição da ferramenta AGE-PET proposta, são bastante eficientes para solução do problema PET.

\section{2. \\ Propostas de Trabalhos Futuros}

Com base nos resultados apresentados e na experiência adquirida no desenvolvimento deste trabalho, são apresentadas as seguintes sugestões para a continuidade do estudo em trabalhos futuros:

- Aperfeiçoamento da ferramenta AGE-PET proposta nesta dissertação através de:

- Aprimoramento do ajuste de parâmetros inerentes à ferramenta por meio de técnicas de ajuste adaptativo durante o processo evolutivo (e.g., variar a proporção da população selecionada pela es- 
tratégia de elitismo a cada geração, com base no nível de diversidade da mesma);

○ Estudo da viabilidade de implementação de novos mecanismos evolutivos específicos, que possam ser melhor adaptados a cada tipo de sistema;

- Aprimoramento da estratégia de diversidade utilizada pelo mecanismo de seleção por clusterização, a fim de realizar de forma mais eficiente o agrupamento das soluções em diferentes classes;

- Adaptação da ferramenta de otimização para a incorporação do problema de compensação de reativo da rede a partir da consideração de um modelo de fluxo de potência AC e da criação de novos índices de sensibilidade, que possam ser também integrados durante o processo evolutivo de solução do AGE-PET;

- Aprimorar e avaliar a ferramenta frente à presença de outras incertezas relacionadas ao problema, como a de alta penetração de fontes de energia renovável e geração distribuída. 


\section{6. \\ Referências Bibliográficas}

1. EMPRESA DE PESQUISA ENERGÉTICA - EPE. Estudos para a expansão da transmissão - Consolidação das análise e pareceres técnicos - Ciclo 2019 - $\mathbf{1}^{\mathbf{0}}$ semestre. Rio de Janeiro. 2019.

2. ASSIS, F. A. Algoritmo Metaheurístico Construtivo para Solução do Problema de Planejamento da Expansão da Transmissão. Tese de Doutorado, PUC-Rio. Rio de Janeiro. 2018.

3. GOMES, P. V.; SARAIVA, J. T. State-of-the-art of transmission expansion planning: A survey from restructuring to renewable and distributed electricity markets. International Journal of Electrical Power \& Energy Systems, 111, October 2019. 411-424.

4. LUMBRERAS, S.; RAMOS, A. The new Challenges to Transmission Expansion Planning. Survey of Recent Practice and Literature Review. Electric Power Systems Research - EPSR, May 2016. 19-29.

5. LEITE DA SILVA, A. M. et al. Performance Comparison of Metaheuristics to Solve the Multi-stage Transmission Expansion Planning Problem. IET Gener. Transm. Distrib., 5, n. 3, 2011. 360-367.

6. HEMMATI, R.; HOOSHMAND, R. A.; KHODABAKHSHIAN, A. State-ofthe-Art of Transmission Expansion Planning: Comprehensive Review. Renewable and Sustainable Energy Reviews 23, p. 312-319, 2013.

7. LATORRE, G. et al. Classification of Publications and Models on Transmission Expansion Planning. IEEE Transactions on Power Systems, 18, May 2003. 938-946.

8. MENDONÇA, I. M.; SILVA JUNIOR, I. C.; MARCATO, A. L. M. Static Planning of the Expansion of Electrical Energy Transmission Systems Using Particle Swarm Optimization. Electrical Power and Energy Systems EPES, 60, 2014. 234-244.

9. DA SILVA, E. L. et al. Transmission network expansion planning under a tabu search approach. IEEE Transactions on Power Systems, 16, n. 1, February 2001. 62-68.

10. GIL, H. A.; DA SILVA, E. L. A Reliable Approach for Solving the Transmission Network Expansion Planning Problem Using Genetic Algorithms. Electric Power Systems Research - EPSR, 58, n. 1, May 2001. 
$45-51$.

11. FREIRE, M. R. Algoritmo Evolutivo Adaptativo Via Multioperadores Aplicado ao Planejamento da Expansão de Sistemas de Transmissão. Tese de Doutorado, Universidade Federal de Itajubá. Itajubá. 2016.

12. LEOU, R.-C. A Multi-year Transmission Planning Under a Derregulated Market. International Journal of Electrical Power \& Energy Systems, 33, n. 3, March 2011. 708-714.

13. YOUSSEF, H. K. M. Dynamic Transmission Planning Using a Constrained Genetic Algorithm. International Journal of Electrical Power \& Energy Systems, 23, n. 8, November 2001. 857-862.

14. POUBEL, R. P. B. et al. Tree Searching Heuristic Algorithm for Multi-Stage Transmission Planning Considering Security Constraints via Genetic Algorithm. Electric Power Systems Research - EPSR, 142, January 2017. 290-297.

15. ESCOBAR, A. H.; GALlEGO, R. A.; ROMERO, R. Multistage and Coordinated Planning of the Expansion of Transmission Systems. IEEE Transactions on Power Systems, 19, n. 2, May 2004. 735-744.

16. REZENDE, L. S. Planejamento da Expansão de Sistemas de Transmissão: Avaliação de Metaheurísticas e Critérios de Segurança. Tese de Doutorado - UNIFEI. Itajubá. 2011.

17. WORKING GROUP 37.10. Methods for Planning Under Uncertainty "Towards Flexibility in Power System Development". Electra, n. 161, p. 143164, August 1995.

18. BAHARVANDI, A. et al. Bundled generation and transmission planning under demand and wind generation uncertainty based on a combination of robust and stochastic otimization. IEEE Transactions on Sustainable Energy, 9, n. 3, July 2018. 1477-1486.

19. BUYGI, M. O. et al. Network planning in unbundled power systems. IEEE Transactions on Power Systems, 21, n. 3, August 2006. 1379 - 1387.

20. RAD, H. K.; MORAVEJ, Z. An approach for simultaneous distribution, subtransmission, and transmission networks expansion planning. International Journal of Electrical Power \& Energy Systems, 91, October 2017. 166-182.

21. EL-KEIB, A. A.; CHOI, J.; TRAN, T. Transmission expansion planning considering ambiguities using fuzzy modeling. IEEE PES Power Systems Conference and Exposition. Atlanta, GA, USA: IEEE. 2006.

22. DA ROCHA, M. C.; SARAIVA, J. T. A discrete evolutionary PSO based approach to the multiyear transmission expansion planning problem 
considering demand uncertainties. International Journal of Electrical Power \& Energy Systems, 45, n. 1, February 2013. 427-442.

23. ESCOBAR, A. H.; ROMERO, R. A.; GALlEGO, R. A. Transmission network expansion planning considering multiple generation scenarios. IEEE/PES Transmission and Distribution Conference and Exposition: Latin America. Bogota, Colombia: IEEE. 2008.

24. MÍNGUEZ, R.; GARCÍA-BERTRAND, R. Robust transmission network expansion planning in energy systems: Improving computational performance. European Journal of Operational Research, 248, n. 1, January 2016. 21-32.

25. RUIZ, C.; CONEJO, A. J. Robust transmission expansion planning. European Journal of Operational Research, 242, n. 2, April 2015. 390-401.

26. CEDEÑO, E. B.; ARORA, S. Performance comparison of transmission network expansion planning under deterministic and uncertain conditions. International Journal of Electrical Power \& Energy Systems, 33, n. 7, September 2011. 1288-1295.

27. NIHARIKA; VERMA, S.; MUKHERJEE, V. Transmission expansion planning: A review. International Conference on Energy Efficient Technologies for Sustainability (ICEETS). Nagercoil, India: IEEE. 2016.

28. RIDER, M. J.; GARCIA, A. V.; ROMERO, R. Power System Transmission Network Expansion Planning Using AC Model. IET Gener. Transm. Distrib., 1, n. 5, September 2007. 731-742.

29. LEITE DA SILVA, A. M. et al. Tabu Search Applied to Transmission Expansion Planning Considering Losses and Interruption Costs. Proceedings of the 10th International Conference on Probablistic Methods Applied to Power Systems. Rincon, Puerto Rico: IEEE. 2008.

30. LEITE DA SILVA, A. M. et al. Transmission Expansion Planning: A Discussion on Reliability and "N-1" Security Criteria. Proceedings of the 11th International Conference on Probabilistic Methods Applied to Power Systems. Singapore, Singapore: IEEE. 2010. p. 244-251.

31. REZENDE, L. S.; LEITE DA SILVA, A. M.; HONÓRIO, L. M. Artificial Immune Systems and Differential Evolution Based Approaches Applied to Multi-Stage Transmission Expansion Planning. 15th International Conference on Intelligent System Applications to Power Systems. Curitiba, Brazil: IEEE. 2009.

32. GARVER, L. L. Transmission Network Estimation Using Linear Programming. IEEE Transactions on Power Apparatus and Systems, PAS89, n. 7, 1970. 1688-1697. 
33. CARREÑO, E. et al. A branch and bound algorithm using the hybrid linear model in the transmission network expansion planning. IEEE Russia Power Tech. St. Petersburg, Russia: IEEE. 2005.

34. BAHIENSE, L. et al. A mixed integer disjunctive model for transmission network expansion. IEEE Transactions on Power Systems, 16, n. 3, August 2001. 560-565.

35. ROMERO, R. et al. Test systems and mathematical models for transmission network expansion planning. IEE Proceedings - Generation, Transmission and Distribution, 149, n. 1, January 2002. 27 - 36.

36. ARROYO, J. E. C. Heurísticas e Metaheurísticas para otimização combinatória multiobjetivo. Tese de Doutorado, Universidade Estadual de Campinas - UNICAMP. Campinas, São Paulo. 2002.

37. LEITE DA SILVA, A. M. et al. Transmission Expansion Planning Based on Relaxed N-1 Criteria and Reliability Indices. Proceedings of the 14th International Conference on Probabilistic Methods Applied to Power Systems. Beijing, China: IEEE. 2016.

38. SILVA, I. D. J. et al. Transmission network expansion planning with security constraints. IEE Proceedings - Generation, Transmission and Distribution, 152, n. 6, November 2005. 828 - 836.

39. WEI, H. et al. Transmission Network Planning With N-1 Security Criterion Based On Improved Multi-objective Genetic Algorithm. Proceedings of the 4th International Conference on Electric Utility Deregulation and Restructuring and Power Technologies (DRPT). Weihai, Shandong, China: IEEE. 2011. p. 1250-1254.

40. CHOI, J.; MOUNT, T. D.; THOMAS, R. J. Transmission expansion planning using contingency criteria. IEEE Transactions on Power Systems, 22, n. 4, November 2007. 2249-2261.

41. YUEHUI, C. et al. An Improved Particle Swarm Optimization Algorithm for Multistage and Coordinated Planning of Transmission Systems. Proceeding of Transmission \& Distribution Conference \& Exposition: Asia and Pacific. Dalian, China: IEEE. 2005. p. 1-6.

42. LI, W.; CHOUDHURY, P. Probabilistic Transmission Planning. IEEE Power and Energy Magazine, v. 5, n. 5, p. 46 - 53, Sept.-Oct. 2007.

43. MANSO, L. A. F.; LEITE DA SILVA, A. M. Probabilistic criteria for power system expansion planning. Electric Power Systems Research - EPSR, 69, n. 1, April 2004. 51-58.

44. LEITE DA SILVA, A. M. et al. Reliability worth applied to transmission expansion planning based on ant colony system. International Journal of 
Electrical Power \& Energy Systems, 32, n. 10, December 2010. 1077-1084.

45. CHOI, J. et al. A method for composite power system expansion planning considering probabilistic reliability criteria. IEEE Power Engineering Society General Meeting. San Francisco, CA, USA: IEEE. 2005.

46. CHOI, J. et al. Probabilistic reliability criterion for planning transmission system expansions. IEE Proceedings - Generation, Transmission and Distribution, 153, n. 6, November 2006. 719 - 727.

47. ASADA, E. N. et al. A Branch-and-Bound algorithm for the multi-stage transmission expansion planning. IEEE Power Engineering Society General Meeting. San Francisco, CA, USA: IEEE. 2005.

48. PEREIRA, M. V. F. et al. A decomposition approach to automated generation/transmission expansion planning. IEEE Transactions on Power Apparatus and Systems, PAS-104, n. 11, November 1985. 3074 - 3083.

49. BINATO, S.; PEREIRA, M. V. F.; GRANVILLE, S. A new Benders decomposition approach to solve power transmission network design problems. IEEE Transactions on Power Systems, 16, n. 2, May 2001. 235 240.

50. ZHANG, H. et al. A mixed-integer linear programming approach for multistage security-constrained transmission expansion planning. IEEE Transactions on Power Systems, 27, n. 2, May 2012. 1125-1133.

51. ZHANG, Y. et al. An extension of reduced disjunctive model for multi-stage security-constrained transmission expansion planning. IEEE Transactions on Power Systems, 33, n. 1, January 2018. 1092-1094.

52. DAS, S.; VERMA, A.; BIJWE, P. R. Security constrained AC transmission network expansion planning. Electric Power Systems Research - EPSR, 172, July 2019. 277-289.

53. ZHANG, $\mathrm{H}$. et al. Transmission expansion planning using an ac model: Formulations and possible relaxations. IEEE Power and Energy Society General Meeting. San Diego, CA, USA: IEEE. 2012.

54. RAHMANI, M. et al. Efficient method for AC transmission network expansion planning. Electric Power Systems Research - EPSR, 80, n. 9, September 2010. 1056-1064.

55. GALlEGO, R. A.; MONTICELLI, A.; ROMERO, R. Transmision system expansion planning by an extended genetic algorithm. IET Gener. Transm. Distrib., 145, n. 3, May 1998. 329-335.

56. LUMBRERAS， S.; RAMOS， A.; BANEZ-CHICHARRO， F. Optimal transmission network expansion planning in real-sized power systems with 
high renewable penetration. Electric Power Systems Research - EPSR, 149, August 2017. 76-88.

57. VILLASANA, R.; GARVER, L. L.; SALON, S. J. Transmission network planning using linear programming. IEEE Transactions on Power Apparatus and Systems, PAS-104, n. 2, February 1985. 349-356.

58. ASGHARIAN, V.; ABDELAZIZ, M. A Linear programming model for coordinated low-carbon generation and transmission expansion planning. Electrical Power and Energy Conference (EPEC). Saskatoon, SK, Canada: IEEE. 2017.

59. ÖZDEMIR, Ö. et al. Economic analysis of transmission expansion planning with price-responsive demand and quadratic losses by successive LP. IEEE Transactions on power systems, 31, n. 2, March 2016. 1096-1107.

60. AL-HAMOUZ, Z. M.; AL-FARAJ, A. S. Transmission Expansion Planning Using Nonlinear Programming. IEEE/PES Transmission and Distribution Conference and Exhibition. Yokohama, Japan, Japan: IEEE. 2002.

61. YOUSSEF, H. K.; HACKAM, R. New transmission planning model. IEEE Transactions on Power Systems, 4, n. 1, February 1989. 9-18.

62. DOMÍNGUEZ, A. H.; ESCOBAR, A. H.; GALLEGO, R. A. An MILP model for the static transmission expansion planning problem including HVAC/HVDC links, security constraints and power losses with a reduced search space. Electric Power Systems Research - EPSR, 143, February 2017. 611-623.

63. TEJADA, D. et al. Transmission network expansion planning considering repowering and reconfiguration. International Journal of Electrical Power \& Energy Systems, 69, July 2015. 213-221.

64. AlgUACIL, N.; MOTTO, A. L.; CONEJO, A. J. Transmission expansion planning: A mixed-integer LP approach. IEEE Transactions on Power Systems, 18, n. 3, August 2003. 1070-1077.

65. KIM, H. et al. Integrated generation and transmission expansion planning using generalized Bender's decomposition method. IEEE International Conference on Computational Intelligence \& Communication Technology. Ghaziabad, India: IEEE. 2015.

66. ROMERO, R.; MONTICELLI, A. A hierarchical decomposition approach for transmission network expansion planning. IEEE Transactions on Power Systems, 9, n. 1, February 1994. 373-380.

67. HAFFNER, S. et al. Branch and bound algorithm for transmission system expansion planning using a transportation model. IEE Proceedings - 
Generation, Transmission and Distribution, 147, n. 3, May 2000. 149-156.

68. LEE, C. W. et al. Transmission Expansion Planning From Past to Future. IEEE PES Power Systems Conference and Exposition. Atlanta, GA, USA: IEEE. 2006.

69. MONTICELLI, A. et al. Interactive Transmission Network Planning Using a Least-Effort Criterion. IEEE Transactions on Power Apparatus and Systems, PAS-101, n. 10, 1982. 3919-3925.

70. BUSTAMANTE-CEDEÑO, E.; ARORA, S. Multi-step simultaneous changes Constructive Heuristic Algorithm for Transmission Network Expansion Planning. Electric Power Systems Research - EPSR, 79, April 2009. 586594.

71. ROMERO, R. et al. Constructive heuristic algorithm for the DC model in network transmission expansion planning. IEE Proceedings - Generation, Transmission and Distribution, 152, n. 2, March 2005. 277 - 282.

72. ROMERO, R. et al. Analysis of heuristic algorithms for the transportation model in static and multistage planning in network expansion systems. IEE Proceedings - Generation, Transmission and Distribution, 150, n. 5, September 2003. 521 - 526.

73. ROMERO, R.; GALLEGO, R. A.; MONTICELLI, A. Transmission system expansion planning by simulated annealing. Proceedings of Power Industry Computer Applications Conference. Salt Lake City, UT, USA, USA: IEEE. 1995.

74. GALLEGO, R. A. et al. Parallel simulated annealing applied to long term transmission network expansion planning. IEEE Transactions on Power Systems, 12, n. 1, February 1997. 181-188.

75. BRAGA, A. S. D.; SARAIVA, T. A multiyear dynamic approach for transmission expansion planning and long-term marginal cost computation. IEEE Transactions on Power Systems, 20, n. 3, August 2005. 1631-1639.

76. WEN, F.; CHANG, C. S. Transmission network optimal planning using the tabu search method. Electric Power Systes Research - EPSR, 42, n. 2, August 1997. 153-163.

77. GALLEGO, R. A.; ROMERO, R.; MONTICELLI, A. J. Tabu search algorithm for network synthesis. IEEE Transactions on Power Systems, 15, n. 2, May 2000. 490-495.

78. LEITE DA SILVA, A. M. et al. Evolution strategies to transmission expansion planning considering unreliability costs. Proceedings of the 9 th International Conference on Probabilistic Methods Applied to Power Systems. 
Stockholm, Sweden: IEEE. 2006.

79. HOLLAND, J. H. Adaptation in natural and artificial systems: An introductory analysis with applications to biology, control and artificial intelligence. Ann Arbor, Michigan, USA: University of Michigan Press, 1975.

80. DONG, Z. Y. et al. A Differential evolution based method for power system planning. IEEE Congress on Evolutionary Computation. Vancouver, BC, Canada: IEEE. 2006. p. 2700-2706.

81. TORRES, S. P.; CASTRO, C. A. Specialized differential evolution technique to solve the alternating current model based transmission expansion planning problem. International Journal of Electrical Power \& Energy Systems, 68, June 2015. 243-251.

82. GEORGILAKIS, P. S. Market-based transmission expansion planning by improved differential evolution. International Journal of Electrical Power \& Energy Systems, 32, n. 5, June 2010. 450-456.

83. LIMSAKUL, P.; POTHIYA, S.; LEEPRECHANON, N. Application of ant colony optimization to transmission network expansion planning with security constraint. 8th International Conference on Advances in Power System Control, Operation and Management. Hong Kong, China, China: IET. 2009.

84. BINATO, S.; DE OLIVEIRA, G. C.; DE ARAÚJO, J. L. A greedy randomized adaptive search procedure for transmission expansion planning. IEEE Transactions on Power Systems, 16, n. 2, May 2001. 247-253.

85. FARIA JR., H. et al. Power transmission network design by greedy randomized adaptive path relinking. IEEE Transactions on Power Systems, 20, n. 1, February 2005. 43-49.

86. BOUSSAÏD, I.; LEPAGNOT, J.; SIARRY, P. A survey on optimization metaheuristics. Infor mation Sciences, 237, July 2013. 82-117.

87. KHORASANI, H. Algoritmo Tabu Search Especializado Para o Problema de Planejamento da Expansão de Sistemas de Transmissão. Tese de Doutorado, Universidade Estadual Paulista. Ilha Solteira. 2015.

88. WANG, X.; GAO, X. Z.; OVASKA, S. J. Artificial immune optimization methods and applications - A survey. IEEE International Conference on Systems, Man and Cybernetics. The Hague, Netherlands: IEEE. 2004.

89. DASGUPTA, D.; YU, S.; NINO, F. Recent advances in artificial immune systems: Models and applications. Applied Soft Computing, 11, n. 2, March 2011. 1574-1587. 
90. DA SILVA, E. L.; GIL, H. A.; AREIZA, J. M. Transmission network expansion planning under an improved genetic algorithm. IEEE Transactions on Power Systems, 15, n. 3, August 2000. 1168-1175.

91. GESTAL, M. et al. Introducción a lo Algoritmos Genético y la Programación Genética. A Coruña: Universidade da Coruña Servizo de Publicacións, 2010. ISBN 978-84-9749-422-9.

92. MACQUEEN, J. B. Some methods for classification and analysis of multivariate observations. Proceedings of the 5th Berkeley Symposium on Mathematical Statistics and Probability. Berkeley, EUA: University of California Press. 1967. p. 281-297.

93. ROMERO, R.; RIDER, M. J.; SILVA, I. J. A metaheuristic to solve the transmission expansion planning. IEEE Trasactions on Power Systems, 22, n. 4, November 2007. 2289-2291.

94. RELIABILITY TEST SYSTEM TASK FORCE OF THE APPLICATION OF PROBABILITY METHODS SUBCOMMITTEE. IEEE reliability test system. IEEE Transactions on Power Apparatus and Systems, PAS-98, n. 6, November 1979. 2047-2054.

95. FANG, R.; HILL, D. J. A new strategy for transmission expansion in competitive electricity markets. IEEE Transactions on Power Systems, 18, n. 1, February 2003. 374-380. 
Anexo A.

Dados do Sistema IEEE-RTS

A.1.

Dados de Barra

Tabela A.1 - Dados de barra - Sistema IEEE-RTS

\begin{tabular}{|c|c|c|c|c|}
\hline Barra & $\begin{array}{c}\text { Geração } \\
\text { Máxima (MW) }\end{array}$ & $\begin{array}{l}\text { Carga } \\
(\mathbf{M W})\end{array}$ & $\begin{array}{l}\text { Prioridade de } \\
\text { Despacho }\end{array}$ & $\begin{array}{c}\text { Nível de } \\
\text { Tensão }(\mathbf{k V})\end{array}$ \\
\hline 1 & 576,00 & 324,00 & 3 & 138 \\
\hline 2 & 576,00 & 291,00 & 1 & 138 \\
\hline 3 & 0,00 & 540,00 & - & 138 \\
\hline 4 & 0,00 & 222,00 & - & 138 \\
\hline 5 & 0,00 & 213,00 & - & 138 \\
\hline 6 & 0,00 & 408,00 & - & 138 \\
\hline 7 & 900,00 & 375,00 & 2 & 138 \\
\hline 8 & 0,00 & 513,00 & - & 138 \\
\hline 9 & 0,00 & 525,00 & - & 138 \\
\hline 10 & 0,00 & 585,00 & - & 138 \\
\hline 11 & 0,00 & 0,00 & - & 230 \\
\hline 12 & 0,00 & 0,00 & - & 230 \\
\hline 13 & 1773,00 & 795,00 & 4 & 230 \\
\hline 14 & 0,00 & 582,00 & - & 230 \\
\hline 15 & 645,00 & 951,00 & 5 & 230 \\
\hline 16 & 465,00 & 300,00 & 7 & 230 \\
\hline 17 & 0,00 & 0,00 & - & 230 \\
\hline 18 & 1200,00 & 999,00 & 9 & 230 \\
\hline 19 & 0,00 & 543,00 & - & 230 \\
\hline 20 & 0,00 & 384,00 & - & 230 \\
\hline 21 & 1200,00 & 0,00 & 8 & 230 \\
\hline 22 & 900,00 & 0,00 & 10 & 230 \\
\hline 23 & 1980,00 & 0,00 & 6 & 230 \\
\hline 24 & 0,00 & 0,00 & - & 230 \\
\hline Total & 10215,00 & 8550,00 & & \\
\hline
\end{tabular}


A.2.

\section{Dados de Ramos}

Tabela A.2 - Dados de ramos - Sistema IEEE-RTS.

\begin{tabular}{|c|c|c|c|c|c|c|}
\hline Ramo & De-Para & $\begin{array}{l}\text { Qtd. de Circuitos } \\
\text { Existentes }\end{array}$ & $\begin{array}{c}\boldsymbol{R}_{i j} \\
(\mathbf{p . u})\end{array}$ & $\begin{array}{c}X_{i j} \\
(\text { p.u) }\end{array}$ & $\begin{array}{c}f_{i j}^{\max } \\
(\mathbf{M W})\end{array}$ & $\begin{array}{c}c_{i j}^{i n v} \\
\text { (Milhões de \$) }\end{array}$ \\
\hline 1 & 01-02 & 1 & 0,0026 & 0,0139 & 175,00 & 3,00 \\
\hline 2 & 01-03 & 1 & 0,0546 & 0,2112 & 175,00 & 55,00 \\
\hline 3 & 01-05 & 1 & 0,0218 & 0,0845 & 175,00 & 22,00 \\
\hline 4 & $02-04$ & 1 & 0,0328 & 0,1267 & 175,00 & 33,00 \\
\hline 5 & $02-06$ & 1 & 0,0497 & 0,1920 & 175,00 & 50,00 \\
\hline 6 & 03-09 & 1 & 0,0308 & 0,1190 & 175,00 & 31,00 \\
\hline 7 & 03-24 & 1 & 0,0023 & 0,0839 & 400,00 & 50,00 \\
\hline 8 & 04-09 & 1 & 0,0268 & 0,1037 & 175,00 & 27,00 \\
\hline 9 & $05-10$ & 1 & 0,0228 & 0,0883 & 175,00 & 23,00 \\
\hline 10 & 06-10 & 1 & 0,0139 & 0,0605 & 175,00 & 16,00 \\
\hline 11 & 07-08 & 1 & 0,0159 & 0,0614 & 175,00 & 16,00 \\
\hline 12 & 08-09 & 1 & 0,0427 & 0,1651 & 175,00 & 43,00 \\
\hline 13 & 08-10 & 1 & 0,0427 & 0,1651 & 175,00 & 43,00 \\
\hline 14 & 09-11 & 1 & 0,0023 & 0,0839 & 400,00 & 50,00 \\
\hline 15 & 09-12 & 1 & 0,0023 & 0,0839 & 400,00 & 50,00 \\
\hline 16 & $10-11$ & 1 & 0,0023 & 0,0839 & 400,00 & 50,00 \\
\hline 17 & $10-12$ & 1 & 0,0023 & 0,0839 & 400,00 & 50,00 \\
\hline 18 & 11-13 & 1 & 0,0061 & 0,0476 & 500,00 & 66,00 \\
\hline 19 & 11-14 & 1 & 0,0054 & 0,0418 & 500,00 & 58,00 \\
\hline 20 & $12-13$ & 1 & 0,0061 & 0,0476 & 500,00 & 66,00 \\
\hline 21 & $12-23$ & 1 & 0,0124 & 0,0966 & 500,00 & 134,00 \\
\hline 22 & $13-23$ & 1 & 0,0111 & 0,0865 & 500,00 & 120,00 \\
\hline 23 & 14-16 & 1 & 0,0050 & 0,0389 & 500,00 & 54,00 \\
\hline 24 & $15-16$ & 1 & 0,0022 & 0,0173 & 500,00 & 24,00 \\
\hline 25 & $15-21$ & 1 & 0,0063 & 0,0490 & 500,00 & 68,00 \\
\hline 26 & $15-24$ & 1 & 0,0067 & 0,0519 & 500,00 & 72,00 \\
\hline 27 & 16-17 & 1 & 0,0033 & 0,0259 & 500,00 & 36,00 \\
\hline 28 & 16-19 & 1 & 0,0030 & 0,0231 & 500,00 & 32,00 \\
\hline 29 & 17-18 & 1 & 0,0018 & 0,0144 & 500,00 & 20,00 \\
\hline 30 & $17-22$ & 1 & 0,0135 & 0,1053 & 500,00 & 146,00 \\
\hline 31 & $18-21$ & 1 & 0,0033 & 0,0259 & 500,00 & 36,00 \\
\hline 32 & $19-20$ & 1 & 0,0051 & 0,0396 & 500,00 & 55,00 \\
\hline 33 & $20-23$ & 1 & 0,0028 & 0,0216 & 500,00 & 30,00 \\
\hline 34 & $21-22$ & 1 & 0,0087 & 0,0678 & 500,00 & 94,00 \\
\hline 35 & 01-08 & 0 & 0,0174 & 0,1344 & 500,00 & 35,00 \\
\hline 36 & $02-08$ & 0 & 0,0164 & 0,1267 & 500,00 & 33,00 \\
\hline 37 & 06-07 & 0 & 0,0249 & 0,1920 & 500,00 & 50,00 \\
\hline 38 & 13-14 & 0 & 0,0058 & 0,0447 & 500,00 & 62,00 \\
\hline 39 & $14-23$ & 0 & 0,0080 & 0,0620 & 500,00 & 86,00 \\
\hline 40 & $16-23$ & 0 & 0,0106 & 0,0822 & 500,00 & 114,00 \\
\hline 41 & $19-23$ & 0 & 0,0078 & 0,0606 & 500,00 & 84,00 \\
\hline
\end{tabular}


Anexo B.

Dados do Sistema Sul Brasileiro (SSB)

B.1.

Dados de Barra

Tabela B.1 - Dados de barra - Sistema Sul Brasileiro (SSB)

\begin{tabular}{|c|c|c|c|c|}
\hline Barra & $\begin{array}{c}\text { Geração } \\
\text { Máxima (MW) }\end{array}$ & $\begin{array}{l}\text { Carga } \\
(\mathbf{M W})\end{array}$ & $\begin{array}{l}\text { Prioridade de } \\
\text { Despacho }\end{array}$ & $\begin{array}{c}\text { Nível de } \\
\text { Tensão }(\mathbf{k V})\end{array}$ \\
\hline 1 & 0,00 & 0,00 & - & 230 \\
\hline 2 & 0,00 & 443,10 & - & 230 \\
\hline 3 & 0,00 & 0,00 & - & 500 \\
\hline 4 & 0,00 & 300,70 & - & 230 \\
\hline 5 & 0,00 & 238,00 & - & 230 \\
\hline 6 & 0,00 & 0,00 & - & 500 \\
\hline 7 & 0,00 & 0,00 & - & 230 \\
\hline 8 & 0,00 & 72,20 & - & 230 \\
\hline 9 & 0,00 & 0,00 & - & 230 \\
\hline 10 & 0,00 & 0,00 & - & 500 \\
\hline 11 & 0,00 & 0,00 & - & 230 \\
\hline 12 & 0,00 & 511,90 & - & 230 \\
\hline 13 & 0,00 & 185,80 & - & 230 \\
\hline 14 & 1257,00 & 0,00 & 10 & 230 \\
\hline 15 & 0,00 & 0,00 & - & 230 \\
\hline 16 & 2000,00 & 0,00 & 11 & 500 \\
\hline 17 & 1050,00 & 0,00 & 2 & 500 \\
\hline 18 & 0,00 & 0,00 & - & 230 \\
\hline 19 & 1670,00 & 0,00 & 1 & 500 \\
\hline 20 & 0,00 & 1091,20 & - & 230 \\
\hline 21 & 0,00 & 0,00 & - & 500 \\
\hline 22 & 0,00 & 81,90 & - & 230 \\
\hline 23 & 0,00 & 458,10 & - & 230 \\
\hline 24 & 0,00 & 478,20 & - & 230 \\
\hline 25 & 0,00 & 0,00 & - & 500 \\
\hline 26 & 0,00 & 231,90 & - & 230 \\
\hline 27 & 220,00 & 0,00 & 6 & 230 \\
\hline 28 & 800,00 & 0,00 & 12 & 500 \\
\hline 29 & 0,00 & 0,00 & - & 230 \\
\hline 30 & 0,00 & 0,00 & - & 500 \\
\hline 31 & 700,00 & 0,00 & 8 & 500 \\
\hline 32 & 500,00 & 0,00 & 7 & 500 \\
\hline 33 & 0,00 & 229,10 & - & 230 \\
\hline 34 & 748,00 & 0,00 & 5 & 230 \\
\hline 35 & 0,00 & 216,00 & - & 230 \\
\hline 36 & 0,00 & 90,10 & - & 230 \\
\hline 37 & 300,00 & 0,00 & 9 & 230 \\
\hline 38 & 0,00 & 216,00 & - & 230 \\
\hline 39 & 600,00 & 0,00 & 3 & 230 \\
\hline
\end{tabular}


(conclusão da Tabela B.1)

\begin{tabular}{|c|c|c|c|c|}
\hline Barra & $\begin{array}{c}\text { Geração } \\
\text { Máxima (MW) }\end{array}$ & $\begin{array}{c}\text { Carga } \\
\text { (MW) }\end{array}$ & $\begin{array}{c}\text { Prioridade de } \\
\text { Despacho }\end{array}$ & $\begin{array}{c}\text { Nível de } \\
\text { Tensão (kV) }\end{array}$ \\
\hline \hline 40 & 0,00 & 262,10 & - & 230 \\
\hline 41 & 0,00 & 0,00 & - & 500 \\
\hline 42 & 0,00 & 1607,90 & - & 230 \\
\hline 43 & 0,00 & 0,00 & - & 500 \\
\hline 44 & 0,00 & 79,10 & - & 230 \\
\hline 45 & 0,00 & 86,70 & - & 230 \\
\hline 46 & 700,00 & 0,00 & 4 & 500 \\
\hline \hline Total & 10545,00 & 6880,00 &
\end{tabular}

B.2.

Dados de Ramos

Tabela B.2 - Dados de ramos - Sistema Sul Brasileiro (SSB)

\begin{tabular}{|c|c|c|c|c|c|c|}
\hline Ramo & De-Para & $\begin{array}{l}\text { Qtd. de Circuitos } \\
\text { Existentes }\end{array}$ & $\begin{array}{c}\boldsymbol{R}_{i j} \\
(\mathbf{p . u})\end{array}$ & $\begin{array}{c}X_{i j} \\
(\mathbf{p . u})\end{array}$ & $\begin{array}{c}f_{i j}^{\max } \\
(\mathbf{M W})\end{array}$ & $\begin{array}{c}c_{i j}^{i n v} \\
(\text { Milhões de \$) }\end{array}$ \\
\hline 1 & 01-07 & 1 & 0,00616 & 0,0616 & 270,00 & 4,349 \\
\hline 2 & 01-02 & 1 & 0,01065 & 0,1065 & 270,00 & 7,076 \\
\hline 3 & 04-09 & 1 & 0,00924 & 0,0924 & 270,00 & 6,217 \\
\hline 4 & 05-09 & 1 & 0,01173 & 0,1173 & 270,00 & 7,732 \\
\hline 5 & 05-08 & 1 & 0,01132 & 0,1132 & 270,00 & 7,480 \\
\hline 6 & 07-08 & 1 & 0,01023 & 0,1023 & 270,00 & 6,823 \\
\hline 7 & 04-05 & 1 & 0,00566 & 0,0566 & 270,00 & 4,046 \\
\hline 8 & $02-05$ & 1 & 0,00324 & 0,0324 & 270,00 & 2,581 \\
\hline 9 & 08-13 & 1 & 0,01348 & 0,1348 & 240,00 & 8,793 \\
\hline 10 & 09-14 & 1 & 0,01756 & 0,1756 & 220,00 & 11,267 \\
\hline 11 & $12-14$ & 1 & 0,00740 & 0,0740 & 270,00 & 5,106 \\
\hline 12 & 14-18 & 1 & 0,01514 & 0,1514 & 240,00 & 9,803 \\
\hline 13 & $13-18$ & 1 & 0,01805 & 0,1805 & 220,00 & 11,570 \\
\hline 14 & $13-20$ & 1 & 0,01073 & 0,1073 & 270,00 & 7,126 \\
\hline 15 & $18-20$ & 1 & 0,01997 & 0,1997 & 200,00 & 12,732 \\
\hline 16 & $19-21$ & 1 & 0,00278 & 0,0278 & 1500,00 & 32,632 \\
\hline 17 & 16-17 & 1 & 0,00078 & 0,0078 & 2000,00 & 10,505 \\
\hline 18 & $17-19$ & 1 & 0,00061 & 0,0061 & 2000,00 & 8,715 \\
\hline 19 & $14-26$ & 1 & 0,01614 & 0,1614 & 220,00 & 10,409 \\
\hline 20 & $14-22$ & 1 & 0,00840 & 0,0840 & 270,00 & 5,712 \\
\hline 21 & $22-26$ & 1 & 0,00790 & 0,0790 & 270,00 & 5,409 \\
\hline 22 & $20-23$ & 1 & 0,00932 & 0,0932 & 270,00 & 6,268 \\
\hline 23 & $23-24$ & 1 & 0,00774 & 0,0774 & 270,00 & 5,308 \\
\hline 24 & $26-27$ & 1 & 0,00832 & 0,0832 & 270,00 & 5,662 \\
\hline 25 & $24-34$ & 1 & 0,01647 & 0,1647 & 220,00 & 10,611 \\
\hline 26 & $24-33$ & 1 & 0,01448 & 0,1448 & 240,00 & 9,399 \\
\hline 27 & $33-34$ & 1 & 0,01265 & 0,1265 & 270,00 & 8,288 \\
\hline 28 & $27-36$ & 1 & 0,00915 & 0,0915 & 270,00 & 6,167 \\
\hline 29 & $27-38$ & 1 & 0,02080 & 0,2080 & 200,00 & 13,237 \\
\hline 30 & $36-37$ & 1 & 0,01057 & 0,1057 & 270,00 & 7,025 \\
\hline 31 & $34-35$ & 1 & 0,00491 & 0,0491 & 270,00 & 3,591 \\
\hline 32 & $35-38$ & 1 & 0,01980 & 0,1980 & 200,00 & 12,631 \\
\hline 33 & $37-39$ & 1 & 0,00283 & 0,0283 & 270,00 & 2,329 \\
\hline 34 & $37-40$ & 1 & 0,01281 & 0,1281 & 270,00 & 8,389 \\
\hline
\end{tabular}


(conclusão da Tabela B.2)

\begin{tabular}{|c|c|c|c|c|c|c|}
\hline Ramo & De-Para & $\begin{array}{l}\text { Qtd. de Circuitos } \\
\text { Existentes }\end{array}$ & $\begin{array}{c}R_{i j} \\
(\mathbf{p . u})\end{array}$ & $\begin{array}{c}X_{i j} \\
(\mathbf{p . u})\end{array}$ & $\begin{array}{l}f_{i j}^{\max } \\
(\mathbf{M W})\end{array}$ & $\begin{array}{c}c_{i j}^{i n v} \\
\text { (Milhões de \$) }\end{array}$ \\
\hline 35 & $37-42$ & 1 & 0,02105 & 0,2105 & 200,00 & 13,388 \\
\hline 36 & $39-42$ & 1 & 0,02030 & 0,2030 & 200,00 & 12,934 \\
\hline 37 & $40-42$ & 1 & 0,00932 & 0,0932 & 270,00 & 6,268 \\
\hline 38 & $38-42$ & 1 & 0,00907 & 0,0907 & 270,00 & 6,116 \\
\hline 39 & $32-43$ & 1 & 0,00309 & 0,0309 & 1400,00 & 35,957 \\
\hline 40 & $42-44$ & 1 & 0,01206 & 0,1206 & 270,00 & 7,934 \\
\hline 41 & $44-45$ & 1 & 0,01864 & 0,1864 & 200,00 & 11,924 \\
\hline 42 & $19-32$ & 1 & 0,00195 & 0,0195 & 1800,00 & 23,423 \\
\hline 43 & $46-19$ & 1 & 0,00222 & 0,0222 & 1800,00 & 26,365 \\
\hline 44 & $46-16$ & 1 & 0,00203 & 0,0203 & 1800,00 & 24,319 \\
\hline 45 & 18-19 & 1 & 0,00125 & 0,0125 & 600,00 & 8,178 \\
\hline 46 & $20-21$ & 1 & 0,00125 & 0,0125 & 600,00 & 8,178 \\
\hline 47 & $42-43$ & 1 & 0,00125 & 0,0125 & 600,00 & 8,178 \\
\hline 48 & 02-04 & 0 & 0,00882 & 0,0882 & 270,00 & 5,965 \\
\hline 49 & 14-15 & 0 & 0,00374 & 0,0374 & 270,00 & 2,884 \\
\hline 50 & $46-10$ & 0 & 0,00081 & 0,0081 & 2000,00 & 10,889 \\
\hline 51 & 04-11 & 0 & 0,02246 & 0,2246 & 240,00 & 14,247 \\
\hline 52 & $05-11$ & 0 & 0,00915 & 0,0915 & 270,00 & 6,167 \\
\hline 53 & 46-06 & 0 & 0,00128 & 0,0128 & 2000,00 & 16,005 \\
\hline 54 & $46-03$ & 0 & 0,00203 & 0,0203 & 1800,00 & 24,319 \\
\hline 55 & 16-28 & 0 & 0,00222 & 0,0222 & 1800,00 & 26,365 \\
\hline 56 & 16-32 & 0 & 0,00311 & 0,0311 & 1400,00 & 36,213 \\
\hline 57 & $17-32$ & 0 & 0,00232 & 0,0232 & 1700,00 & 27,516 \\
\hline 58 & $19-25$ & 0 & 0,00325 & 0,0325 & 1400,00 & 37,748 \\
\hline 59 & $21-25$ & 0 & 0,00174 & 0,0174 & 2000,00 & 21,121 \\
\hline 60 & $25-32$ & 0 & 0,00319 & 0,0319 & 1400,00 & 37,109 \\
\hline 61 & $31-32$ & 0 & 0,00046 & 0,0046 & 2000,00 & 7,052 \\
\hline 62 & $28-31$ & 0 & 0,00053 & 0,0053 & 2000,00 & 7,819 \\
\hline 63 & $28-30$ & 0 & 0,00058 & 0,0058 & 2000,00 & 8,331 \\
\hline 64 & $27-29$ & 0 & 0,00998 & 0,0998 & 270,00 & 6,672 \\
\hline 65 & 26-29 & 0 & 0,00541 & 0,0541 & 270,00 & 3,894 \\
\hline 66 & $28-41$ & 0 & 0,00339 & 0,0339 & 1300,00 & 39,283 \\
\hline 67 & $28-43$ & 0 & 0,00406 & 0,0406 & 1200,00 & 46,701 \\
\hline 68 & $31-41$ & 0 & 0,00278 & 0,0278 & 1500,00 & 32,632 \\
\hline 69 & $32-41$ & 0 & 0,00309 & 0,0309 & 1400,00 & 35,957 \\
\hline 70 & $41-43$ & 0 & 0,00139 & 0,0139 & 2000,00 & 17,284 \\
\hline 71 & $40-45$ & 0 & 0,02205 & 0,2205 & 180,00 & 13,994 \\
\hline 72 & $15-16$ & 0 & 0,00125 & 0,0125 & 600,00 & 8,178 \\
\hline 73 & $46-11$ & 0 & 0,00125 & 0,0125 & 600,00 & 8,178 \\
\hline 74 & $24-25$ & 0 & 0,00125 & 0,0125 & 600,00 & 8,178 \\
\hline 75 & $29-30$ & 0 & 0,00125 & 0,0125 & 600,00 & 8,178 \\
\hline 76 & $40-41$ & 0 & 0,00125 & 0,0125 & 600,00 & 8,178 \\
\hline 77 & $02-03$ & 0 & 0,00125 & 0,0125 & 600,00 & 8,178 \\
\hline 78 & $05-06$ & 0 & 0,00125 & 0,0125 & 600,00 & 8,178 \\
\hline 79 & $09-10$ & 0 & 0,00125 & 0,0125 & 600,00 & 8,178 \\
\hline
\end{tabular}


Anexo C.

Dados do Sistema Geoelétrico Sul do Brasil (SGSB)

C.1.

Dados de Barra

Tabela C.1 - Dados de Barra - Sistema SGSB

\begin{tabular}{|c|c|c|c|c|c|c|c|}
\hline \multirow[t]{2}{*}{ Barra } & \multicolumn{2}{|c|}{$\begin{array}{c}\text { Despacho Geração } \\
\text { (MW) }\end{array}$} & \multicolumn{2}{|c|}{$\begin{array}{l}\text { Carga } \\
\text { (MW) }\end{array}$} & \multicolumn{2}{|c|}{$\begin{array}{c}\text { Prioridade no } \\
\text { Despacho } \\
\text { da Geração }\end{array}$} & \multirow{2}{*}{$\begin{array}{c}\text { Nível de } \\
\text { Tensão }(\mathbf{k V})\end{array}$} \\
\hline & $\begin{array}{l}\text { C. Norte } \\
\text { Seco }\end{array}$ & $\begin{array}{l}\text { C. Norte } \\
\text { Úmido }\end{array}$ & $\begin{array}{l}\text { C. Norte } \\
\text { Seco }\end{array}$ & $\begin{array}{l}\text { C. Norte } \\
\text { Úmido }\end{array}$ & $\begin{array}{l}\text { C. Norte } \\
\text { Seco }\end{array}$ & $\begin{array}{l}\text { C. Norte } \\
\text { Úmido }\end{array}$ & \\
\hline 4290 & 215 & 603 & 0 & 0 & 21 & 10 & 230 \\
\hline 6190 & 0 & 0 & 44 & 44 & - & - & 230 \\
\hline 6601 & 0 & 0 & 160 & 152 & - & - & 230 \\
\hline 6602 & 0 & 0 & 46 & 0 & - & - & 230 \\
\hline 6603 & 0 & 0 & 78 & 0 & - & - & 230 \\
\hline 6608 & 298 & 0 & 0 & 0 & 16 & - & 230 \\
\hline 6615 & 0 & 0 & 207 & 173 & - & - & 230 \\
\hline 6616 & 0 & 0 & 211 & 190 & - & - & 230 \\
\hline 6617 & 0 & 0 & 204 & 173 & - & - & 230 \\
\hline 6618 & 0 & 0 & 181 & 159 & - & - & 230 \\
\hline 6619 & 0 & 0 & 150 & 117 & - & - & 230 \\
\hline 6623 & 0 & 0 & 26 & 26 & - & - & 230 \\
\hline 6624 & 0 & 0 & 266 & 266 & - & - & 230 \\
\hline 6625 & 0 & 0 & 0 & 0 & - & - & 230 \\
\hline 6626 & 0 & 0 & 0 & 0 & - & - & 525 \\
\hline 6627 & 0 & 0 & 145 & 130 & - & - & 230 \\
\hline 6628 & 0 & 2020 & 196 & 0 & - & 35 & 525 \\
\hline 6629 & 0 & 0 & 14 & 14 & - & - & 230 \\
\hline 6630 & 0 & 0 & 0 & 0 & - & - & 525 \\
\hline 6649 & 1472 & 1587 & 0 & 0 & 53 & 2 & 525 \\
\hline 6651 & 0 & 18 & 32 & 0 & - & 32 & 230 \\
\hline 6652 & 0 & 0 & 117 & 128 & - & - & 230 \\
\hline 6653 & 0 & 0 & 126 & 126 & - & - & 230 \\
\hline 6662 & 1410 & 837 & 0 & 0 & 1 & 4 & 525 \\
\hline 6663 & 134 & 100 & 0 & 0 & 29 & 21 & 230 \\
\hline 6664 & 176 & 176 & 0 & 0 & 24 & 19 & 230 \\
\hline 6665 & 0 & 0 & 181 & 157 & - & - & 230 \\
\hline 6673 & 0 & 0 & 0 & 0 & - & - & 230 \\
\hline 6680 & 0 & 0 & 228 & 249 & - & - & 230 \\
\hline 6688 & 0 & 0 & 255 & 248 & - & - & 230 \\
\hline 6708 & 0 & 0 & 174 & 214 & - & - & 230 \\
\hline 6710 & 0 & 0 & 0 & 0 & - & - & 525 \\
\hline 6715 & 295 & 176 & 0 & 0 & 17 & 20 & 230 \\
\hline 6730 & 0 & 0 & 73 & 35 & - & - & 230 \\
\hline
\end{tabular}

(continua) 
(continuação da Tabela C.1)

\begin{tabular}{|c|c|c|c|c|c|c|c|}
\hline \multirow[t]{2}{*}{ Barra } & \multicolumn{2}{|c|}{$\begin{array}{c}\text { Despacho Geração } \\
\text { (MW) }\end{array}$} & \multicolumn{2}{|c|}{$\begin{array}{l}\text { Carga } \\
\text { (MW) }\end{array}$} & \multicolumn{2}{|c|}{$\begin{array}{c}\text { Prioridade no } \\
\text { Despacho } \\
\text { da Geração }\end{array}$} & \multirow{2}{*}{$\begin{array}{c}\text { Nível de } \\
\text { Tensão }(k V)\end{array}$} \\
\hline & $\begin{array}{l}\text { C. Norte } \\
\text { Seco }\end{array}$ & $\begin{array}{l}\text { C. Norte } \\
\text { Úmido }\end{array}$ & $\begin{array}{l}\text { C. Norte } \\
\text { Seco }\end{array}$ & $\begin{array}{l}\text { C. Norte } \\
\text { Úmido }\end{array}$ & $\begin{array}{l}\text { C. Norte } \\
\text { Seco }\end{array}$ & $\begin{array}{l}\text { C. Norte } \\
\text { Úmido }\end{array}$ & \\
\hline 6731 & 0 & 0 & 102 & 12 & - & - & 230 \\
\hline 6732 & 0 & 0 & 124 & 147 & - & - & 230 \\
\hline 6733 & 0 & 0 & 139 & 96 & - & - & 230 \\
\hline 6747 & 0 & 0 & 13 & 13 & - & - & 230 \\
\hline 6754 & 0 & 0 & 267 & 86 & - & - & 230 \\
\hline 6755 & 1052 & 620 & 0 & 0 & 6 & 9 & 525 \\
\hline 6757 & 1061 & 630 & 0 & 0 & 5 & 8 & 525 \\
\hline 6758 & 0 & 0 & 0 & 0 & - & - & 525 \\
\hline 6759 & 0 & 0 & 3 & 3 & - & - & 230 \\
\hline 6761 & 0 & 0 & 171 & 140 & - & - & 230 \\
\hline 6762 & 0 & 0 & 121 & 99 & - & - & 230 \\
\hline 6763 & 0 & 0 & 32 & 23 & - & - & 230 \\
\hline 6764 & 0 & 0 & 170 & 143 & - & - & 230 \\
\hline 6854 & 0 & 0 & 173 & 0 & - & - & 230 \\
\hline 7000 & 0 & 0 & 220 & 122 & - & - & 230 \\
\hline 7001 & 12 & 4 & 23 & 23 & 52 & 34 & 230 \\
\hline 7015 & 0 & 0 & 0 & 0 & - & - & 525 \\
\hline 7020 & 0 & 0 & 0 & 0 & - & - & 230 \\
\hline 7021 & 0 & 0 & 20 & 0 & - & - & 230 \\
\hline 7022 & 0 & 0 & 43 & 0 & - & - & 230 \\
\hline 7023 & 0 & 0 & 50 & 0 & - & - & 230 \\
\hline 7024 & 0 & 0 & 39 & 0 & - & - & 230 \\
\hline 7041 & 0 & 0 & 110 & 110 & - & - & 230 \\
\hline 7042 & 0 & 0 & 0 & 0 & - & - & 230 \\
\hline 7265 & 0 & 0 & 13 & 13 & - & - & 230 \\
\hline 7299 & 0 & 0 & 0 & 0 & - & - & 230 \\
\hline 7300 & 0 & 0 & 0 & 0 & - & - & 525 \\
\hline 7302 & 746 & 443 & 0 & 0 & 9 & 14 & 230 \\
\hline 7304 & 598 & 348 & 0 & 0 & 13 & 16 & 230 \\
\hline 7307 & 0 & 0 & 208,2 & 0 & - & - & 230 \\
\hline 7308 & 111 & 65 & 0 & 0 & 33 & 25 & 230 \\
\hline 7310 & 111 & 65 & 0 & 0 & 34 & 26 & 230 \\
\hline 7312 & 87 & 52 & 0 & 0 & 38 & 30 & 230 \\
\hline 7584 & 0 & 0 & 10 & 10 & - & - & 230 \\
\hline 7624 & 0 & 0 & 22 & 22 & - & - & 230 \\
\hline 7711 & 0 & 0 & 0 & 0 & - & - & 525 \\
\hline 7712 & 0 & 0 & 0 & 0 & - & - & 525 \\
\hline 7713 & 0 & 0 & 0 & 0 & - & - & 525 \\
\hline 7719 & 974 & 570 & 0 & 0 & 7 & 11 & 525 \\
\hline 7722 & 0 & 0 & 0 & 0 & - & - & 525 \\
\hline 7723 & 0 & 0 & 148 & 150 & - & - & 230 \\
\hline 7724 & 22 & 0 & 0 & 0 & 47 & - & 230 \\
\hline 7725 & 0 & 0 & 147 & 132 & - & - & 230 \\
\hline 7731 & 0 & 0 & 374 & 340 & - & - & 230 \\
\hline 7732 & 0 & 0 & 0 & 0 & - & - & 525 \\
\hline 7733 & 0 & 0 & 0 & 0 & - & - & 525 \\
\hline 7734 & 0 & 0 & 295 & 378 & - & - & 230 \\
\hline
\end{tabular}


(continuação da Tabela C.1)

\begin{tabular}{|c|c|c|c|c|c|c|c|}
\hline \multirow[t]{2}{*}{ Barra } & \multicolumn{2}{|c|}{$\begin{array}{c}\text { Despacho Geração } \\
\text { (MW) }\end{array}$} & \multicolumn{2}{|c|}{$\begin{array}{l}\text { Carga } \\
\text { (MW) }\end{array}$} & \multicolumn{2}{|c|}{$\begin{array}{c}\text { Prioridade no } \\
\text { Despacho } \\
\text { da Geração }\end{array}$} & \multirow{2}{*}{$\begin{array}{c}\text { Nível de } \\
\text { Tensão }(k V)\end{array}$} \\
\hline & $\begin{array}{l}\text { C. Norte } \\
\text { Seco }\end{array}$ & $\begin{array}{l}\text { C. Norte } \\
\text { Úmido }\end{array}$ & $\begin{array}{l}\text { C. Norte } \\
\text { Seco }\end{array}$ & $\begin{array}{l}\text { C. Norte } \\
\text { Úmido }\end{array}$ & $\begin{array}{l}\text { C. Nor- } \\
\text { te Seco }\end{array}$ & $\begin{array}{c}\text { C. Norte } \\
\text { Úmido }\end{array}$ & \\
\hline 7736 & 0 & 0 & 0 & 0 & - & - & 525 \\
\hline 7739 & 0 & 0 & 0 & 0 & - & - & 230 \\
\hline 7740 & 0 & 0 & 369 & 327 & - & - & 230 \\
\hline 7741 & 0 & 0 & 0 & 0 & - & - & 525 \\
\hline 7743 & 0 & 0 & 314 & 184 & - & - & 230 \\
\hline 7744 & 0 & 0 & 0 & 0 & - & - & 525 \\
\hline 7745 & 0 & 0 & 135 & 110 & - & - & 230 \\
\hline 7747 & 0 & 0 & 0 & 0 & - & - & 230 \\
\hline 7748 & 0 & 0 & 0 & 0 & - & - & 525 \\
\hline 7749 & 17 & 0 & 0 & 190 & 51 & - & 230 \\
\hline 7750 & 0 & 0 & 0 & 0 & - & - & 525 \\
\hline 7751 & 0 & 0 & 0 & 0 & - & - & 525 \\
\hline 7752 & 0 & 0 & 0 & 0 & - & - & 525 \\
\hline 7753 & 170 & 0 & 0 & 0 & 26 & - & 525 \\
\hline 7755 & 0 & 0 & 301 & 309 & - & - & 230 \\
\hline 7757 & 86 & 0 & 0 & 152 & 39 & - & 230 \\
\hline 7758 & 0 & 0 & 63 & 22 & - & - & 230 \\
\hline 7759 & 0 & 0 & 0 & 0 & - & - & 525 \\
\hline 7760 & 0 & 940 & 38 & 0 & - & 3 & 525 \\
\hline 7982 & 0 & 0 & 121 & 0 & - & - & 230 \\
\hline 7990 & 0 & 0 & 130 & 0 & - & - & 230 \\
\hline 8135 & 0 & 0 & 52 & 46 & - & - & 230 \\
\hline 8321 & 0 & 0 & 38 & 0 & - & - & 230 \\
\hline 8333 & 0 & 0 & 21 & 21 & - & - & 230 \\
\hline 8720 & 20 & 0 & 0 & 0 & 49 & - & 525 \\
\hline 8721 & 0 & 0 & 0 & 0 & - & - & 525 \\
\hline 8731 & 149 & 88 & 0 & 0 & 27 & 22 & 230 \\
\hline 8736 & 121 & 71 & 0 & 0 & 31 & 24 & 230 \\
\hline 8741 & 614 & 0 & 0 & 0 & 11 & - & 525 \\
\hline 8771 & 91 & 0 & 0 & 0 & 37 & - & 525 \\
\hline 8772 & 616 & 0 & 0 & 19 & 10 & - & 525 \\
\hline 8780 & 93 & 44 & 0 & 0 & 36 & 27 & 230 \\
\hline 8952 & 1220 & 725 & 0 & 0 & 3 & 5 & 525 \\
\hline 9002 & 0 & 0 & 100 & 82 & - & - & 230 \\
\hline 9010 & 0 & 0 & 90 & 68 & - & - & 230 \\
\hline 9015 & 0 & 0 & 140 & 114 & - & - & 230 \\
\hline 9020 & 0 & 0 & 241 & 236 & - & - & 230 \\
\hline 9030 & 0 & 0 & 63 & 62 & - & - & 230 \\
\hline 9040 & 0 & 0 & 0 & 0 & - & - & 230 \\
\hline 9045 & 0 & 0 & 53 & 42 & - & - & 230 \\
\hline 9050 & 0 & 0 & 0 & 0 & - & - & 230 \\
\hline 9051 & 0 & 0 & 142 & 0 & - & - & 230 \\
\hline 9060 & 0 & 0 & 0 & 0 & - & - & 230 \\
\hline 9062 & 0 & 0 & 46 & 37 & - & - & 230 \\
\hline 9065 & 0 & 0 & 164 & 135 & - & - & 230 \\
\hline 9066 & 0 & 0 & 118 & 99 & - & - & 230 \\
\hline 9090 & 107 & 63 & 0 & 0 & 35 & 28 & 230 \\
\hline
\end{tabular}


(continuação da Tabela C.1)

\begin{tabular}{|c|c|c|c|c|c|c|c|}
\hline \multirow[t]{2}{*}{ Barra } & \multicolumn{2}{|c|}{$\begin{array}{c}\text { Despacho Geração } \\
\text { (MW) }\end{array}$} & \multicolumn{2}{|c|}{$\begin{array}{l}\text { Carga } \\
\text { (MW) }\end{array}$} & \multicolumn{2}{|c|}{$\begin{array}{c}\text { Prioridade no } \\
\text { Despacho } \\
\text { da Geração }\end{array}$} & \multirow{2}{*}{$\begin{array}{c}\text { Nível de } \\
\text { Tensão (kV }\end{array}$} \\
\hline & $\begin{array}{l}\text { C. Norte } \\
\text { Seco }\end{array}$ & $\begin{array}{l}\text { C. Norte } \\
\text { Úmido }\end{array}$ & $\begin{array}{l}\text { C. Norte } \\
\text { Seco }\end{array}$ & $\begin{array}{l}\text { C. Norte } \\
\text { Úmido }\end{array}$ & $\begin{array}{l}\text { C. Norte } \\
\text { Seco }\end{array}$ & $\begin{array}{c}\text { C. Norte } \\
\text { Úmido }\end{array}$ & \\
\hline 9095 & 0 & 0 & 21 & 21 & - & - & 230 \\
\hline 9097 & 0 & 0 & 39 & 30 & - & - & 230 \\
\hline 9098 & 197 & 0 & 0 & 0 & 22 & - & 230 \\
\hline 9100 & 25,4 & 0 & 0 & 108 & 46 & - & 230 \\
\hline 9110 & 0 & 0 & 207 & 171 & - & - & 230 \\
\hline 9120 & 0 & 0 & 83 & 59 & - & - & 230 \\
\hline 9130 & 0 & 0 & 132 & 127 & - & - & 230 \\
\hline 9140 & 422 & 250 & 0 & 0 & 15 & 17 & 230 \\
\hline 9165 & 0 & 0 & 125 & 181 & - & - & 230 \\
\hline 9170 & 0 & 0 & 30 & 26 & - & - & 230 \\
\hline 9180 & 0 & 0 & 101 & 116 & - & - & 230 \\
\hline 9184 & 0 & 0 & 140 & 113 & - & - & 230 \\
\hline 9188 & 27 & 8 & 0 & 0 & 45 & 33 & 230 \\
\hline 9192 & 21 & 0 & 0 & 120 & 48 & - & 230 \\
\hline 9195 & 19 & 0 & 0 & 36 & 50 & - & 230 \\
\hline 9204 & 0 & 0 & 124 & 114 & - & - & 230 \\
\hline 9206 & 0 & 0 & 131 & 131 & - & - & 230 \\
\hline 9208 & 0 & 0 & 351,2 & 143 & - & - & 230 \\
\hline 9209 & 0 & 0 & 149 & 139 & - & - & 230 \\
\hline 9210 & 0 & 0 & 143 & 122 & - & - & 230 \\
\hline 9213 & 0 & 0 & 75 & 67 & - & - & 230 \\
\hline 9230 & 0 & 0 & 165 & 133 & - & - & 230 \\
\hline 9233 & 70 & 325 & 0 & 0 & 40 & 7 & 230 \\
\hline 9245 & 0 & 0 & 294 & 258 & - & - & 230 \\
\hline 9250 & 142 & 39 & 0 & 0 & 28 & 31 & 230 \\
\hline 9261 & 0 & 0 & 133 & 154 & - & - & 230 \\
\hline 9264 & 0 & 0 & 103 & 81 & - & - & 230 \\
\hline 9265 & 0 & 0 & 59 & 44 & - & - & 230 \\
\hline 9272 & 0 & 0 & 98 & 79 & - & - & 230 \\
\hline 9276 & 0 & 0 & 310 & 296 & - & - & 230 \\
\hline 9280 & 0 & 0 & 141 & 119 & - & - & 230 \\
\hline 9283 & 0 & 0 & 82 & 63 & - & - & 230 \\
\hline 9286 & 0 & 0 & 236 & 176 & - & - & 230 \\
\hline 9290 & 0 & 0 & 116 & 149 & - & - & 230 \\
\hline 9304 & 0 & 0 & 107 & 91 & - & - & 230 \\
\hline 9306 & 0 & 0 & 82 & 71 & - & - & 230 \\
\hline 9310 & 0 & 0 & 117 & 93 & - & - & 230 \\
\hline 9314 & 0 & 0 & 121 & 106 & - & - & 230 \\
\hline 9330 & 0 & 0 & 168 & 129 & - & - & 230 \\
\hline 9340 & 0 & 0 & 0 & 0 & - & - & 230 \\
\hline 9345 & 0 & 0 & 43 & 35 & - & - & 230 \\
\hline 9350 & 0 & 0 & 60 & 127 & - & - & 230 \\
\hline 38853 & 56 & 231 & 0 & 0 & 41 & 18 & 230 \\
\hline 38857 & 224 & 0 & 0 & 0 & 20 & - & 230 \\
\hline 38858 & 46 & 0 & 0 & 135 & 42 & - & 230 \\
\hline 39841 & 227 & 63 & 0 & 0 & 19 & 29 & 230 \\
\hline 39850 & 0 & 0 & 252 & 170 & - & - & 230 \\
\hline
\end{tabular}


(conclusão da Tabela C.1)

\begin{tabular}{|c|c|c|c|c|c|c|c|}
\hline \multirow[t]{2}{*}{ Barra } & \multicolumn{2}{|c|}{$\begin{array}{c}\text { Despacho Geração } \\
\text { (MW) }\end{array}$} & \multicolumn{2}{|c|}{$\begin{array}{l}\text { Carga } \\
\text { (MW) }\end{array}$} & \multicolumn{2}{|c|}{$\begin{array}{c}\text { Prioridade no } \\
\text { Despacho } \\
\text { da Geração }\end{array}$} & \multirow{2}{*}{$\begin{array}{c}\text { Nível de } \\
\text { Tensão } \\
\text { (kV) }\end{array}$} \\
\hline & $\begin{array}{l}\text { C. Norte } \\
\text { Seco }\end{array}$ & $\begin{array}{l}\text { C. Norte } \\
\text { Úmido }\end{array}$ & $\begin{array}{l}\text { C. Norte } \\
\text { Seco }\end{array}$ & $\begin{array}{l}\text { C. Norte } \\
\text { Úmido }\end{array}$ & $\begin{array}{l}\text { C. Norte } \\
\text { Seco }\end{array}$ & $\begin{array}{l}\text { C. Norte } \\
\text { Úmido }\end{array}$ & \\
\hline 44651 & 0 & 0 & 0 & 0 & - & - & 230 \\
\hline 44652 & 0 & 0 & 30 & 30 & - & - & 230 \\
\hline 44653 & 0 & 0 & 22 & 22 & - & - & 230 \\
\hline 44655 & 0 & 0 & 35 & 31 & - & - & 230 \\
\hline 44841 & 0 & 0 & 237 & 180 & - & - & 230 \\
\hline 44900 & 0 & 0 & 158 & 169 & - & - & 230 \\
\hline 44914 & 118 & 0 & 0 & 0 & 32 & - & 230 \\
\hline 44920 & 0 & 0 & 155 & 70 & - & - & 230 \\
\hline 44925 & 0 & 0 & 88 & 0 & - & - & 230 \\
\hline 46851 & 0 & 0 & 205 & 110 & - & - & 230 \\
\hline 46942 & 0 & 0 & 224 & 210 & - & - & 230 \\
\hline 47120 & 33 & 0 & 0 & 0 & 43 & - & 230 \\
\hline 47121 & 0 & 0 & 0 & 0 & - & - & 525 \\
\hline 50211 & 186 & 0 & 0 & 0 & 23 & - & 230 \\
\hline 50212 & 0 & 0 & 0 & 0 & - & - & 525 \\
\hline 50213 & 0 & 0 & 0 & 0 & - & - & 525 \\
\hline 50214 & 0 & 0 & 0 & 0 & - & - & 230 \\
\hline 50215 & 452 & 0 & 0 & 0 & 14 & - & 230 \\
\hline 50216 & 0 & 0 & 0 & 0 & - & - & 230 \\
\hline 50220 & 0 & 0 & 0 & 0 & - & - & 230 \\
\hline 51001 & 0 & 0 & 115 & 85 & - & - & 230 \\
\hline 51002 & 0 & 0 & 0 & 0 & - & - & 230 \\
\hline 51003 & 0 & 0 & 0 & 0 & - & - & 230 \\
\hline 51004 & 0 & 0 & 71,7 & 133 & - & - & 230 \\
\hline 51020 & 0 & 0 & 102 & 0 & - & - & 230 \\
\hline 51457 & 0 & 0 & 79 & 45 & - & - & 230 \\
\hline 51693 & 0 & 0 & 55 & 0 & - & - & 230 \\
\hline 51703 & 0 & 0 & 19 & 19 & - & - & 230 \\
\hline 51704 & 0 & 0 & 0 & 0 & - & - & 230 \\
\hline TOTAL: & $18.944,40$ & $15.049,00$ & $18.527,60$ & $15.001,60$ & & & \\
\hline
\end{tabular}

C.2.

Dados de Ramos Existentes

Tabela C.2 - Dados de ramos existentes - Sistema SGSB

\begin{tabular}{|c|c|c|c|c|c|c|c|}
\hline $\mathbf{N}^{\circ}$ & DE & PARA & $\begin{array}{c}\text { ID do } \\
\text { circuito } \\
\text { no ramo }\end{array}$ & $\begin{array}{c}\boldsymbol{R}_{i j} \\
(\mathbf{p . u .})\end{array}$ & $\begin{array}{c}\boldsymbol{X}_{i j} \\
(\mathbf{p . u .})\end{array}$ & $\begin{array}{c}f_{i j}^{\text {max }} \\
(\mathbf{M W})\end{array}$ & $\begin{array}{c}\text { Contingência } \\
\text { no "N-1" }\end{array}$ \\
\hline \hline 1 & 6601 & 6603 & 1 & 0,00434 & 0,0253 & 390 & $\checkmark$ \\
\hline 2 & 6601 & 7763 & 1 & 0,00853 & 0,04441 & 288 & $\checkmark$ \\
\hline 3 & 6601 & 7776 & 1 & 0,0217 & 0,11229 & 237 & $\checkmark$ \\
\hline 4 & 6603 & 7763 & 1 & 0,00141 & 0,00834 & 390 & $\checkmark$ \\
\hline 5 & 6608 & 6625 & 1 & 0,0107 & 0,0639 & 392 & $\checkmark$ \\
\hline
\end{tabular}

(continua) 
(continuação da Tabela C.2)

\begin{tabular}{|c|c|c|c|c|c|c|c|}
\hline $\mathbf{N}^{\circ}$ & DE & PARA & $\begin{array}{c}\text { ID do } \\
\text { circuito } \\
\text { no ramo }\end{array}$ & $\begin{array}{c}\boldsymbol{R}_{i j} \\
\text { (p.u.) }\end{array}$ & $\begin{array}{c}X_{i j} \\
\text { (p.u.) }\end{array}$ & $\begin{array}{l}f_{i j}^{\max } \\
\text { (MW) }\end{array}$ & $\begin{array}{c}\text { Contingência no } \\
\text { "N-1" }\end{array}$ \\
\hline$\overline{6}$ & 6608 & 444920 & $\overline{11}$ & 0,00458 & 0,0324 & 350 & $\bar{\checkmark} \checkmark$ \\
\hline 7 & 6615 & 6617 & 1 & 0,0026 & 0,0126 & 382 & $\checkmark$ \\
\hline 8 & 6615 & 6618 & 1 & 0,0034 & 0,0164 & 396 & $\checkmark$ \\
\hline 9 & 6615 & 6664 & 1 & 0,0036 & 0,0218 & 385 & $\checkmark$ \\
\hline 10 & 6615 & 44841 & 1 & 0,002 & 0,0098 & 276 & $\checkmark$ \\
\hline 11 & 6616 & 6619 & 1 & 0,007 & 0,0338 & 298 & $\checkmark$ \\
\hline 12 & 6616 & 6619 & 2 & 0,0055 & 0,0335 & 165 & \\
\hline 13 & 6617 & 6619 & 1 & 0,0012 & 0,0074 & 385 & $\checkmark$ \\
\hline 14 & 6617 & 7001 & 1 & 0,00091 & 0,00354 & 420 & \\
\hline 15 & 6619 & 6664 & 1 & 0,0007 & 0,0039 & 386 & $\checkmark$ \\
\hline 16 & 6619 & 6673 & 1 & 0,0002 & 0,0009 & 220 & \\
\hline 17 & 6619 & 6762 & 1 & 0,0038 & 0,0188 & 298 & $\checkmark$ \\
\hline 18 & 6619 & 7739 & 1 & 0,00011 & 0,0001 & 684 & $\checkmark$ \\
\hline 19 & 6619 & 7739 & 2 & 0,00011 & 0,0001 & 684 & \\
\hline 20 & 6624 & 6625 & 1 & 0,00201 & 0,01031 & 350 & \\
\hline 21 & 6624 & 6625 & 2 & 0,0017 & 0,0103 & 357 & $\checkmark$ \\
\hline 22 & 6624 & 6625 & 3 & 0,0022 & 0,0109 & 357 & \\
\hline 23 & 6624 & 7820 & 1 & 0,0122 & 0,0769 & 323 & $\checkmark$ \\
\hline 24 & 6624 & 44925 & 1 & 0,01 & 0,06 & 284 & $\checkmark$ \\
\hline 25 & 6625 & 44925 & 1 & 0,0092 & 0,0575 & 383 & $\checkmark$ \\
\hline 26 & 6626 & 6755 & 1 & 0,0005 & 0,0073 & 1636 & $\checkmark$ \\
\hline 27 & 6626 & 7760 & 1 & 0,00204 & 0,02459 & 2401 & $\checkmark$ \\
\hline 28 & 6627 & 6615 & 1 & 0,0027 & 0,0161 & 328 & $\checkmark$ \\
\hline 29 & 6627 & 6615 & 2 & 0,0027 & 0,0161 & 328 & \\
\hline 30 & 6627 & 6615 & 3 & 0,0034 & 0,017 & 325 & \\
\hline 31 & 6627 & 6618 & 1 & 0,0061 & 0,0325 & 243 & $\checkmark$ \\
\hline 32 & 6627 & 6688 & 1 & 0,0208 & 0,1258 & 335 & $\checkmark$ \\
\hline 33 & 6627 & 6733 & 1 & 0,016 & 0,0807 & 175 & $\checkmark$ \\
\hline 34 & 6627 & 44655 & 1 & 0,00672 & 0,03413 & 300 & $\checkmark$ \\
\hline 35 & 6630 & 6626 & 1 & 0,00081 & 0,01361 & 3096 & $\checkmark$ \\
\hline 36 & 6630 & 6665 & 1 & 0 & 0,015 & 672 & $\checkmark$ \\
\hline 37 & 6630 & 6665 & 2 & 0 & 0,015 & 672 & \\
\hline 38 & 6649 & 6626 & 1 & 0,00069 & 0,01294 & 3455 & $\checkmark$ \\
\hline 39 & 6651 & 6688 & 1 & 0,0159 & 0,0809 & 350 & $\checkmark$ \\
\hline 40 & 6651 & 7042 & 1 & 0,01442 & 0,08049 & 160 & $\checkmark$ \\
\hline 41 & 6653 & 6624 & 1 & 0,0113 & 0,0699 & 323 & $\checkmark$ \\
\hline 42 & 6653 & 7820 & 1 & 0,0015 & 0,0089 & 323 & $\checkmark$ \\
\hline 43 & 6653 & 7820 & 2 & 0,0015 & 0,0089 & 323 & \\
\hline 44 & 6653 & 44920 & 1 & 0,00765 & 0,04795 & 323 & $\checkmark$ \\
\hline 45 & 6662 & 7748 & 1 & 0,0001 & 0,00124 & 2182 & \\
\hline 46 & 6662 & 7748 & 2 & 0,0001 & 0,00127 & 2182 & \\
\hline 47 & 6663 & 6731 & 1 & 0,0134 & 0,0669 & 164 & $\checkmark$ \\
\hline 48 & 6664 & 6629 & 1 & 0,0008 & 0,0047 & 386 & \\
\hline 49 & 6664 & 6747 & 1 & 0,0002 & 0,0013 & 315 & $\checkmark$ \\
\hline 50 & 6665 & 7757 & 1 & 0,02629 & 0,19266 & 338 & $\checkmark$ \\
\hline 51 & 6673 & 6759 & 1 & 0,0022 & 0,0133 & 119 & \\
\hline 52 & 6673 & 44651 & 1 & 0,0008 & 0,0047 & 220 & \\
\hline 53 & 6680 & 7763 & 1 & 0,0031 & 0,0182 & 350 & \\
\hline 54 & 6680 & 7763 & 2 & 0,0031 & 0,0182 & 350 & \\
\hline 55 & 6708 & 6754 & 1 & 0,0036 & 0,0184 & 182 & \\
\hline 56 & 6708 & 6754 & 2 & 0,0036 & 0,0182 & 237 & $\checkmark$ \\
\hline
\end{tabular}


(continuação da Tabela C.2)

\begin{tabular}{|c|c|c|c|c|c|c|c|}
\hline $\mathbf{N}^{\circ}$ & DE & PARA & $\begin{array}{c}\text { ID do } \\
\text { circuito } \\
\text { no ramo }\end{array}$ & $\begin{array}{c}\boldsymbol{R}_{i j} \\
\text { (p.u.) }\end{array}$ & $\begin{array}{c}X_{i j} \\
\text { (p.u.) }\end{array}$ & $\begin{array}{l}f_{i j}^{\max } \\
\text { (MW) }\end{array}$ & $\begin{array}{l}\text { Contingência } \\
\text { no "N-1" }\end{array}$ \\
\hline 57 & 6708 & 7776 & 1 & 0,01514 & 0,07836 & 237 & $\checkmark$ \\
\hline 58 & 6715 & 6651 & 1 & 0,0044 & 0,0356 & 261 & $\checkmark$ \\
\hline 59 & 6715 & 6688 & 1 & 0,011 & 0,0889 & 280 & $\checkmark$ \\
\hline 60 & 6715 & 7042 & 1 & 0,00363 & 0,02654 & 350 & $\checkmark$ \\
\hline 61 & 6730 & 7826 & 1 & 0,01244 & 0,0771 & 417 & $\checkmark$ \\
\hline 62 & 6732 & 6733 & 1 & 0,0042 & 0,0212 & 175 & $\checkmark$ \\
\hline 63 & 6747 & 6761 & 1 & 0,0046 & 0,027 & 315 & $\checkmark$ \\
\hline 64 & 6754 & 6601 & 1 & 0,0078 & 0,0398 & 182 & $\checkmark$ \\
\hline 65 & 6754 & 7763 & 1 & 0,0144 & 0,0727 & 237 & $\checkmark$ \\
\hline 66 & 6757 & 6758 & 1 & 0 & 0,0002 & 363 & \\
\hline 67 & 6757 & 6758 & 2 & 0 & 0,0002 & 363 & \\
\hline 68 & 6757 & 6758 & 3 & 0 & 0,0002 & 363 & \\
\hline 69 & 6757 & 6758 & 4 & 0 & 0,0002 & 363 & \\
\hline 70 & 6761 & 6616 & 1 & 0,0023 & 0,011 & 298 & $\checkmark$ \\
\hline 71 & 6762 & 6761 & 1 & 0,0035 & 0,0168 & 299 & $\checkmark$ \\
\hline 72 & 6763 & 7265 & 1 & 0,0001 & 0,0004 & 103 & \\
\hline 73 & 6763 & 7739 & 1 & 0,0221 & 0,11475 & 259 & $\checkmark$ \\
\hline 74 & 6763 & 7749 & 1 & 0,02474 & 0,12624 & 359 & $\checkmark$ \\
\hline 75 & 6763 & 7778 & 1 & 0,00977 & 0,04708 & 259 & \\
\hline 76 & 6763 & 7778 & 2 & 0,00977 & 0,04708 & 240 & \\
\hline 77 & 6764 & 6618 & 1 & 0,0053 & 0,0267 & 182 & $\checkmark$ \\
\hline 78 & 6764 & 6663 & 1 & 0,0105 & 0,0536 & 182 & $\checkmark$ \\
\hline 79 & 6854 & 6616 & 1 & 0,00037 & 0,00285 & 335 & \\
\hline 80 & 6854 & 6616 & 2 & 0,00037 & 0,00285 & 335 & \\
\hline 81 & 7000 & 6665 & 1 & 0,0076 & 0,0648 & 699 & $\checkmark$ \\
\hline 82 & 7000 & 44914 & 1 & 0,00813 & 0,04877 & 318 & $\checkmark$ \\
\hline 83 & 7020 & 6732 & 1 & 0,0044 & 0,0228 & 259 & \\
\hline 84 & 7020 & 6732 & 2 & 0,0052 & 0,0282 & 333 & $\checkmark$ \\
\hline 85 & 7020 & 7022 & 1 & 0,0093 & 0,0557 & 408 & $\checkmark$ \\
\hline 86 & 7020 & 7023 & 1 & 0,017 & 0,0917 & 333 & $\checkmark$ \\
\hline 87 & 7021 & 7022 & 1 & 0,0172 & 0,0891 & 259 & $\checkmark$ \\
\hline 88 & 7042 & 7023 & 1 & 0,0212 & 0,1143 & 333 & $\checkmark$ \\
\hline 89 & 7042 & 7041 & 1 & 0,00306 & 0,02238 & 350 & \\
\hline 90 & 7299 & 6616 & 1 & 0,0035 & 0,0171 & 164 & $\checkmark$ \\
\hline 91 & 7299 & 6731 & 1 & 0,0099 & 0,0491 & 164 & $\checkmark$ \\
\hline 92 & 7299 & 6761 & 1 & 0,0008 & 0,0046 & 342 & $\checkmark$ \\
\hline 93 & 7299 & 6764 & 1 & 0,0046 & 0,0274 & 342 & $\checkmark$ \\
\hline 94 & 7300 & 7711 & 1 & 0,00137 & 0,01724 & 2214 & $\checkmark$ \\
\hline 95 & 7302 & 7723 & 1 & 0,0006 & 0,00637 & 590 & \\
\hline 96 & 7302 & 7723 & 2 & 0,0006 & 0,00637 & 590 & \\
\hline 97 & 7304 & 7723 & 1 & 0,00378 & 0,02408 & 715 & $\checkmark$ \\
\hline 98 & 7304 & 7747 & 1 & 0,00543 & 0,03731 & 350 & $\checkmark$ \\
\hline 99 & 7304 & 7747 & 2 & 0,00543 & 0,03731 & 350 & \\
\hline 100 & 7304 & 9180 & 1 & 0,00671 & 0,05258 & 350 & $\checkmark$ \\
\hline 101 & 7306 & 7826 & 1 & 0,00649 & 0,04799 & 395 & $\checkmark$ \\
\hline 102 & 7306 & 7826 & 2 & 0,00649 & 0,04799 & 395 & \\
\hline 103 & 7306 & 9130 & 1 & 0,01066 & 0,06729 & 260 & $\checkmark$ \\
\hline 104 & 7306 & 46851 & 1 & 0,00639 & 0,03739 & 284 & \\
\hline 105 & 7306 & 46851 & 2 & 0,00639 & 0,03739 & 284 & \\
\hline 106 & 7307 & 7782 & 1 & 0,00559 & 0,0304 & 232 & $\checkmark$ \\
\hline 107 & 7307 & 7782 & 2 & 0,00559 & 0,0304 & 232 & \\
\hline
\end{tabular}

(continua) 
(continuação da Tabela C.2)

\begin{tabular}{|c|c|c|c|c|c|c|c|}
\hline $\mathbf{N}^{\circ}$ & DE & PARA & $\begin{array}{c}\text { ID do } \\
\text { circuito } \\
\text { no ramo }\end{array}$ & $\begin{array}{c}\boldsymbol{R}_{i j} \\
\text { (p.u.) }\end{array}$ & $\begin{array}{c}X_{i j} \\
\text { (p.u.) }\end{array}$ & $\begin{array}{l}f_{i j}^{\max } \\
\text { (MW) }\end{array}$ & $\begin{array}{l}\text { Contingência } \\
\text { no "N-1" }\end{array}$ \\
\hline 108 & 7307 & 9195 & 1 & 0,00629 & 0,03168 & 160 & $\checkmark$ \\
\hline 109 & 7307 & 9195 & 2 & 0,00629 & 0,03168 & 160 & \\
\hline 110 & 7308 & 7307 & 1 & 0,00021 & 0,00095 & 270 & \\
\hline 111 & 7310 & 7307 & 1 & 0,00169 & 0,0076 & 270 & \\
\hline 112 & 7312 & 7307 & 1 & 0,0037 & 0,01663 & 270 & \\
\hline 113 & 7711 & 7713 & 1 & 0,00065 & 0,00825 & 2214 & $\checkmark$ \\
\hline 114 & 7711 & 7732 & 1 & 0,00146 & 0,01839 & 2214 & $\checkmark$ \\
\hline 115 & 7711 & 7733 & 1 & 0,00054 & 0,00687 & 2214 & $\checkmark$ \\
\hline 116 & 7719 & 7722 & 1 & 0,00073 & 0,00917 & 2363 & $\checkmark$ \\
\hline 117 & 7719 & 7736 & 1 & 0,00047 & 0,00586 & 2363 & $\checkmark$ \\
\hline 118 & 7719 & 7736 & 2 & 0,00035 & 0,0059 & 2187 & \\
\hline 119 & 7722 & 7752 & 1 & 0,00289 & 0,03648 & 2282 & $\checkmark$ \\
\hline 120 & 7722 & 7752 & 2 & 0,00289 & 0,03648 & 2108 & \\
\hline 121 & 7722 & 7766 & 1 & 0,00172 & 0,02348 & 2363 & $\checkmark$ \\
\hline 122 & 7722 & 7766 & 2 & 0,00172 & 0,0217 & 2362 & \\
\hline 123 & 7722 & 8952 & 1 & 0 & 0,0005 & 2350 & \\
\hline 124 & 7722 & 8952 & 2 & 0 & 0,0005 & 2350 & \\
\hline 125 & 7723 & 7779 & 1 & 0,01419 & 0,0672 & 350 & \\
\hline 126 & 7723 & 7779 & 2 & 0,01419 & 0,0672 & 350 & \\
\hline 127 & 7724 & 7758 & 1 & 0,01692 & 0,13278 & 212 & \\
\hline 128 & 7725 & 7790 & 1 & 0,01187 & 0,08966 & 350 & $\checkmark$ \\
\hline 129 & 7725 & 7790 & 2 & 0,01187 & 0,08966 & 350 & \\
\hline 130 & 7732 & 6628 & 1 & 0,0004 & 0,00385 & 2363 & $\checkmark$ \\
\hline 131 & 7732 & 6628 & 2 & 0,00045 & 0,00437 & 2189 & \\
\hline 132 & 7732 & 7300 & 1 & 0,00031 & 0,0041 & 2189 & $\checkmark$ \\
\hline 133 & 7732 & 7748 & 1 & 0,002 & 0,02693 & 2363 & $\checkmark$ \\
\hline 134 & 7733 & 7713 & 1 & 0,00015 & 0,00257 & 2655 & $\checkmark$ \\
\hline 135 & 7733 & 7713 & 2 & 0,00019 & 0,00242 & 2214 & \\
\hline 136 & 7733 & 7736 & 1 & 0,00255 & 0,02922 & 2036 & $\checkmark$ \\
\hline 137 & 7734 & 7731 & 1 & 0,006 & 0,02844 & 350 & \\
\hline 138 & 7734 & 7731 & 2 & 0,00601 & 0,02841 & 350 & $\checkmark$ \\
\hline 139 & 7734 & 7990 & 1 & 0,01588 & 0,06939 & 243 & $\checkmark$ \\
\hline 140 & 7734 & 7990 & 2 & 0,01588 & 0,06939 & 243 & \\
\hline 141 & 7734 & 46942 & 1 & 0,00245 & 0,01267 & 243 & $\checkmark$ \\
\hline 142 & 7734 & 46942 & 2 & 0,0029 & 0,0154 & 243 & \\
\hline 143 & 7736 & 7744 & 1 & 0,00031 & 0,00509 & 2654 & $\checkmark$ \\
\hline 144 & 7736 & 7744 & 2 & 0,00031 & 0,00509 & 2654 & \\
\hline 145 & 7736 & 7748 & 1 & 0,00162 & 0,02048 & 2363 & $\checkmark$ \\
\hline 146 & 7736 & 7752 & 1 & 0,00164 & 0,02769 & 2655 & $\checkmark$ \\
\hline 147 & 7739 & 7794 & 1 & 0,01894 & 0,09774 & 350 & $\checkmark$ \\
\hline 148 & 7739 & 7982 & 1 & 0,0173 & 0,08841 & 350 & $\checkmark$ \\
\hline 149 & 7739 & 7982 & 2 & 0,0173 & 0,08841 & 350 & \\
\hline 150 & 7740 & 7808 & 1 & 0,00235 & 0,01327 & 328 & $\checkmark$ \\
\hline 151 & 7740 & 7745 & 1 & 0,00537 & 0,03449 & 311 & \\
\hline 152 & 7740 & 7926 & 1 & 0,00133 & 0,00873 & 327 & $\checkmark$ \\
\hline 153 & 7740 & 7928 & 1 & 0,00133 & 0,00873 & 327 & $\checkmark$ \\
\hline 154 & 7741 & 7713 & 1 & 0,00058 & 0,01009 & 2655 & $\checkmark$ \\
\hline 155 & 7743 & 7823 & 1 & 0,00524 & 0,02704 & 300 & $\checkmark$ \\
\hline 156 & 7743 & 7824 & 1 & 0,00533 & 0,02744 & 300 & $\checkmark$ \\
\hline 157 & 7743 & 51693 & 1 & 0,0119 & 0,06615 & 354 & $\checkmark$ \\
\hline 158 & 7744 & 7741 & 1 & 0,00148 & 0,02426 & 2654 & $\checkmark$ \\
\hline
\end{tabular}


(continuação da Tabela C.2)

\begin{tabular}{|c|c|c|c|c|c|c|c|}
\hline $\mathbf{N}^{\circ}$ & DE & PARA & $\begin{array}{c}\text { ID do } \\
\text { circuito } \\
\text { no ramo }\end{array}$ & $\begin{array}{c}\boldsymbol{R}_{i j} \\
\text { (p.u.) }\end{array}$ & $\begin{array}{c}X_{i j} \\
\text { (p.u.) }\end{array}$ & $\begin{array}{l}f_{i j}^{\max } \\
\text { (MW) }\end{array}$ & $\begin{array}{l}\text { Contingência } \\
\text { no "N-1" }\end{array}$ \\
\hline 159 & 7744 & 7759 & 1 & 0,0016 & 0,0268 & 3096 & $\checkmark$ \\
\hline 160 & 7744 & 7759 & 2 & 0,0016 & 0,0268 & 3096 & \\
\hline 161 & 7747 & 7725 & 1 & 0,01097 & 0,07542 & 350 & $\checkmark$ \\
\hline 162 & 7747 & 7725 & 2 & 0,01097 & 0,07542 & 350 & \\
\hline 163 & 7747 & 7744 & 1 & 0 & 0,01488 & 672 & $\checkmark$ \\
\hline 164 & 7747 & 7744 & 2 & 0 & 0,01488 & 672 & \\
\hline 165 & 7748 & 6628 & 1 & 0,00212 & 0,02556 & 2363 & $\checkmark$ \\
\hline 166 & 7748 & 6758 & 1 & 0,00052 & 0,00654 & 2363 & $\checkmark$ \\
\hline 167 & 7748 & 7760 & 1 & 0,00159 & 0,02012 & 2162 & $\checkmark$ \\
\hline 168 & 7749 & 7021 & 1 & 0,0193 & 0,0999 & 259 & $\checkmark$ \\
\hline 169 & 7749 & 7820 & 1 & 0,03045 & 0,15738 & 259 & \\
\hline 170 & 7749 & 7820 & 2 & 0,03041 & 0,15718 & 259 & $\checkmark$ \\
\hline 171 & 7750 & 50212 & 1 & 0,00064 & 0,00805 & 3921 & $\checkmark$ \\
\hline 172 & 7750 & 50213 & 1 & 0,00106 & 0,01334 & 3921 & $\checkmark$ \\
\hline 173 & 7751 & 7722 & 1 & 0,00164 & 0,03034 & 2937 & $\checkmark$ \\
\hline 174 & 7751 & 7736 & 1 & 0,00188 & 0,02325 & 2120 & $\checkmark$ \\
\hline 175 & 7751 & 7750 & 1 & 0,00073 & 0,00916 & 2120 & $\checkmark$ \\
\hline 176 & 7752 & 7750 & 1 & 0,00027 & 0,00343 & 2120 & $\checkmark$ \\
\hline 177 & 7755 & 38857 & 1 & 0,0114 & 0,0973 & 669 & $\checkmark$ \\
\hline 178 & 7755 & 39850 & 1 & 0,003 & 0,0257 & 669 & $\checkmark$ \\
\hline 179 & 7757 & 7724 & 1 & 0,00844 & 0,06618 & 212 & \\
\hline 180 & 7759 & 7823 & 1 & 0 & 0,015 & 672 & $\checkmark$ \\
\hline 181 & 7759 & 7823 & 2 & 0 & 0,015 & 672 & \\
\hline 182 & 7759 & 7823 & 3 & 0 & 0,015 & 672 & \\
\hline 183 & 7760 & 7762 & 1 & 0,00086 & 0,01455 & 2546 & $\checkmark$ \\
\hline 184 & 7760 & 7762 & 2 & 0,00086 & 0,01455 & 2546 & \\
\hline 185 & 7760 & 7766 & 1 & 0,00154 & 0,0194 & 2162 & \\
\hline 186 & 7760 & 7766 & 2 & 0,00114 & 0,0202 & 3184 & $\checkmark$ \\
\hline 187 & 7763 & 6651 & 1 & 0,01896 & 0,0987 & 288 & \\
\hline 188 & 7763 & 6651 & 2 & 0,0174 & 0,0869 & 288 & $\checkmark$ \\
\hline 189 & 7763 & 6708 & 1 & 0,01569 & 0,08142 & 238 & $\checkmark$ \\
\hline 190 & 7765 & 7722 & 1 & 0,002 & 0,0276 & 1227 & $\checkmark$ \\
\hline 191 & 7765 & 7722 & 2 & 0,00245 & 0,02973 & 1227 & \\
\hline 192 & 7766 & 6755 & 1 & 0,00076 & 0,01171 & 1636 & $\checkmark$ \\
\hline 193 & 7766 & 6758 & 1 & 0,00056 & 0,00697 & 2363 & $\checkmark$ \\
\hline 194 & 7770 & 7982 & 1 & 0,00188 & 0,00961 & 350 & $\checkmark$ \\
\hline 195 & 7770 & 7982 & 2 & 0,00188 & 0,00961 & 350 & \\
\hline 196 & 7771 & 7757 & 1 & 0,00396 & 0,03366 & 669 & $\checkmark$ \\
\hline 197 & 7771 & 38858 & 1 & 0,00934 & 0,07932 & 669 & $\checkmark$ \\
\hline 198 & 7776 & 7820 & 1 & 0,05052 & 0,17774 & 350 & $\checkmark$ \\
\hline 199 & 7776 & 7820 & 2 & 0,04668 & 0,1778 & 350 & \\
\hline 200 & 7780 & 9276 & 1 & 0,0167 & 0,062 & 179 & $\checkmark$ \\
\hline 201 & 7781 & 8780 & 1 & 0,00406 & 0,02098 & 213 & \\
\hline 202 & 7782 & 9065 & 1 & 0,00338 & 0,01746 & 232 & $\checkmark$ \\
\hline 203 & 7782 & 9276 & 1 & 0,017 & 0,063 & 179 & $\checkmark$ \\
\hline 204 & 7785 & 7743 & 1 & 0,02123 & 0,10955 & 232 & $\checkmark$ \\
\hline 205 & 7785 & 7781 & 1 & 0,00094 & 0,00485 & 232 & $\checkmark$ \\
\hline 206 & 7794 & 6190 & 1 & 0,00836 & 0,04143 & 309 & \\
\hline 207 & 7794 & 6190 & 2 & 0,00836 & 0,04143 & 309 & \\
\hline 208 & 7800 & 7802 & 1 & 0,00014 & 0,00074 & 430 & \\
\hline 209 & 7800 & 7802 & 2 & 0,00014 & 0,00074 & 268 & \\
\hline
\end{tabular}

(continua) 
(continuação da Tabela C.2)

\begin{tabular}{|c|c|c|c|c|c|c|c|}
\hline $\mathbf{N}^{\circ}$ & DE & PARA & $\begin{array}{c}\text { ID do } \\
\text { circuito } \\
\text { no ramo }\end{array}$ & $\begin{array}{c}\boldsymbol{R}_{i j} \\
\text { (p.u.) }\end{array}$ & $\begin{array}{c}X_{i j} \\
\text { (p.u.) }\end{array}$ & $\begin{array}{l}f_{i j}^{\max } \\
\text { (MW) }\end{array}$ & $\begin{array}{l}\text { Contingência } \\
\text { no "N-1" }\end{array}$ \\
\hline 210 & 7802 & 7740 & 1 & 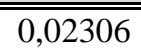 & 0,11923 & 243 & $\bar{s}$ \\
\hline 211 & 7802 & 7808 & 1 & 0,02314 & 0,11882 & 243 & $\checkmark$ \\
\hline 212 & 7802 & 7824 & 1 & 0,00939 & 0,0484 & 243 & \\
\hline 213 & 7802 & 7824 & 2 & 0,00901 & 0,04631 & 243 & $\checkmark$ \\
\hline 214 & 7812 & 7826 & 1 & 0,01505 & 0,07776 & 259 & \\
\hline 215 & 7812 & 7826 & 2 & 0,01503 & 0,07766 & 259 & $\checkmark$ \\
\hline 216 & 7812 & 8321 & 1 & 0,02584 & 0,1309 & 160 & $\checkmark$ \\
\hline 217 & 7812 & 8321 & 2 & 0,02584 & 0,1309 & 160 & \\
\hline 218 & 7820 & 6730 & 1 & 0,01327 & 0,08355 & 417 & $\checkmark$ \\
\hline 219 & 7820 & 7826 & 1 & 0,02493 & 0,1574 & 417 & $\checkmark$ \\
\hline 220 & 7824 & 7823 & 1 & 0,00019 & 0,00097 & 547 & $\checkmark$ \\
\hline 221 & 7824 & 7823 & 2 & 0,00019 & 0,00097 & 547 & \\
\hline 222 & 7830 & 7802 & 1 & 0,00345 & 0,02362 & 300 & $\checkmark$ \\
\hline 223 & 7830 & 7824 & 1 & 0,00509 & 0,03484 & 300 & $\checkmark$ \\
\hline 224 & 7850 & 9170 & 1 & 0,00238 & 0,0116 & 518 & $\checkmark$ \\
\hline 225 & 7904 & 7790 & 1 & 0,00649 & 0,05091 & 350 & $\checkmark$ \\
\hline 226 & 7904 & 7790 & 2 & 0,00649 & 0,05091 & 350 & \\
\hline 227 & 7921 & 9020 & 1 & 0,004 & 0,0209 & 290 & $\checkmark$ \\
\hline 228 & 7921 & 9020 & 2 & 0,004 & 0,0214 & 290 & \\
\hline 229 & 7921 & 9020 & 3 & 0,0042 & 0,0227 & 225 & \\
\hline 230 & 7921 & 9165 & 1 & 0,0167 & 0,0916 & 225 & $\checkmark$ \\
\hline 231 & 7921 & 9209 & 1 & 0,0028 & 0,0135 & 470 & $\checkmark$ \\
\hline 232 & 7921 & 9245 & 1 & 0,001 & 0,0053 & 540 & $\checkmark$ \\
\hline 233 & 7921 & 9276 & 1 & 0,00393 & 0,02173 & 359 & $\checkmark$ \\
\hline 234 & 7921 & 9276 & 2 & 0,00393 & 0,02173 & 359 & \\
\hline 235 & 7921 & 51457 & 1 & 0,01246 & 0,08428 & 494 & $\checkmark$ \\
\hline 236 & 7922 & 9188 & 1 & 0,0144 & 0,0724 & 340 & $\checkmark$ \\
\hline 237 & 7922 & 9265 & 1 & 0,0005 & 0,004 & 335 & $\checkmark$ \\
\hline 238 & 7922 & 9304 & 1 & 0,0095 & 0,0477 & 329 & \\
\hline 239 & 7922 & 9304 & 2 & 0,00804 & 0,04383 & 359 & $\checkmark$ \\
\hline 240 & 7924 & 7923 & 1 & 0,01951 & 0,09565 & 260 & $\checkmark$ \\
\hline 241 & 7924 & 8333 & 1 & 0,0018 & 0,0092 & 329 & \\
\hline 242 & 7924 & 9095 & 1 & 0,00554 & 0,02766 & 270 & $\checkmark$ \\
\hline 243 & 7926 & 7927 & 1 & 0,0008 & 0,00214 & 311 & $\checkmark$ \\
\hline 244 & 7927 & 7900 & 1 & 0,00118 & 0,00776 & 327 & $\checkmark$ \\
\hline 245 & 7928 & 7929 & 1 & 0,0008 & 0,00214 & 311 & $\checkmark$ \\
\hline 246 & 7929 & 7900 & 1 & 0,00118 & 0,00776 & 327 & $\checkmark$ \\
\hline 247 & 7980 & 7770 & 1 & 0,00564 & 0,02883 & 350 & $\checkmark$ \\
\hline 248 & 7980 & 7770 & 2 & 0,00564 & 0,02883 & 350 & \\
\hline 249 & 7990 & 7980 & 1 & 0,01369 & 0,0598 & 243 & $\checkmark$ \\
\hline 250 & 7990 & 7980 & 2 & 0,01369 & 0,0598 & 243 & \\
\hline 251 & 8135 & 9314 & 1 & 0,00698 & 0,03901 & 365 & $\checkmark$ \\
\hline 252 & 8321 & 9195 & 1 & 0,01148 & 0,05818 & 160 & $\checkmark$ \\
\hline 253 & 8321 & 9195 & 2 & 0,01148 & 0,05818 & 160 & \\
\hline 254 & 8720 & 7765 & 1 & 0,0012 & 0,0158 & 1227 & $\checkmark$ \\
\hline 255 & 8721 & 7765 & 1 & 0,00145 & 0,01736 & 1227 & $\checkmark$ \\
\hline 256 & 8721 & 8720 & 1 & 0 & 0,0001 & 9999 & $\checkmark$ \\
\hline 257 & 8731 & 7747 & 1 & 0,00236 & 0,01177 & 243 & \\
\hline 258 & 8736 & 7747 & 1 & 0,00394 & 0,01962 & 243 & \\
\hline 259 & 8741 & 7722 & 1 & 0,00494 & 0,0235 & 800 & \\
\hline 260 & 8771 & 8772 & 1 & 0,00034 & 0,00598 & 3305 & \\
\hline
\end{tabular}


(continuação da Tabela C.2)

\begin{tabular}{|c|c|c|c|c|c|c|c|}
\hline $\mathbf{N}^{\circ}$ & DE & PARA & $\begin{array}{c}\text { ID do } \\
\text { circuito } \\
\text { no ramo }\end{array}$ & $\begin{array}{c}\boldsymbol{R}_{i j} \\
\text { (p.u.) }\end{array}$ & $\begin{array}{c}X_{i j} \\
\text { (p.u.) }\end{array}$ & $\begin{array}{l}f_{i j}^{\max } \\
\text { (MW) }\end{array}$ & $\begin{array}{l}\text { Contingência } \\
\text { no "N-1" }\end{array}$ \\
\hline 261 & 8771 & 8772 & 2 & 0,00034 & 0,00598 & 3305 & \\
\hline 262 & 9002 & 9170 & 1 & 0,0245 & 0,1224 & 270 & $\checkmark$ \\
\hline 263 & 9002 & 9184 & 1 & 0,0158 & 0,079 & 270 & $\checkmark$ \\
\hline 264 & 9002 & 9306 & 1 & 0,0173 & 0,0963 & 290 & $\checkmark$ \\
\hline 265 & 9002 & 9330 & 1 & 0,0242 & 0,1213 & 270 & $\checkmark$ \\
\hline 266 & 9002 & 9340 & 1 & 0,02496 & 0,12366 & 270 & $\checkmark$ \\
\hline 267 & 9002 & 9340 & 2 & 0,02496 & 0,12366 & 270 & \\
\hline 268 & 9010 & 9040 & 1 & 0,0067 & 0,03808 & 290 & $\checkmark$ \\
\hline 269 & 9010 & 9040 & 2 & 0,0067 & 0,03808 & 290 & \\
\hline 270 & 9010 & 9170 & 1 & 0,0289 & 0,1444 & 270 & $\checkmark$ \\
\hline 271 & 9015 & 9110 & 1 & 0,0045 & 0,0231 & 210 & $\checkmark$ \\
\hline 272 & 9015 & 9110 & 2 & 0,0045 & 0,0231 & 210 & \\
\hline 273 & 9015 & 9314 & 1 & 0,00549 & 0,02586 & 235 & $\checkmark$ \\
\hline 274 & 9020 & 7584 & 1 & 0,0026 & 0,0129 & 270 & \\
\hline 275 & 9020 & 7780 & 1 & 0,0083 & 0,0432 & 210 & $\checkmark$ \\
\hline 276 & 9020 & 9045 & 1 & 0,0027 & 0,0126 & 270 & $\checkmark$ \\
\hline 277 & 9020 & 9050 & 1 & 0,0013 & 0,007 & 290 & $\checkmark$ \\
\hline 278 & 9020 & 9051 & 1 & 0,00222 & 0,01228 & 290 & $\checkmark$ \\
\hline 279 & 9020 & 9110 & 1 & 0,0021 & 0,0112 & 290 & $\checkmark$ \\
\hline 280 & 9020 & 9110 & 2 & 0,0021 & 0,0112 & 290 & \\
\hline 281 & 9020 & 9110 & 3 & 0,0021 & 0,0112 & 290 & \\
\hline 282 & 9020 & 9209 & 1 & 0,00283 & 0,0132 & 270 & $\checkmark$ \\
\hline 283 & 9020 & 9245 & 1 & 0,0041 & 0,0225 & 290 & $\checkmark$ \\
\hline 284 & 9020 & 9345 & 1 & 0,0258 & 0,0983 & 179 & $\checkmark$ \\
\hline 285 & 9030 & 9120 & 1 & 0,0171 & 0,0855 & 270 & $\checkmark$ \\
\hline 286 & 9040 & 7753 & 1 & 0,00044 & 0,0125 & 672 & $\checkmark$ \\
\hline 287 & 9040 & 7753 & 2 & 0,00044 & 0,0125 & 672 & \\
\hline 288 & 9045 & 9209 & 1 & 0,0007 & 0,003 & 270 & $\checkmark$ \\
\hline 289 & 9050 & 9110 & 1 & 0,00192 & 0,0101 & 290 & $\checkmark$ \\
\hline 290 & 9060 & 7782 & 1 & 0,0004 & 0,0194 & 210 & $\checkmark$ \\
\hline 291 & 9060 & 7782 & 2 & 0,0004 & 0,0194 & 210 & \\
\hline 292 & 9060 & 8135 & 1 & 0,00385 & 0,02152 & 365 & $\checkmark$ \\
\hline 293 & 9060 & 9015 & 1 & 0,0127 & 0,0592 & 350 & $\checkmark$ \\
\hline 294 & 9060 & 9015 & 2 & 0,0127 & 0,0592 & 350 & \\
\hline 295 & 9060 & 9065 & 1 & 0,00385 & 0,02121 & 276 & $\checkmark$ \\
\hline 296 & 9060 & 9066 & 1 & 0,00387 & 0,01936 & 365 & $\checkmark$ \\
\hline 297 & 9062 & 7782 & 1 & 0,0039 & 0,0213 & 290 & $\checkmark$ \\
\hline 298 & 9062 & 51704 & 1 & 0,0003 & 0,0017 & 365 & $\checkmark$ \\
\hline 299 & 9065 & 7781 & 1 & 0,01247 & 0,06435 & 232 & $\checkmark$ \\
\hline 300 & 9066 & 51704 & 1 & 0,00094 & 0,00422 & 365 & $\checkmark$ \\
\hline 301 & 9090 & 9140 & 1 & 0,0039 & 0,0214 & 290 & \\
\hline 302 & 9090 & 9140 & 2 & 0,0039 & 0,0214 & 365 & $\checkmark$ \\
\hline 303 & 9090 & 9286 & 1 & 0,012 & 0,0664 & 290 & $\checkmark$ \\
\hline 304 & 9090 & 9286 & 2 & 0,01195 & 0,06643 & 290 & \\
\hline 305 & 9095 & 9192 & 1 & 0,0089 & 0,0445 & 270 & $\checkmark$ \\
\hline 306 & 9097 & 9209 & 1 & 0,0047 & 0,023 & 270 & $\checkmark$ \\
\hline 307 & 9100 & 7782 & 1 & 0,004 & 0,02 & 329 & $\checkmark$ \\
\hline 308 & 9100 & 51020 & 1 & 0,00841 & 0,0449 & 265 & $\checkmark$ \\
\hline 309 & 9110 & 7924 & 1 & 0,00224 & 0,0125 & 290 & $\checkmark$ \\
\hline 310 & 9110 & 7924 & 2 & 0,0025 & 0,0125 & 290 & \\
\hline 311 & 9110 & 9051 & 1 & 0,00043 & 0,00236 & 290 & $\checkmark$ \\
\hline
\end{tabular}


(continuação da Tabela C.2)

\begin{tabular}{|c|c|c|c|c|c|c|c|}
\hline $\mathbf{N}^{\circ}$ & DE & PARA & $\begin{array}{c}\text { ID do } \\
\text { circuito } \\
\text { no ramo }\end{array}$ & $\begin{array}{c}\boldsymbol{R}_{i j} \\
\text { (p.u.) }\end{array}$ & $\begin{array}{c}X_{i j} \\
\text { (p.u.) }\end{array}$ & $\begin{array}{l}f_{i j}^{\max } \\
(\mathbf{M W})\end{array}$ & $\begin{array}{c}\text { Contingência } \\
\text { no "N-1" }\end{array}$ \\
\hline 312 & 9110 & 9206 & 1 & 0,0056 & 0,026 & 210 & \\
\hline 313 & 9110 & 9206 & 2 & 0,0052 & 0,0269 & 340 & $\checkmark$ \\
\hline 314 & 9110 & 9208 & 1 & 0,00328 & 0,01542 & 270 & $\checkmark$ \\
\hline 315 & 9110 & 9350 & 1 & 0,00386 & 0,0179 & 210 & $\checkmark$ \\
\hline 316 & 9110 & 51002 & 1 & 0,00623 & 0,03032 & 336 & $\checkmark$ \\
\hline 317 & 9120 & 9020 & 1 & 0,00739 & 0,03689 & 270 & $\checkmark$ \\
\hline 318 & 9120 & 9097 & 1 & 0,00283 & 0,0141 & 270 & $\checkmark$ \\
\hline 319 & 9120 & 51457 & 1 & 0,01761 & 0,08726 & 270 & $\checkmark$ \\
\hline 320 & 9130 & 7812 & 1 & 0,0221 & 0,0875 & 179 & $\checkmark$ \\
\hline 321 & 9130 & 9304 & 1 & 0,0177 & 0,0887 & 270 & $\checkmark$ \\
\hline 322 & 9140 & 9245 & 1 & 0,0334 & 0,1856 & 290 & $\checkmark$ \\
\hline 323 & 9140 & 9250 & 1 & 0,0051 & 0,0286 & 290 & $\checkmark$ \\
\hline 324 & 9140 & 9280 & 1 & 0,0219 & 0,1226 & 290 & $\checkmark$ \\
\hline 325 & 9140 & 9283 & 1 & 0,01231 & 0,06804 & 365 & $\checkmark$ \\
\hline 326 & 9165 & 51020 & 1 & 0,00168 & 0,00898 & 265 & $\checkmark$ \\
\hline 327 & 9184 & 9272 & 1 & 0,0192 & 0,0963 & 340 & $\checkmark$ \\
\hline 328 & 9192 & 7923 & 1 & 0,00682 & 0,0329 & 260 & $\checkmark$ \\
\hline 329 & 9195 & 51703 & 1 & 0 & 0,00002 & 80 & \\
\hline 330 & 9204 & 9206 & 1 & 0,0014 & 0,0086 & 336 & $\checkmark$ \\
\hline 331 & 9204 & 9210 & 1 & 0,0004 & 0,0026 & 336 & $\checkmark$ \\
\hline 332 & 9206 & 9213 & 1 & 0,0016 & 0,0078 & 270 & $\checkmark$ \\
\hline 333 & 9208 & 9209 & 1 & 0,00116 & 0,00567 & 315 & $\checkmark$ \\
\hline 334 & 9209 & 9204 & 1 & 0,00007 & 0,00499 & 362 & $\checkmark$ \\
\hline 335 & 9213 & 51001 & 1 & 0,00249 & 0,01158 & 319 & $\checkmark$ \\
\hline 336 & 9230 & 9233 & 1 & 0,0137 & 0,1161 & 365 & $\checkmark$ \\
\hline 337 & 9230 & 9261 & 1 & 0,0084 & 0,0418 & 270 & $\checkmark$ \\
\hline 338 & 9233 & 9030 & 1 & 0,0374 & 0,1871 & 270 & $\checkmark$ \\
\hline 339 & 9233 & 9040 & 1 & 0,00027 & 0,00179 & 540 & $\checkmark$ \\
\hline 340 & 9233 & 9261 & 1 & 0,0292 & 0,1459 & 270 & $\checkmark$ \\
\hline 341 & 9233 & 9280 & 1 & 0,04033 & 0,21966 & 265 & $\checkmark$ \\
\hline 342 & 9245 & 7624 & 1 & 0,0012 & 0,0062 & 270 & \\
\hline 343 & 9250 & 9165 & 1 & 0,0245 & 0,1354 & 225 & $\checkmark$ \\
\hline 344 & 9250 & 9264 & 1 & 0,01984 & 0,10082 & 319 & $\checkmark$ \\
\hline 345 & 9250 & 9310 & 1 & 0,01459 & 0,05554 & 250 & $\checkmark$ \\
\hline 346 & 9250 & 9345 & 1 & 0,0337 & 0,1255 & 179 & $\checkmark$ \\
\hline 347 & 9265 & 9264 & 1 & 0,00826 & 0,04198 & 319 & $\checkmark$ \\
\hline 348 & 9272 & 9188 & 1 & 0,0192 & 0,0963 & 340 & $\checkmark$ \\
\hline 349 & 9280 & 7780 & 1 & 0,0171 & 0,0931 & 290 & $\checkmark$ \\
\hline 350 & 9283 & 7921 & 1 & 0,02729 & 0,1508 & 365 & $\checkmark$ \\
\hline 351 & 9286 & 9265 & 1 & 0,0172 & 0,0839 & 817 & $\checkmark$ \\
\hline 352 & 9286 & 9306 & 1 & 0,0138 & 0,0766 & 290 & $\checkmark$ \\
\hline 353 & 9286 & 50211 & 1 & 0,023 & 0,112 & 817 & $\checkmark$ \\
\hline 354 & 9290 & 7812 & 1 & 0,0183 & 0,0915 & 210 & $\checkmark$ \\
\hline 355 & 9290 & 9180 & 1 & 0,01688 & 0,08864 & 239 & $\checkmark$ \\
\hline 356 & 9290 & 9310 & 1 & 0,0155 & 0,0591 & 179 & $\checkmark$ \\
\hline 357 & 9314 & 9192 & 1 & 0,0098 & 0,0551 & 365 & $\checkmark$ \\
\hline 358 & 9340 & 9184 & 1 & 0,01264 & 0,10269 & 441 & $\checkmark$ \\
\hline 359 & 9340 & 9330 & 1 & 0,00085 & 0,00477 & 354 & $\checkmark$ \\
\hline 360 & 9350 & 9206 & 1 & 0,00161 & 0,00835 & 340 & $\checkmark$ \\
\hline 361 & 38853 & 39841 & 1 & 0,00361 & 0,02998 & 669 & $\checkmark$ \\
\hline 362 & 38853 & 39841 & 2 & 0,00361 & 0,02998 & 669 & \\
\hline
\end{tabular}


(continuação da Tabela C.2)

\begin{tabular}{|c|c|c|c|c|c|c|c|}
\hline $\mathbf{N}^{\circ}$ & DE & PARA & $\begin{array}{c}\text { ID do } \\
\text { circuito } \\
\text { no ramo }\end{array}$ & $\begin{array}{c}\boldsymbol{R}_{i j} \\
\text { (p.u.) }\end{array}$ & $\begin{array}{c}X_{i j} \\
\text { (p.u.) }\end{array}$ & $\begin{array}{l}f_{i j}^{\max } \\
\text { (MW) }\end{array}$ & $\begin{array}{c}\text { Contingência } \\
\text { no "N-1" }\end{array}$ \\
\hline 363 & 38857 & 4290 & 1 & 0,0108 & 0,0915 & 699 & $\checkmark$ \\
\hline 364 & 38858 & 4290 & 1 & 0,0052 & 0,044 & 699 & $\checkmark$ \\
\hline 365 & 39841 & 39850 & 1 & 0,01961 & 0,1627 & 669 & $\checkmark$ \\
\hline 366 & 39841 & 39850 & 2 & 0,01961 & 0,1627 & 669 & \\
\hline 367 & 44651 & 44652 & 1 & 0,0001 & 0,0002 & 220 & \\
\hline 368 & 44651 & 44653 & 1 & 0,0001 & 0,0001 & 220 & \\
\hline 369 & 44655 & 6618 & 1 & 0,00369 & 0,01845 & 298 & $\checkmark$ \\
\hline 370 & 44655 & 6623 & 1 & 0,00041 & 0,00205 & 103 & \\
\hline 371 & 44841 & 6619 & 1 & 0,0047 & 0,024 & 276 & $\checkmark$ \\
\hline 372 & 44900 & 6625 & 1 & 0,0031 & 0,01858 & 318 & $\checkmark$ \\
\hline 373 & 44900 & 6625 & 2 & 0,00465 & 0,02787 & 318 & \\
\hline 374 & 44900 & 44914 & 1 & 0,01426 & 0,08558 & 318 & $\checkmark$ \\
\hline 375 & 44925 & 6652 & 1 & 0,0092 & 0,0575 & 383 & \\
\hline 376 & 44925 & 6652 & 2 & $\begin{array}{l}0,01 \\
\end{array}$ & 0,06 & 284 & \\
\hline 377 & 46942 & 7740 & 1 & 0,0203 & 0,10519 & 243 & $\checkmark$ \\
\hline 378 & 46942 & 7808 & 1 & 0,0216 & 0,1152 & 243 & $\checkmark$ \\
\hline 379 & 46942 & 7904 & 1 & 0,00625 & 0,04903 & 350 & $\checkmark$ \\
\hline 380 & 46942 & 7904 & 2 & 0,00625 & 0,04903 & 350 & \\
\hline 381 & 47120 & 9261 & 1 & 0,0021 & 0,01045 & 270 & $\checkmark$ \\
\hline 382 & 47121 & 8771 & 1 & 0,00099 & 0,01757 & 3305 & \\
\hline 383 & 47121 & 8771 & 2 & 0,00099 & 0,01757 & 3305 & \\
\hline 384 & 47121 & 47120 & 1 & 0 & 0,0143 & 700 & $\checkmark$ \\
\hline 385 & 47121 & 47120 & 2 & 0 & 0,0143 & 700 & \\
\hline 386 & 47121 & 50213 & 1 & 0,00225 & 0,02829 & 3921 & $\checkmark$ \\
\hline 387 & 47121 & 50213 & 2 & 0,00225 & 0,02829 & 3921 & \\
\hline 388 & 50211 & 7850 & 1 & 0 & 0,0001 & 817 & $\checkmark r$ \\
\hline 389 & 50211 & 9002 & 1 & 0,0115 & 0,0559 & 817 & $\checkmark$ \\
\hline 390 & 50211 & 50220 & 1 & 0,0214 & 0,1002 & 817 & $\checkmark$ \\
\hline 391 & 50212 & 50215 & 1 & 0 & 0,0143 & 672 & $\checkmark$ \\
\hline 392 & 50212 & 50215 & 2 & 0 & 0,0143 & 672 & \\
\hline 393 & 50213 & 7752 & 1 & 0,00036 & 0,0046 & 3921 & $\checkmark$ \\
\hline 394 & 50213 & 7752 & 2 & 0,00036 & 0,0046 & 3921 & \\
\hline 395 & 50213 & 7753 & 1 & 0,00256 & 0,0322 & 3921 & $\checkmark$ \\
\hline 396 & 50213 & 7753 & 2 & 0,00256 & 0,0322 & 3921 & \\
\hline 397 & 50213 & 50212 & 1 & 0,00159 & 0,02 & 3921 & $\checkmark$ \\
\hline 398 & 50213 & 50214 & 1 & 0 & 0,0143 & 672 & $\checkmark$ \\
\hline 399 & 50213 & 50214 & 2 & 0 & 0,0143 & 672 & \\
\hline 400 & 50214 & 7921 & 1 & 0,00383 & 0,0186 & 528 & $\checkmark$ \\
\hline 401 & 50214 & 9120 & 1 & 0,00134 & 0,01211 & 687 & $\checkmark$ \\
\hline 402 & 50214 & 9120 & 2 & 0,00134 & 0,01211 & 687 & \\
\hline 403 & 50215 & 9350 & 1 & 0,00575 & 0,028 & 817 & $\checkmark$ \\
\hline 404 & 50216 & 7924 & 1 & 0,00752 & 0,0365 & 817 & $\checkmark$ \\
\hline 405 & 50216 & 9098 & 1 & 0,0009 & 0,00447 & 400 & \\
\hline 406 & 50216 & 9192 & 1 & 0,0009 & 0,00447 & 400 & $\checkmark$ \\
\hline 407 & 50220 & 7922 & 1 & 0,02205 & 0,1791 & 441 & $\checkmark$ \\
\hline 408 & 50220 & 7922 & 2 & 0,02205 & 0,1791 & 441 & \\
\hline 409 & 50220 & 9184 & 1 & 0,00055 & 0,00448 & 441 & $\checkmark$ \\
\hline 410 & 50220 & 9184 & 2 & 0,00055 & 0,00448 & 441 & \\
\hline 411 & 51001 & 9350 & 1 & 0,00355 & 0,01647 & 319 & $\checkmark$ \\
\hline 412 & 51002 & 51004 & 1 & 0,00012 & 0,00028 & 362 & $\checkmark$ \\
\hline 413 & 51003 & 9210 & 1 & 0,00037 & 0,00178 & 336 & $\checkmark$ \\
\hline
\end{tabular}


(continuação da Tabela C.2)

\begin{tabular}{|c|c|c|c|c|c|c|c|}
\hline $\mathbf{N}^{\circ}$ & DE & PARA & $\begin{array}{c}\text { ID do } \\
\text { circuito } \\
\text { no ramo }\end{array}$ & $\begin{array}{c}\boldsymbol{R}_{i j} \\
\text { (p.u.) }\end{array}$ & $\begin{array}{c}X_{i j} \\
\text { (p.u.) }\end{array}$ & $\begin{array}{l}f_{i j}^{\max } \\
\text { (MW) }\end{array}$ & $\begin{array}{l}\text { Contingência } \\
\text { no "N-1" }\end{array}$ \\
\hline 414 & 51004 & 51003 & 1 & 0,00012 & 0,00028 & 362 & $\checkmark$ \\
\hline 415 & 51457 & 9230 & 1 & 0,02349 & 0,11634 & 270 & $\checkmark$ \\
\hline 416 & 51457 & 47120 & 1 & 0,01514 & 0,1027 & 494 & $\checkmark$ \\
\hline 417 & 51693 & 7923 & 1 & 0,0102 & 0,0567 & 354 & $\checkmark$ \\
\hline 418 & 6710 & 6754 & 1 & 0 & 0,012 & 672 & $\checkmark$ \\
\hline 419 & 6710 & 6754 & 2 & 0 & 0,012 & 672 & \\
\hline 420 & 6710 & 6754 & 3 & 0 & 0,012 & 672 & \\
\hline 421 & 6627 & 6628 & 1 & 0 & 0,0121 & 600 & $\checkmark$ \\
\hline 422 & 6627 & 6628 & 2 & 0 & 0,0121 & 600 & \\
\hline 423 & 6627 & 6628 & 3 & 0 & 0,0121 & 600 & \\
\hline 424 & 6625 & 6626 & 1 & 0 & 0,0127 & 600 & $\checkmark$ \\
\hline 425 & 6625 & 6626 & 2 & 0 & 0,0123 & 600 & \\
\hline 426 & 6625 & 6626 & 3 & 0 & 0,0123 & 600 & \\
\hline 427 & 7299 & 7300 & 1 & 0 & 0,0121 & 672 & $\checkmark$ \\
\hline 428 & 7015 & 7020 & 1 & 0,00032 & 0,0126 & 672 & $\checkmark$ \\
\hline 429 & 7015 & 7020 & 2 & 0,00032 & 0,0126 & 672 & \\
\hline 430 & 7015 & 7020 & 3 & 0,00032 & 0,0126 & 672 & \\
\hline 431 & 7733 & 7734 & 1 & 0,00032 & 0,01259 & 672 & $\checkmark$ \\
\hline 432 & 7733 & 7734 & 2 & 0,00032 & 0,0126 & 672 & \\
\hline 433 & 7733 & 7734 & 3 & 0,00024 & 0,01272 & 672 & \\
\hline 434 & 7723 & 7736 & 1 & 0,00015 & 0,01238 & 672 & \\
\hline 435 & 7723 & 7736 & 2 & 0,00042 & 0,01232 & 672 & \\
\hline 436 & 7723 & 7736 & 3 & 0,00042 & 0,01228 & 672 & $\checkmark$ \\
\hline 437 & 7751 & 9060 & 1 & 0,00018 & 0,01211 & 672 & $\checkmark$ \\
\hline 438 & 7751 & 9060 & 2 & 0,00024 & 0,01236 & 672 & \\
\hline 439 & 7751 & 9060 & 3 & 0,00031 & 0,01291 & 672 & \\
\hline 440 & 7732 & 7739 & 1 & 0,00032 & 0,01282 & 672 & $\checkmark$ \\
\hline 441 & 7732 & 7739 & 2 & 0,00031 & 0,01285 & 672 & \\
\hline 442 & 7732 & 7739 & 3 & 0,00031 & 0,01285 & 672 & \\
\hline 443 & 7750 & 9110 & 1 & 0,0003 & 0,01345 & 672 & \\
\hline 444 & 7750 & 9110 & 2 & 0,00039 & 0,01255 & 672 & \\
\hline 445 & 7750 & 9110 & 3 & 0,00036 & 0,01341 & 672 & \\
\hline 446 & 7750 & 9110 & 4 & 0,0002 & 0,01168 & 672 & $\checkmark$ \\
\hline 447 & 7740 & 7741 & 1 & 0,00044 & 0,01987 & 672 & \\
\hline 448 & 7740 & 7741 & 2 & 0,00044 & 0,01898 & 672 & $\checkmark$ \\
\hline 449 & 7740 & 7741 & 3 & 0,00044 & 0,01898 & 672 & \\
\hline 450 & 7752 & 7921 & 1 & 0,0002 & 0,01234 & 672 & \\
\hline 451 & 7752 & 7921 & 2 & 0,00044 & 0,01174 & 672 & $\checkmark$ \\
\hline 452 & 7752 & 7921 & 3 & 0,0002 & 0,01235 & 672 & \\
\hline 453 & 7752 & 7921 & 4 & 0,0002 & 0,01234 & 672 & \\
\hline 454 & 7765 & 7922 & 1 & 0,00016 & 0,01212 & 672 & $\checkmark$ \\
\hline 455 & 7765 & 7922 & 2 & 0,00016 & 0,01212 & 672 & \\
\hline 456 & 7765 & 7922 & 3 & 0,00023 & 0,01294 & 672 & \\
\hline 457 & 7762 & 7763 & 1 & 0,00039 & 0,01271 & 672 & \\
\hline 458 & 7762 & 7763 & 2 & 0,00016 & 0,01219 & 672 & $\checkmark$ \\
\hline 459 & 7762 & 7763 & 3 & 0,00039 & 0,01271 & 672 & \\
\hline 460 & 7748 & 7749 & 1 & 0,00031 & 0,01266 & 672 & $\checkmark$ \\
\hline 461 & 7713 & 46942 & 1 & 0,00032 & 0,0126 & 672 & $\checkmark$ \\
\hline 462 & 7713 & 46942 & 2 & 0,00032 & 0,0126 & 672 & \\
\hline 463 & 7712 & 7903 & 1 & 0,00032 & 0,0126 & 672 & $\checkmark$ \\
\hline 464 & 7712 & 7903 & 2 & 0,00032 & 0,0126 & 672 & \\
\hline
\end{tabular}

(continua) 
(conclusão da Tabela C.2)

\begin{tabular}{|c|c|c|c|c|c|c|c|}
\hline $\mathbf{N}^{\circ}$ & DE & PARA & $\begin{array}{c}\text { ID do } \\
\text { circuito } \\
\text { no ramo }\end{array}$ & $\begin{array}{c}\boldsymbol{R}_{i j} \\
(\mathbf{p . u .})\end{array}$ & $\begin{array}{c}\boldsymbol{X}_{i j} \\
(\mathbf{p . u .})\end{array}$ & $\begin{array}{c}f_{i j}^{\max } \\
(\mathbf{M W})\end{array}$ & $\begin{array}{c}\text { Contingência } \\
\text { no “N-1" }\end{array}$ \\
\hline \hline 465 & 7711 & 7980 & 1 & 0,00032 & 0,0126 & 672 & $\checkmark$ \\
\hline 466 & 7711 & 7980 & 2 & 0,00032 & 0,0126 & 672 & \\
\hline 467 & 7711 & 7980 & 3 & 0,00032 & 0,0126 & 672 & \\
\hline
\end{tabular}

C.3.

Dados de Ramos Candidatos

Tabela C.3 - Dados de ramos candidatos - Sistema SGSB

\begin{tabular}{|c|c|c|c|c|c|c|c|}
\hline $\mathbf{N}^{\circ}$ & DE & PARA & $\begin{array}{c}\boldsymbol{R}_{i j} \\
\text { (p.u.) }\end{array}$ & $\begin{array}{c}X_{i j} \\
\text { (p.u.) }\end{array}$ & $\begin{array}{l}f_{i j}^{\max } \\
(\mathbf{M W})\end{array}$ & $\begin{array}{c}c_{i j}^{1} \\
\text { (milhões de } \\
\text { R\$) } \\
\end{array}$ & $\begin{array}{c}c_{i j}^{2} \\
\text { (milhóes de } \\
\text { R\$) }\end{array}$ \\
\hline 1 & 6710 & 7762 & 0,0008 & 0,0084 & 1660 & 113,96297 & 182,34075 \\
\hline 2 & 6754 & 6602 & 0,013 & 0,0776 & 320 & 41,9829 & 67,17264 \\
\hline 3 & 7741 & 7759 & 0,001 & 0,0171 & 3096 & 236,92797 & 473,85594 \\
\hline 4 & 6630 & 6649 & 0,00109 & 0,01822 & 3096 & 228,0714 & 364,91424 \\
\hline 5 & 6630 & 6710 & 0,00176 & 0,02948 & 3096 & 386,46143 & 618,33829 \\
\hline 6 & 7712 & 7741 & 0,00043 & 0,00617 & 2616 & 102,01768 & 204,03536 \\
\hline 7 & 7760 & 7015 & 0,00093 & 0,01295 & 3684 & 246,37184 & 492,74368 \\
\hline 8 & 7711 & 7748 & 0,0022 & 0,03146 & 2616 & 383,29021 & 766,58042 \\
\hline 9 & 7711 & 7712 & 0,00057 & 0,00815 & 2616 & 96,83091 & 193,66182 \\
\hline 10 & 6628 & 7015 & 0,00054 & 0,00751 & 3684 & 139,59451 & 279,18902 \\
\hline 11 & 7749 & 7021 & 0,00622 & 0,03031 & 408 & 39,19598 & 78,39196 \\
\hline 12 & 7749 & 7024 & 0,00662 & 0,05205 & 408 & 50,50493 & 101,00986 \\
\hline 13 & 7771 & 7757 & 0,00338 & 0,02857 & 669 & 33,05678 & 66,11356 \\
\hline 14 & 7000 & 6665 & 0,0076 & 0,0648 & 319 & 56,01057 & 112,02114 \\
\hline 15 & 7755 & 39850 & 0,003 & 0,0257 & 669 & 19,16355 & 38,3271 \\
\hline 16 & 7020 & 7022 & 0,0119 & 0,0613 & 259 & 36,18301 & 72,36602 \\
\hline 17 & 7903 & 7731 & 0,00096 & 0,00754 & 408 & 14,00449 & 28,00897 \\
\hline 18 & 38858 & 4290 & 0,0052 & 0,044 & 669 & 45,90389 & 91,80778 \\
\hline 19 & 7980 & 7794 & 0,00168 & 0,0132 & 408 & 19,98944 & 31,98311 \\
\hline 20 & 7785 & 7743 & 0,02123 & 0,10955 & 232 & 27,13762 & 54,27524 \\
\hline 21 & 7020 & 6733 & 0,00407 & 0,01982 & 300 & 24,46486 & 48,92972 \\
\hline 22 & 7020 & 6763 & 0,00814 & 0,03964 & 320 & 47,78913 & 95,57826 \\
\hline 23 & 38857 & 39850 & 0,01188 & 0,10048 & 669 & 94,86244 & 189,72488 \\
\hline 24 & 38857 & 7771 & 0,0111 & 0,09391 & 669 & 70,97594 & 141,95188 \\
\hline 25 & 38857 & 4290 & 0,01096 & 0,0931 & 669 & 90,52966 & 181,05932 \\
\hline 26 & 7024 & 6763 & 0,00855 & 0,04162 & 408 & 51,47191 & 102,94382 \\
\hline 27 & 50212 & 7759 & 0,00227 & 0,02864 & 2937 & 308,37761 & 616,75522 \\
\hline 28 & 47121 & 50213 & 0,00225 & 0,02829 & 2728 & 313,37551 & 626,75102 \\
\hline 29 & 9286 & 50211 & 0,023 & 0,112 & 408 & 158,94587 & 317,89174 \\
\hline 30 & 39841 & 39850 & 0,01811 & 0,15403 & 645 & 142,17421 & 284,34842 \\
\hline 31 & 38853 & 39841 & 0,00469 & 0,03897 & 645 & 45,501 & 91,002 \\
\hline 32 & 7740 & 7900 & 0,00447 & 0,02618 & 284 & 100,93139 & 201,86278 \\
\hline 33 & 7790 & 46942 & 0,01178 & 0,08982 & 338 & 60,70629 & 97,13006 \\
\hline 34 & 6628 & 7300 & 0,00069 & 0,00827 & 2148 & 81,87943 & 163,75886 \\
\hline 35 & 7000 & 7776 & 0,00596 & 0,07137 & 284 & 58,27996 & 116,55992 \\
\hline 36 & 7760 & 6710 & 0,00095 & 0,0166 & 2716 & 158,02832 & 316,05664 \\
\hline 37 & 47121 & 7753 & 0,00115 & 0,0202 & 2716 & 187,86033 & 375,72066 \\
\hline
\end{tabular}

(continua) 
(continuação da Tabela C.3)

\begin{tabular}{|c|c|c|c|c|c|c|c|}
\hline $\mathbf{N}^{\circ}$ & DE & PARA & $\begin{array}{c}\boldsymbol{R}_{i j} \\
\text { (p.u.) }\end{array}$ & $\begin{array}{c}X_{i j} \\
\text { (p.u.) }\end{array}$ & $\begin{array}{l}f_{i j}^{\max } \\
\text { (MW) }\end{array}$ & 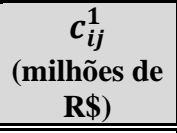 & $\begin{array}{c}c_{i j}^{2} \\
\text { (milhões de } \mathbf{R} \$ \text { ) }\end{array}$ \\
\hline 38 & 7739 & 7794 & 0,01894 & 0,09774 & 350 & $\begin{array}{l}50,75068 \\
\end{array}$ & 101,50136 \\
\hline 39 & 47120 & 9261 & 0,0021 & 0,01045 & 270 & 17,60548 & 35,21096 \\
\hline 40 & 6763 & 7749 & 0,02474 & 0,12624 & 359 & 62,61748 & 125,23496 \\
\hline 41 & 7922 & 9265 & 0,0005 & 0,004 & 335 & 11,79484 & 23,58968 \\
\hline 42 & 7748 & 6758 & 0,00052 & 0,00654 & 2363 & 80,56796 & 161,13593 \\
\hline 43 & 7306 & 9130 & 0,01066 & 0,06729 & 260 & 40,72528 & 81,45056 \\
\hline 44 & 9290 & 7812 & 0,0183 & 0,0915 & 210 & 52,51024 & 105,02048 \\
\hline 45 & 7766 & 6755 & 0,00076 & 0,01171 & 1636 & 118,9381 & 237,8762 \\
\hline 46 & 7763 & 6651 & 0,0174 & 0,0869 & 288 & 52,26472 & 104,52944 \\
\hline 47 & 9110 & 9208 & 0,00328 & 0,01542 & 270 & 16,828 & 33,656 \\
\hline 48 & 7749 & 7820 & 0,03041 & 0,15718 & 259 & 75,38452 & 150,76904 \\
\hline 49 & 7299 & 6616 & 0,0035 & 0,0171 & 164 & 17,76916 & 35,53832 \\
\hline 50 & 7762 & 7763 & 0,00039 & 0,01271 & 672 & 66,06618 & 132,13236 \\
\hline 51 & 7748 & 6628 & 0,00212 & 0,02556 & 2363 & 248,86165 & 497,72329 \\
\hline 52 & 7021 & 7022 & 0,0172 & 0,0891 & 259 & 54,59716 & 109,19432 \\
\hline 53 & 6754 & 6601 & 0,0078 & 0,0398 & 182 & 26,52604 & 53,05208 \\
\hline 54 & 7732 & 7748 & 0,002 & 0,02693 & 2363 & 264,18913 & 528,37826 \\
\hline 55 & 6615 & 44841 & 0,002 & 0,0098 & 276 & 13,67716 & 27,35432 \\
\hline 56 & 6715 & 6688 & 0,011 & 0,0889 & 280 & 53,49232 & 106,98464 \\
\hline 57 & 7732 & 7739 & 0,00031 & 0,01285 & 672 & 66,07 & 132,14 \\
\hline 58 & 6651 & 6688 & 0,0159 & 0,0809 & 350 & 43,46692 & 86,93384 \\
\hline 59 & 6608 & 44920 & 0,00458 & 0,0324 & 350 & 24,15268 & 48,30536 \\
\hline 60 & 6754 & 7763 & 0,0144 & 0,0727 & 237 & 39,70228 & 79,40456 \\
\hline 61 & 7921 & 9209 & 0,0028 & 0,0135 & 470 & 18,34204 & 36,68408 \\
\hline 62 & 7747 & 7725 & 0,01097 & 0,07542 & 350 & 46,2904 & 92,5808 \\
\hline 63 & 7299 & 7300 & 0 & 0,0121 & 672 & 66,07 & 132,14 \\
\hline 64 & 6603 & 7763 & 0,00141 & 0,00834 & 390 & 25,70764 & 51,41528 \\
\hline 65 & 9192 & 7923 & 0,00682 & 0,0329 & 260 & 24,1936 & 48,3872 \\
\hline 66 & 7802 & 7808 & 0,02314 & 0,11882 & 243 & 59,54848 & 119,09696 \\
\hline 67 & 9208 & 9209 & 0,00116 & 0,00567 & 315 & 13,759 & 27,518 \\
\hline 68 & 6665 & 7757 & 0,02629 & 0,19266 & 338 & 102,22804 & 204,45608 \\
\hline 69 & 7734 & 7731 & 0,00601 & 0,02841 & 350 & 25,05292 & 50,10584 \\
\hline 70 & 7299 & 6761 & 0,0008 & 0,0046 & 342 & 13,06336 & 26,12672 \\
\hline 71 & 6627 & 6615 & 0,0034 & 0,017 & 325 & 16,86892 & 33,73784 \\
\hline 72 & 7921 & 9245 & 0,001 & 0,0053 & 540 & 14,12728 & 28,25456 \\
\hline 73 & 7740 & 7808 & 0,00235 & 0,01327 & 328 & 18,01468 & 36,02936 \\
\hline 74 & 6651 & 7042 & 0,01442 & 0,08049 & 160 & 25,95316 & 51,90632 \\
\hline 75 & 6627 & 6618 & 0,0061 & 0,0325 & 243 & 22,63864 & 45,27728 \\
\hline 76 & 7304 & 7747 & 0,00543 & 0,03731 & 350 & 26,19868 & 52,39736 \\
\hline 77 & 6715 & 7042 & 0,00363 & 0,02654 & 350 & 21,86116 & 43,72232 \\
\hline 78 & 7812 & 8321 & 0,02584 & 0,1309 & 160 & 65,23636 & 130,47272 \\
\hline 79 & 9110 & 9051 & 0,00043 & 0,00236 & 290 & 14,49556 & 28,99112 \\
\hline 80 & 6619 & 7739 & 0,00011 & 0,0001 & 684 & 9,74884 & 19,49768 \\
\hline 81 & 7763 & 6708 & 0,01569 & 0,08142 & 238 & 48,3364 & 96,6728 \\
\hline 82 & 7824 & 7823 & 0,00019 & 0,00097 & 547 & 12,04036 & 24,08072 \\
\hline 83 & 6763 & 7739 & 0,0221 & 0,11475 & 259 & 57,58432 & 115,16864 \\
\hline 84 & 6627 & 6733 & 0,016 & 0,0807 & 175 & 43,67152 & 87,34304 \\
\hline 85 & 6649 & 6626 & 0,00069 & 0,01294 & 3455 & 142,70084 & 285,40168 \\
\hline 86 & 7755 & 38857 & 0,0114 & 0,0973 & 669 & 70,88332 & 141,76664 \\
\hline 87 & 7722 & 7752 & 0,00289 & 0,03648 & 2108 & 338,56342 & 677,12683 \\
\hline 88 & 7719 & 7722 & 0,00073 & 0,00917 & 2363 & 103,61062 & 207,22124 \\
\hline 89 & 7751 & 7722 & 0,00164 & 0,03034 & 2937 & 285,79162 & 571,58324 \\
\hline
\end{tabular}


(conclusão da Tabela C.3)

\begin{tabular}{|c|c|c|c|c|c|c|c|}
\hline $\mathbf{N}^{\circ}$ & DE & PARA & $\begin{array}{c}\boldsymbol{R}_{i j} \\
\text { (p.u.) }\end{array}$ & $\begin{array}{c}\boldsymbol{X}_{i j} \\
\text { (p.u.) }\end{array}$ & $\begin{array}{l}f_{i j}^{\max } \\
\text { (MW) }\end{array}$ & \begin{tabular}{|c|c}
$c_{i j}^{1}$ \\
(milhões de \\
R\$) \\
\end{tabular} & $\begin{array}{c}c_{i j}^{2} \\
\text { (milhões de } \\
\mathbf{R} \$ \text { ) } \\
\end{array}$ \\
\hline 90 & 9272 & 9188 & 0,0192 & 0,0963 & 340 & 55,2928 & 110,5856 \\
\hline 91 & 50220 & 7922 & 0,02205 & 0,1791 & 441 & 92,65276 & 185,30552 \\
\hline 92 & 9233 & 9040 & 0,00027 & 0,00179 & 540 & 9,99436 & 19,98872 \\
\hline 93 & 9209 & 9204 & 0,00007 & 0,00499 & 362 & 13,26796 & 26,53592 \\
\hline 94 & 7304 & 9180 & 0,00671 & 0,05258 & 350 & 23,82532 & 47,65064 \\
\hline 95 & 9100 & 7782 & 0,004 & 0,02 & 329 & 56,725 & 113,45 \\
\hline 96 & 7743 & 7823 & 0,00524 & 0,02704 & 300 & 21,1246 & 42,2492 \\
\hline 97 & 9110 & 9350 & 0,00386 & 0,0179 & 210 & 17,76916 & 35,53832 \\
\hline 98 & 7743 & 7824 & 0,00533 & 0,02744 & 300 & 20,92 & 41,84 \\
\hline 99 & 6627 & 6628 & 0 & 0,0121 & 600 & 66,07 & 132,14 \\
\hline 100 & 6625 & 6626 & 0 & 0,0123 & 600 & 66,07 & 132,14 \\
\hline 101 & 7820 & 6730 & 0,01327 & 0,08355 & 417 & 44,81728 & 89,63456 \\
\hline 102 & 6624 & 6625 & 0,0022 & 0,0109 & 357 & 14,25004 & 28,50008 \\
\hline 103 & 7736 & 7752 & 0,00164 & 0,02769 & 2655 & 287,43752 & 574,87504 \\
\hline 104 & 7922 & 9188 & 0,0144 & 0,0724 & 340 & 35,89672 & 71,79344 \\
\hline 105 & 9290 & 9310 & 0,0155 & 0,0591 & 179 & 34,34176 & 68,68352 \\
\hline 106 & 7736 & 7748 & 0,00162 & 0,02048 & 2363 & 203,70216 & 407,40431 \\
\hline 107 & 7751 & 7736 & 0,00188 & 0,02325 & 2120 & 231,47679 & 462,95357 \\
\hline 108 & 7751 & 7750 & 0,00073 & 0,00916 & 2120 & 102,58193 & 205,16386 \\
\hline
\end{tabular}

